\title{
Desconto subjetivo em situações de ressarcimento de danos materiais e morais
}

Ana Paula de Oliveira Silva 
Universidade de Brasília

Instituto de Psicologia

Departamento de Processos Psicológicos Básicos

Programa de Pós-Graduação em Ciências do Comportamento

\title{
Desconto subjetivo em situações de ressarcimento de danos materiais e morais
}

\author{
Ana Paula de Oliveira Silva
}

Tese apresentada ao Programa de Pós-Graduação em Ciências do Comportamento do Instituto de Psicologia da Universidade de Brasília como requisito parcial à obtenção do título de Doutor em Ciências do Comportamento.

Orientador: Prof. Dr. Jorge Mendes de Oliveira Castro Neto 


\section{Comissão Examinadora}

Prof. Dr. Jorge Mendes de Oliveira Castro Neto (Presidente) Universidade de Brasília

Prof. Dr. Diogo Conque Seco Ferreira (Membro Efetivo) Universidade Federal de Sergipe

Prof $^{a}$ Dra Elenice Seixas Hanna (Membro Efetivo) Universidade de Brasília Prof $^{a}$ Dra Raquel Mende Ávila Universidade Católica de Brasília

Prof. Dr. Márcio Moreira Borges (Membro Efetivo) Centro Universitário de Brasília

Prof. Dr. Carlos Augusto de Medeiros (Membro Suplente) Centro Universitário de Brasília 


\section{Agradecimentos}

A realização desse trabalho envolveu direta e indiretamente muitas pessoas. Algumas participaram contribuindo com o conhecimento técnico, outras oferecendo exemplos, tantas mais com acolhimento, paciência e incentivo. Há ainda aquelas que possibilitaram uma série de aprendizados, que vão além dos profissionais. Enfim, cada um dos presentes ao longo dessa etapa, que é agora finalizada com essa tese, teve um papel fundamental e muito especial - sem tais pessoas, essa jornada não seria possível ou seria muito menos rica.

Em primeiro lugar gostaria de agradecer ao professor Jorge por ter me acolhido, orientado, ensinado e ter oferecido esse grande exemplo de competência, gentileza e profissionalismo. Sem ele, esse trabalho não teria sido realizado.

Gostaria de agradecer à professora Josele, que foi uma das grandes responsáveis por eu ter vindo para Brasília - prontamente abriu as portas do grupo de pesquisa que coordena e me recebeu com muito carinho. Aprendi muito em suas aulas e reuniões.

Sou grata a todos os professores do Programa! Aprendi muito com todos eles - Elenice, Raquel, Carlos, Dida, Eileen, João Cláudio, Laércia... Todos foram maravilhosos.

Agradeço ao César, por toda a ajuda, disponibilidade, profissionalismo e cuidado. Ele foi essencial na etapa final desse trabalho.

A minha família foi fundamental em todos os momentos do doutorado: da decisão de fazê-lo até a sua conclusão. Sou eternamente grata aos meus pais - Expedito e Dora - e ao meu irmão Bruno, que me incentivaram, apoiaram e ofereceram todas as condições para que eu seguisse esse caminho. Não tenho palavras para expressar o quanto são essenciais na minha vida! Quero agradecer ao Diego, por toda a ajuda, paciência, carinho, companheirismo e compreensão! Ele foi fundamental.

Sou profundamente grata aos meus tios Paulo e Leila, que tão afetuosamente me receberam em sua casa e me acolheram como uma filha. Mais uma vez, me vejo sem palavras 
para exprimir a importância que tiveram nessa etapa da minha vida. Agradeço também à Layanne, minha "irmã de Brasília", que com seu humor inigualável e seu coração imenso, fez com que eu me sentisse em casa nessa cidade.

Agradeço aos amigos especiais que tive a oportunidade de conhecer na UnB: Ariela, Nagi, Patrícia e Paulo. Eles me ofereceram muito mais que as contribuições intelectuais estiveram sempre ao meu lado. Dividiram comigo os momentos difíceis e deixaram essa jornada muito mais leve!

Agradeço também aos colegas do grupo de pesquisa! Todos ajudaram muito nas discussões e elaboração de ideias! Em especial, gostaria de agradecer ao Rogério, à Carla e à Bárbara! Sempre solícitos, disponíveis e acolhedores.

Agradeço ainda à CAPES e ao CNPq, que financiaram parcialmente a realização desse trabalho. 


\section{Índice}

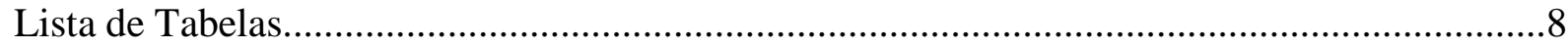

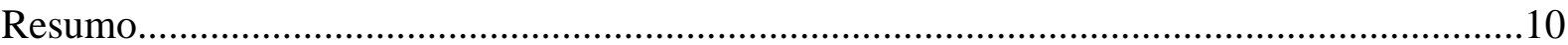

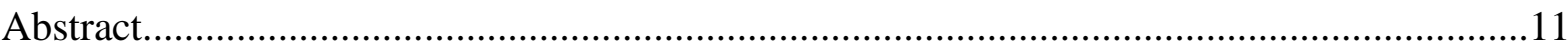

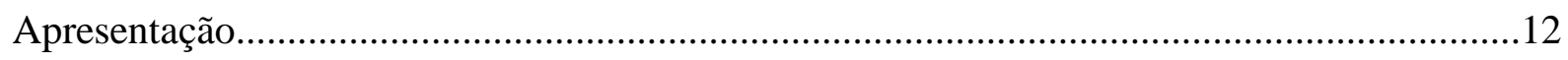

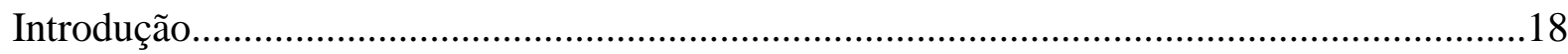

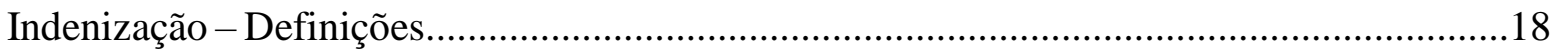

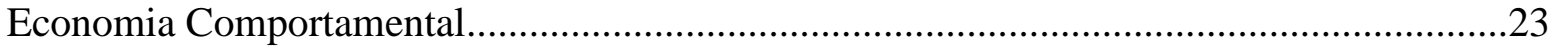

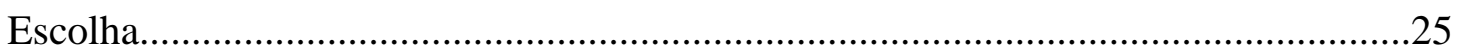

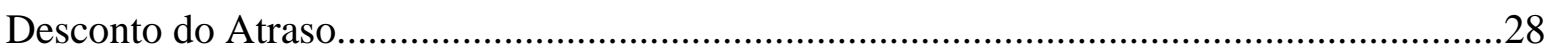

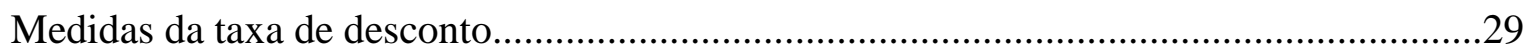

Função hiperbólica e função exponencial...................................................................30

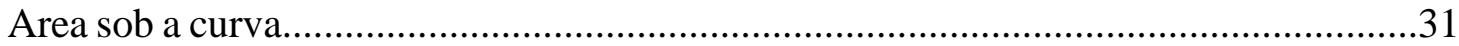

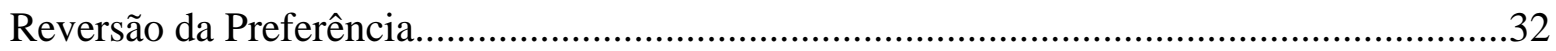

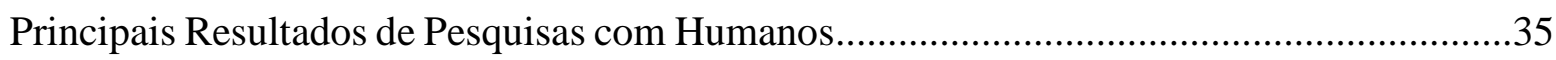

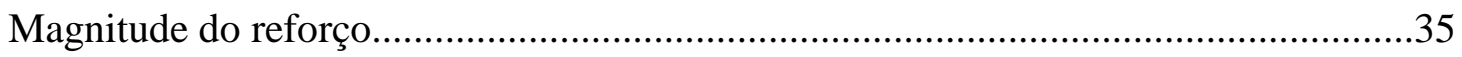

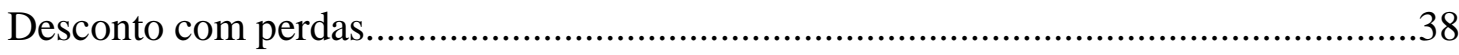

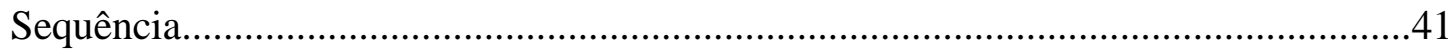

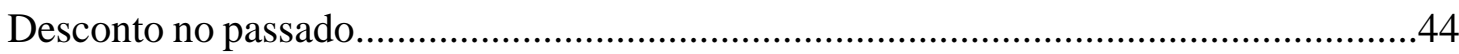

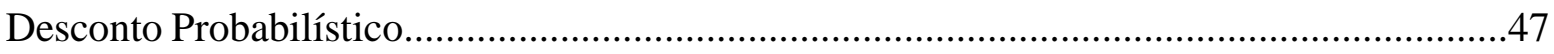

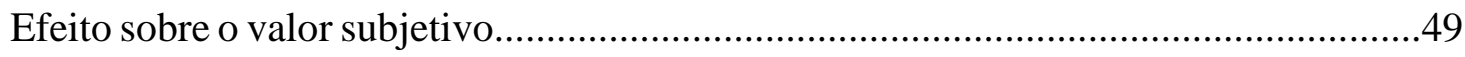

Função hiperbólica...........................................................................................49

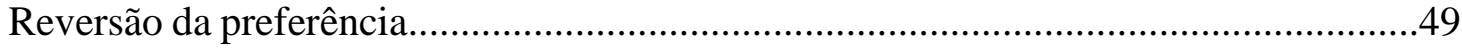

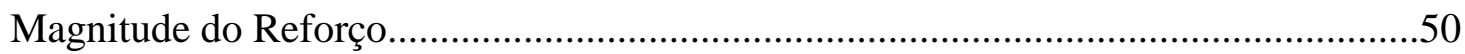

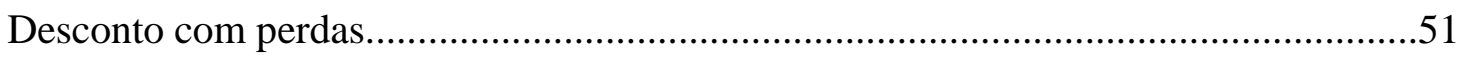




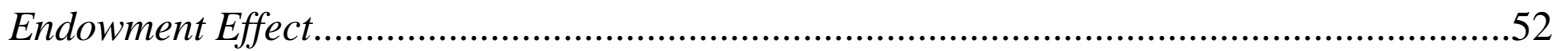

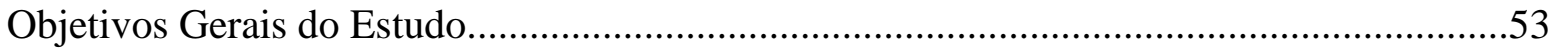

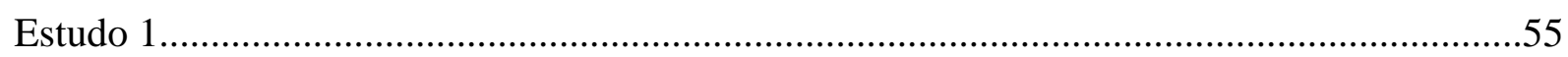

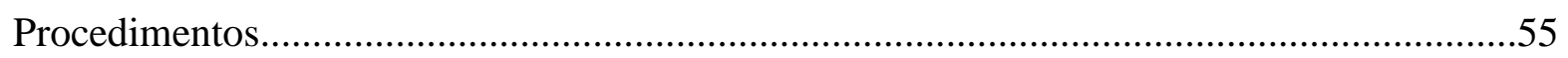

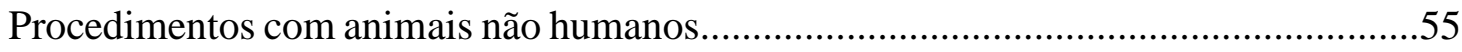

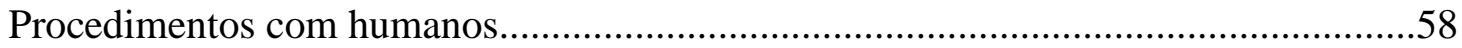

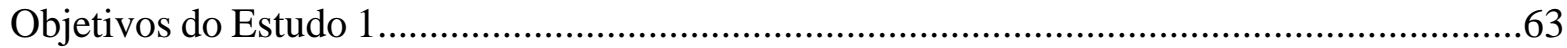

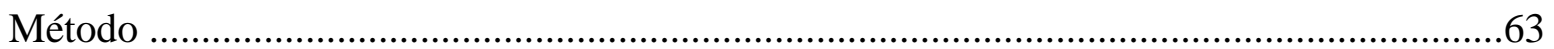

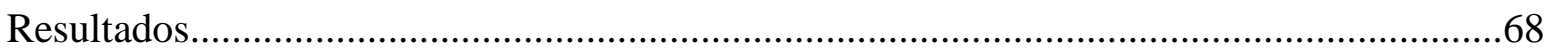

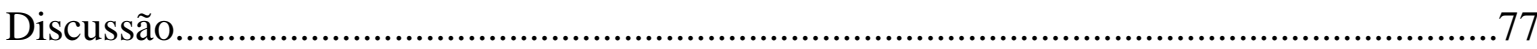

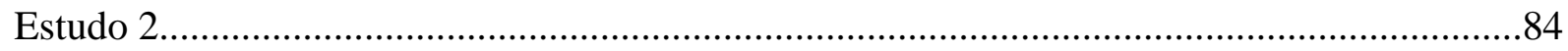

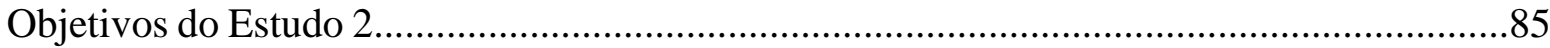

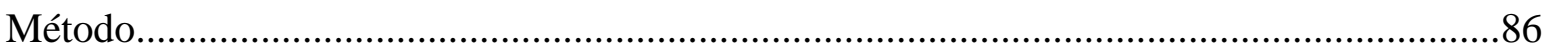

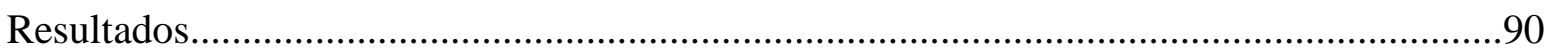

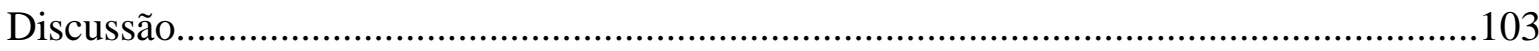

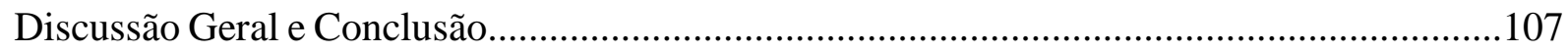

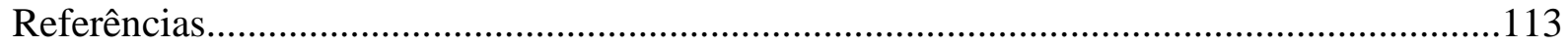

Apêndice 1 - Termo de Consentimento Livre e Esclarecido..................................................128

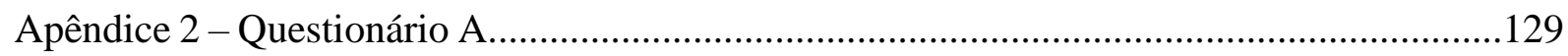

Apêndice 3 - Questionário B....................................................................................139

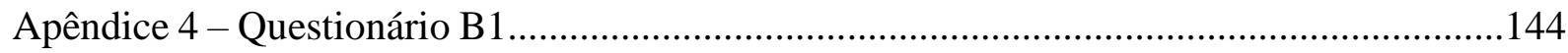

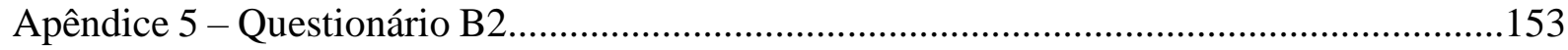

Apêndice 6 - Dados individuais do Estudo 1.......................................................................162

Apêndice 7 - Dados individuais do Estudo 2 .................................................................171

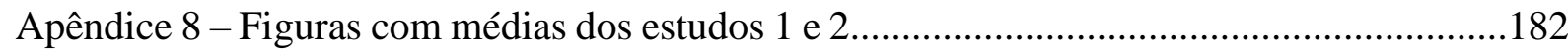




\section{Lista de Tabelas}

\section{Estudo 1}

Tabela 1 - Resumo do procedimento. .68

Tabela 2 - Incidências dos padrões de respostas observados 72

Tabela 3 - Comparação entre as medianas de $R^{2}$ obtidas com as funções hiperbólica e exponenciais .73

Tabela 4 - Comparação entre questionários: medianas de $R^{2}$ (hiperbólica e exponencial).........74

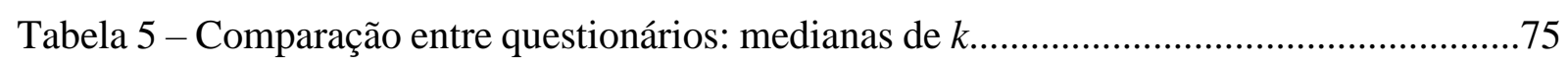

Tabela 6 - Comparação entre questionários: medianas de AUC..............................................76

\section{Estudo 2}

Tabela 7 - Resumo do procedimento . .89

Tabela 8 - Incidências dos padrões de respostas observados: danos materiais

Tabela 9 - Incidência dos padrões de respostas observados: danos morais .94

Tabela 10 - Comparação entre as medianas de $R^{2}$ obtidas com as funções hiperbólica e exponencial .95

Tabela 11 - Comparação entre as medianas de $k$ dos pares de situações 1 e 2, 3 e 4, 5 e 6, 7 e

8 (efeito de magnitude)

Tabela 12 - Comparação entre as medianas de AUC dos pares de situações 1 e 2, 3 e 4, 5 e 6 ,

7 e 8 (efeito de magnitude) .98

Tabela 13 - Comparação entre as medianas de $k$ dos pares de situações 1 e 5,2 e 6, 3 e 7, 4 e

8 (natureza do dano). .99

Tabela 14 - Comparação entre as medianas de AUC dos pares de situações

1 e 5,2 e 6,3 e 7,4 e 8 (natureza do dano). 100 
Tabela 15 - Comparação entre as medianas de $k$ dos pares de situações 1 e 3, 2 e 4, 5 e 7, 6 e

8 (autoria do dano). 102

Tabela 16 - Comparação entre as medianas de AUC dos pares de situações

1 e 3,2 e 4, 5 e 7, 6 e 8 (autoria do dano) 103 


\section{Resumo}

A vida em sociedade produz circunstâncias nas quais pessoas comumente causam danos umas às outras. Aquele que se considera prejudicado geralmente busca - de alguma forma - a reparação desse dano. É possível afirmar que as escolhas em contextos de ressarcimento de danos podem ser interpretadas com base no arcabouço do desconto subjetivo. O quanto a pessoa a ser indenizada considera que deve receber e o quanto a pessoa que deve indenizar está disposta a pagar podem ser interpretados como valores subjetivos que devem sofrer desconto intertemporal. Esse tipo de interpretação possibilita relacionar as escolhas no contexto de ressarcimento a fenômenos já conhecidos - desconto subjetivo e efeito de posse (endowment effect); o que permite identificar variáveis que seriam relevantes cujos efeitos não são conhecidos. O presente trabalho teve como objetivos verificar se (a) o procedimento de estimativa poderia ser utilizado para investigar desconto de consequências passadas no contexto de ressarcimento de danos materiais e morais; (b) qual função (hiperbólica ou exponencial) descreveria melhor os dados obtidos por intermédio desse procedimento; (c) se haveria diferenças entre o desconto observado com danos de naturezas materiais e morais; (d) se haveria alguma correlação entre os descontos observados com danos materiais e morais; (e) se o efeito de magnitude seria observado nesse contexto de reparação de danos e se (f) a autoria do dano (endowment effect) exerceria algum efeito nesse contexto, com essa metodologia de pesquisa. Foram realizados dois estudos: o primeiro investigou as questões relacionadas aos objetivos (a) e (b) e fez uso de dois tipos de questionários impressos diferentes; o segundo investigou as questões referentes aos demais objetivos (b, c, d, e, f) e nele foi utilizado apenas um tipo de questionário impresso - aquele que, diante dos resultados do Estudo 1, apresentou mais vantagens em relação à coleta e aos dados produzidos. Participaram dos dois estudos 167 estudantes de graduação, com idades entre 17 e 28 anos. A aplicação dos questionários ocorreu de forma coletiva e foi realizada em salas de aulas da universidade. Todos os questionários utilizados eram compostos de instruções gerais, tarefas de treino, tarefas de dano material e tarefas de dano moral. Cada tarefa conteve instruções específicas, com a descrição do cenário de ressarcimento e valores monetários hipotéticos. Os participantes deveriam indicar qual valor consideravam justo receber/pagar (a depender da condição) diante de um dano sofrido/causado há algum tempo (sete atrasos foram empregados). No Estudo 1, apenas uma magnitude de dano foi utilizada e no Estudo 2 duas delas foram apresentadas aos participantes. Os dois tipos de questionários utilizados no Estudo 1 produziram dados sistemáticos e semelhantes aos encontrados nas pesquisas de desconto subjetivo. Os dados produzidos foram bem descritos tanto pela função hiperbólica quanto pela exponencial, com ajuste melhor oferecido pela última. Foi possível observar o efeito de magnitude (medianas de $k$ maiores e medianas de AUC menores quando os danos eram de valores pequenos) e verificar que o desconto foi sempre maior nas situações de danos morais. A autoria do dano parece não influenciar as taxas de desconto (diferenças não significativas). De maneira geral, os resultados sugerem que procedimentos de estimativa podem ser utilizados para a investigação do desconto subjetivo de compensação de danos ocorridos no passado; que prejuízos cujos valores não possuem uma medida objetiva sofrem maiores descontos do que aqueles objetivamente mensuráveis e que danos de valores menores sofrem mais desconto do que aqueles de valores maiores.

Palavras-chave: indenização, desconto subjetivo, endowment effect. 


\section{Abstract}

Life in society generates circunstances in which people often harm each other. One who considers himself harmed usually seeks, in some way, liability from that damage. It is possible to affirm that the choices in contexts of reimbursement of damages can be interpreted based on the subjective discount framework. How much the person to be compensated considers that he should receive and how much the person who must pay is willing to pay can be interpreted as subjective values that should suffer intertemporal discount. This type of interpretation makes it possible to relate the choices in the context of reimbursement to the known phenomena previously described, which allows to identify variables that would be relevant whose effects are not known. The present study had as objectives to verify if (a) the estimation procedure could be used to investigate discount of past consequences in the context of compensation material and moral damages; (B) which function (hyperbolic or exponential) would better describe the data obtained through this procedure; (C) whether there would be differences between the discount observed with material and moral damages; (D) whether there is any correlation between the discounts observed with material and moral damages; (E) if the magnitude effect would be observed in this context of liability and if (f) the endowment effect would have any effect in that context, with this research methodology. Two studies were carried out: the first one investigated questions related to objectives (a) and (b) and made use of two types of different printed questionnaires; The second one investigated the questions related to the other objectives (b, c, d, e, f) and it was used only one type of printed questionnaire - that, given the results of Study 1, presented more advantages in relation to the collection and data produced. A total of 167 undergraduate students aged between 17 and 28 participated in the two studies. The data gathering were collective and held in university classrooms. All the questionnaires used were composed of general instructions, training tasks, material damage tasks and moral damage tasks. Each task contained specific instructions, describing the scenario of compensation and hypothetical monetary values. Participants should indicate what amount they considered fair to receive / pay (depending on the condition) in the face of an injury suffered / caused some time ago (seven delays were employed). In Study 1, only one magnitude of damage was used and in Study 2 two of them were presented to the participants. The two types of questionnaires used in Study 1 produced systematic data, similar to those found in subjective discount surveys. The data produced were well described by both the hyperbolic and exponential functions, with a better fit offered by the latter. It was possible to observe the effect of magnitude (medians of larger $k$ and medians of AUC smaller when damages were of small values) and to verify that the discount was always greater in situations of moral damages. The identity of the wrongdoer does not seem to influence discount rates (non-significant differences). In general, the results suggest that estimative procedures can be used to investigate the subjective discount of compensation for harms occurred in the past; that losses whose values do not have an objective measure suffer greater discounts than those objectively measurable and that damages of smaller values suffer more discount than those of larger values.

Keywords: indemnity, subjective discount, endowment effect. 
Na vida em sociedade comumente as pessoas causam danos umas às outras. Aquele que se considera prejudicado geralmente busca, de alguma forma, a reparação desse dano. Isso pode ser feito com base em acordo negociado, no qual as partes envolvidas precisam chegar a um consenso sobre a forma e os valores envolvidos nessa reparação ou indenização. Se não houver acordo, o indivíduo que se sentir prejudicado pode procurar ajuda de terceiros para obter reparação - a exemplo do Estado - por meio do Poder Judiciário - ou formas alternativas de resolução de conflitos, como a arbitragem $^{1}$ (Lei n. 9.307, 1996) e a mediação extrajudicial ${ }^{2}($ Lei n. 13.140, 2015) - o que envolve procedimentos de diferentes naturezas.

Esse tipo de fenômeno social que resulta prejuízo a outras pessoas ocorre tão frequentemente que a maioria dos ordenamentos jurídicos do mundo disciplina a questão e pressupõe que quando alguém é prejudicado, ele tem o direito de exigir de quem deu causa ao dano a reparação adequada.

Na legislação brasileira o direito à indenização é contemplado em vários dispositivos, dos quais se destacam: artigo 927 (combinado com o artigo 186) do Código Civil (Lei n. 10.406, 2000), que trata da responsabilidade civil por ato ilícito; artigo $5^{\circ}$, inciso $\mathrm{X}$ da Constituição Federal, 1988, que assegura a indenização por ofensa à intimidade, à vida privada, à honra e à imagem; artigo 37, parágrafo $6^{\circ}$ da Constituição Federal, 1988, que prevê a responsabilidade civil do Estado.

\footnotetext{
${ }^{1}$ A arbitragem é meio alternativo de solução de controvérsias através da intervenção de uma ou de mais pessoas que recebem seus poderes de uma convenção privada, decorrente do principio da autonomia da conta das partes - para exercer sua função, decidindo com base em tal convenção, sem intervenção estatal, tendo a decisão idêntica eficácia de sentença proferida pelo Poder Judiciário. Tem como objeto do litígio direito patrimonial disponível (Carmona, 2002).

${ }^{2}$ A mediação extrajudicial é um recurso de resolução de conflito, utilizado para solucionar ou prevenir situações de litígio ou de impasse na comunicação ou na negociação. É a criação da oportunidade para que as partes discutam questionem e contestem os seus conflitos abertamente, com fins de solução consensual entre eles. A mediação pode ser utilizada para qualquer tipo de litígio decorrente de relações de direito civil. É um processo confidencial e voluntário, no qual a autoria das decisões negociadas cabe às partes envolvidas. Diferente da resolução judicial, onde a decisão fica transferida a um juiz, na mediação, as partes se mantém autoras de suas próprias soluções e decisões (Carmona, 2002).
} 
A indenização, que corresponde a uma quantia em dinheiro, arbitrada em moeda nacional, consiste no meio de reparação do dano moral ou material por aquele que tem obrigação legal de fazê-lo.

No Brasil não há dados consolidados que permitam apontar com precisão o tempo médio de conclusão de uma ação judicial que vise a reparação de danos. Peculiaridades como a natureza da relação jurídica a ser discutida, a necessidade de produção de provas e a estrutura do órgão julgador, entre outros, influenciam o tempo total de duração de um processo judicial. Todavia, a própria configuração do Poder Judiciário contida no artigo 92 e seguintes da Constituição Federal contribui para o aumento desse tempo médio, ao permitir que uma mesma causa possa ser - a depender do tema debatido - julgada por quatro instâncias diferentes por intermédio de distintos recursos.

Para ilustrar o problema, o Conselho Nacional de Justiça apontou no último diagnóstico anual publicado que "desde o ano de 2011 o quantitativo de processos baixados é inferior ao de casos novos, ou seja, o Poder Judiciário não consegue diminuir o quantitativo de processos ingressados, aumentando ano a ano o número de casos pendentes" (http://wwwftp.cnj.jus.br/Justica_em_Numeros/relatorio_jn2014.pdf, página 35).

A morosidade constante no Poder Judiciário brasileiro ocasionou o surgimento de formas alternativas de resolução de controvérsias, nas quais a pessoa lesada e o autor do dano se valem de procedimentos extrajudiciais para chegar a uma solução para o problema existente. Nesse sentido, pode-se destacar a arbitragem - em que um terceiro imparcial contratado pelas partes decidirá, com base em critérios pré-estabelecidos, litígios relativos a direitos patrimoniais nos termos da Lei n. 9.307, 1996 - e a mediação, em que o "terceiro imparcial sem poder decisório, que, escolhido ou aceito pelas partes, as auxilia e estimula a identificar ou desenvolver soluções consensuais para a controvérsia”, conforme artigo $1^{\circ}$ da Lei n. 13.140, 2015. 
Ressalta-se que é interesse do Estado a resolução de controvérsias, tanto que o Código de Processo Civil (Lei n. 13.105, 2015) estabelece no artigo $3^{\circ}$, parágrafo $3^{\circ}$ que "a conciliação, a mediação e outros métodos de solução consensual de conflitos deverão ser estimulados por juízes, advogados, defensores públicos e membros do Ministério Público, inclusive no curso do processo judicial”. O mesmo diploma legal determina no artigo 139, inciso V, que é dever do juiz, "promover, a qualquer tempo, a autocomposição ${ }^{3}$, preferencialmente com auxílio de conciliadores e mediadores judiciais" e no artigo 165 que "os tribunais criarão centros judiciários de solução consensual de conflitos, responsáveis pela realização de sessões e audiências de conciliação e mediação e pelo desenvolvimento de programas destinados a auxiliar, orientar e estimular a autocomposição".

Ademais, o Conselho Nacional de Justiça promove anualmente a "Semana Nacional da Conciliação", período em que todos os tribunais brasileiros se mobilizam para, após selecionar processos com possibilidade de acordo, realizar audiências específicas visando alcançar uma solução consensual desses conflitos. Em 2014, das 283.719 audiências realizadas, 150.499 acordos foram firmados e homologados. Apesar de todo esse esforço, em 46,95\% dos casos optou-se, por motivos diversos, a seguir com o processo (http://www.cnj.jus.br/images/programas/conciliacao/2014/SNC_global_final.pdf).

Diante desse cenário duas questões podem ser levantadas: quais são as variáveis e como afetam a escolha daquele que sofreu o dano ao decidir entre fazer um acordo ou aguardar que em momento posterior - seja pela ação constritiva do Estado, por meio de arbitragem ou qualquer outra forma de solução de conflitos - venha a ser ressarcido? Pesquisas em Economia Comportamental podem lançar alguma luz sobre as escolhas nesse tipo de situação. Dois tipos

\footnotetext{
${ }^{3}$ A autocomposição é um método de resolução de conflitos entre pessoas e consiste em: um dos indivíduos, ou ambos, abrem mão do seu interesse por inteiro ou de parte dele. Portanto pode se afirmar que é um ajuste de vontades entre as partes (pressupondo pacificada e liberdade), onde pelo menos uma delas abre mão de seus interesses ou de parte deles. Podendo haver a participação de terceiros (árbitro ou mediador) (Vanin, 2015).
} 
de fenômenos parecem se relacionar a esse contexto de escolha, a saber, o desconto subjetivo e o endowment effect.

A linha de pesquisa que investiga o desconto subjetivo busca identificar variáveis que afetam o comportamento de escolha quando há duas alternativas disponíveis, que diferem em mais do que uma dimensão (Green \& Myerson, 2004). As variáveis atraso e probabilidade da consequência têm sido vastamente investigadas.

As pesquisas que são dedicadas à investigação do efeito do atraso de consequências sobre o comportamento de escolha, tradicionalmente apresentam ao participante alternativas em que uma delas é composta por uma consequência imediata e de menor magnitude e a outra composta por uma consequência atrasada e de maior magnitude.

Tal contexto parece assemelhar-se àquele das ações de reparação de danos: escolha entre aceitar um acordo (receber uma quantia menor, em pouco tempo) ou aguardar a decisão definitiva do Poder Judiciário (receber uma quantia maior, dali a bastante tempo). No entanto, nenhum estudo foi realizado para investigar se os resultados encontrados nas pesquisas de desconto do atraso podem ser generalizados para o fenômeno de ressarcimento de danos (como ações de indenização ou situações que ocorrem no dia a dia, quando pessoas causam danos a outras e devem ressarci-las), mesmo diante de suas particularidades - em ações judiciais, por exemplo, o requerente não tem acesso à informação de quanto tempo exatamente levará até que a decisão judicial seja dada; tampouco sabe com exatidão o valor que será recebido. Nos estudos de desconto do atraso, os participantes fazem escolhas entre atrasos de tempo e valores conhecidos.

Além disso, as pesquisas de desconto do atraso investigam, tradicionalmente, ganhos e/ou perdas de reforçadores e não situações que envolvem reparação de danos. As alternativas disponíveis para escolhas, como por exemplo em contextos judiciais e de ressarcimento, parecem abranger (além do atraso) o aspecto "incerteza" - ganhar a causa, perdê-la, receber o 
montante financeiro total requerido ou parte dele são consequências probabilísticas. Há certa chance de que aconteçam. Sabe-se que consequências reforçadoras probabilísticas perdem valor na medida em que a probabilidade de sua ocorrência decresce. A área que se dedica à investigação de como a probabilidade de ocorrência afeta o comportamento de escolha é denominada desconto probabilístico. Não há, no entanto, pesquisas sobre como a incerteza afeta escolhas no contexto de reparação de danos ou como as variáveis probabilidade e atraso, juntas, afetam o comportamento nessa situação - e essa combinação parece ser o que observamos em ações judiciais e demais situações do dia a dia. O resultado de um processo de indenização, por exemplo, demora algum tempo (atraso) e a quantia a ser recebida (ou paga) é incerta.

Ademais, os estudos nesse campo tradicionalmente exploram o efeito do atraso existente entre o momento da escolha do participante e o momento da exposição à consequência. Não há pesquisas que investiguem se o atraso entre um evento ocorrido no passado (um dano, por exemplo) e o momento da escolha (entre fazer / aceitar um acordo ou esperar a decisão do juiz, por exemplo) afeta o valor subjetivo das consequências.

Outra questão interessante emerge da observação dos valores pleiteados nas ações e dos valores propostos em acordos: parece haver diferenças entre o valor que o autor da ação julga justo receber e o valor que o réu julga justo pagar. Uma hipótese a ser levantada para explicar situações nas quais acordos judiciais não são celebrados se deve a esta diferença. Em Economia Comportamental, um fenômeno semelhante é chamado de endowment effect. O endowment effect é a assimetria na atribuição de preço quando um mesmo objeto (ou bem) é vendido e quando é comprado. Por exemplo, vendedores e compradores de uma caneca de café atribuem preços diferentes a ela. Os vendedores sistematicamente atribuem preços mais altos que os compradores. Tal efeito é observado inclusive quando a mesma pessoa ocupa o papel de vendedora da caneca e, posteriormente, torna-se compradora do mesmo objeto (Maddux, Yang, Falk, Adam, Adair, Endo, Carmon, \& Heine, 2012). Há várias replicações, com diversos bens, 
com diferentes populações e com não humanos. O endowment effect é observado inclusive na ausência de valor afetivo sobre o objeto negociado (Kahneman, Knetsch, \& Thaler, 1990; Knetsch, 1989; Thaler, 1980).

A explicação mais comum para o endowment effect é a aversão à perda (Kahneman \& Tversky, 1979). Em outras palavras, perdas teriam mais impacto sobre o comportamento do que ganhos de mesma magnitude e, desse modo, seria coerente esperar que a valoração atribuída a algum objeto por vendedores fosse consistentemente maior do que a valoração atribuída por compradores. Nessa situação, vendedores estariam "perdendo" o objeto vendido e os compradores estariam "ganhando" o objeto comprado (Maddux et. al., 2012).

Em situações de ressarcimento, pode-se fazer uma analogia em que o dano causado é o objeto "comercializado" e dessa forma aquele que causou o dano assumiria o papel de comprador (deverá pagar pelo dano) e aquele que sofreu o dano assumiria o papel de vendedor (receberá pelo dano). Essa analogia, no entanto, deve ser cuidadosamente discutida e experimentos devem ser realizados para ponderar quão válida ela é: no endowment effect o item comercializado é, geralmente, um objeto ou bem. Nos contextos de ressarcimento, no entanto, o dano seria o "objeto ou bem" comercializado. Objetos ou bens e danos são estímulos de naturezas e funções diversas. Essa diferença pode produzir resultados dessemelhantes entre as situações de indenização e de endowment effect.

Além disso, o contexto em que o endowment effect é observado é diferente daquele das ações de reparação de danos - neste caso não há compradores e sim réus ou "culpados pelo dano", que não receberão um produto após oferecerem seu dinheiro; não há vendedores e sim autores ou "pessoas que sofreram um dano", que não entregarão nenhum produto após receber o dinheiro. Ainda, diferentemente das situações de endowment effect, nas situações de indenização uma das partes foi lesada pela outra. 
Vale ressaltar também que em situações de compra e venda há interesse comum entre as partes - uma quer vender e a outra comprar. São ações que se complementam. No caso de indenização, uma das partes acha justo receber uma quantia em dinheiro, mas a outra, via de regra, discorda desse valor e não se sente inclinada a pagá-lo. Há aqui contingências aversivas - enquanto a compra/venda é um modelo de reciprocidade de duas partes, a indenização só ocorre porque há a intervenção (ou ameaça de) potencialmente punitiva de um terceiro, como algum órgão judicial.

O que parece ser semelhante entre os contextos comumente investigados no endowment effect e situações de ressarcimento é que, em ambos, uma das partes envolvida abre mão de dinheiro enquanto a outra o recebe: compra e venda envolvem funcionalmente uma troca entre objeto e dinheiro (substituição); ação de indenização envolve uma relação quantitativa, com certa probabilidade, para as duas partes.

Assim como ocorre nas áreas do desconto subjetivo, não há estudos publicados que investiguem se os dados encontrados na área de endowment effect podem ser generalizados para situações que envolvem reparação de danos.

Dessa forma, o objetivo geral do presente trabalho foi demonstrar como o instrumental conceitual e metodológico das pesquisas em Economia Comportamental podem ser úteis para identificar variáveis que influenciam escolhas em contextos de ressarcimento, como as que ocorrem quando uma pessoa deve decidir entre fazer um acordo por um valor inferior ou aguardar que a reparação seja cumprida integralmente em um momento posterior.

Esses objetivos e os demais pontos abordados acima no presente texto serão explorados nas seções a seguir.

\section{Indenização - Definições}


A palavra indenização tem sua origem na palavra francesa indemniser, que significa "ressarcir uma pessoa de perdas que teve". Deriva do Latim in (negativo) mais damnum (perda, dano, prejuízo) (Perissé, 2010).

O Dicionário Michaelis define indenização como a ação de indenizar; reparar, satisfazer um dano, ressarcir. Cita como sinônimos as palavras compensação, recompensa e reparação. O Dicionário do Aurélio apresenta definição bastante semelhante para indenização: ato ou efeito de indenizar; ressarcimento de dano sofrido.

O Cambridge Dictionaries Online define a palavra indenização (em inglês compeensate for) como proteção contra possível dano ou perda; promessa de pagamento; dinheiro pago se houver dano ou perda. E o Oxford Dictionaries apresenta o significado de indenização (indemnity) como segurança ou proteção contra perda ou outro encargo financeiro; quantia paga em dinheiro como compensação.

Em todos os dicionários acima citados, a palavra "dano" está presente na definição de indenização. Pode-se considerar, então, indenização como o ressarcimento de algum dano. Assim como apresentada nos dicionários, a palavra indenização parece ser utilizada, no cotidiano, tipicamente para fazer referências a situações nas quais alguém foi lesado e julga justo receber o ressarcimento pelo prejuízo causado.

No Direito brasileiro, a palavra indenização está intimamente relacionada com a ideia de Responsabilidade Civil, de responder perante a Justiça pelos atos danosos praticados. "É a responsabilidade civil, ou obrigação de indenizar, que compele o causador a arcar com as consequências advindas da ação violadora, ressarcindo os prejuízos de ordem moral ou patrimonial, decorrente de fato ilícito próprio, ou de outrem a ele relacionado” (Bittar, 1994, p. $561)$.

O dano pode apresentar-se de duas formas distintas: 
Enquanto o dano material, como atrás assinalado, importa em lesão de bem patrimonial, gerando prejuízo econômico passível de reparação, o dano moral é lesão de bem integrante da personalidade, tal como a honra, a liberdade, a saúde, a integridade psicológica, causando dor, sofrimento, tristeza, vexame e humilhação à vítima (Cavalieri Filho, 2003, p. 75).

Ademais, "na avaliação do dano moral o órgão judicante deverá estabelecer uma reparação equitativa, baseada na culpa do agente, na extensão do prejuízo causado e na capacidade econômica do responsável” (Diniz, 2003, p. 93).

Portanto, a ação de cunho indenizatório tem por objetivo assegurar a alguém o ressarcimento ou a reparação de algum dano causado por outrem, em consequência de ato, abstenção de ato ou de algum fato que tenha trazido prejuízo ao autor do processo. Tal ação indica uma reparação pecuniária, seja porque o dano é material e, portanto, possui natureza patrimonial ou porque o dano moral - não quantificável e mensurável - é arbitrado pelo juiz em dinheiro.

O valor da indenização é medido pela extensão do dano ocorrido e pode englobar vários desdobramentos ou consequências além do prejuízo inicial. Os artigos 944 a 954 do Código Civil elencam situações específicas nesse sentido. Por exemplo, no caso de lesão ou outra ofensa à saúde, a pessoa que causou a lesão indenizará aquele que foi lesado arcando com as despesas do tratamento e dos lucros cessantes (o que deixou de lucrar) até ao fim da convalescença, além de algum outro prejuízo que o autor da ação prove haver sofrido. Se o dano/lesão resultar em inaptidão do autor para exercer o seu ofício ou profissão, ou se lhe diminuir a capacidade de trabalho, a indenização, além das despesas do tratamento e lucros cessantes até ao fim da convalescença, incluirá pensão correspondente à importância do trabalho para que se inabilitou, ou da depreciação que ele sofreu. A pessoa prejudicada, se 
preferir, poderá exigir que a indenização seja arbitrada e paga de uma só vez. Já em casos de danos do tipo usurpação ou esbulho do alheio (apossar-se de um bem de outrem, geralmente imóvel), além da restituição do bem, a indenização consistirá em pagar o valor das deteriorações e o devido a título de lucros cessantes; faltando o bem, dever-se-á reembolsar o seu equivalente à pessoa prejudicada. Para a substituição equivalente, quando não exista o próprio bem, estimarse-á seu preço ordinário e um valor de afeição, contanto que o segundo não seja maior que o primeiro.

É importante destacar que a pretensão ao ressarcimento, ou seja, o direito à ação de indenização, por maior e mais grave que tenha sido a extensão do dano, não é eterno. Ele deve ser necessariamente exercido num prazo denominado prescricional, previsto na lei e sujeito a regras específicas de contagem.

As ações de indenização podem - via de regra - ser concluídas de duas formas: mediante o estabelecimento de um acordo entre as partes ou mediante decisão final da Justiça, após findados todos os prazos recursais, o que no Código de Processo Civil é chamado de trânsito em julgado. A forma como a ação será concluída envolve, então, um processo de escolha. As partes podem encerrar a ação com o acordo, no qual geralmente o valor acertado é menor que o valor total da ação, ou podem esperar a decisão definitiva do processo, caso em que o valor e o tempo necessário para a decisão judicial são menos previsíveis do que no acordo, pois dependem de inúmeros fatores peculiares ao sistema judiciário brasileiro.

Em cenários como o descrito acima e em todos os outros que abrangem algum tipo de ressarcimento, as pessoas envolvidas são chamadas a fazerem escolhas. Em situações judiciais, por exemplo, elas devem escolher se preferem encerrar o processo realizando um acordo (encurtando prazo para receber/pagar a quantia estabelecida que é, geralmente, um valor inferior ao valor total da causa) ou esperando a decisão do juiz (aumentando o prazo para receber/paga a quantia estabelecida que é, geralmente, superior a quantia proposta no acordo). 
Em outros cenários não judiciais, como por exemplo em acidentes de trânsito, escolhas também serão feitas - qual o valor correspondente ao dano causado? Esse valor incluirá outras despesas (como táxi para os dias em que o carro ficará na oficina)? Será pago imediatamente ou após o carro ter sido reparado? Entre outras.

Nesse sentido, é importante entender sobre escolha e, mais especificamente, sobre escolhas intertemporais (Green, Fry \& Myerson, 1994) e que envolvam reforçadores de magnitudes diferentes. A decisão entre fazer um acordo ou esperar a sentença definitiva, por exemplo, poderia ser descrita como escolha entre duas alternativas - a do acordo, caracterizada por um atraso menor e um reforço de menor magnitude; e a da decisão judicial, caracterizada por um atraso maior e um reforço de maior magnitude, assumindo-se aqui probabilidades de sucesso da causa constantes. No entanto, há de se considerar que várias dessas escolhas são também probabilísticas, ou seja, decide-se entre alternativas com maior e menor chance de ocorrência. No exemplo da ação de indenização, pode-se supor que a alternativa do acordo apresenta maior chance de receber o dinheiro do réu do que a alternativa da decisão judicial. Além disso, o tempo transcorrido entre a ocorrência do dano e a reparação financeira deste, pode ser uma variável importante na determinação de valores e na "percepção" das chances de recebê-los - os indivíduos podem julgar que é mais provável receber o ressarcimento referente a um dano ocorrido um mês atrás do que aquele referente a um dano ocorrido 10 anos atrás.

Escolhas feitas em contextos de ressarcimento envolvem ainda um caráter punitivo - a pessoa lesada está sob (ou foi submetida a) contingências aversivas em função dos danos sofridos e a pessoa responsável pelo dano está sob ameaça de punição (explícita ou não) caso não repare os prejuízos causados. Escolhas entre alternativas compostas por estímulos aversivos apresentam algumas peculiaridades em relação àquelas que envolvem apenas estímulos reforçadores. 
O fenômeno de ressarcimento de danos parece ser bastante complexo e foi, até agora, pouco explorado. Algumas das variáveis que parecem afetá-lo, como atraso, probabilidade e magnitude já foram largamente investigadas pela área denominada Economia Comportamental. As metodologias utilizadas e os resultados encontrados podem ajudar a compreender escolhas em contextos nos quais alguém foi lesado.

As variáveis atraso, magnitude, natureza do dano (material ou moral) e autor do dano foram investigadas no presente trabalho.

\section{Economia Comportamental}

O campo da economia comportamental (EC) tem sido definido pelo estudo de anomalias em escolhas, isto é, escolhas que não obedecem à teoria da utilidade esperada (Ainslie, 2015), segundo a economia. Essa teoria prediz que os indivíduos farão escolhas que maximizam a utilidade esperada, ou seja, benefícios ou reforços devem ser maximizados e custos ou punições, minimizados (Ainslie, 2015). Por exemplo, dada uma série de opções compostas de ganhos probabilísticos, seria esperado que as alternativas com maior utilidade esperada (ganho $\mathrm{X}$ probabilidade) fossem escolhidas. No entanto, várias pesquisas encontraram que pessoas aparentemente cometem violações a esse princípio da maximização (Ainslie, 2015).

A psicologia tradicionalmente investiga o comportamento humano e pode lançar alguma luz sobre aspectos importantes que influenciam escolhas não previstas pela economia (Rabin, 1998). Duas tendências teóricas distintas têm se dedicado à investigação desses fenômenos: a cognitivista e a comportamental. A EC de base cognitivista tem se concentrado em explorar como o enquadramento (framing) cognitivo afeta as escolhas. Essa tendência de pesquisa identificou uma série de anomalias e, baseando-se nesses achados, contrapõe-se à premissa econômica de maximização. No entanto, a falta de componentes teóricos comuns que expliquem as anomalias encontradas, tem produzido questionamentos sobre o potencial e a adequação dessa abordagem de pesquisa (Oliveira-Castro, 2015). 
A abordagem comportamental de EC teve seu início na década de 1970, com Jonh Kagel e Robin Winkler, que cunharam o termo "economia comportamental" para referir-se à aplicação da análise comportamental de Skinner a escolhas econômicas (Ainslie, 2015). Mais recentemente, essa tendência de pesquisa tem sido denominada economia comportamental operante (Foxall, 2015). A EC operante tem se dedicado à investigação de variáveis que influenciam as escolhas ditas anômalas.

Fantino e Esfandiari (2002), por exemplo, observaram que quando as contingências eram mais "transparentes" (os participantes recebiam informações sobre a probabilidade de reforçamento associada a cada estímulo), o responder ótimo era mais frequente e escolhas anômalas menos observadas. Em outro trabalho, Fantino e Stolarz-Fantino (2013) observaram que o uso do feedback corretivo melhorou a performance em tarefas de solução de problemas, evitando erros como os observados na falácia da conjunção ${ }^{4}$. Essas e muitas outras variáveis têm sido estudadas em pesquisas com humanos e com animais não humanos, dentro dessa abordagem (Oliveira-Castro, 2015).

A combinação entre economia e psicologia operante conjuga o rigor das técnicas experimentais comportamentais com a amplitude conceitual da economia gerando enormes benefícios para a compreensão de fenômenos estudados por esses dois campos do conhecimento (Green \& Freed, 1997). Skinner (1953) afirma que uma ciência do comportamento adequada poderia suprir satisfatoriamente as questões referentes ao comportamento individual, que é responsável pelos dados da economia em geral. Todavia, estudos econômicos revelam que, na verdade, a abordagem comportamental é muito favorecida quando adota princípios econômicos. Um experimento comportamental é um sistema econômico e suas características podem determinar fortemente os resultados (Hursh, 1980).

\footnotetext{
${ }^{4}$ A falácia da conjunção é um erro de lógica clássico identificado por Tversky e Kahneman (1983). Sob certas condições, os participantes julgam a conjunção de dois eventos separadamente. Para saber mais, ver Tversky e Kahneman (1983) e Fantino, E., \& Stolarz-Fantino, S. (2013).
} 
Além disso, a incorporação dos princípios econômicos à análise experimental do comportamento representa um avanço na compreensão dos efeitos do reforçamento. Reforçadores podem ser distinguidos por sua dimensão funcional chamada elasticidade da demanda, que é independente de seu valor relativo e podem interagir enquanto complementares ou substitutos. A EC pode prover um entendimento mais completo do reforçamento e das teorias sobre escolha (Green \& Freed, 1997).

\section{Escolha}

Quando dois ou mais estímulos são acessíveis, a resposta do organismo a um desses estímulos é chamada de escolha. Preferir é responder mais a um dos estímulos disponíveis ou alocar mais tempo em um deles (Skinner, 1950).

Como qualquer resposta que tenha sido reforçada no passado pode ocorrer em um contexto em que outra resposta está sendo mantida por outras consequências (Catania, 1999), as pesquisas básicas em Economia Comportamental têm utilizado, predominantemente, esquemas concorrentes para investigar as variáveis que afetam escolha e preferência (Todorov \& Hanna, 2005). Esquemas concorrentes são aqueles programados, simultaneamente, para duas ou mais respostas (Catania, 1999). Em tais esquemas, duas ou mais opções sinalizadas de respostas estão disponíveis e o organismo pode alternar entre elas em qualquer momento exceto em procedimentos de escolha forçada, nos quais apenas uma alternativa é apresentada por vez e são, geralmente, utilizados para garantir que os organismos sejam expostos a todas as opções programadas (Jacobs, Borrero \& Vollmer, 2013).

Quando esquemas conc VI e o $\mathrm{COD}^{5}$ são utilizados, independentemente do procedimento empregado, os organismos distribuem suas respostas entre as alternativas de

\footnotetext{
5 Esquemas conconcorrentes de intervalo variável (conc VI) são esquemas programados, simultaneamente, para duas ou mais respostas. Nesses esquemas, a apresentação de um reforçador depende da passagem de um príodo variável de tempo e da emissão de uma única resposta. Comumente, os procedimentos concorrentes de VI incorporam um atraso sobre a mudança de alternativa, o COD (changeover delay), que evita que qualquer resposta seja reforçada imediatamente após uma mudança (Catania, 1999).
} 
forma proporcional à distribuição de reforços programados em cada uma delas (Herrnstein, 1961). Tal fenômeno possui tamanha generalidade que foi proposto como lei geral que descreve o comportamento, chamada Lei da Igualação (matching law) (Catania, 1999). A Lei da Igualação é um modelo quantitativo que descreve a maneira como os organismos distribuem suas respostas quando estas são mantidas por esquemas conc VI.

Segundo Jacobs, Borrero e Vollmer (2013), a Lei da Igualação expressa que nenhuma contingência de reforçamento é absoluta. Ao contrário, elas ocorrem em contextos que incluem outras contingências comportamentais. Dessa forma, até mesmo esquemas simples operam concorrentemente a contingências intrínsecas ao experimento (os animais em uma caixa experimental podem emitir a resposta que está sendo medida pelo experimentador ou qualquer outra possível, como cheirar, coçar etc.) (Mazur, 1987).

Estudos empíricos têm demonstrado consistentemente que desvios do desempenho considerado matching são típicos (Baum, 1979). Ou seja, tipicamente a taxa absoluta de respostas em uma alternativa não é "idêntica" à taxa absoluta de reforços disponibilizada nessa alternativa (Baum, 1979). Para acomodar tais desvios, Baum (1974) introduziu a Lei da Igualação Generalizada, na qual parâmetros livres foram acrescentados à equação de Herrnstein (1961) para ajustar a constante preferência por uma alternativa (quando tal preferência não pode ser explicada por diferenças na taxa de reforços) e ajustar as diferenças individuais de sensibilidade à taxa de reforços.

A Lei da Igualação e a Lei da Igualação Generalizada acomodam os resultados encontrados em pesquisas nas quais os procedimentos utilizados disponibilizam reforços de maneira imediata. Ou seja, logo após a resposta do organismo a consequência programada é apresentada. No entanto, fora do laboratório - e às vezes até dentro dele - nem sempre a consequência de um comportamento é imediata à emissão da resposta. É bastante comum que certo tempo decorra entre a resposta e a apresentação do reforço. Esse tempo é chamado de 
atraso (Todorov \& Hanna, 2005). Frequentemente as consequências que compõem alternativas distintas se diferem em mais do que uma dimensão. Por exemplo, uma alternativa pode conter um reforço de magnitude grande, disponibilizado apenas após certo tempo, enquanto outra alternativa pode conter um reforço de magnitude pequena, mas que é disponibilizado logo após a emissão da resposta. A linha de pesquisa que estuda escolha entre alternativas que variam nessas duas dimensões - atraso e magnitude - será explorada a seguir.

No caso de escolhas que envolvem ressarcimento, o atraso necessariamente deve ser considerado pois ele faz parte das alternativas disponíveis. Pode-se considerar, inclusive, que há dois atrasos distintos nesse contexto: aquele presente entre o dano e o momento da escolha entre fazer um acordo ou aguardar a decisão do juiz, e aquele presente entre a escolha e a concretização de ressarcimento (receber a indenização).

O efeito do atraso entre a escolha e o acesso à consequência foi amplamente investigado e os principais resultados serão apresentados abaixo. Não há pesquisas, no entanto, que tenham verificado o efeito do atraso entre um evento ocorrido no passado e o momento da escolha. $\mathrm{E}$ esse é um dos pontos de interesse do presente trabalho. 


\section{Desconto do Atraso}

Desconto do atraso é definido como a desvalorização que consequências atrasadas sofrem em função do atraso existente entre o momento da escolha e o acesso a essas consequências (Odum, 2011). Essas consequências podem ser reforçadoras ou aversivas.

No caso do reforço, o valor pode ser medido de diferentes formas. Uma dessas formas consiste em verificar qual a taxa de respostas suportada (mantida) por uma consequência. De maneira geral, comportamentos mantidos por consequências imediatas ocorrem em maiores taxas que comportamentos mantidos por consequências atrasadas (Odum, Madden \& Bickel, 2002). Outra forma de se medir valor é a escolha ou preferência, mais utilizada no paradigma do desconto do atraso, geralmente, quando os reforços disponibilizados em diferentes alternativas variam apenas no tamanho do atraso, reforços imediatos são preferidos aos atrasados (observa-se maior número de escolhas pelos reforços imediatos em relação às escolhas pelos reforços atrasados). Quando a consequência em questão é um estímulo aversivo, observa-se o contrário: animais não humanos e humanos escolhem a consequência aversiva atrasada, se o atraso for a única dimensão que diferencia as duas alternativas (Odum, Madden \& Bickel, 2002).

No caso de reforços, o valor de consequências atrasadas é descontado (desvalorizado) tornando o reforço imediato preferido. No caso dos aversivos, os custos da alternativa atrasada são descontados, de modo que as consequências imediatas se tornam mais aversivas que as atrasadas (Odum, Madden \& Bickel, 2002).

No entanto, a preferência se torna menos previsível quando as alternativas da escolha diferem em mais de uma dimensão - por exemplo, quando alguém tem que escolher entre uma recompensa de menor magnitude, disponibilizada imediatamente, ou uma recompensa de maior 
magnitude, disponibilizada após algum $\operatorname{atraso}^{6}$ (Green \& Myerson, 2004). Por isso, diversos estudos têm sido dedicados à investigação de variáveis que afetam escolhas intertemporais desse tipo (Chapman, 1996; Chapman \& Elstein, 1995; DeHart \& Odum, 2015; Estle, Green, Myerson \& Holt, 2006; Franck, Koffarnus, House \& Bickel, 2015; Mazur, 1987; Mitchel \& Wilson, 2010; Odum, Madden \& Bickel, 2002; Ostaszewski \& Karzel, 2002; Rachlin, 1990; Stein, Renda, Hinnenkamp \& Madden, 2015). Alguns deles foram realizados com animais não humanos e outros realizados com humanos. Os principais procedimentos empregados nessas pesquisas serão descritos no Experimento 1.

\section{Medidas da Taxa de Desconto}

De maneira geral, os procedimentos utilizados na área do desconto subjetivo apresentam séries de escolhas aos participantes. Geralmente, os participantes devem escolher uma alternativa entre duas apresentadas: uma composta por consequências de magnitude maior, disponibilizadas com algum atraso (maior-atrasado), e outra composta por consequências de magnitude menor, disponibilizada imediatamente após a emissão da resposta de escolha (menor-imediato). Feitas as escolhas, busca-se identificar qual é o atraso em que as escolhas do sujeito são distribuídas de forma indiferente entre dois reforçadores. O ponto em que as escolhas do sujeito entre menor-imediato e maior-atrasado são indiferentes é chamado de ponto de indiferença (PI). O PI é uma medida do desconto no valor do reforço, sofrido em função do atraso (Madden \& Johnson, 2010). Ele aponta o "valor presente" da consequência atrasada; oferece uma estimativa do valor subjetivo do reforço atrasado - pode-se supor que no PI, o

\footnotetext{
${ }^{6} \mathrm{Na}$ literatura da área, as escolhas por alternativas compostas por reforçadores menores e imediatos são, frequentemente, denominadas de "impulsividade" e as escolhas por alternativas compostas por reforçadores maiores e atrasados são denominadas de "autocontrole" (Hanna \& Ribeiro, 2005; Madden \& Johnson, 2010). No entanto, no presente trabalho optou-se por não usar tais termos - eles são muito frequentemente utilizados em contextos clínicos (que não é o contexto desse estudo) e, na linguagem cotidiana, parecem conter conotações que envolvem juízo de valor (autocontrole é "bom" e impulsividade é "ruim"). Além disso, parece inadequado o uso dos termos quando aplicados a ressarcimento de danos.
} 
valor subjetivo do maior-atrasado é igual ao valor do menor-imediato, dado que as escolhas entre as alternativas são indiferentes.

Com base nos pontos de indiferença é possível calcular a taxa do desconto. Essa taxa reflete a velocidade com que um evento (e.g., um valor em dinheiro) é desvalorizado em função de seu atraso (Hursh, Madden, Spiga, DeLeon \& Francisco, 2013).

\section{Função Hiperbólica e Função Exponencial}

Pesquisas com humanos (Green, Fry \& Myerson, 1994; Kirby \& Marakovic, 1995; Rachlin, Raineri \& Cross, 1991), pombos (Mazur, 1987) e outros animais (Bradshaw \& Szabadi, 1992; Richards, Mitchell, de Wit \& Seiden, 1997) indicam que o atraso efetivamente diminui o valor subjetivo da recompensa. Esse desconto no valor da recompensa pode ser descrito por uma função hiperbólica (Mazur, 1987):

$$
\mathrm{V}=A /(1+k D)
$$

Equação 1

onde $V$ é o valor subjetivo da recompensa em um determinado atraso (ou seja, é a "resposta" do participante, o PI - a depender do procedimento utilizado - ou ainda a média ou a mediana de um grupo), $A$ é a magnitude da recompensa (é o valor da recompensa), $D$ é a duração de um dos atrasos utilizados na pesquisa para receber a recompensa (geralmente utilizase de cinco a sete atrasos, porque desse modo tem-se pontos suficientes para que a curva seja "desenhada" com mais precisão), e $k$ é um parâmetro livre que indica a taxa de desconto. Essa equação é aplicada a cada um dos atrasos utilizados, obtendo-se um valor de $k$ para cada atraso. Maiores valores de $k$ indicam uma desvalorização mais acentuada do valor do reforço em função do atraso.

O modelo hiperbólico não é o único utilizado para descrever os achados na área do desconto. Alguns estudos em Economia e de Economia Comportamental apontam que a função exponencial apresenta bom ajuste aos dados (Loewenstein, 1992; Samuelson, 1937). No entanto, há diferenças críticas nas predições desses dois modelos: o modelo hiperbólico, por 
exemplo, prevê a reversão da preferência (descrita em um tópico mais abaixo no presente texto), enquanto que o modelo exponencial não o faz - de acordo com o modelo exponencial, as escolhas deveriam permanecer constantes ao longo do tempo (Kagel, Battalio \& Green, 1995). Além disso, na função exponencial, incrementos iguais nos atrasos produziriam decréscimos proporcionais e constantes no valor subjetivo da consequência, enquanto que na função hiperbólica, incrementos iguais nos atrasos produziriam decréscimos maiores em atrasos pequenos do que em atrasos grandes (Simpson \& Vuchnich, 2000).

A função exponencial é expressa da seguinte forma (Samuelson, 1937):

$$
\mathrm{V}=\mathrm{Ae}^{-k \mathrm{D}} \quad \text { Equação } 2
$$

onde $V, A, k$ e $D$ são idênticos aos da Equação 1 . O $e$ é a base do logaritmo natural.

Vários estudos foram dedicados à comparação entre o ajuste oferecido pelos modelos hiperbólico e exponencial e os dados de desconto (Ainslie, 1992; Green \& Myerson, 1993; Mckerchar, Green, Myerson, Pickford, Hill \& Stout, 2009; Richards, Mitchell, de Wit \& Seiden, 1997; Myerson \& Green, 1995; Simpson \& Vuchinich, 2000). A grande maioria deles encontrou ajustes melhores com a função hiperbólica ou com funções derivadas dela - tipo hiperbólica ou ainda hiperboloide, nas quais há o acréscimo de parâmetros livres.

\section{Área sob a curva}

Além do uso das funções exponencial, hiperbólica e hiperbólicas modificadas para análise do desconto, pode-se utilizar a área sob a curva (do inglês area under the curve - AUC). Myerson, Green e Warusawitharana (2001) propuseram o uso da área abaixo da função empírica do desconto (conjunto de valores obtidos, plotados como função da variável independente), evitando assim potenciais problemas originados na falta de consenso quanto à forma matemática da função do desconto, bem como problemas de análise quantitativa que surgem de propriedades estatísticas dos parâmetros das funções. A AUC é teoricamente neutra 
e pode ser utilizada tanto para dados individuais quanto de grupo, produzidos por quaisquer um dos procedimentos comumente utilizados na literatura.

A AUC é calculada da seguinte forma: normaliza-se o atraso e o valor subjetivo para cada ponto. Isto é, o atraso deve ser expresso como proporção do atraso máximo e o valor subjetivo deve ser expresso como proporção do valor nominal (o valor subjetivo é dividido pelo valor real da consequência atrasada). Esses valores normatizados são utilizados como coordenadas $x$ e $y$, respectivamente, para construir o gráfico de dados do desconto. Linhas verticais são então extraídas de cada ponto do eixo $x$, subdividindo o gráfico em uma série de trapézios. A área sob a função empírica desconto é igual a soma das áreas destes trapézios. A seguinte equação (3) é normalmente utilizada:

$$
\mathrm{X}_{2}-\mathrm{X}_{1}\left[\left(\mathrm{Y}_{1}+\mathrm{Y}_{2}\right) / 2\right]
$$

A ordenada representa a proporção do valor absoluto do reforço (não descontado) e a abcissa a proporção do maior atraso possível para o reforçamento (Smith \& Hantula, 2008). Quanto maior for o desconto (isto é, mais baixo o valor subjetivo das consequências atrasadas) menor será a área sob a curva (Myerson, Green \& Warusawitharana, 2001).

Como os valores dos eixos x e y são normatizados, a AUC pode variar entre 0,0 (maior desconto possível) e 1.0 (sem desconto). O total da AUC se correlaciona negativamente com os valores de $k$ derivados dos modelos quantitativos anteriormente discutidos, ou seja, valores altos de $k$ terão valores baixos de AUC (Reed, Kaplan \& Brewer, 2012).

\section{Reversão da Preferência}

O exemplo clássico de desconto envolve escolher entre uma consequência maior e uma menor, de modo que a consequência menor é disponibilizada antes da consequência maior. Apesar de os indivíduos escolherem a consequência de maior magnitude e mais atrasada quando as duas alternativas estão distantes no futuro, com a passagem do tempo (ou seja, com a aproximação temporal do momento em que as consequências serão disponibilizadas), a 
preferência pode inverter e o indivíduo passa então a escolher a consequência de menor magnitude e mais imediata, isto é, ocorre a reversão ${ }^{7}$ da preferência (Green \& Myerson, 2004). O primeiro artigo a abordar tal fenômeno na literatura foi produzido por Strots, em 1956. O autor afirmou que análises de decisões sobre consumo futuro devem incluir a variável “distância temporal" entre a escolha e o acesso aos bens que serão consumidos. Strots (1956) ressaltou que a mudança dessa distância temporal afetaria a consistência de decisões - as escolhas se alterariam com a passagem do tempo. Assim, alguém que está distante um ano e um mês do acesso ao reforço da alternativa maior-atrasado e distante um ano e um dia do reforço da alternativa menor-imediato, pode inicialmente escolher a opção maior-atrasado. Após um ano ter se passado, tal pessoa, que está agora distante apenas um dia do reforço da alternativa menor-imediato e distante um mês do reforço maior-atrasado, passa a escolher nesse momento a alternativa menor-imediato.

De acordo com Green e Myerson (2004), a reversão da preferência ocorreria porque o valor subjetivo de consequências menores e mais imediatas decresce mais acentuadamente que o valor subjetivo de consequências maiores e atrasadas, quando há um acréscimo equivalente nos atrasos das duas consequências.

Green, Fristoe e Myerson (1994) realizaram um estudo em que a reversão da preferência foi consistentemente demonstrada. Nele, 24 estudantes de graduação fizeram escolhas entre pares de quantias hipotéticas de dinheiro, que seriam disponibilizadas após diferentes atrasos. Foram utilizados três pares de valores monetários: $\$ 20,00$ versus $\$ 50,00 ; \$ 100,00$ versus

\footnotetext{
${ }^{7} \mathrm{Na}$ literatura da área há duas expressões utilizadas na descrição do fenômeno mencionado acima: "reversão da preferência" (do inglês "preference reverse") (Green \& Myerson, 2004; Holanda, 2012) e "inversão da preferência" (Coelho, Hanna \& Todorov, 2003). No presente texto optou-se pelo uso de "reversão da preferência" por ser a expressão mais frequentemente encontrada nos estudos de desconto e porque os dois termos são semanticamente equivalentes - o verbo "reverter", enquanto transitivo direto e pronominal, significa dar ou tomar direção contrária a; tomar ou ganhar sentido oposto àquele em que se encontra (significado distindo de quando é transitivo indireto, cuja definição dicionária é retornar à condição inicial, ao ponto de onde se partiu; regressar etc.) e o verbo "inverter", enquanto transitivo direto e pronomial, significa alterar, trocar, mudar (Michaelis Dicionário Brasileiro da Língua Portuguesa, 2015).
} 
$\$ 250,00$; e $\$ 500,00$ versus $\$ 1.250,00$. Os atrasos das consequências mais imediatas variaram entre nenhum atraso e 20 anos. Os atrasos das consequências atrasadas eram sempre maiores que os das consequências imediatas. A diferença entre os atrasos das consequências imediatas e os atrasos das consequências atrasadas variou de uma semana a 20 anos. Por exemplo, em uma das tentativas os participantes tiveram que escolher entre $\$ 20,00$ imediatos ou $\$ 50,00$ dali seis meses. Quando a alternativa composta pelo reforço de menor magnitude e imediato era escolhida, havia um acréscimo igual de tempo nos atrasos das duas alternativas. Se o participante escolheu $\$ 20,00$ imediatos ao invés de $\$ 50,00$ dali seis meses, na tentativa seguinte o participante deveria escolher entre $\$ 20,00$ disponibilizados dali uma semana ou $\$ 50,00$ disponibilizados dali seis meses e uma semana. Esse procedimento continuou até que o participante mudasse sua escolha para a alternativa composta pelo reforço de maior magnitude e mais atrasado.

Conforme o atraso da alternativa imediata foi estendido, a porcentagem de participantes que escolheu a alternativa atrasada aumentou. Isso foi observado nos três pares de valores monetários e em todos os atrasos utilizados.

Esses resultados foram corroborados por uma série de outros estudos; é um fenômeno robusto na área, observado com humanos e com não humanos (Rachlin \& Green, 1972; Kirby \& Herrnstein, 1995).

No fenômeno da reparação de danos, a reversão da preferência seria algo como a pessoa lesada não aceitar o acordo proposto por quem causou o dano (escolhe a opção maior-atrasado, esperando a decisão judicial) durante a audiência de conciliação e, numa segunda audiência (a de instrução, que serve à produção de provas), o autor decidir rever sua decisão e aceitar o acordo proposto anteriormente pelo réu - caso este mantenha a oferta - ou uma nova proposta ofertada naquele segundo momento pela parte adversa. 
Isso é possível porque como já destacado anteriormente, é interesse recorrente do Estado que haja a resolução de controvérsias. Na hipótese em questão, o artigo 359 do Código de Processo Civil determina que, após instalada a audiência de instrução, o juiz tente conciliar as partes independentemente do emprego anterior de outros métodos de solução consensual de conflitos, como a mediação e a arbitragem.

\section{Principais Resultados de Pesquisas com Humanos}

A partir de 1937, quando o arcabouço do desconto começou a ser desenvolvido a partir do modelo proposto pelo economista Paul Samuelson, intitulado Discounted Utility Model (Frederick, Loewenstein \& O’Donoghue, 2002), muitas variáveis foram estudadas na área, tanto com humanos quanto com outros animais. Em função dos objetivos do presente trabalho, os resultados obtidos com humanos serão explorados a seguir. Mais especificamente, aqueles relacionados aos efeitos das variáveis magnitude do reforço (Chapman \& Winquist, 1998; Thaler, 1981; Loewenstein \& Prelec, 1992; Chapman \& Winquist, 1998), desconto com perdas (Ostaszewski \& Karzel, 2002; Estle, Green, Myerson \& Holt, 2006; Mitchel \& Wilson, 2010; Holt, Green, Myerson \& Estle, 2008; Ohmura, Takahashi \& Kitamura, 2005; Odum, Madden \& Bickel, 2002; e Rachlin, 1990), sequências (Loewenstein \& Prelec, 1993; Loewenstein \& Scherman, 1991; Frederick \& Loewenstein, 2008) e desconto no passado (Bickel, Yi, Kowal \& Gatchalian, 2008; Yi, Gatchalian \& Bickel, 2006; Stieg \& Dixon, 2007).

\section{Magnitude do reforço}

A literatura sobre vieses em escolhas intertemporais tem demonstrado que taxas de descontos são maiores para reforços de menor magnitude do que para reforços de maior magnitude (Chapman \& Winquist, 1998). Thaler (1981), por exemplo, encontrou que participantes que eram indiferentes entre $\$ 15,00$ imediatos e $\$ 60,00$ disponibilizados com um ano de atraso, também eram indiferentes entre $\$ 3.000,00$ imediatos e $\$ 4.000,00$ disponibilizados com um ano de atraso. No primeiro caso $(\$ 15,00$ versus $\$ 60,00)$, a taxa de 
desconto anual é de $300 \%$. No segundo (\$3.000,00 versus $\$ 4.000,00)$, a taxa de desconto anual é de $33 \%$. Ou seja, os reforços de menor magnitude sofreram um desconto muito maior (300\%) do que os reforços de maior magnitude (33\%) atrasados pelo mesmo período de tempo. Esses resultados foram corroborados posteriormente por vários estudos (Chapman \& Winquist, 1998; Grace, Randolph, Sargisson, Rebecca, White \& Geoffrey, 2012; Green, Myerson, Holt, Slevin \& Estle, 2004) e tal achado foi chamado de Efeito de Magnitude.

Loewenstein e Prelec (1992) oferecem uma possível explicação para esse efeito. Segundo os autores, o efeito de magnitude poderia ser o resultado de uma função de utilidade para reforçadores atrasados. Desse modo, a razão entre $\$ 5,00$ e $\$ 10,00$, por exemplo, é menor que a razão entre $\$ 500,00$ e $\$ 1.000,00$. Consequentemente, as pessoas podem preferir $\$ 5,00$ imediatos ao invés de $\$ 10,00$ em um ano e preferirem $\$ 1.000,00$ em um ano ao invés de $\$ 500,00$ imediatos, mesmo que nos dois conjuntos de escolha o "ganho" anual seja de $50 \%$. Os $50 \%$ acrescidos ao reforço de maior magnitude têm valor real maior que os $50 \%$ acrescidos ao reforço de menor magnitude.

Chapman e Winquist (1998) realizaram um estudo cujos resultados corroboram a explicação de Loewenstein e Prelec (1992). Segundo Chapman e Winquist (1998), se a hipótese fornecida por Loewenstein e Prelec (1992) estivesse correta, o efeito de magnitude seria observado em diferentes cenários e com reforçadores de naturezas diversas. Para testar essa predição, 50 participantes responderam dois questionários. Em um deles, os participantes deveriam apontar qual o valor que eles pagariam como gorjeta em três situações diferentes (em um restaurante, em um taxi e em um corte de cabelo) e diante de quatro magnitudes de conta. Por exemplo, se o participante jantasse em um restaurante e o valor final desse jantar fosse $\$ 20,00$, quanto ele deixaria de gorjeta para o garçom? E se o valor final do jantar fosse $\$ 40,00$ ? O segundo questionário respondido pelos participantes era composto de questões típicas da área do Desconto de Atraso. Metade do questionário envolvia ganhos e a outra metade 
envolvia perdas. Nas escolhas intertemporais envolvendo ganhos, os participantes apresentaram taxas maiores de desconto para montantes monetários menores. Nas escolhas envolvendo perdas quase não se observou efeito de magnitude - achado comum na área, que será explorado adiante nesse texto. $\mathrm{O}$ efeito de magnitude foi observado também nos cenários de gorjetas, ou seja, quanto maior o valor total do serviço a ser pago, menor era a porcentagem, referente a esse valor, deixada de gorjeta.

O efeito de magnitude foi encontrado também quando os reforços utilizados eram férias e saúde. Chapman e Elstein (1995) realizaram um estudo que buscou investigar se os efeitos (magnitude e reversão da preferência, principalmente) encontrados nas pesquisas com dinheiro são também observados com saúde e férias. Os participantes responderam a questionários compostos de 48 perguntas sobre escolhas intertemporais divididas em três contextos diferentes: dinheiro, saúde e férias. Nos três contextos as taxas de desconto foram menores (proporcionalmente) para atrasos mais longos e para magnitudes maiores. Tanto o efeito de magnitude quanto a reversão da preferência foram observados para dinheiro, férias e saúde.

O efeito de magnitude foi encontrado também em estudos realizados com animais não humanos (Grace, Sargisson \& White, 2012; Green, Myerson, Holt, Slevin \& Estle, 2004), quando utilizaram procedimentos típicos de Desconto do Atraso com reforçadores positivos. Trata-se, por tanto, de um fenômeno de grande generalidade, mas que, no entanto, nunca foi investigado no contexto de ressarcimento de danos.

Não se sabe, por exemplo, se a magnitude do dano afetaria o desconto subjetivo. A situação de reparação de danos envolve peculiaridades que tornam difícil a "predição teórica" da presença do efeito de magnitude - como dito anteriormente, quando há indenização, um dano ocorreu. Desse modo, tem-se ganhos e perdas envolvidos e a literatura aponta (como será explorado a seguir) que o efeito de magnitude com perdas é pequeno ou inexistente. 


\section{Desconto com perdas}

Algumas pesquisas na área foram dedicadas a investigar se os achados encontrados em Desconto do Atraso envolvendo ganhos poderiam ser generalizados para cenários que envolvem perdas.

Ostaszezewski e Karzel (2002), por exemplo, realizaram um estudo cujos objetivos eram: (1) investigar se o valor subjetivo de perdas também era descontado em função de atrasos; (2) verificar se desconto com perdas seria bem descrito por uma função hiperbólica; e (3) averiguar se havia efeito de magnitude em contextos de perdas monetárias. Estudantes universitários responderam a questionários hipotéticos, no computador, em que deveriam fazer escolhas entre perdas monetárias imediatas e atrasadas. Assim, cada participante deveria escolher entre pagar quantias de dinheiro menores e imediatas ou pagar quantias de dinheiro maiores e atrasadas. As magnitudes utilizadas foram $\$ 200,00 ; \$ 5.000,00$ e $\$ 30.000,00$. Foram apresentados seis atrasos que variaram de um mês a 10 anos.

Os resultados apontaram que o desconto do valor da consequência, em função do atraso, também ocorre quando essa consequência é perder dinheiro. Além disso, o desconto observado com perdas foi bem descrito pela função hiperbólica. Os autores ressaltaram ainda que o valor menor de perda $(\$ 200,00)$ sofreu maior desconto que os valores maiores $(\$ 5.000,00 \mathrm{e}$ $\$ 30.000,00)$, diante dos mesmos atrasos. Não houve diferença entre os descontos sofridos pelos valores maiores, o que, segundo os pesquisadores, pode ser atribuído a um possível "efeito de teto" $-\$ 5.000,00$ e $\$ 30.000,00$ podem ter sido percebidos pelos participantes como valores igualmente altos. Observou-se ainda que o efeito de magnitude foi significativamente menor para perdas do que para ganhos.

Estle, Green, Myerson e Holt (2006) encontraram resultados semelhantes aos apresentados por Ostaszewski e Karzel (2002). Estle e cols. (2006) utilizaram um procedimento semelhante ao descrito acima e também observaram que o desconto no valor subjetivo de 
perdas, em função do atraso, é bem descrito pela função hiperbólica. Além disso, os autores verificaram que o efeito de magnitude foi muito menor para perdas do que para ganhos - quando os valores monetários eram pequenos, observou-se que os ganhos atrasados foram descontados mais acentuadamente do que as perdas atrasadas.

Holt, Green, Myerson e Estle (2008) realizaram um estudo que, além de investigar o efeito de magnitude, verificou se a reversão da preferência também ocorre em cenários com perdas monetárias hipotéticas. O procedimento foi iniciado ajustando-se a diferença nos atrasos para o pagamento de um valor pequeno e para o pagamento de um valor grande, até que os participantes preferissem pagar o valor maior e mais atrasado. Foram utilizadas quatro magnitudes de perdas diferentes e 11 atrasos (esses atrasos, aqui, se referem à diferença entre o atraso do menor-imediato e do maior-atrasado, ou seja, é o valor do atraso do maior-atrasado menos o valor do atraso do menor-imediato), que variaram de uma semana a 20 anos. A partir disso, atrasos com iguais durações foram adicionadas nas duas alternativas para verificar se haveria a reversão da preferência. Os atrasos adicionados variaram de zero a 20 anos.

Em relação ao efeito de magnitude com perdas, novamente os dados obtidos corroboraram a literatura da área, uma vez que não foi estatisticamente significativo. Além disso, os resultados apontaram que a reversão de preferência também ocorre quando pessoas escolhem entre perdas atrasadas. Entretanto, nesse caso, as pessoas preferiram pagar a menor quantia mais imediata quando as duas consequências hipotéticas estavam em um futuro distante. Mas quando essas consequências estavam próximas ao presente, os participantes preferiram a alternativa composta por perda maior e mais atrasada. Vale ressaltar que a reversão da preferência com perdas ocorreu em uma direção diferente da reversão da preferência que se observa com ganhos - com consequências reforçadoras, geralmente as pessoas escolhem a alternativa maior-atrasado quando todas as alternativas estão em um futuro distante e escolhem a alternativa menor-imediato quando todas as alternativas estão próximas ao presente. Os 
autores observaram também que a reversão da preferência com perdas foi afetada tanto pela diferença entre os atrasos do menor-imediato e do maior-atrasado quanto pelos atrasos inseridos nas duas alternativas. O valor absoluto das consequências não apresentou efeito na reversão da preferência.

Estudos com perdas foram realizados também em outros domínios, como por exemplo saúde. Chapman (1996) fez uma série de experimentos em que estudantes universitários deveriam escolher entre perdas e ganhos hipotéticos de dinheiro e de saúde. Os participantes foram solicitados a estimar o valor de perdas e ganhos de dinheiro atrasados em um cassino, e perdas e ganhos atrasados de saúde - perder saúde numa condição de saúde plena presente, e ganhar saúde numa condição de doença presente.

As taxas de desconto encontradas nos dois domínios não apresentaram correlação, ou seja, parece haver uma independência de domínios. No entanto, nos dois domínios o desconto foi afetado pelo atraso, magnitude da consequência e pelo fato de ser perda ou ganho. Tanto para dinheiro quanto para saúde, as taxas de desconto foram maiores (proporcionalmente) para atrasos pequenos, para magnitudes menores e para ganhos.

O fato de os ganhos terem sofrido maior desconto que as perdas na pesquisa de Chapman (1996) corrobora outros estudos na análise do comportamento. Magoon e Critchfield (2008) afirmam que ganhos e perdas exercem efeitos diferentes sobre o comportamento. Os autores realizaram um experimento em que respostas humanas de clicar em um mouse de computador eram mantidas por esquemas concorrentes de perdas (uma condição) e ganhos (em outra condição) de pontos trocáveis por dinheiro. Os esquemas concorrentes envolvidos tanto nas contingências de perdas quanto nas contingências de ganhos eram estruturalmente similares o "tamanho" dos esquemas eram os mesmos, a magnitude do reforço (positivo e negativo) era a mesma, etc. Os resultados apontaram que as perdas exerceram um impacto maior no comportamento do que os ganhos de igual magnitude. 
No paradigma do Desconto do Atraso, a assimetria entre reforços positivos atrasados e reforços negativos atrasados também foi apontada por várias pesquisas e a diferença entre a desvalorização de consequências reforçadoras e de consequências aversivas atrasadas foi denominada de Efeito de Sinal (do inglês Sign Effect). Diversos estudos têm concluído que ganhos são descontados em maior taxa que perdas. Thaler (1981), por exemplo, realizou uma pesquisa em que solicitou que os participantes imaginassem ter recebido uma multa de trânsito que poderia ser paga imediatamente ou com algum atraso. Em um outro cenário os participantes deveriam imaginar que haviam ganhado um prêmio em uma loteria e esse prêmio poderia ser recebido imediatamente ou com algum atraso. Em seguida, os participantes deveriam estimar que valor estariam dispostos a pagar pela multa se o pagamento fosse atrasado por três meses, um ano ou três anos e qual valor o prêmio deveria ter, após esses mesmos atrasos, para que ele fosse tão atraente quanto receber o prêmio imediatamente. As taxas de desconto observadas nas respostas com perdas (pagar a multa) foram menores que as taxas de desconto observada com ganhos.

Tanto prospectos que envolvem perdas quanto aqueles que envolvem ganhos podem conter mais do que uma consequência. Há situações em que se tem uma sequência de eventos, e as escolhas devem ser feitas entre essas sequências. Estudos foram dedicados a esse tipo de investigação e alguns deles estão descritos abaixo.

\section{Sequência de consequências}

Uma sequência é uma série de consequências espaçadas no tempo. Essas consequências podem ser eventos específicos, como atividades em finais de semana consecutivos, ou podem ser eventos mais abstratos, como índices econômicos, por exemplo, salário ao longo de anos consecutivos (Loewenstein \& Prelec, 1993).

Loewenstein e Prelec (1993) afirmam que quando a escolha é percebida como uma sequência de consequências, as sequências que melhoram são mais escolhidas (ocorre o que a 
economia denomina de desconto negativo, ou seja, a sequência preferida contém estímulos preteridos disponibilizados imediatamente e estímulos preferidos disponibilizados após algum atraso). Por exemplo, se alguém ganha jantares em dois restaurantes diferentes, uma sequência que "melhora ao longo do tempo" seria aquela em que o jantar no restaurante preterido seria consumido primeiro e o jantar no restaurante preferido seria consumido por último. Uma sequência que "piora com o passar do tempo", teria a ordem inversa de acesso dos restaurantes.

Ainda segundo os autores, quando as alternativas da escolha são percebidas como prospectos simples (o comportamento fica sob controle de componentes individuais das alternativas), o que se observa, geralmente, é o maior número de escolhas por reforços imediatos (ocorre o que a economia denomina desconto positivo, que é a desvalorização da consequência em função de seu atraso).

Loewenstein e Scherman (1991) realizaram uma pesquisa em que os participantes deveriam escolher entre formas de receber dinheiro ao longo de cinco anos. Dois cenários diferentes foram utilizados e cada participante respondeu apenas a um deles. Um dos cenários solicitava que o participante imaginasse que não estava trabalhando no momento e que havia recebido uma proposta de emprego para os próximos cinco anos. Havia sete opções de forma de pagamento e o participante deveria escolher uma delas. $\mathrm{O}$ outro cenário solicitava que o participante imaginasse que não estava trabalhando e que sua única fonte de renda nos próximos cinco anos seria o aluguel de um pequeno imóvel que ele possuía. Eram apresentadas sete formas de receber os alugueis ao longo desse tempo e o participante deveria escolher uma. As formas de receber o dinheiro, tanto no primeiro cenário quanto no segundo, eram idênticas e continham opções de ganhos crescentes, ganhos fixos e ganhos decrescentes. Independentemente do cenário, a maioria dos participantes preferiu ganhos que melhoram ao longo do tempo em vez de ganhos fixos ou que decrescem, mesmo que esses últimos ofereçam maior ganho monetário imediato. 
Esses resultados corroboram os achados na literatura da área (Hsee, Abelson \& Salovey, 1991; Frederick, Loewenstein \& O’Donoghue, 2002; Varey \& Kahneman, 1992). A preferência por sequências que melhoram foi encontrada também com não humanos (Blanchard, Wolfe, Vlaev, Winston \& Hayden, 2013), com reforços diversos - dinheiro, jantares em restaurantes, filmes, atividades no fim de semana, entre outros (Chapman, 2000; Loewenstein \& Prelec, 1993) e com estímulos aversivos - vale destacar que sequências que melhoram e que envolvem aversivos, são aquelas em que os estímulos mais aversivos são mais imediatos e os menos aversivos são mais atrasados (Kahneman, Fredrickson, Schreiber \& Redelmeier, 1993).

A preferência por sequências que melhoram não foi encontrada, no entanto, quando a metodologia utilizada foi alocação de recursos e precificação. Frederick e Loewenstein (2008) realizaram um estudo que envolveu uma série de cenários diferentes e cuja tarefa dos participantes era distribuir recursos ao longo de oito anos ou atribuir valor monetário às alternativas atrasadas. Em um dos cenários, por exemplo, o participante deveria considerar que só poderia assistir 30 filmes nos próximos oito anos. Ele deveria então distribuir esses 30 filmes ao longo desse período - deveria dizer quantos filmes, desses 30, assistiria no primeiro ano, no segundo, e assim por diante. Em um outro cenário, era dito aos participantes que deveriam distribuir 30 episódios de dor de cabeça, de igual severidade, ao longo de oito anos. Um dos cenários de precificação, dizia que dois laboratórios estavam conduzindo experimentos idênticos. No entanto, o laboratório “A” pagava \$2.000,00 inicialmente aos participantes de tal experimento e mais $\$ 1.000,00$ após o final da pesquisa, enquanto que o laboratório "B pagava" apenas \$1.000,00 inicialmente e mais alguma quantia ao final do experimento. Era solicitado então que o participante estimasse um valor a ser pago pelo laboratório "B", ao final da pesquisa, para que as duas alternativas (participar do experimento do laboratório A ou do laboratório B) fossem igualmente atraentes. 
Os dados encontrados não apontaram evidências de preferência por sequências que melhoram. As sequências mais escolhidas, tanto no procedimento de alocação quanto no de precificação, foram as de distribuição igualitária ao longo do tempo. Os autores assinalam que tais resultados se devem, provavelmente, ao tipo de procedimento empregado. Segundo eles, a maneira como as perguntas foram apresentadas pode ter explicitado que um futuro melhor acontece às custas de um presente pior. Os procedimentos tradicionalmente utilizados na área (escolha entre duas ou mais sequências) não destacaria esse aspecto, gerando resultados diferentes.

\section{Desconto no passado}

Trope e Liberman (2003) afirmam que as mesmas variáveis que afetam a percepção de distância temporal de eventos futuros afetaria a percepção de outras dimensões como distâncias temporais de eventos passados. Tal predição implicaria na similaridade dos resultados obtidos, na área de desconto do atraso, com consequências distantes no futuro e distantes no passado. No entanto, há apenas três estudos que foram dedicados à investigação de desconto do atraso no passado.

Um desses estudos foi o de Yi, Gatchalian e Bickel (2006), cujo objetivo geral foi verificar se o desconto no valor de consequências distantes no passado seria similar ao desconto observado com consequências distantes no futuro. Os objetivos específicos dessa pesquisa foram avaliar (1) se o desconto de consequências passadas seria bem descrito pela função hiperbólica; (2) se haveria efeito de magnitude e (3) se o efeito de sinal seria observado. Vinte e oito estudantes responderam a questionários de desconto no futuro, no passado, com ganhos, com perdas, e com duas magnitudes $(\$ 10,00$ e $\$ 1.000,00)$. As consequências eram todas hipotéticas. Foram apresentados seis atrasos, tanto no futuro quanto no passado, que variaram de uma semana a cinco anos. No cenário de ganhos no futuro, os participantes deveriam escolher entre um ganho monetário que seria recebido dali uma hora $(\$ 10,00$ ou $\$ 1.000,00$, 
dependendo da condição) ou um ganho monetário maior e mais atrasado. No cenário de ganhos no passado, os participantes deveriam dizer se preferiam ter recebido um valor monetário ( $\$ 10,00$ ou $\$ 1.000,00$, dependendo da condição) uma hora antes ou se preferiam ter recebido um valor maior mais distante no passado. Os cenários de perdas, tanto futuras quanto passadas, eram semelhantes aos cenários de ganhos - a única diferença era a palavra "perda" que aparecia no lugar da palavra "ganho" nos questionários. As mesmas magnitudes e atrasos foram utilizados nesses cenários.

Os dados obtidos nas condições de futuro e passado foram bastante semelhantes. A função hiperbólica apresentou melhor ajuste (que a exponencial) tanto para o desconto de consequências futuras quanto passadas. Além disso, o efeito de magnitude foi observado para ganhos futuros e passados, mas, no entanto, não foi observado para perdas (nem futuras, nem passadas). O efeito de sinal foi observado apenas com as consequências futuras - não houve diferença na taxa de desconto entre perdas e ganhos no passado. Os autores sugerem que replicações sejam feitas para verificar se a ausência de efeito de sinal foi referente apenas aos dados desse estudo ou se é uma característica do desconto com consequências passadas. Outro dado interessante apresentado pelos pesquisadores foi a alta correlação entre o desconto no futuro e no passado - aqueles participantes que apresentaram altas taxas de desconto futuro, também apresentaram altas taxas de desconto passado.

Stieg e Dixon (2007) elaboraram um estudo que obteve resultados semelhantes aos obtidos por Yi, Gatchalian e Bickel (2003). Foram selecionados oito participantes entre jogadores de pôquer, que foram divididos em dois grupos - pessoas que apostavam $\$ 10,00$ ou menos formaram um dos grupos e pessoas que apostavam mais que $\$ 10,00$ formaram o outro grupo. Todos os participantes passaram por três fases. A primeira delas consistia em uma tarefa de desconto que era realizada antes de o participante entrar no torneio de pôquer do dia. Nela, escolhas entre consequências monetárias hipotéticas eram feitas - o montante atrasado era 
sempre $\$ 1.000,00$ e o montante imediato variou de $\$ 1.000,00$ a $\$ 10,00$. Foram apresentados sete atrasos que variaram de uma semana a dez anos. Após a conclusão da primeira fase da pesquisa, o participante era liberado para entrar no torneio de pôquer. Após o torneio, o participante retornava à coleta de dados e realizava as outras duas fases, que consistiam em fazer novamente a tarefa do desconto com consequências futuras e fazer uma tarefa de desconto com consequências distantes no passado, respectivamente. Os atrasos e as magnitudes dos reforços eram os mesmos daqueles apresentados na primeira fase.

Os autores relataram que tanto o desconto no valor de consequências distantes no futuro quanto o desconto no valor de consequências distantes no passado foram bem descritos pela função hiperbólica. Além disso, foi observado que os participantes que apostavam mais dinheiro no pôquer (mais que $\$ 10,00$ ) apresentaram taxas de desconto maiores que aqueles que apostavam menos dinheiro ( $\$ 10,00$ ou menos) e que houve maior desconto na tarefa realizada antes do torneio do que na tarefa realizada após o torneio.

Com objetivo de ampliar os achados em desconto de consequências distantes no passado para outras populações, Bickel, Yi, Kowal e Gatchalian (2008) elaboraram um estudo que comparou taxas de desconto obtidas com fumantes e com não fumantes. Os participantes dos dois grupos (fumantes versus não fumantes) fizeram escolhas entre consequências monetárias hipotéticas em um computador. Foram apresentados questionários de desconto com ganhos e com perdas, no futuro e no passado. Em todos foram utilizadas três magnitudes da consequência $(\$ 10,00 ; \$ 100,00 ; \$ 1.000,00)$ e sete atrasos (um dia a 25 anos). A forma de apresentação das alternativas foi semelhante à utilizada por Yi, Gatchalian e Bickel (2006).

Corroborando os estudos anteriores, a hipérbole foi a função que apresentou melhor ajuste tanto para os dados dos cenários de futuro quanto para os cenários de passado. Foi observado maior taxa de desconto de ganhos para o grupo de fumantes, tanto futuros quanto passados. Notou-se também o efeito de magnitude para ganhos no futuro e no passado. No 
entanto, os dados não apontaram correlação entre perdas no passado e perdas no futuro (para nenhum dos grupos) e não foi possível observar efeito de sinal.

Apesar dos resultados das pesquisas descritas acima apontarem similaridades entre desconto de consequências futuras e de consequências passadas, mais estudos precisam ser realizados. Parece haver consistência nos achados que se referem a ganhos no futuro e no passado - alta correlação entre eles, presença do efeito de magnitude nos dois casos e bom ajuste da hipérbole em ambos. Porém, os dados referentes ao desconto de perdas futuras e passadas não são consistentes - a correlação entre o desconto nesses casos foi baixa ou inexistente. Além disso, o efeito de sinal foi observado apenas com consequências futuras (ganhos ou perdas). O efeito de magnitude foi observado apenas com ganhos (futuros ou passados). Ademais, há aspectos que não foram investigados como, por exemplo, a reversão da preferência no passado e a utilização de procedimentos diferentes do de titulação, tais como os procedimentos de ajuste e de estimativa (descritos no Estudo 1). Nenhum dos estudos citados acima investigou os efeitos do atraso entre um evento passado (como um dano, por exemplo) e o momento da escolha, no desconto subjetivo.

\section{Desconto de Consequências Probabilísticas}

A ideia de que as pessoas se comportam de forma semelhante em face de probabilidades e atrasos foi proposta pela primeira vez por Rotter (1954) e testada por Mischel (1966) no contexto de "atraso de gratificação." Segundo Rotter, as pessoas escolhem recompensas menores e imediatas - ao invés de recompensas maiores e mais atrasadas - porque "aprendem" em seus ambientes que promessas de recompensas muito atrasadas raramente são cumpridas. Em outras palavras, os atrasos longos seriam percebidos (no sentido de afetar o comportamento) como probabilidades baixas. Em situações fora do laboratório, recompensas que são atrasadas por muito tempo se tornam, de fato, menos certas. Portanto, recompensas obtidas após atrasos 
mais longos podem ser compreendidas como sendo menos certas do que recompensas obtidas após atrasos mais curtos (Logue, 1988; Mischel \& Grusec, 1967; Rotter, 1954).

Rachlin, Logue, Gibbon e Frankel (1986) sugeriram que o contrário também pode acontecer: uma série de recompensas probabilísticas (incertas) pode ser experimentada como uma série de recompensas atrasadas. Por exemplo, lançar uma moeda repetidamente e apostar em um dos lados a cada vez, resultaria numa série de vitórias e derrotas. $\mathrm{O}$ atraso entre vitórias pode determinar o valor efetivo da recompensa. Assim, quanto maior o número de perdas entre vitórias, maior será o atraso entre as recompensas.

Alguns pesquisadores sugerem que o desconto do atraso e o desconto probabilístico são ocasionados fundamentalmente pelo mesmo processo. Diversos estudos investigaram paralelos entre desconto do atraso e desconto probabilístico (e.g., Coelho, Hanna \& Todorov, 2003; Keren \& Roelofsma, 1995; Rachlin, Logue, Gibbon, \& Frankel, 1986) ou efeitos análogos (do atraso e da probabilidade) sobre o comportamento de escolha (Chapman, 1997; Gafni \& Torrance, 1984; Myerson, Green, Hanson, Holt, \& Estle, 2003). No entanto, algumas pesquisas têm apontado que determinadas variáveis afetam de forma distinta o desconto do atraso e o desconto probabilístico. As principais similaridades e diferenças entre ambos, que estejam relacionadas aos objetivos do presente trabalho, serão abordadas a seguir. É importante ressaltar que os métodos de coleta de dados utilizados no desconto probabilístico são muito semelhantes aos utilizados no desconto do atraso, descritos anteriormente. Aqui, entretanto, nos procedimentos com humanos, os participantes são solicitados a escolher entre conjuntos de ganhos certos e probabilísticos a fim de determinar o ponto de indiferença - ponto no qual o valor subjetivo do ganho probabilístico é igual ao valor do ganho certo (Mellers, Schwartz, \& Cooke, 1998). 


\section{Efeito sobre o valor subjetivo}

Correspondentemente ao efeito que o atraso exerce sobre o valor subjetivo de consequências, o valor de uma recompensa probabilística diminui à medida que a probabilidade de sua ocorrência decresce (Richards, Zhang, Mitchell \& de Wit, 1999). Se o mesmo processo subjaz tanto o desconto do atraso quanto o probabilístico, indivíduos que apresentarem acentuado desconto no valor de uma recompensa devido ao aumento de seu atraso também deverão apresentar acentuado desconto devido à diminuição da probabilidade de ocorrência. Desse modo, haveria preferência por recompensas mais certas (maior probabilidade de ocorrência).

Richards, Zhang, Mitchell e de Wit (1999) realizaram um experimento para testar essas predições. Os resultados indicam que (a) tanto o desconto do atraso quanto o desconto probabilístico foram bem descritos por uma função hiperbólica; e (b) as taxas de desconto do atraso e probabilístico foram correlacionadas positivamente. Esses resultados são corroborados pelos achados em outros estudos (Du, Green \& Myerson, 2002; Ostaszewski, Green \& Myerson, 1998; Prelec \& Loewenstein, 1991; Richards, Zhang, Mitchell \& De Wit, 1999).

\section{Função hiperbólica}

Alguns estudos dedicaram-se à investigação de qual seria a função matemática que melhor descreve o desconto probabilístico. Assim como ocorre com o desconto do atraso, a função hiperbólica (e as derivadas dela) é a que melhor se ajusta aos dados obtidos com consequências probabilísticas (Chapman \& Weber, 2006; Green \& Myerson, 2004; Richards, Zhang, Mitchell \& de Wit, 1999).

\section{Reversão da preferência}

A reversão da preferência, observada no desconto do atraso, parece ter um paralelo no desconto probabilístico - o common ratio effect (Chapman \& Weber, 2006). Quando há uma redução na probabilidade das duas alternativas, a preferência desloca-se da consequência menor 
e mais provável para a consequência maior e menos provável (Kahneman \& Tversky, 1979). Por exemplo, alguém pode preferir uma alternativa composta de $50 \%$ de chance de ganhar $\$ 100,00$ à outra composta de $25 \%$ de chance de ganhar $\$ 200,00$. Quando ambas as probabilidades são divididas por um mesmo fator 10, a preferência muda e a alternativa composta de 2,5\% de chance de ganhar \$200,00 é escolhida ao invés da alternativa composta de $5 \%$ de chance de ganhar $\$ 100,00$. O common ratio effect pode ser caracterizado pela maior propensão a escolhas por risco quando as probabilidades são pequenas do que quando as probabilidades são maiores (Chapman \& Weber, 2006).

\section{Magnitude do reforço}

A magnitude das consequências também influencia as escolhas sob incerteza. Aumentando-se as magnitudes dos reforços das duas alternativas disponíveis - multiplicandoas pelo mesmo fator - nota-se uma mudança de preferência para a recompensa menor e mais provável (Du, Green \& Myerson, 2002; Green, Myerson, \& Ostaszewski, 1999; Holt, Green \& Myerson, 2003; Markowitz, 1952; Myerson et al., 2003; Rachlin, Brown, \& Cruz, 2000). Esse efeito é denominado de peanuts effect (Chapman \& Weber, 2006). Em outras palavras, observase maior disposição a assumir riscos quando as consequências são de magnitudes pequenas. Por exemplo, alguém poderia preferir uma chance de 50\% de receber $\$ 2,00$ à chance de $100 \%$ de receber \$1,00 dólar. Quando ambos os reforços são multiplicados por 100, no entanto, a pessoa passa a preferir $\$ 100,00$ com $100 \%$ de chance do que $\$ 200,00$ com $50 \%$ de chance. Tanto no efeito de magnitude (observado no desconto do atraso) quanto no peanuts effect há uma mudança nas preferências quando as recompensas são aumentadas. No efeito de magnitude, o desconto temporal torna-se menos acentuado quando a magnitude é aumentada. No peanuts effect, a aversão ao risco aumenta à medida que a magnitude se torna maior. Os efeitos de magnitude e o peanuts effect parecem caminhar para direções opostas - no desconto do atraso, o aumento da magnitude "favorece" a escolha da opção maior e mais atrasada; no desconto 
probabilístico, o aumento da magnitude "favorece" a escolha da opção menor e menos arriscada (Du et al, 2002; Green et al, 999; Holt et al., 2003; Myerson et al., 2003).

\section{Desconto com perdas}

Estle, Green, Myerson e Holt (2006) compararam ganhos e perdas hipotéticos, atrasados e probabilísticos. Os autores encontraram que os ganhos atrasados são descontados significativamente de forma mais acentuada do que as perdas atrasadas, mas somente para pequenas magnitudes. Quando as consequências eram probabilísticas, observou-se que os ganhos foram descontados significativamente de forma mais acentuada do que as perdas, mas apenas para magnitudes maiores.

Diferenças entre o desconto de perdas e ganhos atrasados e probabilísticos também foram encontradas por Shead e Hodgins (2009). Os pesquisadores encontraram uma correlação negativa e alta entre as taxas de desconto de perdas e ganhos probabilísticos - ou seja, indivíduos que apresentaram baixas taxas de desconto para ganhos probabilísticos apresentaram

altas taxas de desconto para perdas probabilísticas e vice-versa. Esses dados não foram observados com desconto de perdas e ganhos atrasados - não foi encontrada correlação entre as taxas de desconto de perdas e ganhos atrasados.

Outras variáveis foram investigadas, tais como o efeito da inflação sobre o valor subjetivo de recompensas probabilísticas e atrasadas (Ostaszewski \& Myerso, 1998), diferenças culturais no desconto do atraso e probabilístico (Green \& Myerson, 2002) e escolhas entre alternativas compostas por combinações de perdas e ganhos probabilísticos (Ostaszewski \& Bialaszek, 2010). Essas pesquisas e as acima citadas apresentam uma série de similaridades e de diferenças entre o desconto do atraso e o desconto probabilístico. Provavelmente, essa é a origem da falta de consenso na área sobre a existência de um processo comum subjacente a ambos. 


\section{Endowment Effect}

A compensação mínima que pessoas estão dispostas a aceitar em troca de ceder um bem que elas possuem é, geralmente, maior do que o valor máximo o qual estão dispostas a pagar para adquirir o mesmo bem. Thaler (1980) chamou esse fenômeno de endowment effect, sugerindo que um objeto é mais valorado por quem o possui do que o é por um possível comprador. No laboratório, esse padrão foi demonstrado por alguns estudos.

Knetsch e Sinden (1984), por exemplo, realizaram uma pesquisa em que os participantes possuíam inicialmente um bilhete de loteria ou $\$ 2,00$. Algum tempo depois, cada participante teve a oportunidade de trocar seu bilhete por dinheiro e vice-versa. Pouquíssimos participantes escolheram trocar o que já possuíam e, entre os que fizeram a troca, a maioria era do grupo que inicialmente possuía apenas o dinheiro.

Outra demonstração do endowment effect foi fornecida pelo estudo de Kahneman, Knetsch e Thaler (1990). Estudantes foram divididos em dois grupos - um em que recebiam uma caneca (vendedores) e outro em que não recebiam nada e poderiam comprar canecas do primeiro grupo (vendedores). Foi perguntado aos vendedores qual o menor preço pelo qual estariam dispostos a vender a caneca, e aos compradores qual o maior preço pelo qual estariam dispostos a comprar a caneca. A média de preços atribuídos pelos vendedores foi mais do que duas vezes maior do que a média de preços atribuídos pelos compradores.

Há várias replicações, com diversos bens, com diferentes populações (Harbaugh, Krause \& Vesterlund, 2001) e com não humanos (Brosnan, Jones, Gardner, Lambeth \& Schapiro, 2012). O endowment effect é observado inclusive na ausência de valor afetivo do objeto negociado (Kahneman, Knetsch, \& Thaler, 1990; Knetsch, 1989; Thaler, 1980) e quando a posse do bem em questão é hipotética (Carmon \& Ariely, 2000).

O endowment effect é um dos vieses mais bem estabelecidos pela economia (Korobkin, 2003) e a explicação mais comum para ele é a aversão à perda. Assim, quando um item é de 
posse de alguém, abrir mão desse item é percebido como uma perda, enquanto que a oportunidade de comprar o mesmo item é percebida como uma possibilidade de ganho. De acordo com a ideia básica da aversão à perda - de que perdas têm maior impacto sobre o comportamento do que ganhos têm - desfazer-se de um objeto seria mais aversivo do que não o obter. A diferença entre preços atribuídos a um bem, por vendedores e compradores, refletiria a diferença na aversividade das duas situações (Kahneman \& Tversky, 1979; Tversky \& Kahneman, 1991; Carmon \& Ariely, 2000).

\section{Objetivos Gerais do Estudo}

De acordo com o exposto acima, seria possível afirmar que as escolhas em contextos de ressarcimento de danos - quando alguém deve indenizar outra pessoa por danos que causou podem ser interpretadas com base no arcabouço do desconto subjetivo. O quanto a pessoa a ser indenizada considera que deve receber e o quanto a pessoa que deve indenizar está disposta a pagar podem ser interpretados como valores subjetivos que devem sofrer desconto intertemporal e/ou probabilístico. Esse tipo de interpretação possibilita relacionar as escolhas no contexto de ressarcimento aos fenômenos já conhecidos descritos anteriormente, o que permite identificar variáveis que seriam relevantes cujos efeitos não são conhecidos.

O presente trabalho teve como objetivos verificar: (a) se o procedimento de estimativa (Chapman \& Elstein, 1995 e Chapman, 1996) poderia ser utilizado para investigar desconto de consequências passadas no contexto de ressarcimento de danos materiais e morais; (b) qual a função (hiperbólica ou exponencial) descreveria melhor os dados obtidos por intermédio desse procedimento; (c) se haveria diferenças entre o desconto observado com danos de naturezas materiais e morais; (d) se haveria alguma correlação entre os descontos observados com danos materiais e morais; (e) se o efeito de magnitude seria observado nesse contexto de reparação de danos e se (f) a autoria do dano (endowment effect) exerceria algum efeito nesse contexto, com essa metodologia de pesquisa. 
Vale ressaltar que o presente estudo investigou os aspectos acima citados no âmbito do desconto temporal - o desconto probabilístico não foi aqui explorado.

Foram realizados dois estudos. O primeiro deles investigou as questões relacionadas aos objetivos (a) e (b) mencionados anteriormente; para isso fez-se uso de dois tipos de questionários diferentes. O segundo estudo investigou as questões referentes aos demais objetivos - (b), (c), (d), (e) e (f). No Estudo 2 foi utilizado apenas um tipo de questionário aquele que, diante dos resultados do Estudo 1, apresentou mais vantagens em relação à coleta e aos dados produzidos. 


\section{Estudo 1}

Há fenômenos que ocorreram no passado e têm consequências presentes. Em situações de reparação de danos, por exemplo, o prejuízo ocorre e - frequentemente - apenas algum tempo depois acontece o momento de fazer escolhas sobre como e de quanto será o ressarcimento. Desse modo, o tipo de questão utilizada nos estudos de desconto do atraso no passado não seria apropriado para a investigação do comportamento de escolha em contextos nos quais alguém busca reparação por danos. Tais questões solicitam que o participante expresse a preferência entre ter recebido algo num passado mais distante ou tê-lo recebido num passado imediato (geralmente, o atraso da alternativa imediata é de uma hora atrás) (Yi, Gatchalian e Bickel, 2006). Se essas questões fossem adaptadas para o contexto de ressarcimento de danos, seria solicitado que a pessoa escolhesse entre ter recebido o valor, referente ao prejuízo, logo após o dano ter ocorrido, ou receber esse valor depois, num passado mais próximo. Parece mais adequado, na investigação desse fenômeno, perguntar qual seria o valor que o participante julga justo pagar/receber (a depender se ele causou ou sofreu o dano) após determinado tempo ter transcorrido - esse tipo de questão guarda maior similaridade com a situação real.

No entanto, não há pesquisas que tenham utilizado esse tipo de pergunta para eventos que tenham ocorrido no passado e que envolvam ressarcimento de danos. Os procedimentos mais tradicionalmente utilizados nas investigações do desconto subjetivo serão descritos a seguir.

\section{Procedimentos com animais não humanos}

Concorrentes Encadeados. No modelo proposto por Rachlin (1970), os organismos são expostos a um esquema concorrente encadeado. Dois esquemas são programados concorrentemente em dois operanda diferentes, durante os elos iniciais. Cada um desses dois esquemas (alternativas) está correlacionado a um elo terminal específico. Quando o organismo 
atende às exigências do elo inicial escolhido, ele tem acesso ao elo terminal correspondente. Um dos elos terminais é composto por um atraso longo e por um reforço de maior magnitude que é liberado ao final desse atraso. O outro elo terminal é composto por um reforço de menor magnitude que é apresentado após um atraso curto. Habitualmente esse procedimento possui algumas tentativas de escolha forçada - apenas uma alternativa (maior-atrasado ou menorimediato) está disponível em cada tentativa - e tentativas de escolha livre - as duas alternativas estão disponíveis ao mesmo tempo e o sujeito deve escolher entre elas. O uso das tentativas de escolha forçada tem o objetivo de garantir que o animal entre em contato com as duas alternativas programadas. As tentativas de escolha livre fornecem a medida de preferência, ou seja, qual das duas alternativas foi escolhida na maioria das vezes.

Ajuste do Atraso. Nesse procedimento, o sujeito deve escolher entre a alternativa composta por um reforçador maior, disponibilizado apenas após um atraso ajustável (maioratrasado), versus a alternativa composta por um reforçador menor, disponibilizado após um atraso fixo (menor-imediato) (Mazur, 1987).

No procedimento típico de Ajuste do Atraso, os sujeitos completam duas tentativas de escolha forçada seguidas por duas tentativas de escolha livre. Se a alternativa menor-imediato é escolhida nas duas tentativas livres, a alternativa preterida é manipulada de forma a tornar-se mais atrativa - o atraso que a compõe é reduzido - no bloco de tentativas seguinte. Caso o sujeito escolha consistentemente a alternativa maior-atrasado, o atraso dessa alternativa é aumentado no bloco seguinte de tentativas, tornando-a menos atrativa. Tal ajuste no atraso é feito até que o sujeito escolha indiferentemente entre as duas alternativas. Aqui, o PI é fornecido pelo último atraso, para o reforço de maior magnitude, que antecede a mudança da preferência. Ou seja, é o atraso mais longo tolerado pelo sujeito, antes que sua preferência mude em direção ao reforçador menor e imediato Madden \& Johnson, 2010). 
Ajuste da Magnitude. Esse procedimento é similar ao de Ajuste do Atraso - nos dois casos a escolha do sujeito em uma tentativa/bloco de tentativas embasa uma mudança em uma das alternativas na tentativa/bloco de tentativas seguinte, até que o ponto de indiferença seja alcançado. No caso do procedimento de Ajuste da Magnitude, a mudança ocorre na magnitude do reforço da alternativa menor-imediato (Madden \& Johnson, 2010).

Nos experimentos de Richards, Mitchell, de Wit e Seiden (1997), ratos privados de água escolhiam entre uma pequena quantidade de água, disponibilizada após um maior atraso fixo, versus uma quantidade ainda menor de água, disponibilizada imediatamente. Se a alternativa com atraso fixo fosse escolhida, o reforço da alternativa menor-imediato sofria aumento em sua magnitude. $\mathrm{O}$ oposto ocorria (diminuição na magnitude do reforço da alternativa menorimediato) caso o sujeito escolhesse o menor-imediato.

Evenden e Ryan. Segundo Madden e Johnson (2010), provavelmente esse é o procedimento mais utilizado na área, em estudos com animais não humanos. O procedimento de Evenden e Ryan fornece medidas de sensibilidade à magnitude do reforço e ao atraso, em cada sessão. Isso é vantajoso na construção de linhas de base que antecederão alguns tipos de manipulações.

Cada sessão é composta por cinco blocos de oito tentativas. Em cada bloco, as duas primeiras tentativas são de escolha forçada e as demais de escolha livre. Em cada escolha livre, o sujeito escolhe entre a alternativa menor-imediato e a maior-atrasado. Ao longo dos blocos de oito tentativas, o atraso que compõe a alternativa maior-atrasado é sistematicamente aumentado, variando tipicamente de $0 \mathrm{~s}$ no primeiro bloco até $60 \mathrm{~s}$ no último bloco.

Dessa forma, a primeira tentativa de cada bloco fornece uma medida de sensibilidade à diferença de magnitude dos dois reforçadores, e os blocos de tentativas seguintes, fornecem uma medida de sensibilidade ao aumento progressivo do atraso. 


\section{Procedimentos com humanos}

Os procedimentos mais comumente utilizados com humanos são derivados do procedimento desenvolvido por Rachlin, Raineri e Cross (1991). Nesse estudo, os participantes foram requisitados a escolher entre duas recompensas hipotéticas. As escolhas deveriam ser feitas entre uma alternativa contendo $\$ 1.000,00$ disponibilizados imediatamente e outra contendo $\$ 1.000,00$ disponibilizados com algum atraso, que variava de um mês a 50 anos. Quando as magnitudes das recompensas imediata e atrasada eram iguais, os participantes geralmente preferiam a alternativa imediata.

Um procedimento de ajuste da magnitude, em que o valor da alternativa imediata era gradualmente diminuído, foi empregado em cada um dos atrasos, até que os valores das alternativas fossem $\$ 1,00$ disponibilizado imediatamente e $\$ 1.000,00$ disponibilizados com atraso. O procedimento era repetido em ordem crescente de valores da alternativa imediata e depois em ordem decrescente desses mesmos valores. O PI foi obtido pela média dos valores das recompensas atrasada e imediata, no momento em que o participante mudava sua preferência. Em outras palavras, se o participante estivesse escolhendo consistentemente a alternativa com recompensa imediata (aqui a recompensa imediata tem seu valor decrescido de tentativa para tentativa), e a partir da escolha entre $\$ 400,00$ imediatos ou $\$ 1.000,00$ com um mês de atraso, o participante passasse a escolher consistentemente as alternativas com recompensas atrasadas, o valor do PI era a média obtida dos valores 400 e 1.000, ou seja, 700. Desse modo, no estudo de Rachlin e cols. (1991), um PI foi obtido para cada um dos sete atrasos utilizados.

Tal procedimento mostrou-se interessante não apenas porque poderia acessar estimativas de desconto de forma rápida e simples, mas também porque os dados obtidos através dele são bem descritos pela função hiperbólica - o que já era observado nos resultados obtidos com animais não humanos (Madden \& Johnson, 2010). Experimentos subsequentes, 
que utilizaram recompensas hipotéticas, mas com reforços de naturezas e magnitudes diferentes (Chapman, 1996; Green, Myerson \& McFadden, 1997; Kirby \& Marakovic, 1995; Myerson \& Green, 1995; Odum, Madden \& Bickel, 2002;) replicaram os resultados obtidos por Rachlin e cols. (1991). Variações do procedimento de Rachlin e cols. foram desenvolvidas posteriormente e serão descritas mais abaixo.

As taxas de desconto obtidas em estudos que utilizaram escolhas entre reforços hipotéticos, bem como a forma da curva de desconto, não se diferem das encontradas em estudos que utilizaram recompensas reais em seus procedimentos. As pesquisas que fizeram uso de alguma proporção de reforços reais, majoritariamente o fizeram garantindo aos participantes que havia alguma chance de que eles recebessem os valores por eles escolhidos. Teoricamente essa contingência aumentaria a probabilidade de que os participantes fizessem escolhas como se fossem reais. No entanto, o que se observou é que não houve diferença entre os resultados obtidos com escolhas hipotéticas e escolhas envolvendo diversos graus de chance de ganhar a recompensa real (Johnson \& Bickel, 2002; Locey, Bryan \& Rachlin, 2011; Logorio \& Madden, 2005; Madden et. al., 2003). Em função disso, tipicamente os estudos de desconto do atraso que utilizem quaisquer procedimentos padrões na área - titulação, ajuste e estimativa - são compostos de questionários que possuem cenários de escolhas entre consequências hipotéticas.

Nos procedimentos de titulação e ajuste, os participantes fazem escolhas repetidas entre reforçadores menores (menor magnitude ou menos preferido) e imediatos (ou menos atrasados) e reforçadores maiores (maior magnitude ou preferido) e atrasados (ou mais atrasados que o da alternativa menor-imediato). Dependendo da escolha do sujeito em uma tentativa, a quantia de um dos reforços (maior-atrasado ou menor-imediato) é alterada na tentativa seguinte. Se, por exemplo, o participante escolheu a alternativa maior-atrasado na primeira tentativa, o valor do reforço menor-imediato será aumentado na segunda tentativa. Se o participante escolheu a 
opção menor-imediato na primeira tentativa, o valor do reforço dessa mesma alternativa será diminuído na segunda tentativa ou o valor do reforço maior-atrasado pode ser aumentado.

Esse "ajuste de acordo com a escolha" é repetido até o ponto em que o valor subjetivo das alternativas menor-imediato e maior-atrasado seja o mesmo. Nesse ponto, observa-se indiferença entre as escolhas do sujeito pelas opções menor-imediato e maior-atrasado, e assim o valor do PI é obtido (Hursh, Madden, Spiga, DeLeon \& Francisco, 2013).

No procedimento de titulação, o ajuste do valor do reforço ocorre sempre na alternativa escolhida pelo sujeito na tentativa anterior. Assim, se o sujeito escolheu a opção maior-atrasado em uma tentativa, o valor dessa mesma alternativa será alterado na tentativa seguinte. No entanto, se o sujeito escolheu a opção menor-imediato, o valor dessa alternativa é que será alterado na tentativa seguinte. Por exemplo, uma tentativa apresentada solicita que o participante escolha entre receber $\mathrm{R} \$ 10,00$ imediatamente ou receber $\mathrm{R} \$ 20,00$ com $24 \mathrm{~h}$ de atraso. Caso o participante escolha receber os $\mathrm{R} \$ 10,00$ imediatamente, a tentativa seguinte será ajustada e o valor do reforço imediato será agora $\mathrm{R} \$ 8,00$.

No procedimento de ajuste, uma das alternativas (maior-atrasado ou menor-imediato) é sempre constante e a outra alternativa varia. Por exemplo, se a alternativa fixa é a maioratrasado, a alternativa que sempre irá variar em função da escolha do sujeito é a menorimediato. Se em uma tentativa o sujeito escolheu a opção maior-atrasado, na tentativa seguinte o valor da menor-imediato será aumentado. Se em uma tentativa o sujeito escolheu a alternativa menor-imediato, na tentativa seguinte o valor da opção menor-imediato será diminuído (Hursh, Madden, Spiga, DeLeon \& Francisco, 2013).

Algumas variações nesses procedimentos (titulação e ajuste) são possíveis. Pode-se variar apenas os atrasos, a cada bloco de tentativas, mantendo-se os valores dos reforços (imediato e atrasado) constantes (Madden \& Bickel, 2010); ou ainda, pode-se variar uma das dimensões dos reforços (magnitude do reforço que compõe as alternativas menor-imediato ou 
maior-atrasado, ou o tamanho do atraso), mantendo-se o restante constante, independentemente do desempenho do sujeito em tentativas anteriores (Reed \& Martens, 2011).

Rodzon, Berry e Odum (2011) compararam procedimentos em que havia ajuste da magnitude do reforço imediato, em função da escolha do participante, e procedimentos em que não havia ajuste - as magnitudes eram fixas e os atrasos variavam apenas entre blocos de tentativas. Não foram observadas diferenças significativas nas taxas de desconto obtidas através dos diferentes métodos. Além disso, encontrou-se alta correlação entre os resultados dos dois procedimentos investigados.

No método de estimativa, diferentemente dos métodos de titulação e ajuste, o PI é diretamente solicitado ao participante. É perguntado, em cada tentativa, que valor a alternativa maior-atrasado deveria ter para ser igualmente atraente a menor-imediato. Nesse caso, o valor da opção menor-imediato é mantido constante entre as tentativas, os valores de atraso são variados e os valores das alternativas maior-atrasado são solicitados ao participante. Poder-seia perguntar, por exemplo, que valor um prêmio a ser recebido em um mês deveria ter para que fosse igualmente atraente a receber $\mathrm{R} \$ 50,00$ imediatamente (Chapman \& Elstein, 1995; Chapman, 1996)

O procedimento de estimativa também pode apresentar variações. Uma possibilidade é a apresentação de uma lista de valores abaixo da pergunta de que valor tornaria a consequência atrasada tão atraente quanto a imediata. Nesse caso, em vez de o participante escrever o valor estimado, ele escolhe um valor presente na lista e o seleciona (com um " $\mathrm{x}$ " ou sublimando-o, circulando-o, etc.).

Weatherly e Derenne (2011) investigaram se essas variações no procedimento de estimativa produziriam taxas de desconto diferentes. Os participantes fizeram escolhas entre consequências imediatas e atrasadas, de naturezas diversas (encontrar um namorado, dinheiro, cigarros, etc.). Os resultados indicaram que os diferentes métodos produziram taxas de desconto 
distintas, com variações em função do tipo de consequência envolvida. Mas de maneira geral, o método em que o participante escreve o valor da consequência em vez de selecioná-lo em uma lista, produziu taxas de desconto maiores.

Smith e Hantula (2008) testaram se o procedimento de estimativa (sem a lista de valores) produziria taxas de desconto diferentes das obtidas através dos métodos binários (titulação e ajuste). Os autores compararam tais procedimentos utilizando duas magnitudes de reforço. Os resultados indicaram que os métodos binários produzem taxas de desconto maiores que o método de estimativa. Em outras palavras, os participantes apresentaram maior tendência a esperar pelo reforço de maior magnitude quando o método de estimativa foi utilizado.

Comparando-se os resultados obtidos por Smith e Hantula (2008) obtidos por Weatherly e Derenne (2011), pode-se concluir que os procedimentos de titulação e de ajuste produzem as maiores taxas de desconto, e o procedimento de estimativa com a lista de valores produz as menores taxas. O procedimento de estimativa sem a lista de valores produz taxas de desconto "intermediarias".

Apesar das inúmeras pesquisas com os procedimentos acima, não se pode assumir que sejam adequados à investigação do fenômeno de interesse do presente trabalho. Como já foi mencionado anteriormente, o contexto de ressarcimento apresenta diferenças em relação aos contextos comumente explorados no desconto subjetivo. Em função disso, o objetivo do Estudo 1 foi averiguar a adequação de dois dos procedimentos acima descritos - estimativa com e sem lista de valores - para investigar ressarcimento de danos. Os procedimentos de ajuste e titulação foram descartados em função do tipo de pergunta que requerem - parece inapropriado, em função do fenômeno de interesse, perguntar se o participante prefere ter sido ressarcido de um dano logo após o prejuízo ter ocorrido ou se prefere ter recebido a indenização algum tempo depois. Tal pergunta não guarda semelhanças com o que acontece de fato: as pessoas lesadas são solicitadas a estipular um valor que consideram reparar o dano. 
Ademais, nos procedimentos de ajuste e titulação, os cenários geralmente utilizados contêm perguntas cujos atrasos se referem ao tempo entre receber a recompensa e o momento da escolha. No presente estudo, o atraso de interesse é o que existe entre o dano e o momento da escolha. $\mathrm{O}$ procedimento de estimativa permite que a pergunta seja modificada para atender aos objetivos deste trabalho, continuando clara e coerente; enquanto que nos procedimentos de ajuste e titulação, quando a pergunta é modificada, ela se torna incoerente.

\section{Objetivos}

O Estudo 1 teve como objetivos (1) avaliar se os procedimentos de estimativa com e sem lista de valores são apropriados para a investigação de ressarcimento de danos materiais e morais que tenham ocorrido no passado, ou seja, se os dados, obtidos com base nos procedimentos utilizados, são sistemáticos e comparáveis com situações típicas de desconto. E

(2) testar qual a função matemática (hiperbólica ou exponencial) descreve melhor os dados produzidos por cada procedimento.

\section{Método}

\section{Participantes}

Participaram desse estudo 95 estudantes de graduação de uma universidade localizada no Distrito Federal. Todos eles leram e assinaram o Termo de Consentimento Livre e Esclarecido (Apêndice 1). Após essa etapa, iniciou-se o experimento.

Os participantes tinham idades entre 17 e 25 anos, eram de cursos variados (psicologia, direito, fisioterapia, enfermagem, arquitetura, economia), mas todos estavam cursando alguma disciplina de psicologia (introdução à psicologia, economia comportamental, análise experimental do comportamento) - situação na qual a coleta ocorreu. Do total, 53 eram mulheres e 42 eram homens.

Foram utilizados dois tipos de questionários - A e B (descritos mais adiante); 45 participantes respoderam ao Questionário A e 50 responderam ao Questionário B. 


\section{Local e coleta}

Os dados foram coletados nas salas de aulas da universidade, durante as aulas de disciplinas de psicologia cujos professores concordaram em colaborar com a equipe de pesquisa. As coletas tiveram duração entre 20 e 25 minutos.

As coletas foram coletivas, realizadas em 4 salas diferentes, e o número de alunos presente em cada uma delas variou entre 15 e 31 . Foram utilizados questionários impressos em papel (apêndices 2 e 3 ) e canetas.

\section{Procedimento}

Alguns aspectos do procedimento adotado foram definidos a partir de um estudo piloto, realizado anteriormente ao Estudo 1, do qual participaram 65 estudantes de graduação de uma universidade particular localizada no Distrito Federal. Esses participantes tinham idades entre 18 e 35 anos, eram de cursos variados (enfermagem, farmácia, educação física e nutrição) e todos estavam cursando a disciplina de introdução à psicologia - ocasião em que as coletas foram realizadas. Os formatos dos questionários utilizados no Estudo 1, a linguagem adotada na descrição dos cenários, bem como a forma da resposta solicitada aos participantes, foram escolhidos em função das observações feitas ao longo do estudo piloto. A descrição detalhada dos questionários e cenários utilizados no Estudo 1 está a seguir.

Questionários e cenários. Foram utilizados dois questionários (A e B), que se diferenciavam apenas quanto à forma da resposta do participante: em um deles, o valor solicitado era escrito no espaço destinado a isso e, no outro, o valor escolhido deveria ser assinalado em uma lista de valores. Cada questionário era composto de instruções gerais, duas tarefas de treino, duas tarefas de dano material e duas tarefas de dano moral. Cada tarefa conteve instruções específicas, com a descrição do cenário de ressarcimento e valores monetários hipotéticos. Cada participante respondeu a apenas um questionário e a ordem de apresentação das tarefas foi contrabalanceada. No entanto, as tarefas de treino sempre foram as primeiras a 
serem feitas e as de dano moral sempre as últimas. Os questionários serão descritos detalhadamente abaixo e um modelo foi anexado ao final do presente trabalho (apêndices $2 \mathrm{e}$ $3)$.

Instruções gerais. A primeira página de cada questionário continha as seguintes instruções gerais: "Abaixo encontram-se algumas situações hipotéticas. Imagine que você faz parte dessas situações e responda às questões como se as situações fossem reais. Por favor, em suas respostas, considere apenas sua decisão pessoal, sem se preocupar com as opiniões do experimentador ou de qualquer outra pessoa. Por favor, não use calculadoras".

Tarefas de treino. O objetivo das tarefas de treino foi facilitar a compreensão das instruções peloparticipante e reduzir, assim, a perda de dados em função de erros de compreensão da tarefa. Durante as tarefas de treino, os participantes poderiam tirar dúvidas com o experimentador e não poderiam fazê-lo durante as tarefas seguintes. As tarefas de treino foram apresentadas logo após as instruções gerais e elas reproduziram as demais tarefas do questionário, porém, utilizando valor monetário menor e menor quantidade de atrasos $-\mathrm{R} \$$ 20,00 e cinco atrasos. Nas instruções específicas da primeira tarefa de treino, o participante foi solicitado a imaginar que alguém completamente desconhecido causou a ele um prejuízo de $\mathrm{R} \$$ 20,00 a algum tempo atrás e ele (participante) está diante da última oportunidade de receber esse dinheiro. Foi perguntado então que valor ele consideraria justo receber hoje, da pessoa que causou o prejuízo, se tal prejuízo foi causado em determinados intervalos de tempo, no passado. A segunda tarefa de treino era idêntica à primeira, com exceção de algumas palavras da instrução específica da tarefa: em vez de "alguém totalmente desconhecido lhe causou um dano", empregou-se "você causou um dano a alguém totalmente desconhecido"; e no lugar de “que valor você julga justo receber" utilizou-se a expressão “que valor você julga justo pagar”. No Questionário A, o participante deveria marcar um " $\mathrm{X}$ " em frente ao valor que considerava justo receber, em uma lista que continha 18 valores, de $\mathrm{R} \$ 20,00$ a $\mathrm{R} \$ 280,00$. Foi utilizado 
apenas o atraso de uma semana. No Questionário B o participante deveria preencher os espaços deixados em frente a cada atraso com o valor que considerasse justo receber, em números. Foram utilizados cinco atrasos - 1 semana, 2 semanas, 1 mês, 6 meses e 1 ano.

Tarefas de dano material. O objetivo dessas tarefas foi obter taxas de desconto em contextos de ressarcimento financeiro. As instruções específicas delas eram idênticas as das tarefas de treino. Em uma delas, o participante deveria dizer qual valor julga justo receber para considerar o dano sofrido compensado e, na outra, o participante deveria dizer qual valor julga justo pagar pelo dano que causou. Foram apresentados uma magnitude de reforço - $\mathrm{R} \$ 100,00$ - e sete atrasos - 1 semana, 2 semanas, 1 mês, 6 meses, 1 ano, 5 anos e 10 anos, em cada uma das tarefas de dano material.

Questionário A. Os atrasos foram apresentados em blocos. Para cada um dos sete atrasos utilizados, um bloco de valores de $\mathrm{R} \$ 100,00$ a $\mathrm{R} \$ 1.040,00$ foi apresentado. Os blocos foram apresentados em forma de tabela. As colunas continham os valores e, ao lado de cada valor, havia um espaço para a resposta (um “x”) do participante.

Questionário B. Os atrasos foram apresentados sequencialmente, todos juntos, em uma tabela de duas colunas. A coluna da esquerda continha os sete atrasos, dispostos um abaixo do outro, e a coluna da direita estava em branco e deveria ser preenchida pelo participante, com valor em números.

Tarefas de dano moral. O objetivo dessas tarefas foi obter taxas de desconto em contextos de ressarcimento por prejuízos de natureza moral. As instruções específicas delas solicitaram que o participante imaginasse que, além do dano material causado/sofrido por ele, tal fato tenha trazido grandes aborrecimentos. Foi perguntado, então, que valor ele consideraria justo pagar/receber hoje, para compensar os aborrecimentos se isso ocorreu nos seguintes intervalos de tempo, no passado: 1 semana, 2 semanas, 1 mês, 6 meses, 1 ano, 5 anos e 10 anos. Foi apresentada a mesma magnitude utilizada nos cenários de danos materiais - $\mathrm{R} \$ 100,00$. 
Foram apresentados tanto o cenário contendo as palavras "alguém totalmente desconhecido lhe causou um dano" (denominada Situação 3A, no Questionário A, e Situação 3B, no Questionário B) quanto o cenário com as palavras "você causou um dano" (denominada Situação 4A, no Questionário A, e Situação 4B, no Questionário B).

O formato de apresentação das tarefas de danos morais foi o mesmo nos questionários A e B - os atrasos foram apresentados todos juntos, sequencialmente, como pode ser verificado nos apêndices 1 e 2. Não foi possível coletar os dados utilizando o formato de blocos de valores os valores indenizatórios de danos morais podem alcançar uma amplitude enorme, dada a sua total subjetividade. Sendo assim, nenhuma extensão de valores colocados em uma tabela poderia ser suficiente. Isso foi observado no estudo piloto - alguns participantes, por exemplo, colocaram "zero" em todas as respostas das tarefas de dano moral (apesar de terem respondido corretamente as tarefas de dano material).

Desse modo, as seguintes combinações entre autor e tipo de dano (material/moral) foram apresentadas:

- "Alguém totalmente desconhecido lhe causou um dano material de $\mathrm{R} \$ 100,00 "$ (Situação 1 - dano material sofrido, Sit1).

- "Você causou um dano material de $\mathrm{R} \$ 100,00$ a alguém totalmente desconhecido" (Situação 2 - dano material causado, Sit2).

- "Além do dano material $(\mathrm{R} \$ 100,00)$ sofrido por você, tal fato lhe trouxe grandes aborrecimentos" (Situação 3 - dano moral sofrido, Sit3).

- “Além do dano material $(\mathrm{R} \$ 100,00)$ causado por você, tal fato trouxe grandes aborrecimentos a esse alguém totalmente desconhecido" (Situação 4 - dano moral causado, Sit4.

A Tabela 1 apresenta o resumo do procedimento adotado no Estudo 1. 
Tabela 1

Número de participantes que responderam aos Questionários $A$ e B, e ordem de exposição às situações - contrabalanceamento feito na apresentação dos cenários em que o participante causa ou sofre um dano.

Número de Quest. Ordem de exposição às tarefas e situações participantes

A Treino, Dano material (Sit1, Sit2), Dano moral (Sit3, Sit4)

25 B Treino, Dano material (Sit2, Sit1), Dano moral (Sit4, Sit3)

\section{Resultados}

Os valores subjetivos da recompensa (ou seja, as respostas de cada participante, para cada atraso) foram plotados em função do tempo para o cálculo da área sob a curva e o valor de $k$ foi obtido através de regressões não-lineares hiperbólica e exponencial. Os parâmetros $k$, $R^{2}$ e a AUC foram calculados para cada um dos participantes. Em seguida, as medianas de $k$, $R^{2}$ e AUC foram obtidas para cada uma das situações. Todas essas análises foram realizadas utilizando-se uma rotina matemática semi-automatizada feita sob medida (Matlab 7.0; Mathworks, Natick, MA, EUA).

O teste de Kolmogorov-Smirnov foi executado para testar a normalidade da distribuição dos dados das variáveis quantitativas. Foram utilizados os dados absolutos de todos os participantes e em cada uma das situações. Desse modo, a normalidade de cada situação foi testada. Como as variáveis apresentaram distribuição não-paramétrica, o teste de MannWhitney foi utilizado para verificar a hipótese nula nas diferentes situações estudadas. 
Todas as análises estatísticas foram realizadas com o programa Statistical Package for Social Science (IBM SPSS Statistics para Windows, versão 20.0, Armonk, NY, EUA, IBM Corp.) O nível de significância estabelecido para todas as análises foi de 5\% e os resultados estão expressos na forma de mediana e intervalo interquartil. Os resultados foram apresentados em forma de tabela (mediana, intervalo interquartil e p-valor obtido através do teste de MannWhitney) pois as figuras construídas com tais resultados não possibilitaram que estes fossem visualizados. Os dados individuais foram anexados ao presente trabalho (Apêndice 6).

\section{Descrição geral dos dados}

Dos 95 participantes desse estudo, 45 responderam o Questionário A e 50 responderam o Questionário B. Todos os participantes responderam a quatro situações apresentadas - duas de dano material ("alguém lhe causou um dano" e "você causou um dano") e duas de dano moral ("alguém lhe causou um dano" e "você causou um dano"). No total, obteve-se então 380 situações respondidas. Não foi observado efeito de ordem - não houve diferença significativa entre os resultados daqueles que iniciaram os questionários pelo cenário em que haviam causado um dano e daqueles que iniciaram pelo cenário em que haviam sofrido um dano.

Foi possível observar oito padrões de respostas, que serão descritos abaixo. As incidências de cada padrão serão apresentadas na Tabela 2.

- Padrão 1: participantes que colocaram “zero" em atrasos longos (cinco e 10 anos).

- Padrão 2: participantes que colocaram o mesmo valor - $\mathrm{R} \$ 100,00$, que era o valor do dano - em todos os atrasos.

- Padrão 3: participantes que responderam com apenas dois valores - colocaram o mesmo valor até certo atraso e, em todos os atrasos seguintes, colocaram outro valor, maior que o primeiro.

- Padrão 4: responderam “zero" em todos os atrasos. 
- Padrão 5: o valor das respostas diminui nos atrasos de cinco e 10 anos (mas é diferente de zero).

- Padrão 6: o valor das respostas diminui sistematicamente conforme os atrasos aumentam.

- Padrão 7: respostas irregulares, que não variaram de acordo com os atrasos.

- Padrão 8: os valores das respostas aumentaram conforme os atrasos ficaram maiores (respostas “típicas” em desconto).

A frequência de cada padrão, em cada uma das situações, está apresentada na Tabela 2. Os dados estão apresentados na forma de frequência absoluta (primeiro número) e frequência relativa (segundo número, em \%), para cada situação estudada. A frequência relativa total (última coluna) foi calculada considerando-se os dados das tarefas de dano material e moral. É importante destacar que as situações 1A, 2A, 3A e 4A referem-se ao Questionário A, enquanto que as situações 1B, 2B, 3B e 4B referem-se ao Questionário B. Optou-se por apresentar os dados dessa maneira porque frequentemente um mesmo participante demonstrou padrões diferentes em situações diferentes. Por exemplo, há participantes que responderam a Situação 1A com valores que aumentam em função do atraso e a Situação 3A com zeros para todos os atrasos.

Duas das três medidas aqui adotadas $-k$ e $R^{2}$, foram calculadas tanto com a função hiperbólica quanto com a função exponencial. A AUC foi calculada através da técnica dos trapezoides, descrita na introdução do presente estudo. $\mathrm{O} k$ foi obtido através das Equações 1 (hiperbólica) e 2 (exponencial) também descritas na introdução do presente trabalho. Para os cálculos da AUC, do $k$ e do $R^{2}$, apenas as respostas de acordo com os padrões 8 e 3 foram consideradas - são padrões tipicamente encontrados em estudos de desconto e adotá-los para análises no presente estudo permite compará-los com a literatura da área. Com base nesses 
critérios, o número de participantes com dados utilizados para análise variou entre 16 (Situação 1A) e 29 (Situação 4B).

Nos padrões 2 e 4 não se observa desconto, portanto não é possível estudar o fenômeno, visto que ele não ocorreu. No Padrão 7, as respostas parecem não ter ficado sob controle dos atrasos - elas variaram assistematicamente. No Padrão 6, as respostas diminuíram conforme os atrasos foram aumentados. Nesse caso, não é possível afirmar que o participante compreendeu a tarefa (ou a pergunta) corretamente. Nos padrões 1 e 5, as respostas aos atrasos longos (cinco e 10 anos) parecem ter ficado sob controle de outras variáveis que não apenas o tempo decorrido entre o dano e o momento da escolha. Essas possíveis variáveis são apontadas na Discussão do Estudo 1. Como pode ser observado na Tebela 2, quase metade dos participantes $(47,5 \%)$ respondeu de acordo com o Padrão 8. O segundo padrão mais observado foi o Padrão 2, com 41,3\%. Os padrões com menor incidência foram o 6 e o 7 .

\section{Comparações entre equações hiperbólica e exponencial}

Foram realizadas comparações entre o ajuste aos dados obtido pela função hiperbólica (Equação 1) e aquele obtido com base na função exponencial (Equação 2), para cada um dos questionários para todas as quatro situações apresentadas aos participantes. A Tabela 3 mostra a mediana, com intervalos interquartis e amplitude, dos valores de $R^{2}$ - para todas as situações dos questionários A e B.

As duas equações, hiperbólica e exponencial, geraram valores de $R^{2}$ bastante altos, variando de 0,854 (Sit3 hipérbole, Questionário A) a 0,977 (Sit2 exponencial, Questionário B). Em todas as situações - dos dois questionários - as medianas de $R^{2}$ foram maiores quando obtidas pela equação exponencial. Essas diferenças foram estatisticamente significativas para quatro das oito situações, a saber, as diferenças entre os $R^{2} \mathrm{~s}$ (hiperbólico e exponencial) das situações 2A, 3A e 4A, e da situação 4B (comparações “intra-situações”). Quando todos os $R^{2}$ 
obtidos através da equação hiperbólica - de todas as situações - são comparados a todos àqueles obtidos através da equação exponencial, a diferença entre eles é estatisticamente significativa.

Tabela 2

Frequências absoluta e relativa (\%) dos padrões de respostas dos participantes do Estudo 1 , por situação e ao longo de todo o estudo.

\begin{tabular}{|c|c|c|c|c|c|c|c|c|c|}
\hline Padrões & Sit1A & Sit1B & Sit2A & Sit2B & Sit3A & Sit3B & Sit4A & Sit4B & $\begin{array}{c}\text { Freq. total } \\
(\%)\end{array}$ \\
\hline \multirow[t]{2}{*}{1} & 0 & 4 & 1 & 3 & 1 & 3 & 1 & 3 & $4,2 \%$ \\
\hline & $(0 \%)$ & $(8,0 \%)$ & $(2,2 \%)$ & $(6,0 \%)$ & $(2,2 \%)$ & $(6,0 \%)$ & $(2,2 \%)$ & $(6,0 \%)$ & \\
\hline \multirow[t]{2}{*}{2} & 25 & 21 & 22 & 20 & 17 & 18 & 17 & 16 & $41,3 \%$ \\
\hline & $(55,5 \%)$ & $(42 \%)$ & $(48,8 \%)$ & $(40 \%)$ & $(37,7 \%)$ & $(36,0 \%)$ & $(37,7 \%)$ & $(32) \%$ & \\
\hline \multirow[t]{2}{*}{3} & 3 & 2 & 2 & 1 & 1 & 1 & 1 & 1 & $3,9 \%$ \\
\hline & $(6,6 \%)$ & $(4,0 \%)$ & $(4,4 \%)$ & $(2,0 \%)$ & $(2,2 \%)$ & $(2,0 \%)$ & $(2,2 \%)$ & $(2,0 \%)$ & \\
\hline \multirow[t]{2}{*}{4} & 0 & 0 & 1 & 0 & 3 & 1 & 4 & 0 & $2,3 \%$ \\
\hline & $(0 \%)$ & $(0 \%)$ & $(2,2 \%)$ & $(0 \%)$ & $(6,6 \%)$ & $(2,0 \%)$ & $(8,8 \%)$ & $(0 \%)$ & \\
\hline \multirow[t]{2}{*}{5} & 3 & 1 & 1 & 0 & 1 & 0 & 0 & 1 & $1,8 \%$ \\
\hline & $(6,6 \%)$ & $(2,0 \%)$ & $(2,2 \%)$ & $(0 \%)$ & $(2,2 \%)$ & $(0 \%)$ & $(0 \%)$ & $(2,0 \%)$ & \\
\hline \multirow[t]{2}{*}{6} & 0 & 1 & 0 & 1 & 0 & 1 & 0 & 0 & $0,78 \%$ \\
\hline & $(0 \%)$ & $(2,0 \%)$ & $(0 \%)$ & $(2,0 \%)$ & $(0 \%)$ & $(2,0 \%)$ & $(0 \%)$ & $(0 \%)$ & \\
\hline \multirow[t]{2}{*}{7} & 1 & 0 & 0 & 0 & 2 & 0 & 0 & 0 & $0,78 \%$ \\
\hline & $(2,2 \%)$ & $(0 \%)$ & $(0 \%)$ & $(0 \%)$ & $(4,4 \%)$ & $(0 \%)$ & $(0 \%)$ & $(0 \%)$ & \\
\hline \multirow[t]{2}{*}{8} & 13 & 21 & 18 & 25 & 20 & 26 & 22 & 29 & $45,7 \%$ \\
\hline & $(28,8 \%)$ & $(42 \%)$ & $(40 \%)$ & $(50 \%)$ & $(44,4 \%)$ & $(52 \%)$ & $(48,8 \%)$ & $(58 \%)$ & \\
\hline
\end{tabular}


Tabela 3

Número de participantes (N), mediana, intervalo interquartil e amplitude de $R^{2}$, de todas as situações dos questionários A e B. As medidas $k$ e $R^{2}$ foram calculas utilizando-se as funções hiperbólica e exponencial.

\begin{tabular}{|c|c|c|c|c|c|c|}
\hline Questionário & Situação & Função & $\mathrm{N}$ & Mediana & $\begin{array}{l}\text { Intervalo } \\
\text { Interquartil } \\
\qquad\left(1^{\circ}-3^{\circ}\right)\end{array}$ & Amplitude \\
\hline \multirow[t]{8}{*}{ A } & Sit1 & Hipérbole & 16 & 0,920 & $(0,864-0,954)$ & $0,348-1,000$ \\
\hline & & Exponencial & & 0,957 & $(0,933-0,979)$ & $0,819-1,000$ \\
\hline & Sit2 & Hipérbole & 20 & 0,904 & $(0,703-0,927)$ & $0,686-1,000$ \\
\hline & & Exponencial & & 0,965 & $(0,933-0,976)$ & $0,782-1,000$ \\
\hline & Sit3 & Hipérbole & 21 & 0,854 & $(0,771-0,946)$ & $0,296-1,000$ \\
\hline & & Exponencial & & 0,944 & $(0,918-0,994)$ & $0,848-1,000$ \\
\hline & Sit4 & Hipérbole & 23 & 0,917 & $(0,806-0,954)$ & $0,516-1,000$ \\
\hline & & Exponencial & & 0,965 & $(0,905-0, .979)$ & $0,820-1,000$ \\
\hline \multirow[t]{8}{*}{ B } & Sit1 & Hipérbole & 23 & 0,924 & $(0,753-0,973)$ & $0,190-0,995$ \\
\hline & & Exponencial & & 0,963 & $(0,926-0,982)$ & $0,375-0,999$ \\
\hline & Sit2 & Hipérbole & 26 & 0,919 & $(0,808-0,974)$ & $0,190-0,995$ \\
\hline & & Exponencial & & 0,977 & $(0,920-0,988)$ & $0,375-0,999$ \\
\hline & Sit3 & Hipérbole & 27 & 0,943 & $(0,786-0,973)$ & $0,321-0,989$ \\
\hline & & Exponencial & & 0,969 & $(0,921-0,979)$ & $0,341-0,996$ \\
\hline & Sit4 & Hipérbole & 30 & 0,900 & $(0,775-0,944)$ & $0,321-0,989$ \\
\hline & & Exponencial & & 0,959 & $(0,918-0,990)$ & $0,841-0,997$ \\
\hline
\end{tabular}




\section{Comparações entre questionários}

Foram realizadas análises para comparar os questionários, valendo-se dos parâmetros $R^{2}$ e $k$ - calculados tanto com a função hiperbólica quanto com a exponencial - e da AUC para todas as quatro situações apresentadas aos participantes. A Tabela 4 mostra a mediana dos valores $R^{2}$, a Tabela 5 apresenta as medianas de $k$ e a Tabela 6 contém a AUC, de todas as situações, dos dois questionários. Tais tabelas serão apresentadas e comentadas abaixo.

\section{Parâmetro $R^{2}$}

As medianas de $R^{2}$, obtidas através das equações hiperbólica e exponencial, dos questionários A e B, estão apresentadas na Tabela 4.

Tabela 4

Situação, questionário, número de participantes $(N)$, mediana e intervalo interquartil de $R^{2}$ para as funções hiperbólica e exponencial.

\begin{tabular}{|c|c|c|c|c|c|c|}
\hline Situação & Quest. & $\mathrm{N}$ & & Mediana de $R^{2}$ & & \\
\hline & & & Hiperbólica & $\begin{array}{c}\text { Interv. } \\
\text { Interq. }\left(1^{\mathrm{o}}-3^{\circ}\right)\end{array}$ & Exponencial & $\begin{array}{c}\text { Interv. } \\
\text { Interq. }\left(1^{\mathrm{o}}-3^{\circ}\right)\end{array}$ \\
\hline \multirow[t]{2}{*}{ Sit1 } & A & 16 & 0,920 & $(0,864-0,954)$ & 0,957 & $(0,933-0,979)$ \\
\hline & B & 23 & 0,924 & $(0,753-0,973)$ & 0,963 & $(0,926-0,982)$ \\
\hline \multirow[t]{2}{*}{ Sit2 } & A & 20 & 0,904 & $(0,703-0,927)$ & 0,965 & $(0,933-0,976)$ \\
\hline & B & 26 & 0,919 & $(0,808-0,974)$ & 0,977 & $(0,920-0,988)$ \\
\hline \multirow[t]{2}{*}{ Sit3 } & A & 21 & 0,854 & $(0,771-0,946)$ & 0,944 & $(0,918-0,994)$ \\
\hline & B & 27 & 0,943 & $(0,786-0,973)$ & 0,969 & $(0,921-0,979)$ \\
\hline \multirow[t]{2}{*}{ Sit4 } & A & 23 & 0,917 & $(0,806-0,954)$ & 0,965 & $(0,905-0,979)$ \\
\hline & B & 30 & 0,900 & $(0,775-0,944)$ & 0,959 & $(0,918-0,990)$ \\
\hline
\end{tabular}


As medianas de $R^{2}$, obtidas através da função hiperbólica, foram maiores no Questionário B em quase todas as situações - a única exceção é a Sit4, na qual o $R^{2}$ foi maior no Questionário A. As diferenças encontradas, no entanto, não foram significativas.

Quando as medianas de $R^{2}$ foram comparadas, o Questionário B apresenta valores maiores nas situações 1, 2 e 3. Na Situação 4, a mediana de $R^{2}$ foi maior no Questionário A. Nenhuma das diferenças, no entanto, foi significativa.

\section{Parâmetro $k$}

As medianas de $k$, obtidas através das equações hiperbólica e exponencial, dos questionários A e B, estão apresentadas na Tabela 5.

Tabela 5

Situação, questionário, número de participantes $(N)$, mediana e intervalo interquartil de $k$. Foram utilizadas as funções hiperbólica e exponencial.

\begin{tabular}{ccccccc}
\hline Situação & Quest. & N & \multicolumn{3}{c}{ Mediana de $k$} \\
\hline & & & Hiperbólica & Interv. & Exponencial & Interv. \\
& & & & Interq. $\left(1^{\circ}-3^{\circ}\right)$ & & Interq. $\left(1^{\circ}-3^{\circ}\right)$ \\
\hline \multirow{2}{*}{ Sit1 } & A & 16 & 0,009 & $(0,001-0,021)$ & 0,022 & $(0,010-0,033)$ \\
& B & 23 & 0,009 & $(0,003-0,039)$ & 0,024 & $(0,004-0,050)$ \\
Sit2 & A & 20 & 0,005 & $(0,001-0,030)$ & 0,026 & $(0,010-0,041)$ \\
& B & 26 & 0,013 & $(0,003-0,040)$ & 0,029 & $(0,018-0,202)$ \\
& A & 21 & 0,024 & $(0,002-0,128)$ & 0,036 & $(0,022-0,280)$ \\
& B & 27 & 0,020 & $(0,003-0,165)$ & 0,038 & $(0,019-0,038)$ \\
& A & 23 & 0,013 & $(0,002-0,068)$ & 0,041 & $(0,021-0,075)$ \\
& B & 30 & 0,018 & $(0,003-0,169)$ & 0,087 & $(0,028-0,302)$ \\
\hline
\end{tabular}


Quando a equação hiperbólica foi utilizada, observou-se que as medianas de $k$ foram sempre maiores no Questionário B, com exceção da Sit1, em que os valores das medianas de $k$ são idênticos como exposto na Tabela 5. Nenhuma das diferenças encontradas, no entanto, foi significativa.

Em relação às medianas de $k$, os valores foram maiores no Questionário B em todas as situações. No entanto, nenhuma das diferenças observadas foi significativa.

\section{AUC}

A AUC também foi calculada e está apresentada na Tabela 6.

Tabela 6

Número de participantes (N), mediana, intervalo interquartil das AUCs de todas as situações, dos questionários A e B, e p-valor obtido através da comparação entre questionários.

Situação Questionário N $\quad$ Mediana $\quad$ Intervalo interquartil $\quad \mathrm{p}$

$\left(1^{\circ}-3^{\circ}\right)$

\begin{tabular}{lccccc}
\hline Sit1 & A & 16 & 0,364 & $(0,284-0,648)$ & 1,000 \\
& B & 23 & 0,390 & $(0,200-0,679)$ & \\
Sit2 & A & 20 & 0,514 & $(0,283-0,753)$ & 0,461 \\
& B & 26 & 0,373 & $(0,200-0,789)$ & \\
& A 3 & 21 & 0,272 & $(0,167-0,615)$ & 0,868 \\
& B & 27 & 0,278 & $(0,086-0,686)$ & \\
& A & 23 & 0,355 & $(0,202-0,723)$ & 1,000 \\
& B & 30 & 0,233 & $(0,079-0,512)$ & \\
\hline
\end{tabular}


Em duas situações (2 e 4) a mediana da AUC foi maior no Questionário A e em outras duas (1 e 3) a mediana da AUC foi maior em B. Nenhuma das diferenças observadas foi significativa.

O valor de $k$ e a AUC, como esperado, estão negativamente correlacionados. Valores de $k$ maiores significam grandes descontos, assim como valores pequenos da AUC. Os valores de $k$ foram quase sempre menores e os da AUC, maiores, no Questionário A.

\section{Discussão}

O Estudo 1 do presente trabalho teve como objetivos verificar se (1) o procedimento de estimativa (Chapman \& Elstein, 1995 e Chapman, 1996) - com e sem lista de valores - pode ser utilizado para investigar desconto de consequências passadas no contexto de ressarcimento danos materiais e morais e (2) qual a função matemática (hiperbólica ou exponencial) descreve melhor os dados obtidos por intermédio desse procedimento.

Os dois tipos de questionários utilizados - estimativa com e sem lista de valores produziram dados sistemáticos, nos quais o valor subjetivo da consequência "ressarcimento" decresceu em função do atraso existente entre a ocorrência do dano e o momento da escolha. Isso ocorreu tanto para danos de natureza material quanto para danos de natureza moral. Do total de situações respondidas, 49,6\% dos dados são semelhantes aos encontrados na literatura de desconto (padrões de respostas 3 e 8). Os outros padrões observados (que somados correspondem a $51,16 \%$ do total) podem ter sofrido influência de diversas variáveis não controladas pelo presente estudo.

Os padrões 1 (“"zero em atrasos longos”) e 5 ("valores diminuem em atrasos longos, mas são diferentes de zero") podem ter sido influenciados por fatores culturais e jurídicos brasileiros: a morosidade do Poder Judiciário para concluir definitivamente certas ações tem ensejado a ocorrência da prescrição da pretensão do autor. Isso significa que o valor devido não pode mais ser exigido. Desse modo, "zeros" colocados nos atrasos de cinco e 10 anos podem 
indicar que se entende não haver mais nada a receber/pagar - um dos participantes, inclusive, escreveu a palavra "prescreveu" em frente a esses atrasos. Valores pequenos escritos nesses mesmos atrasos talvez expressem que, diante de um ressarcimento "perdido", qualquer valor (mesmo que pequeno) é vantajoso.

Há estudos que reportaram diferenças no desconto do atraso em função de diferenças culturais. Du e cols. (2002), por exemplo, investigaram se o desconto do atraso, envolvendo recompensa monetária hipotética seria diferente entre japoneses, chineses e americanos. Os dados foram coletados em uma universidade norte americana e os estudantes chineses e americanos apresentaram taxas de desconto semelhantes entre si e superiores aos japoneses. Em outro estudo, De Wit, Flory, Acheson, McCloskey, \& Manuck (2007) relataram que adultos caucasianos descontaram dinheiro hipotético de forma menos acentuada que afro americanos.

Ostaszewski, Green e Myerson (1998) também verificaram a influência de uma contingência "macro", assim como cultura e leis, no desconto subjetivo - avaliaram os efeitos da inflação sobre a desvalorização de consequências atrasadas e de consequências probabilísticas. O estudo foi conduzido na Polônia em dois momentos diferentes - os experimentos 1 e 2 foram coletados em 1994, momento em que a Polônia tinha altíssimas taxas de inflação; e o experimento 3 foi coletado em 1996, dois anos depois de uma nova moeda ter sido introduzida e a inflação ter sido controlada. O desconto do atraso foi mais acentuado quando a coleta ocorreu em 1994.

No Brasil, um estudo semelhante ao de Ostaszewski, Green e Myerson (1998) foi conduzido por Todorov, Coelho e Hanna (1998). O Experimento 1 foi coletado antes do controle da inflação. O desconto com a moeda brasileira da época (Cruzeiro) foi maior que o desconto observado no Experimento 3, realizado dois anos após o controle da inflação, com a então nova moeda brasileira (Real). 
Além da influência de fatores amplos (como cultura, arcabouço jurídico, inflação) sobre o desconto do atraso, há pesquisas que relatam a relação entre características pessoais e desvalorização de consequências atrasadas (Odum \& Baumann, 2010). Idade, sexo, QI, raça, nível de escolaridade e renda foram explorados por alguns poucos estudos (De Wit e cols. 2007; Green, et. al., 1994; Olson, Hooper, Collins, \& Luciana, 2007) e foram encontradas relações com o desconto subjetivo.

Talvez características pessoais e experiências prévias tenham influenciado as respostas que foram aqui agrupadas no Padrão 2 - o mesmo valor $(\mathrm{R} \$ 100,00)$ foi colocado em todos os atrasos. Esse padrão foi o segundo mais frequente (41,3\%), ficando atrás apenas do Padrão 8 (responder típico em desconto, com 45,7\%). Os dados do presente trabalho foram coletados com estudantes universitários, com idades entre 17 e 25 anos. Pode-se supor que a maioria desses alunos tiveram poucas experiências com operações monetárias (i.e. transações bancárias, empréstimos, contato com juros) e com situações de ressarcimento de danos.

Outra possibilidade é que a expressão "alguém totalmente desconhecido" não tenha controlado o comportamento desses participantes (e, imaginando que esse "alguém" é um amigo, "faria sentido" manter apenas o valor do dano apesar do tempo) - sabe-se que a distância social exerce influência sobre escolhas (Jones \& Rachlin, 2009). Isso pode ter ocorrido também com os participantes que apresentaram o Padrão 4 (escreveram "zero" em todos os atrasos em alguma situação). Além do comportamento não ficar sob controle dessa parte da instrução, a magnitude do dano utilizada pode ter sido demasiadamente pequena - $\mathrm{R} \$ 100,00$ - e nesse caso a dívida poderia ser facilmente "perdoada".

Os padrões 6 e 7 (valores diminuem conforme os atrasos aumentam e respostas assistemáticas, respectivamente) podem ser atribuídos à compreensão da instrução ter sido diferente daquela planejada pelo experimentador, ou ainda ao desinteresse e fadiga. Essas 
variáveis, inclusive, podem ter influenciado todos os padrões considerados “atípicos" - 1, 2, 4, 5,6 e 7.

Outro fator a ser considerado em relação aos padrões "atípicos" é o uso de danos e consequências hipotéticas. Apesar de vários estudos em desconto não apontarem diferenças entre recompensas hipotéticas e reais (Johnson \& Bickel, 2002; Locey, Bryan \& Rachlin, 2011; Logorio \& Madden, 2005; Madden et. al., 2003), a questão da validade ecológica do uso de reforços hipotéticos ainda é frequentemente levantada (Matta, Gonçalves, \& Bizarro, 2012). Kirby (1997), por exemplo, comparou o desconto de consequências reais e hipotéticas ao longo de três estudos. Os resultados encontrados por ele sugerem que recompensas reais sofrem maior desvalorização em função do atraso do que as hipotéticas. No entanto, estudos que utilizam consequências reais tipicamente exploram magnitudes e atrasos muito limitados. Os resultados observados não podem então ser atribuídos seguramente à diferença hipotético/real - o efeito de magnitude e o tamanho reduzido dos atrasos também estão relacionados a descontos mais acentuados (Johnson \& Bickel, 2002).

No presente trabalho utilizou-se consequências hipotéticas (como em outros estudos de desconto) e danos hipotéticos - pela primeira vez explorados. Não há ainda pesquisas que tenham investigado os efeitos de consequências hipotéticas/reais nesse contexto. Os padrões de respostas observados aqui podem ter sido influenciados por esse aspecto (diferenças entre real/hipotético).

Os questionários A e B fizeram uso de consequências e danos hipotéticos, morais e materiais. Independentemente do procedimento adotado (selecionar o valor do ressarcimento de uma lista ou escrevê-lo), do tipo do dano e de quem o causou (o participante ou alguém completamente desconhecido), os dados produzidos foram melhor descritos pela função exponencial. 
Esse achado, apesar de não corroborar a maioria dos estudos em desconto, é semelhante aos encontrados em algumas pesquisas da economia (Loewenstein, 1992; Samuelson, 1937). O modelo exponencial surgiu a partir de teorias econômicas normativas (Johnson et al., 2007) e permite supor que cada unidade de atraso adicional corresponde a um aumento marginal no grau de risco (i.e., a escolha do evento imediato pode ser considerada segura, enquanto que a escolha do evento atrasado implica o risco de a recompensa nunca ser entregue; Myerson et al., 2001). O modelo hiperbólico presume que a escolha entre uma recompensa imediata e uma atrasada é o mesmo que escolher entre dois reforços que, a cada unidade de atraso, têm seus valores subjetivos reduzidos (Green \& Myerson, 1996; Matta, Gonçalves, \& Bizarro, 2012; Myerson et al. 2001).

Nesse sentido, a suposição subjacente ao modelo exponencial parece ter alguma similaridade à situação de reparação de danos - de maneira geral, os montantes em discussão são atrasados e incertos. Não se sabe quais serão o veredito, o atraso e o valor de uma causa que aguarda a decisão judicial, por exemplo. Assim, não seria surpreendente se os atrasos fossem “experimentados” enquanto risco, nessas circunstâncias.

Outra característica importante do modelo exponencial é que nele não há a predição da reversão da preferência. Os questionários aqui utilizados continham em suas instruções a frase "você está diante da última oportunidade de receber esse dinheiro". Essa frase indicava que não haveria outra possibilidade de escolha. Os questionários utilizados tradicionalmente na área não fazem referência à possibilidade (ou à ausência dela) de novas escolhas. Além disso, no presente trabalho não havia atraso entre a escolha e o acesso à consequência - momento no qual se observa a reversão. Diante disso, uma questão importante pode ser levantada: a reversão da preferência poderia ocorrer em situações nas quais não se pode alterar o momento de se receber a recompensa? Para certos eventos passados a única variável temporal possível de ser manipulada é o quanto no passado o evento ocorreu. 
Quando os ajustes das curvas exponenciais (e hiperbólicas) dos questionários A e B foram comparados, não foi observado (na grande maioria dos casos) diferenças significativas, bem como as AUCs e os $k$ s. Tais resultados apontam que tanto o Questionário A quanto o Questionário B se mostraram igualmente adequados para a investigação do fenômeno de interesse dessa pesquisa.

As pequenas diferenças observadas entre A e B corroboram o estudo de Weatherly e Derenne (2011): questionários que contêm uma lista de valores (como o Questionário A, do presente estudo) produzem descontos menos acentuados do que aqueles que não a contêm. Além disso, a mesma relação entre $k$ e AUC encontrada na literatura da área - são inversamente correlacionados - também foi observada aqui.

Quanto ao tempo de aplicação, os dois questionários foram novamente semelhantes: 25 min em média. Smith e Hantula (2008) apontam o tempo de coleta e a fadiga como principais desvantagens dos métodos binários (séries de pares de alternativas são apresentadas). Tarefas binárias grandes podem exceder 100 tentativas. Madden, Bickel e Jacobs (1999), por exemplo, utilizaram 189 pares de escolhas. Nesses casos, o problema da fadiga e das respostas inacuradas são mais prováveis.

Smith e Hantula (2008) afirmam ainda que há vantagens óbvias no procedimento de estimativa: necessita de menos tempo do que as tarefas binárias e minimiza, em função disso, efeitos de fadiga. Quanto às desvantagens, os autores salientam que esse procedimento requer mais instruções, favorecendo interpretações diversificadas das perguntas por parte dos participantes. Essas vantagens e desvantagens foram observadas no uso dos questionários A e B do presente estudo. Aqui, no entanto, identificou-se ainda outros dois benefícios do procedimento de estimativa, relacionados ao fenômeno de interesse desse estudo: possibilita que perguntas semelhantes àquelas que ocorrem no contexto real de indenizações sejam feitas no contexto hipotético e se adequa melhor quando o foco de investigação é o ressarcimento de 
um dano moral. O valor de reparação de um dano moral é bastante subjetivo, oferecer pares de alternativas com valores determinados para que o indivíduo escolha uma delas parece bastante distante de como esse valor costuma ser, na realidade, estabelecido.

Várias pesquisas têm indicado que métodos diferentes de investigação de desconto têm produzido estimativas similares (Epstein et al., 2003; Green et al., 2007; Johnson \& Bickel, 2002; Logorio \& Madden, 2005; Jaroni, Wright, Lerman, \& Epstein, 2004; entre outros). As diferenças geralmente encontradas nos níveis de desconto, e que se devem aos procedimentos distintos são pequenas (Odum \& Baumann, 2010), assim como foi observado no Estudo 1, quando os questionários A e B foram comparados.

Apesar de todas as semelhanças entre os questionários utilizados, o Questionário B apresentou algumas pequenas vantagens em relação ao Questionário A e, por isso, foi utilizado no Estudo 2. O Questionário B produziu mais situações respondidas de acordo com os padrões 3 e 8 (28\%) do que o Questionário A (21\%). Além disso, o Questionário B apresentou, no geral, valores de $R^{2}$ maiores do que os observados na análise de dados do Questionário A. A terceira e última vantagem do Questionário B em relação ao Questionário A é que ele guarda maior semelhança com o fenômeno real. Quando situações de reparação de danos ocorrem, não há listas de valores para que o montante financeiro seja estabelecido.

Diante dos resultados obtidos, conclui-se que o procedimento de estimativa, com ou sem a lista de valores, parece adequado para a investigação de alguns aspectos de situações de ressarcimento. No Estudo 2, o procedimento de estimativa sem a lista de valores foi utilizado para investigar o efeito de algumas variáveis (magnitude, natureza do dano, atraso e autor do dano) sobre o desconto subjetivo, no contexto de indenização. 


\section{Estudo 2}

Os estudos de desconto do atraso com consequências passadas envolvem sempre perdas ou ganhos. As situações de indenizações envolvem, via de regra, um dano e posteriormente a reparação desse dano. No Dicionário Aurélio, dano é definido como “estrago ou prejuízo sofrido ou causado por alguém; o que se perdeu e os prejuízos resultantes da falta do perdido". Dano pode ser considerado, de alguma forma, um tipo de perda. As palavras indenizar, ressarcir, reparar e compensar são definidas, nesse mesmo dicionário, como "recuperar o que se perdeu; retratar; suprir a falta de; ficar com o que é de outrem em compensação do que esse outrem tem de nós”. Nesse sentindo, obter a reparação de danos é diferente de obter ganhos no primeiro caso, a consequência parece ser reforçadora negativa ("remoção" ou compensação dos efeitos da perda) e no segundo caso, a consequência parece ser reforçadora positiva.

No contexto de indenizações, tem-se primeiro uma perda - punição negativa - e depois uma compensação - reforço negativo. Nos estudos de desconto tem-se apenas perdas - punição negativa - ou apenas ganhos - reforço positivo. Além dessas diferenças entre o tipo e o número de consequências investigadas tradicionalmente na literatura de desconto e as observadas no fenômeno de ressarcimento de danos (o contexto de indenizações envolve variáveis relacionadas à natureza do dano causado (material e moral, por exemplo). Diante dessas particularidades do fenômeno de interesse do presente trabalho, faz-se necessária a investigação de fatores tipicamente examinados em pesquisas sobre desconto subjetivo e variáveis especificamente relacionadas ao contexto de indenização. O primeiro deles, abordado nessa pesquisa, se refere ao efeito de magnitude: há, na compensação de danos, efeito de magnitude?

Os estudos na área de desconto subjetivo apontam que o efeito de magnitude é observado quando as consequências envolvidas são ganhos (Chapman \& Winquist, 1998; Chapman \& Elstein, 1995; Grace e cols. 2012; Green e cols. 2004; Loewenstein \& Prelec, 1992; Thaler, 1981), no futuro e no passado (Yi e cols. 2003; Stieg \& Dixon, 2007). Quando as 
consequências são perdas, o efeito de magnitude encontrado é pequeno ou inexistente (Ostaszezewski \& Kargel, 2002; Estle e cols. 2006; Holt e cols. 2008), tanto no futuro quanto no passado (Yi e cols. 2003; Stieg \& Dixon, 2007). O ressarcimento de danos, como exposto anteriormente, envolve perdas (no passado) e compensações (no futuro); portanto, torna-se difícil predizer a existência ou não do efeito de magnitude nesse caso. É importante ressaltar novamente que o atraso no passado aqui utilizado é o que existe entre o dano e o momento da escolha e não aquele tipicamente investigado, entre a escolha e o acesso à consequência.

O segundo aspecto de interesse do Estudo 2 se refere a diferenças entre danos morais e materiais. A literatura de desconto aponta que reforços diferentes produzem descontos diferentes (Chapman, 2006; Madden, Petry, Badger \& Bickel, 1997; Vuchinich \& Simpson, 1998; Bickel, Odum \& Madden, 1999; Chapman \& Weber, 2004; Chapman \& Winquist, 1998). No entanto, não se sabe se danos de naturezas diferentes também os produziriam.

O terceiro foco de investigação dessa pesquisa diz respeito à autoria do dano - o desconto das consequências envolvidas é diferente para quem causou e para quem sofreu o prejuízo? Os contextos de indenização envolvem pelo menos duas pessoas, que no âmbito judicial seriam o autor da ação e o réu. No caso de acordos, demandantes e demandados devem entrar em consenso sobre o valor a ser pago/recebido. As pesquisas em endowment effect apontam que em situações semelhantes, onde há vendedores e compradores, a atribuição de valores a bens não costuma ser consensual (Kahneman, Knetsch \& Thaler, 1991; Thaler, 1980; Tversky \& Kahneman, 1991; Kahneman \& Tversky, 1979). No entanto, não há investigações sobre a existência desse fenômeno em contextos indenizatórios.

\section{Objetivos}

O presente estudo tem o objetivo de investigar (1) se há efeito de magnitude quando as consequências utilizadas são passadas e são caracterizadas como ressarcimento de danos; (2) se há diferenças nas taxas de desconto obtidas com danos financeiros e com danos morais; e 
por fim (3) se há diferenças entre estimar o valor de um dano sofrido pela pessoa ou causado por ela (endowment effect).

\section{Método}

\section{Participantes}

Participaram desse estudo 72 estudantes de graduação (nenhum deles havia participado do Estudo 1) de uma universidade localizada no Distrito Federal. Todos eles leram e assinaram o Termo de Consentimento Livre e Esclarecido (Apêndice 1). Após essa etapa, iniciou-se o experimento.

Os participantes tinham idades entre 18 e 28 anos, eram de graduações variadas (psicologia, direito, fisioterapia, enfermagem, arquitetura, economia), mas todos estavam cursando alguma disciplina de psicologia (introdução à psicologia, economia comportamental, análise experimental do comportamento) - situação na qual a coleta ocorreu. Do total, 37 eram mulheres e 35 eram homens.

Foram utilizados dois tipos de questionários - B1 e B2 (descritos mais adiante); 40 participantes respoderam ao Questionário B1 e 32 responderam ao Questionário B2.

\section{Local e coleta}

Os dados foram coletados nas salas de aulas da universidade, durante as aulas de disciplinas de introdução à psicologia cujos professores concordaram em colaborar com a equipe de pesquisa. As coletas tiveram duração entre 20 e 25 minutos.

As coletas foram coletivas, realizadas em 3 salas diferentes, e o número de alunos presente em cada uma delas variou entre 18 e 33. Foram utilizados questionários impressos em papel e canetas.

\section{Procedimento}

Questionários e cenários. Os questionários e cenários empregados foram idênticos ao Questionário B do Estudo 1. A única diferença foi o número de magnitudes do dano 
apresentado: no Estudo 1 apenas a magnitude de $\mathrm{R} \$ 100,00$ foi utilizada; no Estudo 2 foram exploradas as magnitudes de $\mathrm{R} \$ 100,00$ e de $\mathrm{R} \$ 10.000,00$, tanto para danos de natureza moral quanto para os de natureza material, totalizando oito situações (descritas mais adiante).

No Estudo 2 foram utilizados dois questionários - B1 e B2 - que diferiram entre si apenas na ordem de apresentação das situações que continham as expressões "você causou" e "alguém lhe causou". Alguns participantes foram expostos à ordem "alguém lhe causou / você causou” (Questionário B1) e outros, à ordem “você causou / alguém lhe causou” (Questionário B2). Cada participante respondeu apenas a um questionário.

As tarefas de treino sempre foram as primeiras a serem feitas e as de dano moral, as últimas. A magnitude de $\mathrm{R} \$ 100,00$ sempre foi a primeira a ser apresentada. Modelos dos questionários utilizados no Estudo 2 foram anexados ao final do presente trabalho (apêndices 4 e 5).

Instruções gerais. A instruções gerais foram idênticas às do Questionário B do Estudo 1.

Tarefas de treino. O objetivo das tarefas de treino, o formato, a aplicação, os valores e atrasos utilizados foram idênticos aos das tarefas de treino do Questionário B, do Estudo 1.

Tarefas de dano material. Os objetivos dessas tarefas são (a) obter taxas de desconto em contextos de ressarcimento financeiro; (b) verificar diferenças nessas taxas em função da magnitude da consequência; (c) verificar se há diferenças nas taxas de desconto obtidas com danos financeiros e com danos morais; e por fim (c) verificar se há efeito de autoria do dano (endowment effect).

As instruções específicas dessas tarefas foram idênticas às utilizadas no Questionário B do Estudo 1. Como mencionado acima, a única diferença foi apresentação da magnitude do dano de $\mathrm{R} \$ 10.000,00$, além da magnitude de $\mathrm{R} \$ 100,00$. 
Tarefas de dano moral. Os objetivos dessas tarefas são (a) obter taxas de desconto em contextos de ressarcimento moral; (b) verificar diferenças nessas taxas em função da magnitude da consequência; (c) verificar se há diferenças nas taxas de desconto obtidas com danos financeiros e com danos morais; e por fim (c) verificar se há efeito de autoria do dano (endowment effect).

As instruções específicas dessas tarefas foram idênticas às utilizadas no Questionário B do Estudo 1. Novamente, a única diferença foi a apresentação de cenários adicionais, cuja magnitude do dano foi de $\mathrm{R} \$ 10.000,00$.

Desse modo, as seguintes combinações entre magnitude, tipo de dano e autor, foram apresentadas:

- "Alguém totalmente desconhecido lhe causou um dano material de $\mathrm{R} \$ 100,00 "$ (Situação 1, dano material, Sit1).

- "Alguém totalmente desconhecido lhe causou dano material de $\mathrm{R} \$ 10.000,00 "$ (Situação 2, dano material, Sit2).

- "Você causou um dano material de $\mathrm{R} \$ 100,00$ a alguém totalmente desconhecido" (Situação 3, dano material, Sit3).

- "Você causou um dano material de $\mathrm{R} \$ 10.000,00$ a alguém totalmente desconhecido" (Situação 4, dano material, Sit4).

- “Além do dano material $(\mathrm{R} \$ 100,00)$ sofrido por você, tal fato lhe trouxe grandes aborrecimentos" (Situação 5, dano moral, Sit5).

- “Além do dano material $(\mathrm{R} \$ 10.000,00)$ sofrido por você, tal fato lhe trouxe grandes aborrecimentos" (Situação 6, dano moral, Sit6).

- “Além do dano material $(\mathrm{R} \$ 100,00)$ causado por você, tal fato trouxe grandes aborrecimentos a esse alguém totalmente desconhecido" (Situação 7, dano moral, Sit7). 
- “Além do dano material $(\mathrm{R} \$ 10.000,00)$ causado por você, tal fato trouxe grandes aborrecimentos a esse alguém totalmente desconhecido" (Situação 8, dano moral, Sit8).

Os participantes que receberam o Questionário B1, responderam às situações na ordem Sit1, Sit2, Sit3, Sit4, Sit5, Sit6, Sit7 e Sit8, enquanto que os participantes que receberam o Questionário B2, seguiram a ordem Sit3, Sit4, Sit1, Sit2, Sit7, Sit8, Sit5 e Sit6. A Tabela 7 resume o procedimento utilizado.

Tabela 7

Número de participantes que responderam aos Questionários B1 e B2, e ordem de exposição às situações - contrabalanceamento feito na apresentação dos cenários em que o participante causa ou sofre um dano.

Número de Quest. Ordem de exposição às tarefas e situações
participantes

37

B1 Treino, Dano material (Sit1, Sit2, Sit3, Sit4), Dano moral

(Sit5, Sit6, Sit7, Sit8)

36

B2 Treino, Dano material (Sit3, Sit4, Sit1, Sit2), Dano moral

(Sit7, Sit8, Sit5, Sit6) 


\section{Resultados}

Assim como no Estudo 1, os valores subjetivos da recompensa (ou seja, as respostas de cada participante, para cada atraso) foram plotados em função do tempo para o cálculo da AUC e o valor de $k$ foi obtido através de regressões não-lineares hiperbólica e exponencial. Os parâmetros $k, R^{2}$ e a AUC foram calculados para cada um dos participantes. Em seguida, as medianas de $k, R^{2}$ e AUC foram obtidas para cada uma das situações. Todas essas análises foram realizadas utilizando-se uma rotina matemática semi-automatizada desenvolvida sob medida (Matlab 7.0; Mathworks, Natick, MA, EUA).

Novamente, o teste de Kolmogorov-Smirnov foi executado para testar a normalidade da distribuição dos dados das variáveis quantitativas. Foram utilizados os dados absolutos de todos os participantes e em cada uma das situações. Desse modo, a normalidade de cada situação foi testada. Como as variáveis apresentaram distribuição não-paramétrica, o teste de MannWhitney foi utilizado para a testar a hipótese nula nas diferentes situações estudadas, de que o valor de $k$ não diferia em função (1) da magnitude do dano; (2) da natureza do dano; e (3) do autor do dano.

Para testar a possível correlação dos valores de $k$ entre os danos moral e material, nas diferentes situações estudadas, empregou-se o teste de correlação de Spearman. Nele, pares de dados foram utilizados (ou seja, o $k$ de uma situação de dano material e o $k$, do mesmo participante, da situação de dano moral correspondente). Desse modo, buscou-se verificar se a variabilidade do valor de $k$ de uma determinada situação correlacionava-se, positiva ou negativamente, com a variabilidade de $k$ de outra situação.

A análise de variância com três fatores (ANOVA three-way) foi utilizada para testar as hipóteses nulas de que a área sob a curva e o valor de $k$ não seriam modificados pelos efeitos:

1. da natureza do dano; 
2. do valor do dano;

3. do autor do dano;

4. da interação entre natureza do dano $x$ valor do dano $x$ autor do dano.

O teste ANOVA foi executado a partir dos valores individuais que compuseram o valor da situação (mediana). A homogeneidade das variâncias foi verificada com o teste de Levene e a análise dos resíduos foi conduzida para testar as suposições da ANOVA com três fatores.

Todas as análises estatísticas foram realizadas com o programa Statistical Package for Social Science (IBM SPSS Statistics para Windows, versão 20.0, Armonk, NY, EUA, IBM Corp.) O nível de significância estabelecido para todas as análises foi de 5\% e os resultados estão expressos na forma de mediana e intervalo interquartil.

Os resultados foram apresentados em forma de tabela (mediana, intervalo interquartil e p-valor obtido através do teste de Mann-Whitney) pois as figuras construídas com tais resultados não possibilitaram que estes fossem visualizados. Os dados individuais foram anexados ao presente trabalho (Apêndice 7)

\section{Descrição geral dos dados}

Dos 72 participantes desse estudo, 40 responderam o Questionário B1 e 32 responderam o Questionário B2. Todos os participantes responderam a oito situações apresentadas - quatro de dano material e quatro de dano moral. No total, obteve-se então 576 situações respondidas. Foi possível observar seis padrões de respostas, dos quais cinco também foram encontrados no Estudo 1. Os padrões serão descritos abaixo - as mesmas definições utilizadas no Estudo 1 foram utilizadas aqui. No entanto, nos dados do Estudo 2 não foram encontrados os padrões 4, 6 e 7. Por isso as descrições deles não serão reproduzidas aqui e não constarão nas tabelas 8 e 9, que apresentaram as frequências de cada padrão. A Tabela 8 mostra os dados referentes às tarefas de dano material e a Tabela 9 os dados referentes às tarefas de dano moral.

- Padrão 1: participantes que colocaram "zero" em atrasos longos (cinco e 10 anos). 
- Padrão 2: participantes que colocaram o mesmo valor $(\mathrm{R} \$ 100,00)$, que era o valor do dano, em todos os atrasos.

- Padrão 3: participantes que responderam com apenas dois valores - colocaram o mesmo valor até certo atraso e, em todos os atrasos seguintes, colocaram outro valor, maior que o primeiro.

- Padrão 5: o valor das respostas diminui nos atrasos de cinco e 10 anos (mas é diferente de zero).

- Padrão 8: os valores das respostas aumentaram conforme os atrasos ficaram maiores (respostas “típicas” em desconto).

- Padrão 9: os valores das respostas são menores que os valores dos danos.

Como pode ser observado nas tabelas 8 e 9 , o padrão mais frequente foi o 8 , com 58,33\%. Em seguida está o Padrão 2 (com 27,71\%), e depois o Padrão 3 (com 2,20\%) seguido pelos padrões $5(1,9 \%)$ e $9(1,04 \%)$. Assim como no Estudo 1, apenas as respostas de acordo com os padrões 8 e 3 foram consideradas para os cálculos da AUC, do k e do R². Essa seleção se baseou nas seguintes considerações: no Padrão 2 não se observa desconto; nos padrões 1 e 5, as respostas aos atrasos longos (cinco e 10 anos) parecem ter ficado sob controle de outras variáveis que não apenas o tempo decorrido entre o dano e o momento da escolha. Essas possíveis variáveis foram apontadas na Discussão do Estudo 1. No Padrão 9, as repostas têm valores menores do que o valor do dano. Nesse caso, não é possível afirmar que o participante compreendeu a tarefa (ou a pergunta) como o planejado pelo experimentador.

As primeiras comparações realizadas foram entre os questionários B1 e B2, para verificar se houve diferença entre os parâmetros $k, R^{2}$ e AUC em função da ordem de apresentação das situações. Para isso, compararam-se as medianas dos parâmetros acima citados, para cada uma das situações. Por exemplo, a Situação 1 do Questionário B1 foi comparada ( $k, R^{2}$ e AUC) à 
Situação 1 do Questionário B2. A Situação 2 do Questionário B1 foi comparada à Situação 2 do Questionário B2, e assim em diante, até a Situação 8.

As comparações realizadas apontaram que não houve nenhuma diferença significativa entre os dois questionários quanto aos valores dos parâmetros $k, R^{2}$ (tanto para hipérbole quanto para exponencial) e AUC. Em função disso, optou-se por realizar todas as análises seguintes com todos os dados (dos dois questionários) juntos.

Tabela 8

Frequências absoluta (primeiro número) e relativa (segundo número) (\%) dos padrões de respostas dos participantes do Estudo 2, nas situações de dano material e ao longo de todo o estudo. A frequência relativa total (última coluna) foi calculada considerando-se os dados das tarefas de dano material e moral.

\begin{tabular}{|c|c|c|c|c|c|c|c|c|c|}
\hline Padrões & Sit1B1 & Sit1B2 & Sit2B1 & Sit2B2 & Sit3B1 & Sit3B2 & Sit4B1 & Sit4B2 & $\begin{array}{l}\text { Freq. } \\
\text { total }\end{array}$ \\
\hline \multirow[t]{2}{*}{1} & 5 & 2 & 0 & 1 & 2 & 0 & 0 & 0 & $2,77 \%$ \\
\hline & $(12 \%)$ & $(6,25 \%)$ & $(0 \%)$ & $(3,12 \%)$ & $(5 \%)$ & $(0 \%)$ & $(0 \%)$ & $(0 \%)$ & \\
\hline \multirow[t]{2}{*}{2} & 7 & 12 & 11 & 9 & 12 & 6 & 11 & 7 & $27,71 \%$ \\
\hline & $(17,5)$ & $(37,5)$ & $(27,5 \%)$ & $(28,12 \%)$ & $(30 \%)$ & $(18,75 \%)$ & $(27,5 \%)$ & $(21,87 \%)$ & \\
\hline \multirow[t]{2}{*}{3} & 1 & 0 & 1 & 2 & 4 & 1 & 0 & 2 & $2,20 \%$ \\
\hline & $(2,5 \%)$ & $(0 \%)$ & $(2,5 \%)$ & $(6,25 \%)$ & $(10 \%)$ & $(3,12 \%)$ & $(0 \%)$ & $(6,25 \%)$ & \\
\hline \multirow[t]{2}{*}{5} & 3 & 0 & 0 & 0 & 0 & 0 & 0 & 0 & $1,90 \%$ \\
\hline & $(7,5 \%)$ & $(0 \%)$ & $(0 \%)$ & $(0 \%)$ & $(0 \%)$ & $(0 \%)$ & $(0 \%)$ & $(0 \%)$ & \\
\hline \multirow[t]{2}{*}{8} & 18 & 18 & 22 & 20 & 17 & 25 & 23 & 23 & $58,33 \%$ \\
\hline & $(45 \%)$ & $(56,3 \%)$ & $(55 \%)$ & $(62,5 \%)$ & $(42,5 \%)$ & $(78,2 \%)$ & $(57,5 \%)$ & $(71,9 \%)$ & \\
\hline \multirow[t]{2}{*}{9} & 1 & 0 & 1 & 0 & 0 & 0 & 1 & 0 & $1,04 \%$ \\
\hline & $(2,5 \%)$ & $(0 \%)$ & $(2,5 \%)$ & $(0 \%)$ & $(0 \%)$ & $(0 \%)$ & $(2,5 \%)$ & $(0 \%)$ & \\
\hline
\end{tabular}


Tabela 9

Frequências absoluta (primeiro número) e relativa (segundo número) (\%) dos padrões de respostas dos participantes do Estudo 2, nas situações de dano moral e ao longo de todo o estudo. A frequência relativa total (última coluna) foi calculada considerando-se os dados das tarefas de dano material e moral.

\begin{tabular}{|c|c|c|c|c|c|c|c|c|c|}
\hline Padrões & Sit5B1 & Sit5B2 & Sit6B1 & Sit6B2 & Sit7B1 & Sit7B2 & Sit8B1 & Sit8B2 & $\begin{array}{l}\text { Freq. } \\
\text { total }\end{array}$ \\
\hline \multirow[t]{2}{*}{1} & 2 & 1 & 1 & 1 & 1 & 0 & 0 & 0 & $2,77 \%$ \\
\hline & $(5 \%)$ & $(3,12 \%)$ & $(2,5 \%)$ & $(3,12 \%)$ & $(2,5 \%)$ & $(0 \%)$ & $(0 \%)$ & $(0 \%)$ & \\
\hline \multirow[t]{2}{*}{2} & 8 & 8 & 12 & 10 & 9 & 4 & 11 & 6 & $27,71 \%$ \\
\hline & $(20 \%)$ & $(25 \%)$ & $(30 \%)$ & $(31,25 \%$ & $(22,5 \%)$ & $(12,5 \%)$ & $(27,5 \%)$ & $(18,75 \%)$ & \\
\hline \multirow[t]{2}{*}{3} & 0 & 1 & 0 & 3 & 0 & 4 & 0 & 3 & $2,20 \%$ \\
\hline & $(0 \%)$ & $(3,12 \%)$ & $(0 \%)$ & $(9,37 \%)$ & $(0 \%)$ & $(12,5 \%)$ & $(0 \%)$ & $(9,37 \%)$ & \\
\hline \multirow[t]{2}{*}{5} & 3 & 0 & 2 & 0 & 2 & 0 & 1 & 0 & $1,9 \%$ \\
\hline & $(7,5 \%)$ & $(0 \%)$ & $(5 \%)$ & $(0 \%)$ & $(5 \%)$ & $(0 \%)$ & $(2,5 \%)$ & $(0 \%)$ & \\
\hline \multirow[t]{2}{*}{8} & 22 & 20 & 20 & 17 & 23 & 23 & 23 & 22 & $58,33 \%$ \\
\hline & $(55 \%)$ & $(62,5 \%)$ & $(50 \%)$ & $(53,1 \%)$ & $(57,5 \%)$ & $(71,87 \%)$ & $(57,5 \%)$ & $(68,8 \%)$ & \\
\hline \multirow[t]{2}{*}{9} & 0 & 1 & 0 & 1 & 0 & 1 & 0 & 0 & $1,04 \%$ \\
\hline & $(0 \%)$ & $(3,12 \%)$ & $(0 \%)$ & $(3,12 \%)$ & $(0 \%)$ & $(3,12 \%)$ & $(0 \%)$ & $(0 \%)$ & \\
\hline
\end{tabular}

\section{Funções hiperbólica e exponencial}

Para verificar qual função apresentou o melhor ajuste aos dados, os $R^{2}$ obtidos (através das equações hiperbólica e exponencial) em cada situação foram comparados. A Tabela 10 apresenta as medianas de $R^{2}$, de cada uma das situações, obtidas com as funções hiperbólica e exponencial. 
Tabela 10

Número de participantes $(N)$, mediana e intervalo interquartil de $R^{2}$, calculados com as funções hiperbólica e exponencial, de todas as situações dos questionários B1 e B2 juntos.

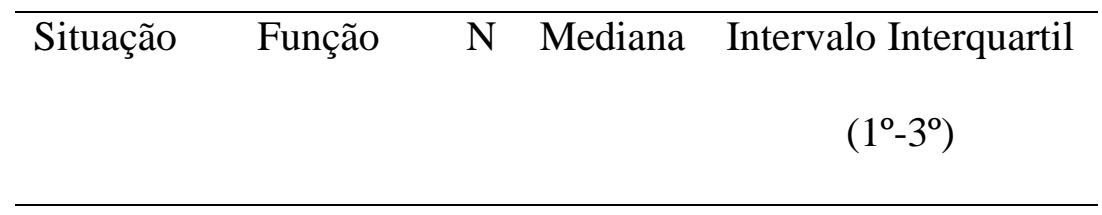

\begin{tabular}{|c|c|c|c|c|}
\hline \multirow[t]{2}{*}{ Sit1 } & Hipérbole & 37 & 0,934 & $0,838-0,972$ \\
\hline & Exponencial & & 0,972 & $0,937-0,987$ \\
\hline \multirow[t]{2}{*}{ Sit2 } & Hipérbole & 45 & 0,968 & $0,901-0,988$ \\
\hline & Exponencial & & 0,978 & $0,953-0,992$ \\
\hline \multirow[t]{2}{*}{ Sit3 } & Hipérbole & 47 & 0,922 & $0,868-0,974$ \\
\hline & Exponencial & & 0,970 & $0,941-0,986$ \\
\hline \multirow[t]{2}{*}{ Sit4 } & Hipérbole & 48 & 0,963 & $0,866-0,990$ \\
\hline & Exponencial & & 0,981 & $0,951-0,992$ \\
\hline \multirow[t]{2}{*}{ Sit5 } & Hipérbole & 43 & 0,937 & $0,833-0,974$ \\
\hline & Exponencial & & 0,977 & $0,932-0,988$ \\
\hline \multirow[t]{2}{*}{ Sit6 } & Hipérbole & 40 & 0,915 & $0,822-0,969$ \\
\hline & Exponencial & & 0,961 & $0,934-0,982$ \\
\hline \multirow[t]{2}{*}{ Sit7 } & Hipérbole & 50 & 0,934 & $0,794-0,974$ \\
\hline & Exponencial & & 0,965 & $0,927-0,987$ \\
\hline \multirow[t]{2}{*}{ Sit8 } & Hipérbole & 48 & 0,905 & $0,760-0,980$ \\
\hline & Exponencial & & 0,975 & $0,937-0,988$ \\
\hline
\end{tabular}

Os valores das medianas de $R^{2}$ foram maiores para a equação exponencial em todos os casos. Como a função exponencial foi a que ofereceu o melhor ajuste aos dados, as análises 
seguintes (efeito de magnitude, natureza do dano e autoria do dano) utilizaram os parâmetros $k$ e $R^{2}$ obtidos através dessa função.

\section{Efeito de magnitude}

Para verificar se o desconto se alterou em função da magnitude do dano, as situações 1, 3, 5 e 7 (nas quais a magnitude do dano era $\mathrm{R} \$ 100,00$ ) foram comparadas com as situações 2 , 4, 6 e 8 (nas quais a magnitude do dano era $\mathrm{R} \$ 10.000,00$ ), respectivamente, valendo-se das medidas de $k$ e AUC. Para essa análise, utilizou-se as medianas de $k$ e AUC, de cada situação, obtida através dos $k$ s e AUCs individuais. Ou seja, o $k$ e a AUC foram calculados para cada participante, em cada situação e, a partir desses valores, a mediana de cada situação foi extraída.

A Tabela 11 mostra a comparação entre as medianas de $k$ dos pares de situações acima mencionados. Como pode ser observado, todas as diferençaa entre as medianas de $k$, de todos os pares de situações comparados, foram significativas, com exeção das situações 5 e 6 (dano moral). As medianas de $k$ foram sempre maiores nas situações cuja magnitude do dano era menor.

A Tabela 12 apresenta as medianas das AUCs, o intervalo interquartil e o p-valor das comparações entre as situações de menor magnitude com as de maior magnitude. As medianas da AUC foram sempre maiores nas situações nas quais o dano tinha o valor de R 10 mil, independentemente da natureza (financeira ou moral) e do autor (alguém ou você) do prejuízo. Todas as diferenças entre as medianas das AUCs, obtidas através das comparações feitas, foram significativas.

\section{Danos materiais e danos morais}

Para verificar se o desconto se alterou em função da natureza do dano, comparou-se os seguintes pares de situações: 1 e 5; 2 e $6 ; 3$ e 7; 4 e 8 . A primeira situação do par sempre é referente ao dano moral e a segunda ao dano material. As magnitudes de cada uma das situações são idênticas às do seu par de comparação. Desse modo, a magnitude utilizada na Situação 1 é 
a mesma utilizada na 5; a empregada na Situação 2 é idêntica à usada na 6, e assim em diante. As comparações foram realizadas valendo-se dos parâmetros $k$ e AUC.

As medianas de $k$ foram sempre maiores nas situações de dano moral, como pode ser observado na Tabela 13.

\section{Tabela 11}

Mediana e intervalo interquartil dos ks, de cada situação. $O$ p-valor foi obtido através das comparações entre as situações 1 e 2; 3 e 4; 5 e 6; 7 e 8.

\begin{tabular}{|c|c|c|c|c|}
\hline Situações & $\mathrm{N}$ & Mediana & $\begin{array}{l}\text { Intervalo Interquartil } \\
\qquad\left(1^{\mathrm{o}}-3^{\mathrm{o}}\right)\end{array}$ & p-valor \\
\hline Sit1 & 37 & 0,015 & $(0,007-0,033)$ & 0,001 \\
\hline Sit2 & 45 & 0,004 & $(0,002-0,014)$ & \\
\hline Sit3 & 47 & 0,016 & $(0,005-0,026)$ & 0,011 \\
\hline Sit4 & 48 & 0,004 & $(0,001-0,019)$ & \\
\hline Sit5 & 43 & 0,022 & $(0,012-0,154)$ & 0,337 \\
\hline Sit6 & 40 & 0,017 & $(0,004-0,185)$ & \\
\hline Sit7 & 50 & 0,029 & $(0,019-0,064)$ & 0,022 \\
\hline Sit8 & 48 & 0,015 & $(0,004-0,038)$ & \\
\hline
\end{tabular}


Tabela 12

Número de participantes (N), mediana e intervalo interquartil das AUCs, de cada situação. $O$ p-valor foi obtido através das comparações entre as situações 1 e 2; 3 e 4; 5 e 6; 7 e 8.

\begin{tabular}{|c|c|c|c|c|}
\hline Situação & $\mathrm{N}$ & Mediana & $\begin{array}{l}\text { Intervalo interquartil } \\
\qquad\left(1^{\mathrm{o}}-3^{\mathrm{o}}\right)\end{array}$ & p-valor \\
\hline Sit1 & 37 & 0,500 & $0,309-0,704$ & 0,002 \\
\hline Sit2 & 45 & 0,707 & $0,551-0,904$ & \\
\hline Sit3 & 47 & 0,544 & $0,417-0,706$ & 0,001 \\
\hline Sit4 & 48 & 0,723 & $0,587-0,874$ & \\
\hline Sit5 & 43 & 0,299 & $0,184-0,573$ & 0,001 \\
\hline Sit6 & 40 & 0,593 & $0,380-0,842$ & \\
\hline Sit7 & 50 & 0,304 & $0,149-0,512$ & 0,001 \\
\hline Sit8 & 48 & 0,661 & $0,452-0,831$ & \\
\hline
\end{tabular}


Tabela 13

Mediana e intervalo interquartil dos ks, de cada situação. $O$ p-valor foi obtido através das comparações entre as situações 1 e 5; 2 e 6; 3 e 7; 4 e 8.

\begin{tabular}{cccc}
\hline Situação & Mediana & Intervalo Interquartil & p-valor \\
& & $\left(1^{\text {o }}-^{\text {o }}\right)$ & \\
Sit1 & 0,015 & $0,007-0,033$ & 0,135 \\
Sit5 & 0,022 & $0,012-0,154$ & \\
& & & \\
Sit2 & 0,004 & $0,002-0,014$ & 0,005 \\
Sit6 & 0,017 & $0,004-0,185$ & \\
& & & \\
Sit3 & 0,016 & $0,005-0,026$ & 0,001 \\
Sit7 & 0,029 & $0,019-0,064$ & \\
Sit8 & 0,004 & $0,001-0,019$ & \\
& & $0,004-0,038$ & \\
\hline
\end{tabular}

As diferenças entre as medianas de $k$ foram todas estatisticamente significativas, com exeção da diferença encontrada no par Sit1 e Sit5.

A AUC foi calculada para cada uma das situações e está apresentada na Tabela 14, juntamente com o p-valor de cada comparação feita. 
Tabela 14

Número de participantes (N), mediana e intervalo interquartil das AUCs, de cada situação. $O$ p-valor foi obtido através das comparações entre as situações 1 e 2; 3 e 4; 5 e 6; 7 e 8.

\begin{tabular}{|c|c|c|c|c|}
\hline Situação & $\mathrm{N}$ & Mediana & $\begin{array}{l}\text { Intervalo interquartil } \\
\qquad\left(1^{\mathrm{o}}-3^{\mathrm{o}}\right)\end{array}$ & p-valor \\
\hline Sit1 & 37 & 0,500 & $0,309-0,704$ & 0,018 \\
\hline Sit5 & 43 & 0,299 & $0,184-0,573$ & \\
\hline Sit2 & 45 & 0,707 & $0,551-0,904$ & 0,073 \\
\hline Sit6 & 40 & 0,593 & $0,380-0,842$ & \\
\hline Sit3 & 47 & 0,544 & $0,417-0,706$ & 0,001 \\
\hline Sit7 & 50 & 0,304 & $0,149-0,512$ & \\
\hline Sit4 & 48 & 0,723 & $0,587-0,874$ & 0,018 \\
\hline Sit8 & 48 & 0,661 & $0,452-0,831$ & \\
\hline
\end{tabular}

Como é possível observar, as medianas da AUC foram maiores nas situações nas quais o dano era de natureza material. Todas as comparações apresentaram diferenças significativas, com exceção da comparação entre as situações 2 e 6.

Entre todas as medianas das AUCs, a Sit4 (dano material de R \$ 10.000,00) apresentou o maior valor, seguida pelas Sit2 (dano material de $\mathrm{R} \$ 10.000,00$ ), Sit8 (dano moral de $\mathrm{R} \$$ 10.000,00), Sit6 (dano moral de R\$ 10.000,00), Sit3 (dano material de R \$ 100,00), Sit1 (dano material de R\$100,00), Sit5 (dano moral de R\$100,00) e Sit7 (dano moral de R\$ 100,00). Essa 
ordenação sugere que quando a magnitude do dano é igual, ressarcimentos de danos morais são mais descontados do que os de natureza material. Quando a magnitude é diferente, no entanto, valores menores são mais descontados do que valores maiores, independentemente da natureza do dano. É possível observar ainda que nas situações em que o autor do dano é o participante ("você causou"), a AUC é sempre maior (com exceção da Sit7) do que nas situações em que o autor é alguém desconhecido. No entanto, não houve diferença significativa para a interação entre o valor do dano x tipo do dano $\mathrm{x}$ autor do dano $(\mathrm{p}=0,658)$, nem pela interação dos fatores quando analisado dois-a-dois: valor do dano $\mathrm{x}$ tipo do dano $(\mathrm{p}=0,265)$; valor do dano $\mathrm{x}$ autor do dano $(\mathrm{p}=0,463)$; tipo do dano $\mathrm{x}$ autor do dano $(\mathrm{p}=0,496)$.

Similarmente, a interação entre o valor do dano x tipo do dano x autor do dano não foi significativa $(\mathrm{p}=0,928)$, bem como a a interação dos fatores quando analisados dois-a-dois: valor do dano $\mathrm{x}$ tipo do dano $(\mathrm{p}=0,613)$; valor do dano $\mathrm{x}$ autor do dano $(\mathrm{p}=0,510)$; tipo do dano $\mathrm{x}$ autor do dano $(\mathrm{p}=0,911)$.

\section{Autoria do dano (endowment effect)}

Para verificar se a autoria do dano exerceu alguma influência sobre o nível de desconto, foram feitas comparações entre as situações 1 e 3; 2 e 4; 5 e 7; e 6 e 8 . Na primeira situação de cada par comparado o dano foi sempre causado por alguém e na segunda o dano foi causado pelo participante. A magnitude e natureza do dano de cada uma das situações são idênticas às do seu par de comparação. Desse modo, a magnitude e natureza utilizadas na Situação 1 são as mesmas utilizadas na 5; aquelas empregadas na Situação 2 são idênticas às usadas na 6, e assim em diante. Novamente, as comparações foram realizadas valendo-se dos parâmetros $k$ e AUC.

A Tabela 15 mostra as medianas de $k$ das situações em que danos foram causados pelos participantes comparadas às medianas de $k$ das situações em que danos foram sofridos pelos participantes. 
Tabela 15

Mediana e intervalo interquartil dos ks, de cada situação. $O$ p-valor foi obtido através das comparações entre as situações 1 e 3; 2 e 4; 5 e 7; 6 e 8.

\begin{tabular}{cccc}
\hline Situação & Mediana & Intervalo interquartil & p-valor \\
& & $\left(1^{\circ}-3^{\circ}\right)$ & \\
& & & \\
Sit1 & 0,015 & $0,007-0,033$ & 0,383 \\
Sit3 & 0,016 & $0,005-0,026$ & \\
& & & \\
& & & \\
Sit2 & 0,004 & $0,002-0,014$ & 0,812 \\
Sit4 & 0,005 & $0,001-0,019$ & \\
& & & \\
& & 0,521 \\
Sit5 & 0,022 & $0,012-0,154$ & \\
Sit7 & 0,029 & $0,019-0,064$ & \\
& & 0,668 \\
Sit6 & 0,017 & $0,004-0,185$ & \\
\hline & 0,015 & $0,004-0,038$ & \\
\hline
\end{tabular}

Como pode ser observado, as medianas são menores nas situações em que o dano é sofrido pelos participantes em três (entre quatro) comparações. No entanto, as diferenças não são significativas.

A Tabela 16 apresenta as comparações entre as medianas das AUCs dos pares de situações 1 e $3 ; 2$ e $4 ; 5$ e 7; e 6 e 8 . 
Tabela 16

Número de participantes $(N)$, mediana e intervalo interquartil das AUCs, de cada situação. $O$ p-valor foi obtido através das comparações entre as situações 1 e 3; 2 e 4; 5 e 7; 6 e 8.

\begin{tabular}{|c|c|c|c|c|}
\hline Situação & $\mathrm{N}$ & Mediana & $\begin{array}{l}\text { Intervalo interquartil } \\
\qquad\left(1^{\mathrm{o}}-3^{\mathrm{o}}\right)\end{array}$ & $\mathrm{p}$-valor \\
\hline Sit1 & 37 & 0,500 & $0,309-0,704$ & 0,661 \\
\hline Sit3 & 47 & 0,544 & $0,417-0,706$ & \\
\hline Sit2 & 45 & 0,707 & $0,551-0,904$ & 0,679 \\
\hline Sit4 & 48 & 0,723 & $0,587-0,874$ & \\
\hline Sit5 & 43 & 0,299 & $0,184-0,573$ & 0,615 \\
\hline Sit7 & 50 & 0,304 & $0,149-0,512$ & \\
\hline Sit6 & 40 & 0,593 & $0,380-0,842$ & 0,875 \\
\hline Sit8 & 48 & 0,661 & $0,452-0,831$ & \\
\hline
\end{tabular}

Como pode ser observado na Tabela 16, em todas as situações a mediana da AUC foi maior quando o dano foi causado pelo participante. No entanto, nenhuma das diferenças observadas foi significativa.

\section{Discussão}

Os dados coletados no Estudo 2 puderam ser agrupados em seis padrões de respostas diferentes, sendo que cinco deles também foram observados no Estudo 1. O Padrão 9, no qual as respostas dos participantes possuíam valores menores do que os valores dos danos, foi visto 
apenas no Estudo 2. Tal padrão pode se dever ao fato da compreensão da questão ou da tarefa ter sido diferente daquela planejada pelo experimentador - o participante pode ter entendido que deveria colocar o valor que somado ao dano resultaria no montante que desejaria receber. Outra possibilidade é que a situação, que é diferente da tipicamente investigada, pode sugerir que o dano é um valor que dificilmente será recuperado e qualquer quantia reparada é, nesse caso, vantajosa.

Os seis padrões de respostas foram observados nos dois questionários utilizados (B1 e B2). Os dados produzidos pelos dois questionários foram bastante similares, apesar de apresentarem as situações em ordens diferentes aos participantes.

Assim como no Estudo 1, o melhor ajuste se deu com a utilização da equação exponencial, em todos os casos. Esse achado difere daqueles típicos na literatura de desconto e possíveis explicações foram exploradas na Discussão do Estudo 1. As únicas diferenças entre os procedimentos adotados nos Estudos 1 e 2 foram a magnitude do dano (no Estudo 1 apenas a magnitude de $\mathrm{R} \$ 100,00$ foi utilizada enquanto que no Estudo 2 empregou-se também a magnitude de $\mathrm{R} \$ 10.000,00)$ e a apresentação das situações em ordens diferentes (no Estudo 1 apenas uma sequência foi utilizada - alguém causou o dano e depois você o causou - enquanto no Estudo 2 duas sequências foram empregadas - alguns participantes iniciaram pelas situações nas quais haviam sofrido dano e outros iniciaram por aquelas em que o haviam causado).

Essas diferenças entre procedimentos foram planejadas para investigar (1) se havia efeito de magnitude quando as consequências utilizadas são passadas e são caracterizadas como ressarcimento de danos; (2) se havia diferenças nas taxas de desconto obtidas com danos financeiros e com danos morais; e por fim (3) se a autoria do dano exerceu algum efeito sobre o desconto subjetivo nesse contexto.

Em relação ao efeito de magnitude, observou-se que as medianas de $k$ s foram maiores quando os danos eram menores, em todas as situações. Isso sugere que as situações investigadas 
se assemelharam àquelas envolvendo ganhos, tipicamente estudas nas pesquisas sobre desconto temporal. Nesses estudos, consequências de magnitudes menores sofrem descontos maiores (Chapman \& Winquist, 1998; Grace, Randolph, Sargisson, Rebecca, White \& Geoffrey, 2012; Green, Myerson, Holt, Slevin \& Estle, 2004), como o que foi observado aqui.

O efeito de magnitude foi observado independentemente do tipo do dano. Tal resultado se assemelha àqueles encontrados por Chapman (1996) e Chapman e Elstein (1996), que investigaram o efeito de magnitude utilizando consequências de naturezas diferentes - dinheiro, saúde e férias. No presente estudo, entretanto, não se utilizou consequências de naturezas diferentes (o ressarcimento era sempre em dinheiro), apenas os danos eram de naturezas diferentes (material e moral). Ainda assim, vale notar que, tanto nos trabalhos de Chapman (1996) e Chapman e Elstein (1996) quanto na presente pesquisa, o efeito de magnitude ocorre mesmo quando estímulos de naturezas diversas são utilizados.

Quando outras comparações entre danos morais e materiais foram feitas, notou-se que as medianas de $k$ foram maiores nas situações de danos morais. Além disso, como esperado nesse caso, a AUC foi sempre maior para danos materiais. Isso significa que compensações de danos morais foram mais descontadas que as de danos materiais. Há uma diferença que vale ser ressaltada quanto à arbitragem do valor da indenização moral e material: quando há um dano material, há um prejuízo objetivamente mensurável; no caso de danos morais, a magnitude do prejuízo não é acompanhada de valores objetivos. Os resultados do presente trabalho parecem indicar que a falta de uma medida objetiva da magnitude do dano o deixa mais suscetível à desvalorização em função do atraso. Ou seja, os danos de natureza moral sofreram descontos maiores do que os de natureza material.

No presente estudo, não houve correlação entre o desconto de danos materiais e morais, resultado que se assemelha aos encontrados por Chapman (1996), os quais apresentaram ausência de correlação entre desconto de saúde e dinheiro. Ainda assim, tal similaridade deve 
ser considerada com ressalvas pois o presente estudo não explorou consequências de naturezas diferentes. Não há estudos que tenham investigado desconto subjetivo envolvendo danos, tampouco diferentes tipos de danos. Portanto, as comparações com os trabalhos existentes devem ser feitas com cautela.

Além das comparações entre magnitudes e naturezas dos danos, foram realizadas análises que permitiriam observar o efeito da autoria do dano sobre o desconto subjetivo. As medianas de $k$ s são menores nas situações em que o dano é sofrido pelos participantes em três (entre quatro) comparações. Ou seja, o desconto foi menor nessas situações. No entanto, as diferenças não são significativas.

Resultados opostos foram encontrados quando as análises das AUCs foram feitas, sendo maiores quando o participante causou o dano. É importante destacar, no entanto, que as diferenças entre as AUCs também não foram significativas.

Geralmente, utilizam-se situações de compra e venda para investigar o endowment effect. Talvez esse fenômeno não tenha sido observado no presente trabalho exatamente pela diferença de contexto. Como mencionado anteriormente, há diferenças importantes entre as formas como o endowment effect é tipicamente explorado e a que foi empregada aqui. Nos cenários de compras (frequentes no endowment effect), um objeto ou bem é comercializado. Nos contextos de indenização, o dano exerceria a função desse "objeto ou bem" - objetos ou bens e danos são estímulos de naturezas e funções diferentes. Em indenizações não há compradores e vendedores, há autores e vítimas dos danos. Essas e outras dessemelhanças já apontadas, podem ter influenciado os resultados do Estudo 2. No entanto, a presente pesquisa não permite identificar quais das diferenças no procedimento adotado pode explicar as discrepâncias entre os resultados encontrados aqui e os tipicamente vistos na literatura da área. Estudos futuros poderiam tentar identificar quais das diferenças nos procedimentos estão associadas à falta de efeito significativo. 
Outro fator que pode ter sido reponsável, pelo menos em parte, pelos dados observados é o controle social: escolhas financeiras são frequentemente associadas a normas e informações da comunidade na qual o indivíduo está inserido (Smith \& Hantula, 2008). Os participantes podem ter respondido os questionários igualando os valores a serem pagos aos que gostariam de receber por entenderem que isso, talvez, fosse socialmente desejado.

É importante considerar, ainda, que as regras sociais para transações comerciais (cenários comuns nas pesquisas de endowment effect) não parecem ser as mesmas daquelas presentes em processos de reparação de danos. As situações de indenização envolvem questões relativas ao que é justo ou moralmente aceitável - alguém que causa prejuízo a outrem tem uma espécie de "obrigação moral" de compensar tal prejuízo. Por tanto, regras sociais podem ter exercido uma influência maior nas respostas dos participantes desta pesquisa do que em estudos que fazem uso de contextos de compra e venda.

\section{Discussão Geral e Conclusão}

O presente trabalho teve como objetivos verificar se (a) o procedimento de estimativa (Chapman \& Elstein, 1995 e Chapman, 1996) poderia ser utilizado para investigar desconto de consequências passadas no contexto de ressarcimento danos materiais e morais; (b) qual função (hiperbólica ou exponencial) descreveria melhor os dados obtidos por intermédio desse procedimento; (c) se haveria diferenças entre o desconto observado com danos de naturezas materiais e morais; (d) se haveria correlação entre os descontos observados com danos materiais e morais; (e) se haveria efeito de magnitude; e se (f) a autoria do dano produziria algum efeito no desconto subjetivo, com essa metodologia de pesquisa. Para isso foram realizados dois estudos. O primeiro deles investigou as questões relacionadas aos procedimentos típicos de desconto subjetivo (itens a e b; utilizou-se dois tipos diferentes de questionários, com apenas uma magnitude de dano); o segundo investigou as questões referentes ao desconto do atraso (itens c, d, e, f; utilizou-se apenas um tipo de questionário, com duas magnitudes de dano). 
De maneira geral, os resultados indicaram que procedimentos de estimativa (com e sem lista de valores) podem ser utilizados para a investigação de desconto subjetivo de compensação de danos ocorridos no passado. No entanto, além dos padrões de respostas tipicamente encontrados nos estudos de desconto (desvalorização da consequência em função do tempo), outros padrões foram observados, tais como o valor não se alterar em função do atraso, colocar zero em todos os atrasos, responder valores de ressarcimento menores que os valores dos danos, entre outros.

Não é possível afirmar, contudo, que esses padrões de respostas "atípicos" não são encontrados em outras investigações de desconto subjetivo - não há estudos publicados que tenham explorado esses padrões diversos. Geralmente, as respostas que não variam em função dos atrasos são retiradas das análises e não são mencionadas em artigos. Diante disso, não há possibilidade de comparação desses resultados do presente estudo com outros na literatura.

Pode-se supor que esses padrões "atípicos", que foram observados tanto no Estudo 1 quanto no Estudo 2 podem ter ocorrido em função do procedimento adotado na presente pesquisa. Todavia, o presente estudo não permite identificar quais características do procedimento podem ter produzido tais padrões de respostas. As respostas que não variaram em função dos atrasos foram observadas em todos os questionários utilizados.

Em relação aos questionários, entre os dois utilizados no Estudo 1, aquele que não faz uso de lista de valores apresentou a vantagem de permitir perguntas mais semelhantes às que ocorrem no contexto real de ressarcimento de danos. No entanto, outras formas de coleta devem ser testadas em estudos futuros - variações sistemáticas no responder podem ocorrer simplesmente como resultado do modo como se coleta os dados (e-mail, telefone, pessoalmente, via computador) (Smith \& Hantula, 2008). Isso é ainda mais relevante quando a informação requerida se refere a algum comportamento socialmente desejável (por exemplo, comportamento sexual, como no estudo de Gribble, Miller, Rogers \& Turner, 1999). Nesses 
casos, as pessoas tendem dar respostas mais íntimas quando a coleta ocorre de forma impessoal (via computador, por exemplo) (Smith \& Hantula, 2008).

Isso é importante para as tarefas de desconto porque escolhas financeiras são associadas a regras sociais. Desse modo, os participantes poderiam estar menos inclinados a "mascarar" decisões impulsivas ou arriscadas se a coleta for feita através do computador, por exemplo (Smith \& Hantula, 2008). Isso pode ser verdade também para a investigação do endowment effect - pode parecer socialmente desejável atribuir valores idênticos quando se paga ou se recebe indenizações. Portanto, outras formas de coleta devem ser testadas. Outra possibilidade que, talvez, permitisse explorar o endowment effect nas situações de ressarcimento de danos, seria cada participante responder apenas a um tipo de situação - ou aquela em que causou o dano ou aquela em que o sofreu. Isso poderia evitar que valores equivalentes fossem empregados. Além disso, tal procedimento poderia separar as situações percebidas como perdas daquelas percebidas como ganhos. Dessa forma seria possível, inclusive, comparar o efeito de magnitude, de cada situação, com a literatura de desconto com perdas e com ganhos. No presente trabalho, todas as situações foram apresentadas para todos os sujeitos. Isso pode ter afetado tanto o efeito de magnitude quanto o endowment effect.

Os dados coletados foram bem descritos pelas funções hiperbólica e exponencial. A função exponencial, no entanto, apresentou melhor ajuste que a hiperbólica independentemente da natureza e do autor do dano. Como foi apontando na Discussão do Estudo 1, alguns fatores específicos do tipo da pergunta feita (presença da frase "você está diante da última oportunidade de receber esse dinheiro", que indica a impossibilidade de fazer outras escolhas no futuro; questionários tradicionais não fazem referência à possibilidade de uma nova escolha ou à ausência dela; além disso, no presente trabalho não havia atraso entre a escolha e o acesso à consequência) podem ter alguma influência nesse resultado. Ademais, o atraso utilizado não foi aquele tipicamente empregado em estudos de desconto subjetivo: neles os atrasos se referem 
ao tempo entre o momento da escolha e receber a recompensa, diferentemente do que ocorreu no presente estudo, no qual o atraso utilizado foi o que existe entre o dano e o momento da escolha.

Os resultados observados no presente trabalho sugerem que algumas das variáveis manipuladas (atrasos, magnitude do dano e natureza do dano) podem ter implicações em questões jurídicas. Por exemplo, danos de valores menores sofreram maiores descontos que os de valores maiores. Desse modo, pode-se esperar que quando o prejuízo a ser ressarcido é de menor valor, a chance de que acordos sejam feitos é maior - a pessoa lesada estaria mais "disposta" a aceitar valores menores (afinal a consequência perde muito do seu valor subjetivo) para considerar o dano compensado.

Outra implicação interessante diz respeito à duração dos processos na justiça - tanto a função exponencial quanto a hiperbólica sugerem que o desconto subjetivo é mais acentuado quando os atrasos são menores (proporcionalmente). Assim, supõe-se que processos ou acordos temporalmente próximos ao dano ocorrido favoreceriam o entendimento monetário entre as partes. Ou seja, o fato da consequência perder muito do seu valor subjetivo em atrasos curtos poderia aproximar o valor desejado pelo autor daquele proposto pelo réu.

Além do tempo entre o dano causado e a oportunidade de compensação desse, a possibilidade de prescrição parece afetar a desvalorização subjetiva da quantia indenizatória. No presente estudo, alguns participantes colocaram valores muito pequenos (ou zeros) em atrasos muito longos (cinco e 10 anos), sugerindo que não há mais nenhum valor devido ou que é tão improvável receber o ressarcimento que qualquer valor seria satisfatório. Como mencionado anteriormente, um deles escreveu a palavra "prescreveu" em frente aos atrasos mais longos. Diante disso, pode-se supor que prazos prescricionais extensos seriam acompanhados de uma desvalorização subjetiva mais "lenta", enquanto que prazos 
prescricionais mais curtos seriam acompanhados de descontos mais íngremes. O segundo, por tanto, favoreceria acordos mais imediatos entre autores e réus.

Os resultados relacionados à natureza do dano (material x moral) sugerem que prejuízos cujos valores não possuem uma medida objetiva sofrem maiores descontos do que aqueles objetivamente mensuráveis. No entanto, outros danos de estimativas pouco objetivas deveriam ser estudados, como por exemplo prejuízos envolvendo obras de artes e artigos de marca. Além disso, não foram investigadas compensações de naturezas diferentes. Seria interessante que estudos futuros explorassem ressarcimentos envolvendo dinheiro, retratação pessoal, reposição do bem material em si, etc. No presente trabalho, não se observou correlação entre os descontos obtidos com danos materiais e morais. No entanto, a consequência envolvida era sempre dinheiro. Seria interessante investigar se o mesmo resultado seria observado com compensações de naturezas diferentes. Os estudos da área (e.g. Chapman, 1996; Chapman \& Elstein, 1996) apontam não haver correlações entre diferentes tipos de consequências. Porém, não há investigações que tenham utilizado, como consequências, diferentes tipos de ressarcimentos de danos.

Além da natureza do dano e do ressarcimento, o aspecto probabilidade deve ser explorado em trabalhos futuros. A compensação de prejuízos envolve, via de regra, certo grau de incerteza - não se sabe se a sentença judicial será favorável ao autor ou ao réu e qual o valor da condenação (se houver). Consequências probabilísticas perdem valor na medida em que a probabilidade de sua ocorrência decresce. Não há, no entanto, pesquisas sobre como a incerteza afeta escolhas no contexto de reparação de danos ou como as variáveis probabilidade e atraso, juntas, afetam o comportamento nessa situação - e essa combinação parece ser o que observamos em ações judiciais e demais situações do dia a dia. O resultado de um processo de indenização, por exemplo, demora algum tempo (atraso) e a quantia a ser recebida (ou paga) é incerta. 
O presente trabalho pôde lançar alguma luz sobre o fenômeno de reparação de danos. Os dados apontaram que uma das metodologias tipicamente encontrada na literatura do desconto subjetivo é apropriada para o estudo de alguns aspectos da compensação de danos; que nesse contexto o desconto é mais acentuado para danos de magnitudes menores; que a função exponecial foi a que apresentou o melhor ajuste aos dados - ou seja, incrementos iguais nos atrasos produziram decréscimos proporcionais e constantes no valor subjetivo da consequência (Simpson \& Vuchnich, 2000); que, de maneira geral, a reparação de danos morais sofre mais desconto que a reparação de danos materiais; que não há correlação entre os descontos das situações de danos morais e materiais e que, por último, a autoria do dano parece não influenciar as taxas de desconto. 


\section{Referências}

Ainslie, G. (1992). Psychoeconomics: The strategic interaction of successive motivational states within the person. New York, NY: Cambridge University Press.

Ainslie, G. (2015). The cardinal anomalies that led to behavioral economics: cognitive or motivational? Managerial and Decision Economics. Publicação eletrônica antecipada. doi: $10.1002 /$ mde. 2715

Baum, W. M. (1974). On two types of deviation from the matching law: Bias and undermatching. Journal of the Experimental Analysis of Behavior, 22, 231-242.

Baum, W. M. (1979). Matching, undermatching, and overmatching in studies of choice. Journal of the Experimental Analysis of Behavior, 32, 269-281.

Bickel, W. K., Mackillop, J., Madden, G. J., Odum, A. L., \& Yi, R. (2015). Experimental manipulations of delay discounting \& related process: An introduction to the special issue. Journal of the Experimental Analysis of Behavior, 103, 1-9.

Bickel, W. K., Odum, A. L, \& Madden, G. J. (1999). Impulsivity and cigarette smoking: Delay discounting in current, never, and ex-smokers. Psychopharmacobgy (Berlin), 146, 447154.

Bickel, W. K., Yi, R., Kowal, B. P., \& Gatchalian, K. M. (2008). Cigarette smokers discount past and future rewards symmetrically and more than controls: Is discounting a measure of impulsivity? Drug and Alcohol Dependence, 96, 256-262.

Bittar, C. A. (1994). Curso de direito civil. Rio de Janeiro, RJ: Forense.

Blackburn, M., \& El-Deredy, W. (2013). The future is risky: discounting of delayed and uncertain outcomes. Behavioral Processes, 94, 9-18.

Blanchard, T., Wolfe, L., Vlaev, I., Winston, J., \& Hayden, B. (2014). Biased preferences for sequences in monkeys. Cognition, 130, 289-299. 
Bradshaw, C. M., \& Szabadi, F. (1992). Choice between delayed reinforces in a discrete-trials schedule: The effect of deprivation level. The Quarterly Journal of Experimental Pychology, 44(1), 1-6.

Brosnan, S. F., Jones, O. D., Gardner, M., Lambeth, S. P., \& Schapiro, S. J. (in press). Evolution and the expression of biases: situational value changes the endowment effect in chimpanzés. Evolution and Human Behavior. Recuperado em www2.gsu.edu/ wwwcbs/pdf/Brosnan\%20et\%20al\%20EHB\%202012.pdf

Cambridge Dictionaries Online. (2015). Retirado de http://dictionary.cambridge.org/

Carmon, Z., \& Ariely, D. (2000). Focusing on the forgone: How value can appear so different to buyers and sellers. Journal of Consumer Research, 27(3), 360-370.

Catania, A. C. (1999). Aprendizagem: comportamento, linguagem e cognição (4a ed). Porto Alegre, RS: Artmed.

Cavalieri Filho, S. (2003). Programa de responsabilidade civil. São Paulo, SP: Malheiros Editores.

Chapman, G. B. (1996a). Temporal discounting and utility for health and money. Journal of Experimental Psychology: Learning, Memory, and Cognition, 22, 771-791.

Chapman, G. B. (1996b). Expectations and preferences for sequences of health and money. Organizational Behavior and Human Decision Processes, 67, 59-75.

Chapman, G. B. (2000). Preferences for improving and declining sequences of health outcomes. Journal of Behavioral Decision Making, 13, 203-218.

Chapman, G. B. (2001). Time preferences for the very long term. Acta Psychologica, 108, 95116.

Chapman, G. B. (2002). Your money or your health: Time preferences and trading money for health. Medical Decision Making, 22, 410-416. 
Chapman, G. B. (2005). Short-term cost for long-term benefit: Time preference and cancer control. Health Psychology, 24, 41-48.

Chapman, G. B., \& Elstein, A. S. (1995). Valuing the future: Discounting health and money. Medical Decision Making, 15, 373-386.

Chapman, G. B., \& Weber, B. J. (2006). Decision biases in intertemporal choice and choice under uncertainty: Testing a common account. Memory \& Cognition, 34(3), 589-602.

Chapman, G. B., \& Winquist, J. R. (1998). The magnitude effect: Temporal discount rates and restaurant tips. Psychonomic Bulletin and Review, 5(1), 119-123.

Conselho Nacional de Justiça (2014). Programas de conciliação. Recuperado em www.cnj.jus.br/images/programas/conciliacao/2014/SNC_global_final.pdf.

Conselho Nacional de Justiça (2014). Relatório justiça em números. Recuperado em ftp://ftp.cnj.jus.br/Justica_em_Numeros/relatorio_jn2014.pdf, página 35

Constituição da República Federativa do Brasil de 1988. (1998). Brasília, DF. Recuperado em Www.planalto.gov.br/ccivil_03/constituicao/constituicao.htm

DeHart, W. B., \& Odum, A. L. (2015). The effects of the Framing of time on delay discounting. Journal of the Experimental Analysis of Behavior, 103, 10-21.

De Wit, H, Flory, J. D., Acheson, A., McCloskey, M., \& Manuck, S. B. (2007). IQ and nonplanning impulsivity are independently associated with delay discounting in middleaged adults. Personality and Individual Differences, 42, 111-121.

Diniz, M. E. (2003). Curso de Direito Civil brasileiro. São Paulo, SP: Saraiva.

Du, W., Green, L., \& Myerson, J. (2002). Cross-cultural comparisons of discounting delayed and probabilistic rewards. The Psychological Record, 52, 479-492.

Estle, S. J., Green, L., Myerson, J., \& Holt, D. D. (2006). Differential effects of amount on temporal and probability discounting of gains and losses. Memory \& Cognition, 34, 914928. 
Evenden, J. L., \& Ryan, C. N. (1996). The pharmacology of impulsive behaviour in rats: The effects of drugs on response choice with varying delays of reinforcement. Psychopharmacobgy (Berlin), 128, 161-170.

Fantino, E., \& Esfandiari, A. (2002). Probability matching: Encouraging optimal responding in humans. Canadian Journal of Experimental Psychology, 56, 58-63.

Fantino, E., \& Stolarz-Fantino, S. (2013). The logic and illogic of human ressoning. Em G. J. Madden, W. V. Dube, G. Hanley, T. Hackenberg \& K. A. Lattal (Eds.), American Psychological Association Handbook of Behavior Analysis. Washington, DC: American Psychological Association.

Frederick, S., \& Loewenstein, G. (2008). Conflicting motives in evaluations of sequences. Journal of Risk and Uncertainty, 37, 221-235.

Frederick, S., Loewenstein, G., \& O’Donoghue, T. (2002). Time discounting and time preference: A critical review. Journal of Economic Literature, 40, 351-401.

Gafni, A., \& Torrance, G. W. (1984). Risk attitude and time preference in health. Management Science, 30, 440-451.

Grace, R. C., Sargisson, R. J., \& White, K. G. (2012). Evidence for a magnitude effect in temporal discounting with pigeons. Journal of Experimental Psychology: Animal Behavior Processes, 38(1), 102-108.

Green, L, Myerson, J., Holt, D. D., Slevin, J. R., \& Estle, S. J. (2004). Discounting of delayed food rewards in pigeons and rats: Is there a magnitude effect? Journal ofthe Experimental Analysis of Behavior, 81, 39-50.

Green, L. \&. (1997). Behavioral economics. Em W. O'Donohue, Learning and Behavior Therapy (pp. 274-300). USA: Allyn and Bacon.

Green, L., \& Myerson, J. (1993). Alternative frameworks for the analysis of self control. Behavior and Philosophy, 21, 37-47. 
Green, L., \& Myerson, J. (2004). A discounting framework for choice with delayed and probabilistic rewards. Psychological Bulletin, 130, 769-792.

Green, L., \&. Estle, S. J. (2003). Preference reversals with food and water reinforcers in rats. Journal of the Experimental Analysis of Behavior, 79, 233-242.

Green, L., Fristoe, N., \& Myerson, J. (1994). Temporal discounting and preference reversals in choice between delayed outcomes. Psychonomic Bulletin \& Review, 1, 383-389.

Green, L., Fry, A. F., \&. Myerson, J. (1994). Discounting of delayed rewards: A life-span comparison. Psychobgical Science, 5, 33-36.

Green, L., Myerson, J., \& McFadden, E. (1997). Rate of temporal discounting decreases with amount of reward. Memory \& Cognition, 25, 715-723.

Green, L., Myerson, J., \& Ostaszewski, P. (1999). Amount of reward has opposite effects on the discounting of delayed and probabilistic outcomes. Journal of Experimental Psychology: Learning, Memory, \& Cognition, 25, 418-427.

Hanna, E. S., \& Ribeiro, M. R. (2005). Autocontrole: um caso especial de comportamento de escolha. Em Abreu-Rodrigues, J. \& Ribeiro, M. R. (Orgs.), Análise do comportamento: pesquisa, teoria e aplicação. Porto Alegre : Artmed, 2005.

Harbaugh, W. T., Krause, K., \& Vesterlund, L. (2001). Are adults better behaved than children? Age, experience, and the endowment effect. Economics Letters, 70(2), 175-181.

Herrnstein, R. J. (1961). Relative and absolute strength of response as a function of frequency of reinforcement. Journal of the Experimental Analysis of Behavior, 4, 267-272.

Herrnstein, R. J. (1970). On the law of effect. Journal of the Experimental Analysis of Behavior, 13(2), 243-266.

Herrnstein, R. J., \& Loveland, D. H. (1975). Maximizing and matching on concurrent ratio schedules. Journal of the Experimental Analysis of Behavior, 24(1), 107-116. 
Ho, M., Mobini, S., Chiang, T., Bradshaw, C. M., \& Szabadi, E. (1999). Theory and method in the quatitative analysis of "impulsive choice" behavior: Implications for psychopharmacology. Psychopharmacology, 146, 362-372.

Holanda, A. B. (2010). Míni Dicionário Aurélio da Língua Portuguesa - Nova Ortografia (8a Ed). Curitiba, PR: Positivo.

Holt, D. D., Green, L., \& Myerson, J. (2003). Is discounting impulsive? Evidence from temporal and probability discounting in gambling and non-gambling college students. Behavioural Processes, 64, 355-367.

Holt, D. D., Green, L., Myerson, J., \& Estle, S. J. (2008). Preference reversals with losses. Psychonomic Bulletin \& Review, 15, 89-95.

Hsee, C. K., Abelson, R. P., \& Salovey, P. (1991). The relative weighting of position and velocity in satisfaction. Psychological Science, 2(4), 263-266

Hursh, S. R. (1980). Economic concepts for the analysis of behavior. Journal of the Experimental Analysis of Behavior, 34, 219-238.

Hursh, S. R., Madden, G. J., Spiga, R., DeLeon, I., \& Francisco, M. T. (2013). Thetranslational utility of behavioral economics: The experimental analysis of consumption and choice. Em G. J. Madden, W. V. Dube, G. Hanley, T. Hackenberg \& K. A. Lattal (Eds.), American Psychological Association Handbook of Behavior Analysis. Washington, DC: American Psychological Association.

Jacobs, E. A., Borrero, J. C., \& Vollmer, T. R. (2013). Translational applications of quantitative choice models. In G. J. Madden (Ed.), APA Handbook of Behavior Analysis, Vol. 2: Translating Principles into Practice. Washington, DC: American Psychological Association. 
Johnson, M. W., \& Bickel, W. K. (2002). Within-subject comparison of real and hypothetical money rewards in delay discounting. Journal of the Experimental Analysis of Behavior, 77(2), 129-146.

Kagel, J. H., Battalio, R. C., Green, L. (1995). Economic Choice Theory. In Experimental Analysis of Animal Behavior. USA: Cambridge University Press.

Kahneman, D., \& Tversky, A. (1979). Prospect theory: An analysis of decision under risk. Econometrica, 47, 263-291.

Kahneman, D., Fredrickson, B. L., Schreiber, C. A., \& Redelmeier, D. A. (1993). When more pain is preferred to less: Adding a better end. Psychological Science, 4, 401-405.

Kahneman, D., Knetsch, J., \& Thaler, R. (1990). Experimental tests of the endowment effect and coase theorem. Journal of Political Economy, 98, 1325-1348.

Kahneman, D., Jack L. Knetsch, J. L., \& Thaler, R. H. (1991). Anomalies: The endowment effect, loss aversion, and status quo bias. Journal of Economic Perspectives, 5(1), 193-206.

Keren, G., \& Roelofsma, P. (1995). Immediacy and certainty in intertemporal choice. Organizational Behavior \& Human Decision Processes, 63, 287-297.

Killeen, P. R. (2009). An additive-utility model of delay discounting. Psychological Review, $116,602-619$.

Kim, H. J.; Fay, M. P.; Feuer, E. J.; \& Midthune, D. N. (2000). Permutation tests for joinpoint regression with applications to cancer rates. Stat Med, 19, 335-51 (correction: 2001;20:655).

Kirby, K. N., \& Herrnstein, R. J. (1995). Preference reversals due to myopic discounting of delayed reward. Psychological Science, 6, 83-89.

Kirby, K. N., \& Marakovi'c, N. N. (1995). Modeling myopic decisions: Evidence for hyperbolic delay-discounting within subjects and amounts. Organizational Behavior \& Human Decision Processes, 64, 22-30. 
Knetsch, J. L. (1989). The endowment effect and evidence of nonreversible indifference curves. The American Economic Review, 79(5), 1277-1284.

Knetsch, J. L., \& Sinden, J. A. (1984). Willingness to pay and compensation demanded: Experimental evidence of na inexpected disparity in measures of value. Quarterly Journal of Economics, 99, 507-521.

Korobkin, R. B. (2003). The endowment effect and legal analysis. Northwestern University Law Review, 97, 1227-1291.

Krebs, C. A., \& Anderson, K. G. (2012). Preference reversals and effects of D-amphetamine on delay discounting in rats. Behavioural Pharmacology, 23(3), 228-240.

Lagorio, C. H., \& Madden, G. J. (2005). Delay discounting when the consequence of every choice is real. Behavioural Processes, 69, 173-187.

Lei n. 10.406, de 10 de janeiro de 2002. (2002). Institui o Código Civil. Brasília, DF. Recuperado em www.planalto.gov.br/ccivil_03/Leis/2002/L10406.htm

Lei n. 13.105, de 16 de março de 2015. (2015). Código de Processo Civil. Brasília, DF. Recuperado em www.planalto.gov.br/CCIVIL_03/_Ato2015-2018/2015/Lei/L13105.htm Lei n. 13.140, de 26 de junho de 2015. (2015). Dispõe sobre a mediação entre particulares como meio de solução de controvérsias e sobre a autocomposição de conflitos no âmbito da administração pública; altera a Lei no 9.469, de 10 de julho de 1997, e o Decreto no 70.235, de 6 de março de 1972; e revoga o § 2o do art. 6o da Lei no 9.469, de 10 de julho de 1997. Brasília, DF. Recuperado em www.planalto.gov.br/CCIVIL_03/_Ato20152018/2015/Lei/L13140.htm

Lei n. 9.307, de 23 de setembro de 1996. (1996). Dispõe sobre a arbitragem. Brasília, DF. Recuperado em www.planalto.gov.br/ccivil_03/Leis/L9307.htm

Locey, M. L., Jones, B. A., \& Rachlin, H. (2011). Real and hypothetical rewards in social discounting. Judgment and Decision Making, 6, 552-564. 
Loewenstein, F. G., \& Prelec, D. (1993). Preferences for sequences of outcomes. Psychological Review, 100(1), 91-108.

Loewenstein, G., \& Prelec, D. (1992). Anomalies in intertemporal choice: Evidence and interpretation. Quarterly Journal of Economics, 107, 573-597.

Loewenstein, G., \& Sicherman, N. (1991). Do workers prefer increasing wage profiles? Journal of Labor Economics, 9(1), 67-84.

Logue, A. W. (1988). Research in self-control: An integrating frame- work. Behavioral \& Brain Sciences, 11, 665-709.

Logue, A. W. (1995). Self-control: Waiting until tomorrow for what you want today. Engelwood Cliffs, NJ: Prentice-Hall.

Madden, G. J., \& Bickel, W. K. (Eds.). (2010) Impulsivity: The behavioral and neurological science of discounting. Washington, DC: American Psychological Association.

Madden, G. J., \& Johnson, P. S. (2010). A delay-discounting primer. In: G. J Madden, \& W. K. Bickel (Eds.), Impulsivity: The behavioral and neurological science of discounting (pp. 11-37). Washington, DC: American Psychological Association.

Madden, G. J., Begotka, A. M., Raiff, B. R., Kastern, L. L. (2003). Delay discounting of real and hypothetical rewards. Experimental and Clinical Psychopharmacology, 11, $139-145$.

Madden, G. J., Petry, N. M., Badger, G. J., \& Bickel, W. K. (1997). Impulsive and self-control choices in opioid-dependent patients and non-drug-using control patients: Drug and monetary rewards. Experimental and Clinical Psychopharmacology, 5(3), 256-262.

Maddux, W., Yang, H., Falk, C., Adam, H., Adair, W., Endo, Y., Carmon, Z., \& Heine, S. (2010). For whom is parting from possessions more painful: Cultural differences in the endowment effect. Psychological Science, 21(12), 1910-1917. 
Magoon, M.A., \& Critchfield, T.S. (2008). Concurrent schedules of positive and negative reinforcement: differential-impact and differential-outcomes hypotheses. Journal of the Experimental Analysis of Behavior, 90, 1-22.

Markowitz, H. (1952). The utility of wealth. Journal of Political Economy, 60, 151-158.

Mazur, J. E. (1987). An adjusting procedure for studying delayed reinforcement. Em M. L. Commons, J. E. Mazur, J. A. Nevin, \& H. Rachlin (Eds.), Quantitative Analysis of Behavior: Vol 5. The Effect of Delay and Intervening Events on Reinforcement Value (pp. 55-73). Hillsdale, NJ: Erlbaum.

Mckerchar, T. L., Green, L., Myerson, J., Pickford, T. S., Hill, J. C., \& Stout, S. C. (2009). A comparison of four models of delay discounting in humans. Behavioural Processes, 81, 256-259.

Mellers, B. A., Schwartz, A., \& Cooke, D. J. (1998). Judgment and decision making. Annual Review Psychology, 49, 447-477.

Michaelis: Moderno Dicionário da Língua Portuguesa. (2009). São Paulo, SP: Companhia Melhoramentos.

Mischel, W. (1966). Theory and research on the antecedents of self-imposed delay of reward. Em B. A. Maher (Ed.), Progress in Experimental Personality Research (Vol. 3 pp. 85131). New York: Academic Press.

Mischel, W., \& Grusec, I. (1967). Waiting for rewards and punishments: Effects of time and probability on choice. Journal of Personality and Social Psychology, 5, 24-31.

Mitchell, S. H., \& Wilson, V. B. (2010). The subjective value of delayed and probabilistic outcomes: Outcome size matters for gains but not for losses. Behavioural Processes, 83, 36-40.

Myerson J., \& Green, L. (1995). Discounting of delayed rewards: Models of individual choice. Journal of the Experimental Analysis of Behavior, 64, 263-276. 
Myerson, J., Green, L., \& Warusawitharana, M. (2001). Area under the curve as a measure of discounting. Journal of the Experimental Analysis of Behavior, 76, 235- 243.

Myerson, J., Green, L., Hanson, J. S., Holt, D. D., \& Estle, S. J. (2003). Discounting delayed and probabilistic rewards: Processes and traits. Journal of Economic Psychology, 24, 619635.

Odum, A. L. (2011). Delay discounting: I'm a k, you're a k. Journal of the Experimental Analysis of Behavior, 96, 427-439.

Odum, A. L., Madden, G. J., \& Bickel, W. K. (2002). Discounting of delayed health gains and losses by current, never- and ex-smokers of cigarettes. Nicotine \& Tobacco Research, 4, 295-303.

Ohmura, Y., Takahashi, T., \& Kitamura, N. (2005). Discounting delayed and probabilistic monetary gains and losses by smokers of cigarettes. Psychopharmacology, 16, 1-8.

Oliveira-Castro, J. M. (2015). Economia comportamental operante: Aplicações ao comportamento do consumidor e ao direito. Projeto de pesquisa sobmetido ao CNPq.

Ostaszewski, P., \& Karzel, K. (2002). Discounting of delayed and probabilistic losses of different amounts. European Psychologist, 7, 295-301.

Ostaszewski, P., Białaszek, W. (2010). Probabilistic discounting in "certain gain-uncertain loss" and "certain loss-uncertain gain" conditions. Behavioural Processes, 83, 344-348.

Ostaszewski, P., Green, L., \& Myerson, J. (1998). Effects of inflation on the subjective value. Psychological Bulletin \& Review, 5, 324-333.

Oxford Dictionary of English. (2010). USA: Oxford University Press.

Perissé, G. (2010). Palavras e origens. São Paulo, SP: Saraiva.

Pierce, W. D., \& Cheney, C. D. (2004). Behavior analysis and learning. Mahwah (NJ): Lawrence Erlbaum. 
Prelec, D., \& Loewenstein, G. (1991). Decision making over time and under uncertainty: a common approach. Management Science, 37, 770-786.

Rabin, M. (1998). Psychology and economics. Journal of Economic Literature, XXXVI, 11-46.

Rachlin, H. (1970). Introduction to modern behaviorism. San Francisco: W. H. Freeman and Co.

Rachlin, H. (1990). Why do people gamble and keep gambling despite heavy losses? Psychological Science, 1, 294-297.

Rachlin, H., Brown, J., \& Cross, J. (2000). Discounting in judgments of delay and probability. Journal of Behavioral Decision Making, 13, 145-159.

Rachlin, H., Logue, A. W., Gibbon, J., \& Frankel, M. (1986). Cognition and behavior in studies of choice. Psychological Review, 93, 33-45.

Rachlin, H., Raineri, A., \& Cross, D. (1991). Subjective probability and delay. Journal of the Experimental Analysis of Behavior, 55, 233-244.

Reed, D. D., \& Martens, B. K. (2011). Temporal discounting predicts student responsiveness to exchange delays in a clamenor-imediatooom token system. Journal of Applied Behavior Analysis, 44, 1-17.

Reed, D. D., Kaplan, B. A., \& Brewer, A. T. (2012). A tutorial on the use of excel 2010 and excel for Mac 2011 for conducting delay-discounting analyses. Journal of Applied Behavior Analysis, 45, 375-386.

Richards, J. B., Mitchell, S. H., de Wit, H., \& Seiden, L. S. (1997). Determination of discount function with an adjusting amount procedure in rats. Journal of the Experimetal Analysis of Behavior, 67, 353-366.

Richards, J. B., Zhang, L., Mitchell, S. H., \& de Wit, H. (1999). Delay or probability discouting in a model of impulsive behavior: effect of alcohol. Journal of the Experimetal Analysis of Behavior, 71, 121-143. 
Rodzon, K., Berry, M. S., \& Odum, A. L. (2011). Within-subject comparison of degree of delay discounting using titrating and fixed sequence procedures. Behavioural Processes, 86(1), 164-167.

Rotter, J.B. (1954). Social learning and clinical psychology. Englewood Cliffs, NJ: PrenticeHall.

Shead, N. W., \& Hodgins, D. C. (2009). Probability discounting of gains and losses. Implications for risk attitudes and impulsivity. Journal of the Experimental Analysis of Behavior, 92, 1-16.

Simpson, C. A., \& Vuchinich, R. E. (2000b). Reliability of a measure of temporal discounting. The Psychological Record, 50, 3-16.

Skinner, B. F. (1953). Ciência e Comportamento Humano. São Paulo, SP: Martins Fontes.

Skinner, B. F. (1950). Are theories of learning necessary? Psychological Review, 57, 193-216.

Smith, C. L., \& Hantula, D. A. (2008). Pricing effects on foraging in a simulate internet shopping mal. Journal of Economic Psychology, 24(5), 653-674.

Stein, J. S., Renda, R., Hinnenkamp, J. E., \& Madden, G. J. (2015). Impulsive choice, alcohol consumption, and pre-exposure to delayed rewards: II potential mechanisms. Journal of the Experimental Analysis of Behavior, 103, 33-49.

Stevenson, M. K. (1992). The impact of temporal context and risk on the judged value of future outcomes. Organizational Behavior and Human Decision Processes, 52, 455-491.

Stieg, M. D., \& Dixon, M. R. (2007). Discounting of past and future rewards of Texas Hold'em gambles. European Journal of Behavior Analysis, 8, 93-97.

Strotz, R. H. (1956). Myopia and inconsistency in dynamic utility maximization. Review of Economic Studies, 23, 165-180.

Thaler, R. (1980). T'oward a positive theory of consumer choice. Journal of Economic Behavior and Organization, 1, 39-60. 
Thaler, R. H. (1981). Some empirical evidence on dynamic inconsistency. Economic Letters, 8, 201-207.

Todorov, J. C. \& Hanna, E. S. (2005). Quantificação de Escolhas e Preferências, In Análise do Comportamento: Pesquisa, Teoria e Aplicação. Porto Alegre, RS: Artmed.

Trope, Y., \& Liberman, N. (2003). Temporal Construal. Psychological Review, 110(3), 403421.

Tversky, A., \& Kahneman, D. (1983). Extensional versus intuitive reasoning: The conjunction fallacy in probability judgment. Psychological Review, 90, 293-315. Doi: 10.1037/0033295X.90.4.293

Tversky, A., \& Kahneman, D. (1991). Loss aversion in riskless choice: A reference-dependent model. Quarterly Journal of Economics, 106, 1039-1061.

Vanderveldt, A., Green, L., \& Myerson, J. (2015) Discounting of monetary rewards that are both delayed and probabilistic: Delay and probability combine multiplicatively, not additively. Journal of Experimental Psychology: Learning, Memory, and Cognition, 41(1), $148-162$.

Varey, C., \& Kahneman, D. (1992). Experiences extended across time: Evaluation of moments and episodes. Journal of Behavioral Decision Making, 5, 169-195.

Vuchinich, R. E., \& Simpson, C. A. (1998) Hyperbolic temporal discounting in social drinkers and problem drinkers. Experimental and Clinical Psychopharmacology, 6, 292-305.

Weatherly, J.N., \& Derenne, A. (2011). Comparing delay discounting rates when using the fillinthe-blank and multiple-choice methods. Journal of General Psychology, 138, 300-318.

Weber, B. J., \& Chapman, G. B. (2005). Playing for peanuts: Why is risk seeking more common for low-stakes gambles? Organizational Behavior \& Human Decision Processes, 97, 3146. 
Yi, R., de la Piedad, X., \& Bickel, W. K. (2006). The combined effects of delay and probability in discounting. Behavioural Processes, 73, 149-155.

Yi, R., Gatchalian, K. M., \& Bickel, W. K. (2003). Discounting of past outcomes. Experimental and Clinical Psychopharmacology, 14(3), 311-317.

Yi, R., Gatchalian, K., \& Bickel, W. K. (2006). Discounting of past outcomes. Experimental and Clinical Psychopharmacology, 14, 311-317. 


\section{Apêndice 1}

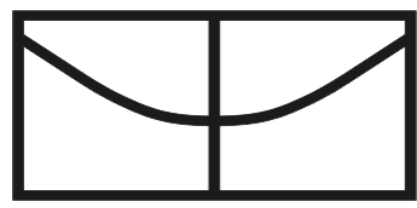

Universidade de Brasília

Instituto de Psicologia

Departamento de Processos Psicológicos Básicos

Programa de Pós-Graduação em Ciências do comportamento

TERMO DE CONSENTIMENTO LIVRE E ESCLARECIDO

(Em acordo às Normas da resolução 196/96 do Conselho Nacional de Saúde-MS)

Nome do participante da pesquisa:

Idade: anos

Pesquisadora Responsável: Ana Paula de Oliveira Silva

Professor orientador: $\mathrm{Dr}^{\circ} \cdot$ Jorge Oliveira-Castro

Data:

Você está sendo convidado (a) para participar dessa pesquisa, que tem por objetivo investigar alguns aspectos do comportamento de escolhas financeiras.

Sua tarefa consistirá em fazer escolhas financeiras hipotéticas em resposta a um questionário formulado em diferentes situações.

Para proteger sua privacidade, asseguramos que seu nome não constará na análise dos dados, e em nenhum outro material de publicação. As folhas do questionário serão identificadas apenas por um número não associado a esse termo de consentimento. Assim, será mantido o mais rigoroso sigilo por meio da omissão total de quaisquer informações que permitam identificá-lo(a).

Você pode se recusar a responder qualquer questão que lhe traga constrangimento, e pode desistir de participar da pesquisa em qualquer momento, sem nenhum prejuízo. Sua participação é voluntária, isto é, não há pagamento por sua colaboração.

Se você tiver qualquer pergunta sobre esta pesquisa, faça-a agora.

Eu li as informações sobre o procedimento e concordo em responder às questões. Eu entendo que minha participação é voluntária.

Nome/Assinatura

e-mail: Telefone: 


\section{Apêndice 2}

\section{QUESTIONÁRIO A}

Abaixo encontram-se algumas situações hipotéticas. Imagine que você faz parte dessas situações e responda às questões como se as situações fossem reais. Por favor, em suas respostas, considere apenas sua decisão pessoal, sem se preocupar com as opiniões do experimentador ou de qualquer outra pessoa.

Por favor, não use calculadoras.

Agradecemos por sua participação!

\section{Treino 1: tire as dúvidas com o experimentador}

Imagine que ALGUÉM totalmente desconhecido lhe causou um prejuízo de 20 reais a algum tempo atrás. Você está diante da última oportunidade de receber esse dinheiro. Marque um " $X$ " ao lado do valor que você consideraria justo receber hoje, dessa pessoa, se tal prejuízo foi causado no seguinte intervalo de tempo, no passado:

\section{O prejuízo foi causado 1 semana atrás}

\begin{tabular}{|l|l|l|l|l|l|}
\hline & 20,00 & & 80,00 & & 180,00 \\
\hline & 30,00 & & 90,00 & & 200,00 \\
\hline 40,00 & & 100,00 & & 220,00 \\
\hline 50,00 & & 120,00 & 240,00 \\
\hline 60,00 & & 140,00 & 260,00 \\
\hline 70,00 & & 160,00 & & 280,00 \\
\hline
\end{tabular}

\section{Treino 2: tire as dúvidas com o experimentador.}

Imagine que VOCÊ causou um prejuízo de 20 reais a alguém totalmente desconhecido, a algum tempo atrás. Você está diante da última oportunidade de pagar esse dinheiro. Marque um "X" ao lado do valor que você consideraria justo pagar hoje, para essa pessoa, se tal prejuízo foi causado no seguinte intervalo de tempo, no passado:

\section{O prejuízo foi causado 1 semana atrás}

\begin{tabular}{|l|l|l|l|l|l|}
\hline & 20,00 & & 80,00 & & 180,00 \\
\hline & 30,00 & & 90,00 & & 200,00 \\
\hline & 40,00 & & 100,00 & & 220,00 \\
\hline & 50,00 & & 120,00 & & 240,00 \\
\hline & 60,00 & & 140,00 & 260,00 \\
\hline & 70,00 & & 160,00 & & 280,00 \\
\hline
\end{tabular}


Quando estiver pronto para começar vire a página. Você deverá responder às próximas situações sozinho, sem a ajuda do experimentador. 
Não volte páginas. Após concluir uma página, siga para a seguinte e a responda sem voltar às anteriores.

\section{Situação 1A}

Imagine que ALGUÉM totalmente desconhecido lhe causou um prejuízo de 100 reais, a algum tempo atrás. Você está diante da última oportunidade de receber esse dinheiro. Que valor você consideraria justo receber hoje, dessa pessoa, se tal prejuízo foi causado nos seguintes intervalos de tempo, no passado:

\section{Se o prejuízo foi causado 1 semana atrás:}

Marque um "X" no quadrado ao lado do valor que você consideraria justo receber hoje, da pessoa que lhe causou um prejuízo de $\mathrm{R} \$ 100$ reais 1 semana atrás.

\begin{tabular}{|l|l|l|l|l|l|l|l|l|l|l|l|}
\hline & 100,00 & 260,00 & & 420,00 & & 580,00 & & 740,00 & & 900,00 \\
\hline & 120,00 & 280,00 & & 440,00 & & 600,00 & & 760,00 & & 920,00 \\
\hline 140,00 & 300,00 & & 460,00 & & 620,00 & & 780,00 & & 940,00 \\
\hline & 160,00 & 320,00 & & 480,00 & & 640,00 & & 800,00 & & 960,00 \\
\hline 180,00 & 340,00 & 500,00 & & 660,00 & & 820,00 & & 980,00 \\
\hline 200,00 & 360,00 & & 520,00 & & 680,00 & & 840,00 & & $1.000,00$ \\
\hline 220,00 & 380,00 & & 540,00 & & 700,00 & & 860,00 & & $1.020,00$ \\
\hline & 240,00 & 400,00 & 560,00 & & 720,00 & & 880,00 & & $1.040,00$ \\
\hline
\end{tabular}

\section{Se o prejuízo foi causado 2 semanas atrás:}

Marque um "X" no quadrado ao lado do valor que você consideraria justo receber hoje, da pessoa que lhe causou um prejuízo de $\mathrm{R} \$ 100$ reais 2 semanas atrás.

\begin{tabular}{|l|l|l|l|l|l|l|l|l|l|l|l|}
\hline & 100,00 & 260,00 & & 420,00 & & 580,00 & & 740,00 & & 900,00 \\
\hline & 120,00 & 280,00 & & 440,00 & & 600,00 & & 760,00 & & 920,00 \\
\hline & 140,00 & 300,00 & & 460,00 & & 620,00 & & 780,00 & & 940,00 \\
\hline 160,00 & 320,00 & & 480,00 & & 640,00 & & 800,00 & & 960,00 \\
\hline & 180,00 & 340,00 & 500,00 & & 660,00 & & 820,00 & & 980,00 \\
\hline 200,00 & 360,00 & & 520,00 & & 680,00 & & 840,00 & & $1.000,00$ \\
\hline 220,00 & 380,00 & & 540,00 & & 700,00 & & 860,00 & & $1.020,00$ \\
\hline & 240,00 & 400,00 & 560,00 & & 720,00 & & 880,00 & & $1.040,00$ \\
\hline
\end{tabular}




\section{Se o prejuízo foi causado 1 mês atrás:}

Marque um "X" no quadrado ao lado do valor que você consideraria justo receber hoje, da pessoa que lhe causou um prejuízo de $\mathrm{R} \$ 100$ reais 1 mês atrás.

\begin{tabular}{|l|l|l|l|l|l|l|l|l|l|l|l|}
\hline & 100,00 & 260,00 & & 420,00 & & 580,00 & & 740,00 & & 900,00 \\
\hline & 120,00 & 280,00 & & 440,00 & & 600,00 & & 760,00 & & 920,00 \\
\hline & 140,00 & 300,00 & & 460,00 & & 620,00 & & 780,00 & & 940,00 \\
\hline 160,00 & 320,00 & & 480,00 & & 640,00 & & 800,00 & & 960,00 \\
\hline & 180,00 & 340,00 & & 500,00 & & 660,00 & & 820,00 & & 980,00 \\
\hline 200,00 & 360,00 & & 520,00 & & 680,00 & & 840,00 & & $1.000,00$ \\
\hline 220,00 & 380,00 & & 540,00 & & 700,00 & & 860,00 & & $1.020,00$ \\
\hline & 240,00 & 400,00 & 560,00 & & 720,00 & & 880,00 & & $1.040,00$ \\
\hline
\end{tabular}

\section{Se o prejuízo foi causado 6 meses atrás:}

Marque um " $\mathrm{X}$ " no quadrado ao lado do valor que você consideraria justo receber hoje, da pessoa que lhe causou um prejuízo de $\mathrm{R} \$ 100$ reais 6 meses atrás.

\begin{tabular}{|l|l|l|l|l|l|l|l|l|l|l|l|}
\hline & 100,00 & 260,00 & & 420,00 & & 580,00 & & 740,00 & & 900,00 \\
\hline & 120,00 & 280,00 & & 440,00 & & 600,00 & & 760,00 & & 920,00 \\
\hline & 140,00 & 300,00 & & 460,00 & & 620,00 & & 780,00 & & 940,00 \\
\hline 160,00 & 320,00 & & 480,00 & & 640,00 & & 800,00 & & 960,00 \\
\hline & 180,00 & 340,00 & 500,00 & & 660,00 & & 820,00 & & 980,00 \\
\hline 200,00 & 360,00 & & 520,00 & & 680,00 & & 840,00 & & $1.000,00$ \\
\hline 220,00 & 380,00 & & 540,00 & & 700,00 & & 860,00 & & $1.020,00$ \\
\hline & 240,00 & 400,00 & 560,00 & & 720,00 & & 880,00 & & $1.040,00$ \\
\hline
\end{tabular}

\section{Se o prejuízo foi causado 1 ano atrás:}

Marque um "X" no quadrado ao lado do valor que você consideraria justo receber hoje, da pessoa que lhe causou um prejuízo de $\mathrm{R} \$ 100$ reais 1 ano atrás.

\begin{tabular}{|l|l|l|l|l|l|l|l|l|l|l|l|}
\hline & 100,00 & 260,00 & & 420,00 & & 580,00 & & 740,00 & & 900,00 \\
\hline & 120,00 & 280,00 & & 440,00 & & 600,00 & & 760,00 & & 920,00 \\
\hline & 140,00 & 300,00 & & 460,00 & & 620,00 & & 780,00 & & 940,00 \\
\hline 160,00 & 320,00 & & 480,00 & & 640,00 & & 800,00 & & 960,00 \\
\hline & 180,00 & 340,00 & 500,00 & & 660,00 & & 820,00 & & 980,00 \\
\hline 200,00 & 360,00 & & 520,00 & & 680,00 & & 840,00 & & $1.000,00$ \\
\hline 220,00 & 380,00 & & 540,00 & & 700,00 & & 860,00 & & $1.020,00$ \\
\hline & 240,00 & 400,00 & 560,00 & & 720,00 & & 880,00 & & $1.040,00$ \\
\hline
\end{tabular}




\section{Se o prejuízo foi causado 5 anos atrás:}

Marque um "X" no quadrado ao lado do valor que você consideraria justo receber hoje, da pessoa que lhe causou um prejuízo de $\mathrm{R} \$ 100$ reais 5 anos atrás.

\begin{tabular}{|l|l|l|l|l|l|l|l|l|l|l|}
\hline & 100,00 & 260,00 & & 420,00 & & 580,00 & & 740,00 & & 900,00 \\
\hline & 120,00 & 280,00 & & 440,00 & & 600,00 & & 760,00 & & 920,00 \\
\hline & 140,00 & 300,00 & & 460,00 & & 620,00 & & 780,00 & & 940,00 \\
\hline 160,00 & 320,00 & & 480,00 & & 640,00 & & 800,00 & & 960,00 \\
\hline & 180,00 & 340,00 & 500,00 & 660,00 & 820,00 & 980,00 \\
\hline 200,00 & 360,00 & & 520,00 & & 680,00 & & 840,00 & & $1.000,00$ \\
\hline & 220,00 & 380,00 & & 540,00 & & 700,00 & & 860,00 & & $1.020,00$ \\
\hline & 240,00 & 400,00 & 560,00 & & 720,00 & & 880,00 & & $1.040,00$ \\
\hline
\end{tabular}

\section{Se o prejuízo foi causado 10 anos atrás:}

Marque um " $\mathrm{X}$ " no quadrado ao lado do valor que você consideraria justo receber hoje, da pessoa que lhe causou um prejuízo de $\mathrm{R} \$ 100$ reais 10 anos atrás.

\begin{tabular}{|l|l|l|l|l|l|l|l|l|l|l|l|}
\hline & 100,00 & 260,00 & & 420,00 & & 580,00 & & 740,00 & & 900,00 \\
\hline & 120,00 & 280,00 & & 440,00 & & 600,00 & & 760,00 & & 920,00 \\
\hline & 140,00 & 300,00 & & 460,00 & & 620,00 & & 780,00 & & 940,00 \\
\hline & 160,00 & 320,00 & & 480,00 & & 640,00 & & 800,00 & & 960,00 \\
\hline & 180,00 & 340,00 & & 500,00 & & 660,00 & & 820,00 & & 980,00 \\
\hline & 200,00 & 360,00 & & 520,00 & & 680,00 & & 840,00 & & $1.000,00$ \\
\hline & 220,00 & 380,00 & & 540,00 & & 700,00 & & 860,00 & & $1.020,00$ \\
\hline & 240,00 & 400,00 & & 560,00 & & 720,00 & & 880,00 & $1.040,00$ \\
\hline
\end{tabular}


Não volte páginas. Após concluir uma página, siga para a seguinte e a responda sem voltar às anteriores.

\section{Situação 2A}

Imagine que VOC $\hat{\mathbf{E}}$ causou um prejuízo de $\mathbf{1 0 0}$ reais a alguém totalmente desconhecido, a algum tempo atrás. Você está diante da última oportunidade de pagar esse dinheiro. Que valor você consideraria justo pagar hoje, a essa pessoa, se tal prejuízo foi causado nos seguintes intervalos de tempo, no passado:

\section{Se o prejuízo foi causado 1 semana atrás:}

Marque um " $X$ " no quadrado ao lado do valor que você consideraria justo pagar hoje, a pessoa que sofreu um prejuízo de $\mathrm{R} \$ 100$ reais, causado por você, 1 semana atrás.

\begin{tabular}{|c|c|c|c|c|c|}
\hline 100,00 & 260,00 & 420,00 & 580,00 & 740,00 & 900,00 \\
\hline 120,00 & 280,00 & 440,00 & 600,00 & 760,00 & 920,00 \\
\hline 140,00 & 300,00 & 460,00 & 620,00 & 780,00 & 940,00 \\
\hline 160,00 & 320,00 & 480,00 & 640,00 & 800,00 & 960,00 \\
\hline 180,00 & 340,00 & 500,00 & 660,00 & 820,00 & 980,00 \\
\hline 200,00 & 360,00 & 520,00 & 680,00 & 840,00 & $1.000,00$ \\
\hline 220,00 & 380,00 & 540,00 & 700,00 & 860,00 & $1.020,00$ \\
\hline 240,00 & 400,00 & 560,00 & 720,00 & 880,00 & $1.040,00$ \\
\hline
\end{tabular}

\section{Se o prejuízo foi causado 2 semanas atrás:}

Marque um " $X$ " no quadrado ao lado do valor que você consideraria justo pagar hoje, a pessoa que sofreu um prejuízo de $\mathrm{R} \$ 100$ reais, causado por você, 2 semanas atrás.

\begin{tabular}{|l|l|l|l|l|l|l|l|l|l|l|l|}
\hline & 100,00 & 260,00 & & 420,00 & & 580,00 & & 740,00 & & 900,00 \\
\hline & 120,00 & 280,00 & & 440,00 & & 600,00 & & 760,00 & & 920,00 \\
\hline 140,00 & 300,00 & & 460,00 & & 620,00 & & 780,00 & & 940,00 \\
\hline & 160,00 & 320,00 & & 480,00 & & 640,00 & & 800,00 & & 960,00 \\
\hline 180,00 & 340,00 & & 500,00 & & 660,00 & & 820,00 & & 980,00 \\
\hline 200,00 & 360,00 & & 520,00 & & 680,00 & & 840,00 & & $1.000,00$ \\
\hline 220,00 & 380,00 & & 540,00 & & 700,00 & & 860,00 & & $1.020,00$ \\
\hline & 240,00 & 400,00 & & 560,00 & & 720,00 & & 880,00 & & $1.040,00$ \\
\hline
\end{tabular}




\section{Se o prejuízo foi causado 1 mês atrás:}

Marque um "X" no quadrado ao lado do valor que você consideraria justo pagar hoje, a pessoa que sofreu um prejuízo de $\mathrm{R} \$ 100$ reais, causado por você, 1 mês atrás.

\begin{tabular}{|l|l|l|l|l|l|l|l|l|l|l|l|}
\hline & 100,00 & 260,00 & & 420,00 & & 580,00 & & 740,00 & & 900,00 \\
\hline & 120,00 & 280,00 & & 440,00 & & 600,00 & & 760,00 & & 920,00 \\
\hline & 140,00 & 300,00 & & 460,00 & & 620,00 & & 780,00 & & 940,00 \\
\hline 160,00 & 320,00 & & 480,00 & & 640,00 & & 800,00 & & 960,00 \\
\hline & 180,00 & 340,00 & & 500,00 & & 660,00 & & 820,00 & & 980,00 \\
\hline 200,00 & 360,00 & & 520,00 & & 680,00 & & 840,00 & & $1.000,00$ \\
\hline 220,00 & 380,00 & & 540,00 & & 700,00 & & 860,00 & & $1.020,00$ \\
\hline & 240,00 & 400,00 & 560,00 & & 720,00 & & 880,00 & & $1.040,00$ \\
\hline
\end{tabular}

\section{Se o prejuízo foi causado 6 meses atrás:}

Marque um " $X$ " no quadrado ao lado do valor que você consideraria justo pagar hoje, a pessoa que sofreu um prejuízo de $\mathrm{R} \$ 100$ reais, causado por você, 6 meses atrás.

\begin{tabular}{|l|l|l|l|l|l|l|l|l|l|l|l|}
\hline & 100,00 & & 260,00 & & 420,00 & & 580,00 & & 740,00 & & 900,00 \\
\hline & 120,00 & 280,00 & & 440,00 & & 600,00 & & 760,00 & & 920,00 \\
\hline & 140,00 & 300,00 & & 460,00 & & 620,00 & & 780,00 & & 940,00 \\
\hline 160,00 & 320,00 & & 480,00 & & 640,00 & & 800,00 & & 960,00 \\
\hline 180,00 & 340,00 & 500,00 & & 660,00 & & 820,00 & & 980,00 \\
\hline 200,00 & 360,00 & & 520,00 & & 680,00 & & 840,00 & & $1.000,00$ \\
\hline 220,00 & 380,00 & & 540,00 & & 700,00 & & 860,00 & & $1.020,00$ \\
\hline & 240,00 & 400,00 & 560,00 & & 720,00 & & 880,00 & & $1.040,00$ \\
\hline
\end{tabular}

\section{Se o prejuízo foi causado 1 ano atrás:}

Marque um " $\mathrm{X}$ " no quadrado ao lado do valor que você consideraria justo pagar hoje, a pessoa que sofreu um prejuízo de $\mathrm{R} \$ 100$ reais, causado por você, 1 ano atrás.

\begin{tabular}{|l|l|l|l|l|l|l|l|l|l|l|l|}
\hline & 100,00 & 260,00 & & 420,00 & & 580,00 & & 740,00 & & 900,00 \\
\hline & 120,00 & 280,00 & & 440,00 & & 600,00 & & 760,00 & & 920,00 \\
\hline & 140,00 & 300,00 & & 460,00 & & 620,00 & & 780,00 & & 940,00 \\
\hline 160,00 & 320,00 & & 480,00 & & 640,00 & & 800,00 & & 960,00 \\
\hline 180,00 & 340,00 & 500,00 & & 660,00 & & 820,00 & & 980,00 \\
\hline 200,00 & 360,00 & & 520,00 & & 680,00 & & 840,00 & & $1.000,00$ \\
\hline 220,00 & 380,00 & & 540,00 & & 700,00 & & 860,00 & & $1.020,00$ \\
\hline & 240,00 & 400,00 & 560,00 & & 720,00 & & 880,00 & & $1.040,00$ \\
\hline
\end{tabular}




\section{Se o prejuízo foi causado 5 anos atrás:}

Marque um "X" no quadrado ao lado do valor que você consideraria justo pagar hoje, a pessoa que sofreu um prejuízo de $\mathrm{R} \$ 100$ reais, causado por você, 5 anos atrás.

\begin{tabular}{|l|l|l|l|l|l|l|l|l|l|l|}
\hline & 100,00 & 260,00 & & 420,00 & & 580,00 & & 740,00 & & 900,00 \\
\hline & 120,00 & 280,00 & & 440,00 & & 600,00 & & 760,00 & & 920,00 \\
\hline & 140,00 & 300,00 & & 460,00 & & 620,00 & & 780,00 & & 940,00 \\
\hline & 160,00 & 320,00 & & 480,00 & & 640,00 & & 800,00 & & 960,00 \\
\hline & 180,00 & 340,00 & & 500,00 & & 660,00 & & 820,00 & & 980,00 \\
\hline & 200,00 & 360,00 & & 520,00 & & 680,00 & & 840,00 & & $1.000,00$ \\
\hline & 220,00 & 380,00 & & 540,00 & & 700,00 & & 860,00 & & $1.020,00$ \\
\hline & 240,00 & 400,00 & & 560,00 & & 720,00 & & 880,00 & & $1.040,00$ \\
\hline
\end{tabular}

\section{Se o prejuízo foi causado 10 anos atrás:}

Marque um " $X$ " no quadrado ao lado do valor que você consideraria justo pagar hoje, a pessoa que sofreu um prejuízo de $\mathrm{R} \$ 100$ reais, causado por você, 10 anos atrás.

\begin{tabular}{|l|l|l|l|l|l|l|l|l|l|l|l|}
\hline & 100,00 & & 260,00 & & 420,00 & & 580,00 & & 740,00 & & 900,00 \\
\hline & 120,00 & 280,00 & & 440,00 & & 600,00 & & 760,00 & & 920,00 \\
\hline & 140,00 & 300,00 & & 460,00 & & 620,00 & & 780,00 & & 940,00 \\
\hline 160,00 & 320,00 & & 480,00 & & 640,00 & & 800,00 & & 960,00 \\
\hline 180,00 & 340,00 & 500,00 & & 660,00 & & 820,00 & & 980,00 \\
\hline 200,00 & 360,00 & & 520,00 & & 680,00 & & 840,00 & & $1.000,00$ \\
\hline 220,00 & 380,00 & & 540,00 & & 700,00 & & 860,00 & & $1.020,00$ \\
\hline & 240,00 & 400,00 & 560,00 & & 720,00 & & 880,00 & & $1.040,00$ \\
\hline
\end{tabular}


Não use calculadora. Não volte páginas.

\section{Situação 3A}

Imagine ainda que, além do dano material sofrido por você (100 reais), tal fato tenha lhe trazido grandes aborrecimentos. Que valor você consideraria justo receber hoje, dessa pessoa, para compensar os aborrecimentos que você sofreu, se isso ocorreu nos seguintes intervalos de tempo, no passado:

\begin{tabular}{|l|l|}
\hline $\begin{array}{l}\text { Tempo transcorrido desde o prejuízo } \\
\text { causado até o momento presente de } \\
\text { receber o valor em dinheiro }\end{array}$ & $\begin{array}{l}\text { Valor em dinheiro que você considera } \\
\text { justo receber hoje (complete apenas com } \\
\text { números) }\end{array}$ \\
\hline 1 semana atrás & $\mathrm{R} \$$ \\
\hline 2 semanas atrás & $\mathrm{R} \$$ \\
\hline 1 mês atrás & $\mathrm{R} \$$ \\
\hline 6 meses atrás & $\mathrm{R} \$$ \\
\hline 1 ano atrás & $\mathrm{R} \$$ \\
\hline 5 anos atrás & $\mathrm{R} \$$ \\
\hline 10 anos atrás & $\mathrm{R} \$$ \\
\hline
\end{tabular}


Não use calculadora. Não volte páginas.

\section{Situação 4A}

Imagine ainda que, além do dano material causado por você (100 reais), tal fato tenha trazido grandes aborrecimentos a esse alguém desconhecido. Que valor você consideraria justo pagar hoje, a essa pessoa, para compensar os aborrecimentos se isso ocorreu nos seguintes intervalos de tempo, no passado:

\begin{tabular}{|l|l|}
\hline $\begin{array}{l}\text { Tempo transcorrido desde o prejuízo } \\
\text { causado até o momento presente de } \\
\text { pagar o valor em dinheiro }\end{array}$ & $\begin{array}{l}\text { Valor em dinheiro que você considera } \\
\text { justo pagar hoje (complete apenas com } \\
\text { números) }\end{array}$ \\
\hline 1 semana atrás & $\mathrm{R} \$$ \\
\hline 2 semanas atrás & $\mathrm{R} \$$ \\
\hline 1 mês atrás & $\mathrm{R} \$$ \\
\hline 6 meses atrás & $\mathrm{R} \$$ \\
\hline 1 ano atrás & $\mathrm{R} \$$ \\
\hline 5 anos atrás & $\mathrm{R} \$$ \\
\hline 10 anos atrás & $\mathrm{R} \$$ \\
\hline
\end{tabular}


Apêndice 3

\section{QUESTIONÁRIO B}

Abaixo encontram-se algumas situações hipotéticas. Imagine que você faz parte dessas situações e responda às questões como se as situações fossem reais. Por favor, em suas respostas, considere apenas sua decisão pessoal, sem se preocupar com as opiniões do experimentador ou de qualquer outra pessoa.

Por favor, não use calculadoras.

Agradecemos por sua participação!

Treino 1: tire as dúvidas com o experimentador

Imagine que ALGUÉM totalmente desconhecido lhe causou um prejuízo de 20 reais a algum tempo atrás. Você está diante da última oportunidade de receber esse dinheiro. Que valor você consideraria justo receber hoje, dessa pessoa, se tal prejuízo foi causado nos seguintes intervalos de tempo, no passado:

\begin{tabular}{|l|l|}
\hline $\begin{array}{l}\text { Tempo transcorrido desde o prejuízo } \\
\text { causado até o momento presente de } \\
\text { receber o valor em dinheiro }\end{array}$ & $\begin{array}{l}\text { Valor em dinheiro que você considera } \\
\text { justo receber hoje complete apenas } \\
\text { com números) }\end{array}$ \\
\hline 1 semana atrás & $\mathrm{R} \$$ \\
\hline 2 semanas atrás & $\mathrm{R} \$$ \\
\hline 1 mês atrás & $\mathrm{R} \$$ \\
\hline 6 meses atrás & $\mathrm{R} \$$ \\
\hline 1 ano atrás & $\mathrm{R} \$$ \\
\hline
\end{tabular}

Treino 2: tire as dúvidas com o experimentador.

Imagine que VOCÊ causou um prejuízo de 20 reais a alguém totalmente desconhecido, a algum tempo atrás. Você está diante da última oportunidade de pagar esse dinheiro. Que valor você consideraria justo receber hoje, dessa pessoa, se tal prejuízo foi causado nos seguintes intervalos de tempo, no passado:

\begin{tabular}{|l|l|}
\hline $\begin{array}{l}\text { Tempo transcorrido desde o prejuízo } \\
\text { causado até o momento presente de } \\
\text { pagar o valor em dinheiro }\end{array}$ & $\begin{array}{l}\text { Valor em dinheiro que você considera } \\
\text { justo pagar hoje (complete apenas com } \\
\text { números) }\end{array}$ \\
\hline 1 semana atrás & $\mathrm{R} \$$ \\
\hline 2 semanas atrás & $\mathrm{R} \$$ \\
\hline 1 mês atrás & $\mathrm{R} \$$ \\
\hline 6 meses atrás & $\mathrm{R} \$$ \\
\hline 1 ano atrás & $\mathrm{R} \$$ \\
\hline
\end{tabular}


Quando estiver pronto para começar vire a página. Você deverá responder às próximas situações sozinho, sem a ajuda do experimentador.

Não volte páginas. Após concluir uma página, siga para a seguinte e a responda sem voltar às anteriores.

\section{Situação 1B}

Imagine que ALGUÉM totalmente desconhecido lhe causou um prejuízo de $\mathbf{1 0 0}$ reais, a algum tempo atrás. Você está diante da última oportunidade de receber esse dinheiro. Que valor você considera justo receber hoje, dessa pessoa, se tal prejuízo foi causado nos seguintes intervalos de tempo, no passado:

\begin{tabular}{|l|l|}
\hline $\begin{array}{l}\text { Tempo transcorrido desde o prejuízo } \\
\text { causado até o momento presente de } \\
\text { receber o valor em dinheiro }\end{array}$ & $\begin{array}{l}\text { Valor em dinheiro que você considera } \\
\text { justo receber hoje (complete apenas com } \\
\text { números) }\end{array}$ \\
\hline 1 semana atrás & $\mathrm{R} \$$ \\
\hline 2 semanas atrás & $\mathrm{R} \$$ \\
\hline 1 mês atrás & $\mathrm{R} \$$ \\
\hline 6 meses atrás & $\mathrm{R} \$$ \\
\hline 1 ano atrás & $\mathrm{R} \$$ \\
\hline 5 anos atrás & $\mathrm{R} \$$ \\
\hline 10 anos atrás & $\mathrm{R} \$$ \\
\hline
\end{tabular}


Não use calculadora. Não volte páginas.

\section{Situação 2B}

Imagine que VOC $\hat{\mathbf{E}}$ causou um prejuízo de 100 reais a alguém totalmente desconhecido, a algum tempo atrás. Você está diante da última oportunidade de pagar esse dinheiro. Que valor você consideraria justo pagar hoje, a essa pessoa, se tal prejuízo foi causado nos seguintes intervalos de tempo, no passado:

\begin{tabular}{|l|l|}
\hline $\begin{array}{l}\text { Tempo transcorrido desde o prejuízo } \\
\text { causado até o momento presente de } \\
\text { pagar o valor em dinheiro }\end{array}$ & $\begin{array}{l}\text { Valor em dinheiro que você considera } \\
\text { justo pagar hoje (complete apenas com } \\
\text { números) }\end{array}$ \\
\hline 1 semana atrás & $\mathrm{R} \$$ \\
\hline 2 semanas atrás & $\mathrm{R} \$$ \\
\hline 1 mês atrás & $\mathrm{R} \$$ \\
\hline 6 meses atrás & $\mathrm{R} \$$ \\
\hline 1 ano atrás & $\mathrm{R} \$$ \\
\hline 5 anos atrás & $\mathrm{R} \$$ \\
\hline 10 anos atrás & $\mathrm{R} \$$ \\
\hline
\end{tabular}


Não use calculadora. Não volte páginas.

\section{Situação 3B}

Imagine ainda que, além do dano material sofrido por você (100 reais), tal fato tenha lhe trazido grandes aborrecimentos. Que valor você consideraria justo receber hoje, dessa pessoa, para compensar os aborrecimentos que você sofreu, se isso ocorreu nos seguintes intervalos de tempo, no passado:

\begin{tabular}{|l|l|}
\hline $\begin{array}{l}\text { Tempo transcorrido desde o prejuízo } \\
\text { causado até o momento presente de } \\
\text { receber o valor em dinheiro }\end{array}$ & $\begin{array}{l}\text { Valor em dinheiro que você considera } \\
\text { justo receber hoje (complete apenas com } \\
\text { números) }\end{array}$ \\
\hline 1 semana atrás & $\mathrm{R} \$$ \\
\hline 2 semanas atrás & $\mathrm{R} \$$ \\
\hline 1 mês atrás & $\mathrm{R} \$$ \\
\hline 6 meses atrás & $\mathrm{R} \$$ \\
\hline 1 ano atrás & $\mathrm{R} \$$ \\
\hline 5 anos atrás & $\mathrm{R} \$$ \\
\hline 10 anos atrás & $\mathrm{R} \$$ \\
\hline
\end{tabular}


Não use calculadora. Não volte páginas.

\section{Situação 4B}

Imagine ainda que, além do dano material causado por você (100 reais), tal fato tenha trazido grandes aborrecimentos a esse alguém desconhecido. Que valor você consideraria justo pagar hoje, a essa pessoa, para compensar os aborrecimentos se isso ocorreu nos seguintes intervalos de tempo, no passado:

\begin{tabular}{|l|l|}
\hline $\begin{array}{l}\text { Tempo transcorrido desde o prejuízo } \\
\text { causado até o momento presente de } \\
\text { pagar o valor em dinheiro }\end{array}$ & $\begin{array}{l}\text { Valor em dinheiro que você considera } \\
\text { justo pagar hoje (complete apenas com } \\
\text { números) }\end{array}$ \\
\hline 1 semana atrás & $\mathrm{R} \$$ \\
\hline 2 semanas atrás & $\mathrm{R} \$$ \\
\hline 1 mês atrás & $\mathrm{R} \$$ \\
\hline 6 meses atrás & $\mathrm{R} \$$ \\
\hline 1 ano atrás & $\mathrm{R} \$$ \\
\hline 5 anos atrás & $\mathrm{R} \$$ \\
\hline 10 anos atrás & $\mathrm{R} \$$ \\
\hline
\end{tabular}




\section{Apêndice 4 \\ QUESTIONÁRIO B1}

Abaixo encontram-se algumas situações hipotéticas. Imagine que você faz parte dessas situações e responda às questões como se as situações fossem reais. Por favor, em suas respostas, considere apenas sua decisão pessoal, sem se preocupar com as opiniões do experimentador ou de qualquer outra pessoa.

Por favor, não use calculadoras.

Agradecemos por sua participação!

\section{Treino 1: tire as dúvidas com o experimentador}

Imagine que ALGUÉM totalmente desconhecido lhe causou um prejuízo de 20 reais algum tempo atrás. Você está diante da última oportunidade de receber esse dinheiro. Que valor você consideraria justo receber hoje, dessa pessoa, se tal prejuízo foi causado nos seguintes intervalos de tempo, no passado:

\begin{tabular}{|l|l|}
\hline $\begin{array}{l}\text { Tempo transcorrido desde o prejuízo } \\
\text { causado até o momento presente de } \\
\text { receber o valor em dinheiro }\end{array}$ & $\begin{array}{l}\text { Valor em dinheiro que você considera } \\
\text { justo receber hoje (complete apenas } \\
\text { com números) }\end{array}$ \\
\hline 1 semana atrás & $\mathrm{R} \$$ \\
\hline 2 semanas atrás & $\mathrm{R} \$$ \\
\hline 1 mês atrás & $\mathrm{R} \$$ \\
\hline 6 meses atrás & $\mathrm{R} \$$ \\
\hline 1 ano atrás & $\mathrm{R} \$$ \\
\hline
\end{tabular}

\section{Treino 2: tire as dúvidas com o experimentador.}

Imagine que VOC $\hat{\mathbf{E}}$ causou um prejuízo de 20 reais a alguém totalmente desconhecido, algum tempo atrás. Você está diante da última oportunidade de pagar esse dinheiro. Que valor você consideraria justo pagar hoje, a essa pessoa, se tal prejuízo foi causado nos seguintes intervalos de tempo, no passado:

\begin{tabular}{|l|l|}
\hline $\begin{array}{l}\text { Tempo transcorrido desde o prejuízo } \\
\text { causado até o momento presente de } \\
\text { pagar o valor em dinheiro }\end{array}$ & $\begin{array}{l}\text { Valor em dinheiro que você considera } \\
\text { justo pagar hoje (complete apenas com } \\
\text { números) }\end{array}$ \\
\hline 1 semana atrás & $\mathrm{R} \$$ \\
\hline 2 semanas atrás & $\mathrm{R} \$$ \\
\hline 1 mês atrás & $\mathrm{R} \$$ \\
\hline 6 meses atrás & $\mathrm{R} \$$ \\
\hline 1 ano atrás & $\mathrm{R} \$$ \\
\hline
\end{tabular}

Quando estiver pronto para começar vire a página. Você deverá responder às próximas situações sozinho, sem a ajuda do experimentador. 
Não volte páginas. Após concluir uma página, siga para a seguinte e a responda sem voltar às anteriores.

\section{Situação 1}

Imagine que ALGUÉM totalmente desconhecido lhe causou um prejuízo de 100 reais, algum tempo atrás. Você está diante da última oportunidade de receber esse dinheiro. Que valor você consideraria justo receber hoje, dessa pessoa, se tal prejuízo foi causado nos seguintes intervalos de tempo, no passado:

\begin{tabular}{|l|l|}
\hline $\begin{array}{l}\text { Tempo transcorrido desde o prejuízo } \\
\text { causado até o momento presente de } \\
\text { receber o valor em dinheiro }\end{array}$ & $\begin{array}{l}\text { Valor em dinheiro que você considera } \\
\text { justo receber hoje (complete apenas com } \\
\text { números) }\end{array}$ \\
\hline 1 semana atrás & $\mathrm{R} \$$ \\
\hline 2 semanas atrás & $\mathrm{R} \$$ \\
\hline 1 mês atrás & $\mathrm{R} \$$ \\
\hline 6 meses atrás & $\mathrm{R} \$$ \\
\hline 1 ano atrás & $\mathrm{R} \$$ \\
\hline 5 anos atrás & $\mathrm{R} \$$ \\
\hline 10 anos atrás & $\mathrm{R} \$$ \\
\hline
\end{tabular}


Não use calculadora. Não volte páginas.

\section{Situação 2}

Imagine que ALGUÉM totalmente desconhecido lhe causou um prejuízo de $\mathbf{1 0}$ mil reais, algum tempo atrás. Você está diante da última oportunidade de receber esse dinheiro. Que valor você consideraria justo receber hoje, dessa pessoa, se tal prejuízo foi causado nos seguintes intervalos de tempo, no passado:

\begin{tabular}{|l|l|}
\hline $\begin{array}{l}\text { Tempo transcorrido desde o prejuízo } \\
\text { causado até o momento presente de } \\
\text { receber o valor em dinheiro }\end{array}$ & $\begin{array}{l}\text { Valor em dinheiro que você considera } \\
\text { justo receber hoje (complete apenas com } \\
\text { números) }\end{array}$ \\
\hline 1 semana atrás & $\mathrm{R} \$$ \\
\hline 2 semanas atrás & $\mathrm{R} \$$ \\
\hline 1 mês atrás & $\mathrm{R} \$$ \\
\hline 6 meses atrás & $\mathrm{R} \$$ \\
\hline 1 ano atrás & $\mathrm{R} \$$ \\
\hline 5 anos atrás & $\mathrm{R} \$$ \\
\hline 10 anos atrás & $\mathrm{R} \$$ \\
\hline
\end{tabular}


Não use calculadora. Não volte páginas.

\section{Situação 3}

Imagine que VOCÊE causou um prejuízo de 100 reais a alguém totalmente desconhecido, algum tempo atrás. Você está diante da última oportunidade de pagar esse dinheiro. Que valor você consideraria justo pagar hoje, a essa pessoa, se tal prejuízo foi causado nos seguintes intervalos de tempo, no passado:

\begin{tabular}{|l|l|}
\hline $\begin{array}{l}\text { Tempo transcorrido desde o prejuízo } \\
\text { causado até o momento presente de } \\
\text { pagar o valor em dinheiro }\end{array}$ & $\begin{array}{l}\text { Valor em dinheiro que você considera } \\
\text { justo pagar hoje (complete apenas com } \\
\text { números) }\end{array}$ \\
\hline 1 semana atrás & $\mathrm{R} \$$ \\
\hline 2 semanas atrás & $\mathrm{R} \$$ \\
\hline 1 mês atrás & $\mathrm{R} \$$ \\
\hline 6 meses atrás & $\mathrm{R} \$$ \\
\hline 1 ano atrás & $\mathrm{R} \$$ \\
\hline 5 anos atrás & $\mathrm{R} \$$ \\
\hline 10 anos atrás & $\mathrm{R} \$$ \\
\hline
\end{tabular}


Não use calculadora. Não volte páginas.

\section{Situação 4}

Imagine que VOCÊE causou um prejuízo de 10 mil reais a alguém totalmente desconhecido, algum tempo atrás. Você está diante da última oportunidade de pagar esse dinheiro. Que valor você consideraria justo pagar hoje, a essa pessoa, se tal prejuízo foi causado nos seguintes intervalos de tempo, no passado:

\begin{tabular}{|l|l|}
\hline $\begin{array}{l}\text { Tempo transcorrido desde o prejuízo } \\
\text { causado até o momento presente de } \\
\text { pagar o valor em dinheiro }\end{array}$ & $\begin{array}{l}\text { Valor em dinheiro que você considera } \\
\text { justo pagar hoje (complete apenas com } \\
\text { números) }\end{array}$ \\
\hline 1 semana atrás & $\mathrm{R} \$$ \\
\hline 2 semanas atrás & $\mathrm{R} \$$ \\
\hline 1 mês atrás & $\mathrm{R} \$$ \\
\hline 6 meses atrás & $\mathrm{R} \$$ \\
\hline 1 ano atrás & $\mathrm{R} \$$ \\
\hline 5 anos atrás & $\mathrm{R} \$$ \\
\hline 10 anos atrás & $\mathrm{R} \$$ \\
\hline
\end{tabular}


Não use calculadora. Não volte páginas.

\section{Situação 5}

Imagine ainda que, além do dano material sofrido por você (100 reais), tal fato tenha lhe trazido grandes aborrecimentos. Que valor você consideraria justo receber hoje, dessa pessoa, para compensar os aborrecimentos que você sofreu, se isso ocorreu nos seguintes intervalos de tempo, no passado:

\begin{tabular}{|l|l|}
\hline $\begin{array}{l}\text { Tempo transcorrido desde o prejuízo } \\
\text { causado até o momento presente de } \\
\text { receber o valor em dinheiro }\end{array}$ & $\begin{array}{l}\text { Valor em dinheiro que você considera } \\
\text { justo receber hoje (complete apenas com } \\
\text { números) }\end{array}$ \\
\hline 1 semana atrás & $\mathrm{R} \$$ \\
\hline 2 semanas atrás & $\mathrm{R} \$$ \\
\hline 1 mês atrás & $\mathrm{R} \$$ \\
\hline 6 meses atrás & $\mathrm{R} \$$ \\
\hline 1 ano atrás & $\mathrm{R} \$$ \\
\hline 5 anos atrás & $\mathrm{R} \$$ \\
\hline 10 anos atrás & $\mathrm{R} \$$ \\
\hline
\end{tabular}


Não use calculadora. Não volte páginas.

\section{Situação 6}

Imagine ainda que, além do dano material sofrido por você (10 mil reais), tal fato tenha lhe trazido grandes aborrecimentos. Que valor você consideraria justo receber hoje, dessa pessoa, para compensar os aborrecimentos que você sofreu, se isso ocorreu nos seguintes intervalos de tempo, no passado:

\begin{tabular}{|l|l|}
\hline $\begin{array}{l}\text { Tempo transcorrido desde o prejuízo } \\
\text { causado até o momento presente de } \\
\text { receber o valor em dinheiro }\end{array}$ & $\begin{array}{l}\text { Valor em dinheiro que você considera } \\
\text { justo receber hoje (complete apenas com } \\
\text { números) }\end{array}$ \\
\hline 1 semana atrás & $\mathrm{R} \$$ \\
\hline 2 semanas atrás & $\mathrm{R} \$$ \\
\hline 1 mês atrás & $\mathrm{R} \$$ \\
\hline 6 meses atrás & $\mathrm{R} \$$ \\
\hline 1 ano atrás & $\mathrm{R} \$$ \\
\hline 5 anos atrás & $\mathrm{R} \$$ \\
\hline 10 anos atrás & $\mathrm{R} \$$ \\
\hline
\end{tabular}


Não use calculadora. Não volte páginas.

\section{Situação 7}

Imagine ainda que, além do dano material causado por você (100 reais), tal fato tenha trazido grandes aborrecimentos a esse alguém desconhecido. Que valor você consideraria justo pagar hoje, a essa pessoa, para compensar os aborrecimentos se isso ocorreu nos seguintes intervalos de tempo, no passado:

\begin{tabular}{|l|l|}
\hline $\begin{array}{l}\text { Tempo transcorrido desde o prejuízo } \\
\text { causado até o momento presente de } \\
\text { pagar o valor em dinheiro }\end{array}$ & $\begin{array}{l}\text { Valor em dinheiro que você considera } \\
\text { justo pagar hoje (complete apenas com } \\
\text { números) }\end{array}$ \\
\hline 1 semana atrás & $\mathrm{R} \$$ \\
\hline 2 semanas atrás & $\mathrm{R} \$$ \\
\hline 1 mês atrás & $\mathrm{R} \$$ \\
\hline 6 meses atrás & $\mathrm{R} \$$ \\
\hline 1 ano atrás & $\mathrm{R} \$$ \\
\hline 5 anos atrás & $\mathrm{R} \$$ \\
\hline 10 anos atrás & $\mathrm{R} \$$ \\
\hline
\end{tabular}


Não use calculadora. Não volte páginas.

\section{Situação 8}

Imagine ainda que, além do dano material causado por você (10 mil reais), tal fato tenha trazido grandes aborrecimentos a esse alguém desconhecido. Que valor você consideraria justo pagar hoje, a essa pessoa, para compensar os aborrecimentos se isso ocorreu nos seguintes intervalos de tempo, no passado:

\begin{tabular}{|l|l|}
\hline $\begin{array}{l}\text { Tempo transcorrido desde o prejuízo } \\
\text { causado até o momento presente de } \\
\text { pagar o valor em dinheiro }\end{array}$ & $\begin{array}{l}\text { Valor em dinheiro que você considera } \\
\text { justo pagar hoje (complete apenas com } \\
\text { números) }\end{array}$ \\
\hline 1 semana atrás & $\mathrm{R} \$$ \\
\hline 2 semanas atrás & $\mathrm{R} \$$ \\
\hline 1 mês atrás & $\mathrm{R} \$$ \\
\hline 6 meses atrás & $\mathrm{R} \$$ \\
\hline 1 ano atrás & $\mathrm{R} \$$ \\
\hline 5 anos atrás & $\mathrm{R} \$$ \\
\hline 10 anos atrás & $\mathrm{R} \$$ \\
\hline
\end{tabular}




\section{Apêndice 5 \\ QUESTIONÁRIO B2}

Abaixo encontram-se algumas situações hipotéticas. Imagine que você faz parte dessas situações e responda às questões como se as situações fossem reais. Por favor, em suas respostas, considere apenas sua decisão pessoal, sem se preocupar com as opiniões do experimentador ou de qualquer outra pessoa.

Por favor, não use calculadoras.

Agradecemos por sua participação!

\section{Treino 1: tire as dúvidas com o experimentador}

Imagine que ALGUÉM totalmente desconhecido lhe causou um prejuízo de 20 reais algum tempo atrás. Você está diante da última oportunidade de receber esse dinheiro. Que valor você consideraria justo receber hoje, dessa pessoa, se tal prejuízo foi causado nos seguintes intervalos de tempo, no passado:

\begin{tabular}{|l|l|}
\hline $\begin{array}{l}\text { Tempo transcorrido desde o prejuízo } \\
\text { causado até o momento presente de } \\
\text { receber o valor em dinheiro }\end{array}$ & $\begin{array}{l}\text { Valor em dinheiro que você considera } \\
\text { justo receber hoje (complete apenas } \\
\text { com números) }\end{array}$ \\
\hline 1 semana atrás & $\mathrm{R} \$$ \\
\hline 2 semanas atrás & $\mathrm{R} \$$ \\
\hline 1 mês atrás & $\mathrm{R} \$$ \\
\hline 6 meses atrás & $\mathrm{R} \$$ \\
\hline 1 ano atrás & $\mathrm{R} \$$ \\
\hline
\end{tabular}

Treino 2: tire as dúvidas com o experimentador.

Imagine que VOC $\hat{E}$ causou um prejuízo de 20 reais a alguém totalmente desconhecido, a algum tempo atrás. Você está diante da última oportunidade de pagar esse dinheiro. Que valor você consideraria justo pagar hoje, a essa pessoa, se tal prejuízo foi causado nos seguintes intervalos de tempo, no passado:

\begin{tabular}{|l|l|}
\hline $\begin{array}{l}\text { Tempo transcorrido desde o prejuízo } \\
\text { causado até o momento presente de } \\
\text { pagar o valor em dinheiro }\end{array}$ & $\begin{array}{l}\text { Valor em dinheiro que você considera } \\
\text { justo pagar hoje (complete apenas com } \\
\text { números) }\end{array}$ \\
\hline 1 semana atrás & $\mathrm{R} \$$ \\
\hline 2 semanas atrás & $\mathrm{R} \$$ \\
\hline 1 mês atrás & $\mathrm{R} \$$ \\
\hline 6 meses atrás & $\mathrm{R} \$$ \\
\hline 1 ano atrás & $\mathrm{R} \$$ \\
\hline
\end{tabular}

Quando estiver pronto para começar vire a página. Você deverá responder às próximas situações sozinho, sem a ajuda do experimentador. 
Não volte páginas. Após concluir uma página, siga para a seguinte e a responda sem voltar às anteriores.

\section{Situação 3}

Imagine que VOCÊ causou um prejuízo de 100 reais a alguém totalmente desconhecido, algum tempo atrás. Você está diante da última oportunidade de pagar esse dinheiro. Que valor você consideraria justo pagar hoje, a essa pessoa, se tal prejuízo foi causado nos seguintes intervalos de tempo, no passado:

\begin{tabular}{|l|l|}
\hline $\begin{array}{l}\text { Tempo transcorrido desde o prejuízo } \\
\text { causado até o momento presente de } \\
\text { pagar o valor em dinheiro }\end{array}$ & $\begin{array}{l}\text { Valor em dinheiro que você considera } \\
\text { justo pagar hoje (complete apenas com } \\
\text { números) }\end{array}$ \\
\hline 1 semana atrás & $\mathrm{R} \$$ \\
\hline 2 semanas atrás & $\mathrm{R} \$$ \\
\hline 1 mês atrás & $\mathrm{R} \$$ \\
\hline 6 meses atrás & $\mathrm{R} \$$ \\
\hline 1 ano atrás & $\mathrm{R} \$$ \\
\hline 5 anos atrás & $\mathrm{R} \$$ \\
\hline 10 anos atrás & $\mathrm{R} \$$ \\
\hline
\end{tabular}


Não use calculadora. Não volte páginas.

\section{Situação 4}

Imagine que VOC $\hat{E}$ causou um prejuízo de 10 mil reais a alguém totalmente desconhecido, algum tempo atrás. Você está diante da última oportunidade de pagar esse dinheiro. Que valor você consideraria justo pagar hoje, a essa pessoa, se tal prejuízo foi causado nos seguintes intervalos de tempo, no passado:

\begin{tabular}{|l|l|}
\hline $\begin{array}{l}\text { Tempo transcorrido desde o prejuízo } \\
\text { causado até o momento presente de } \\
\text { pagar o valor em dinheiro }\end{array}$ & $\begin{array}{l}\text { Valor em dinheiro que você considera } \\
\text { justo pagar hoje (complete apenas com } \\
\text { números) }\end{array}$ \\
\hline 1 semana atrás & $\mathrm{R} \$$ \\
\hline 2 semanas atrás & $\mathrm{R} \$$ \\
\hline 1 mês atrás & $\mathrm{R} \$$ \\
\hline 6 meses atrás & $\mathrm{R} \$$ \\
\hline 1 ano atrás & $\mathrm{R} \$$ \\
\hline 5 anos atrás & $\mathrm{R} \$$ \\
\hline 10 anos atrás & $\mathrm{R} \$$ \\
\hline
\end{tabular}


Não use calculadora. Não volte páginas.

\section{Situação 1}

Imagine que ALGUÉM totalmente desconhecido lhe causou um prejuízo de 100 reais algum tempo atrás. Você está diante da última oportunidade de receber esse dinheiro. Que valor você consideraria justo receber hoje, dessa pessoa, se tal prejuízo foi causado nos seguintes intervalos de tempo, no passado:

\begin{tabular}{|l|l|}
\hline $\begin{array}{l}\text { Tempo transcorrido desde o prejuízo } \\
\text { causado até o momento presente de } \\
\text { receber o valor em dinheiro }\end{array}$ & $\begin{array}{l}\text { Valor em dinheiro que você considera } \\
\text { justo receber hoje (complete apenas com } \\
\text { números) }\end{array}$ \\
\hline 1 semana atrás & $\mathrm{R} \$$ \\
\hline 2 semanas atrás & $\mathrm{R} \$$ \\
\hline 1 mês atrás & $\mathrm{R} \$$ \\
\hline 6 meses atrás & $\mathrm{R} \$$ \\
\hline 1 ano atrás & $\mathrm{R} \$$ \\
\hline 5 anos atrás & $\mathrm{R} \$$ \\
\hline 10 anos atrás & $\mathrm{R} \$$ \\
\hline
\end{tabular}


Não use calculadora. Não volte páginas.

\section{Situação 2}

Imagine que ALGUÉM totalmente desconhecido lhe causou um prejuízo de $\mathbf{1 0}$ mil reais a algum tempo atrás. Você está diante da última oportunidade de receber esse dinheiro. Que valor você consideraria justo receber hoje, dessa pessoa, se tal prejuízo foi causado nos seguintes intervalos de tempo, no passado:

\begin{tabular}{|l|l|}
\hline $\begin{array}{l}\text { Tempo transcorrido desde o prejuízo } \\
\text { causado até o momento presente de } \\
\text { receber o valor em dinheiro }\end{array}$ & $\begin{array}{l}\text { Valor em dinheiro que você considera } \\
\text { justo receber hoje (complete apenas com } \\
\text { números) }\end{array}$ \\
\hline 1 semana atrás & $\mathrm{R} \$$ \\
\hline 2 semanas atrás & $\mathrm{R} \$$ \\
\hline 1 mês atrás & $\mathrm{R} \$$ \\
\hline 6 meses atrás & $\mathrm{R} \$$ \\
\hline 1 ano atrás & $\mathrm{R} \$$ \\
\hline 5 anos atrás & $\mathrm{R} \$$ \\
\hline 10 anos atrás & $\mathrm{R} \$$ \\
\hline
\end{tabular}


Não use calculadora. Não volte páginas.

\section{Situação 7}

Imagine ainda que, além do dano material causado por você (100 reais), tal fato tenha trazido grandes aborrecimentos a esse alguém totalmente desconhecido. Que valor você consideraria justo pagar hoje, a essa pessoa, para compensar os aborrecimentos se isso ocorreu nos seguintes intervalos de tempo, no passado:

\begin{tabular}{|l|l|}
\hline $\begin{array}{l}\text { Tempo transcorrido desde o prejuízo } \\
\text { causado até o momento presente de } \\
\text { pagar o valor em dinheiro }\end{array}$ & $\begin{array}{l}\text { Valor em dinheiro que você considera } \\
\text { justo pagar hoje (complete apenas com } \\
\text { números) }\end{array}$ \\
\hline 1 semana atrás & $\mathrm{R} \$$ \\
\hline 2 semanas atrás & $\mathrm{R} \$$ \\
\hline 1 mês atrás & $\mathrm{R} \$$ \\
\hline 6 meses atrás & $\mathrm{R} \$$ \\
\hline 1 ano atrás & $\mathrm{R} \$$ \\
\hline 5 anos atrás & $\mathrm{R} \$$ \\
\hline 10 anos atrás & $\mathrm{R} \$$ \\
\hline
\end{tabular}


Não use calculadora. Não volte páginas.

\section{Situação 8}

Imagine ainda que, além do dano material causado por você (10 mil reais), tal fato tenha trazido grandes aborrecimentos a esse alguém totalmente desconhecido. Que valor você consideraria justo pagar hoje, a essa pessoa, para compensar os aborrecimentos se isso ocorreu nos seguintes intervalos de tempo, no passado:

\begin{tabular}{|l|l|}
\hline $\begin{array}{l}\text { Tempo transcorrido desde o prejuízo } \\
\text { causado até o momento presente de } \\
\text { pagar o valor em dinheiro }\end{array}$ & $\begin{array}{l}\text { Valor em dinheiro que você considera } \\
\text { justo pagar hoje (complete apenas com } \\
\text { números) }\end{array}$ \\
\hline 1 semana atrás & $\mathrm{R} \$$ \\
\hline 2 semanas atrás & $\mathrm{R} \$$ \\
\hline 1 mês atrás & $\mathrm{R} \$$ \\
\hline 6 meses atrás & $\mathrm{R} \$$ \\
\hline 1 ano atrás & $\mathrm{R} \$$ \\
\hline 5 anos atrás & $\mathrm{R} \$$ \\
\hline 10 anos atrás & $\mathrm{R} \$$ \\
\hline
\end{tabular}


Não use calculadora. Não volte páginas.

\section{Situação 5}

Imagine ainda que, além do dano material sofrido por você (100 reais), tal fato tenha lhe trazido grandes aborrecimentos. Que valor você consideraria justo receber hoje, dessa pessoa, para compensar os aborrecimentos que você sofreu, se isso ocorreu nos seguintes intervalos de tempo, no passado:

\begin{tabular}{|l|l|}
\hline $\begin{array}{l}\text { Tempo transcorrido desde o prejuízo } \\
\text { causado até o momento presente de } \\
\text { receber o valor em dinheiro }\end{array}$ & $\begin{array}{l}\text { Valor em dinheiro que você considera } \\
\text { justo receber hoje (complete apenas com } \\
\text { números) }\end{array}$ \\
\hline 1 semana atrás & $\mathrm{R} \$$ \\
\hline 2 semanas atrás & $\mathrm{R} \$$ \\
\hline 1 mês atrás & $\mathrm{R} \$$ \\
\hline 6 meses atrás & $\mathrm{R} \$$ \\
\hline 1 ano atrás & $\mathrm{R} \$$ \\
\hline 5 anos atrás & $\mathrm{R} \$$ \\
\hline 10 anos atrás & $\mathrm{R} \$$ \\
\hline
\end{tabular}


Não use calculadora. Não volte páginas.

\section{Situação 6}

Imagine ainda que, além do dano material sofrido por você (10 mil reais), tal fato tenha lhe trazido grandes aborrecimentos. Que valor você consideraria justo receber hoje, dessa pessoa, para compensar os aborrecimentos que você sofreu, se isso ocorreu nos seguintes intervalos de tempo, no passado:

\begin{tabular}{|l|l|}
\hline $\begin{array}{l}\text { Tempo transcorrido desde o prejuízo } \\
\text { causado até o momento presente de } \\
\text { receber o valor em dinheiro }\end{array}$ & $\begin{array}{l}\text { Valor em dinheiro que você considera } \\
\text { justo receber hoje (complete apenas com } \\
\text { números) }\end{array}$ \\
\hline 1 semana atrás & $\mathrm{R} \$$ \\
\hline 2 semanas atrás & $\mathrm{R} \$$ \\
\hline 1 mês atrás & $\mathrm{R} \$$ \\
\hline 6 meses atrás & $\mathrm{R} \$$ \\
\hline 1 ano atrás & $\mathrm{R} \$$ \\
\hline 5 anos atrás & $\mathrm{R} \$$ \\
\hline 10 anos atrás & $\mathrm{R} \$$ \\
\hline
\end{tabular}


Apêndice 6

Dados individuais do Estudo 1 - Questionário A

\begin{tabular}{|c|c|c|c|c|c|}
\hline \multirow{2}{*}{$\begin{array}{l}\text { HIPERB. } \\
\text { Quest. A }\end{array}$} & & & \multicolumn{3}{|l|}{ HIPÉRB. } \\
\hline & & & Quest. A & & \\
\hline & \multicolumn{2}{|c|}{ Sit1 } & & \multicolumn{2}{|c|}{ Sit2 } \\
\hline Participante & $\mathbf{k}$ & $\mathbf{R 2}$ & Participante & $\mathbf{k}$ & $\mathbf{R 2}$ \\
\hline A4 & 0,002851 & 0,9203 & A4 & 0,002851 & 0,9203 \\
\hline A6 & 0,007589 & 0,8642 & A5 & 0,001196 & 0,6892 \\
\hline A8 & 0,00989 & 0,9465 & A6 & 0,04117 & 0,6858 \\
\hline A9 & 0,02206 & 0,9498 & A8 & 0,009407 & 0,9557 \\
\hline A13 & 2,69E-19 & 1 & A9 & 0,07038 & 0,9273 \\
\hline A14 & 0,01173 & 0,909 & A13 & $2,69 \mathrm{E}-19$ & 1 \\
\hline A17 & 0,01622 & 0,9805 & A14 & 0,04408 & 0,9034 \\
\hline A21 & 0,02164 & 0,954 & A17 & 0,002613 & 0,9352 \\
\hline A22 & 0,0005228 & 0,8764 & A21 & 0,0179 & 0,8746 \\
\hline A27 & 0,0003686 & 0,3479 & A22 & 0,0009433 & 0,7033 \\
\hline A33 & 0,02819 & 0,9414 & A24 & 0,0003347 & 0,7527 \\
\hline A34 & 0,03086 & 0,9041 & A27 & 0,0009433 & 0,7033 \\
\hline A38 & 0,01553 & 0,9647 & A29 & 0,005144 & 0,9177 \\
\hline A39 & 0,006492 & 0,8379 & A33 & 0,0258 & 0,9041 \\
\hline \multirow[t]{7}{*}{ A42 } & \begin{tabular}{|l}
0,0009079 \\
\end{tabular} & 0,78 & A34 & 0,03086 & 0,9041 \\
\hline & & & A38 & 0,01553 & 0,9647 \\
\hline & & & A39 & 0,007965 & 0,8752 \\
\hline & & & A41 & 0,003211 & 0,8734 \\
\hline & & & A42 & 0,002324 & 0,6755 \\
\hline & & & A44 & 0,00106 & 0,8057 \\
\hline & & & A45 & 0,01271 & 0,9561 \\
\hline
\end{tabular}

\begin{tabular}{|c|c|c|c|c|c|}
\hline HIPÉRB. & & & HIPÉRB. & & \\
\hline Quest. A & & & Quest. A & & \\
\hline & \multicolumn{2}{|c|}{ Sit3 } & & \multicolumn{2}{|c|}{ Sit4 } \\
\hline Participante & $\mathbf{k}$ & R2 & Participante & $\mathbf{k}$ & R2 \\
\hline A4 & 0,006121 & 0,8063 & A4 & 0,006121 & 0,8063 \\
\hline A5 & 2,052 & 0,8111 & A5 & 2,052 & 0,8111 \\
\hline A6 & 0,06154 & 0,6871 & A6 & 0,0283 & 0,5388 \\
\hline A8 & 0,02473 & 0,9294 & A8 & 0,06821 & 0,95 \\
\hline A9 & 0,03711 & 0,9469 & A9 & 0,02206 & 0,9498 \\
\hline A13 & $2,69 \mathrm{E}-19$ & 1 & A13 & $2,69 \mathrm{E}-19$ & 1 \\
\hline A14 & 0,01366 & 0,8573 & A14 & 0,02871 & 0,9174 \\
\hline A17 & 0,05918 & 0,9821 & A17 & 0,01378 & 0,8127 \\
\hline A21 & 0,128 & 0,8627 & A20 & 0,128 & 0,8627 \\
\hline
\end{tabular}




\begin{tabular}{|l|l|l|l|l|l|}
\hline A22 & 0,1723 & 0,9956 & A21 & 0,1723 & 0,9956 \\
\hline A24 & 0,008632 & 0,771 & A22 & 0,00386 & 0,9546 \\
\hline A27 & 0,0002977 & 0,2958 & A24 & 0,00063 & 0,6421 \\
\hline A29 & 0,00106 & 0,8057 & A27 & 0,0009103 & 0,516 \\
\hline A33 & 0,002052 & 0,6037 & A29 & 0,005144 & 0,9177 \\
\hline A34 & 0,1394 & 0,8547 & A30 & 0,002104 & 0,9738 \\
\hline A38 & 0,03086 & 0,9041 & A33 & 0,03317 & 0,9085 \\
\hline A39 & 0,004929 & 0,7828 & A34 & 0,03086 & 0,9041 \\
\hline A41 & 0,001478 & 0,7466 & A39 & 0,01022 & 0,8357 \\
\hline A42 & 0,001726 & 1 & A42 & 0,001464 & 0,6567 \\
\hline A44 & 0,001726 & 0,6137 & A44 & 0,01402 & 0,7916 \\
\hline
\end{tabular}

\begin{tabular}{|c|c|c|c|c|c|}
\hline EXPON. & & & EXPON. & & \\
\hline Quest. A & & & Quest. A & & \\
\hline & \multicolumn{2}{|c|}{ Sit1 } & & \multicolumn{2}{|c|}{ Sit2 } \\
\hline Participante & $\mathbf{k}$ & $\mathbf{R 2}$ & Participante & $\mathbf{k}$ & $\mathbf{R 2}$ \\
\hline A4 & 0,00528 & 0,9332 & A4 & 0,00528 & 0,9332 \\
\hline A6 & 0,02365 & 0,9187 & A5 & $6,63 \mathrm{E}-07$ & 0,7819 \\
\hline A8 & 0,006285 & 0,9719 & A6 & 0,3821 & 0,9692 \\
\hline A9 & 0,02531 & 0,9572 & A8 & 0,0135 & 0,941 \\
\hline A13 & 0,04167 & 1 & A9 & 0,2228 & 0,9362 \\
\hline A14 & 0,01492 & 0,9275 & A13 & 0,04167 & 1 \\
\hline A17 & 0,01571 & 0,9776 & A14 & 0,05055 & 0,9872 \\
\hline A21 & 0,02023 & 0,9503 & A17 & 0,01058 & 0,9824 \\
\hline A22 & 0,00528 & 0,9332 & A21 & 0,02419 & 0,8942 \\
\hline A27 & 0,08766 & 0,9694 & A22 & 0,0267 & 0,9698 \\
\hline A33 & 0,03303 & 0,9799 & A24 & $6,63 \mathrm{E}-07$ & 0,7819 \\
\hline A34 & 0,0406 & 0,9548 & A27 & 0,0267 & 0,9698 \\
\hline A38 & 0,02245 & 0,9794 & A29 & 0,01859 & 0,9652 \\
\hline A39 & 0,0294 & 0,9868 & A33 & 0,03652 & 0,9762 \\
\hline \multirow[t]{7}{*}{ A42 } & 0,01057 & 0,8189 & A34 & 0,0406 & 0,9548 \\
\hline & & & A38 & 0,02245 & 0,9794 \\
\hline & & & A39 & 0,02696 & 0,9906 \\
\hline & & & A41 & 0,01264 & 0,9467 \\
\hline & & & A42 & 0,03915 & 0,9478 \\
\hline & & & A44 & 0,01291 & 0,9445 \\
\hline & & & A45 & 0,01892 & 0,9712 \\
\hline
\end{tabular}

\begin{tabular}{|c|c|c|c|c|c|}
\hline EXPON. & & & EXPON. & & \\
\hline Quest. A & & & Quest. A & & \\
\hline & \multicolumn{2}{|c|}{ Sit3 } & & Sit4 & \\
\hline Participante & $\mathbf{k}$ & $\mathbf{R 2}$ & Participante & $\mathbf{k}$ & $\mathbf{R 2}$ \\
\hline
\end{tabular}




\begin{tabular}{|l|l|l|l|l|l|}
\hline A4 & 0,02925 & 0,9188 & A4 & 0,02925 & 0,9188 \\
\hline A5 & 0,8128 & 0,9653 & A5 & 0,8128 & 0,9653 \\
\hline A6 & 0,6256 & 0,885 & A6 & 0,9256 & 0,8977 \\
\hline A8 & 0,01988 & 0,9372 & A8 & 0,05683 & 0,9708 \\
\hline A9 & 0,03132 & 0,9609 & A9 & 0,02531 & 0,9572 \\
\hline A13 & 0,04167 & 1 & A13 & 0,04167 & 1 \\
\hline A14 & 0,02233 & 0,8969 & A14 & 0,02231 & 0,9059 \\
\hline A17 & 0,035 & 0,994 & A17 & 0,02183 & 0,8547 \\
\hline A21 & 0,2802 & 0,9289 & A20 & 0,2802 & 0,9289 \\
\hline A22 & 0,07551 & 0,9947 & A21 & 0,07551 & 0,9947 \\
\hline A24 & 0,03668 & 0,9952 & A22 & 0,002912 & 0,9707 \\
\hline A27 & 0,2337 & 0,9747 & A24 & 0,07157 & 0,8201 \\
\hline A29 & 0,01291 & 0,9445 & A27 & 0,04457 & 0,9832 \\
\hline A33 & 0,01928 & 0,8479 & A29 & 0,01859 & 0,9652 \\
\hline A34 & 0,282 & 0,9388 & A30 & 0,00194 & 0,9795 \\
\hline A38 & 0,0406 & 0,9548 & A33 & 0,04765 & 0,9868 \\
\hline A39 & 0,03434 & 0,9374 & A34 & 0,0406 & 0,9548 \\
\hline A41 & 0,02567 & 0,9106 & A39 & 0,03428 & 0,9666 \\
\hline A42 & 0,5839 & 0,9899 & A42 & 0,2978 & 0,8722 \\
\hline A44 & 0,02349 & 0,8414 & A43 & 0,5768 & 0,9896 \\
\hline & & & A44 & 0,03143 & 0,8437 \\
\hline
\end{tabular}

Dados individuais do Estudo 1 - Questionário B

\begin{tabular}{|c|c|c|c|c|c|}
\hline HIPÉRB. & & & HIPÉRB. & & \\
\hline Quest. B & & & Quest. B & & \\
\hline & \multicolumn{2}{|c|}{ Sit1 } & & \multicolumn{2}{|c|}{ Sit2 } \\
\hline Participante & $\mathbf{k}$ & $\mathbf{R 2}$ & Participante & $\mathbf{k}$ & $\mathbf{R 2}$ \\
\hline B1 & 0,02209 & 0,986 & B1 & 0,04786 & 0,9791 \\
\hline B2 & 0,004392 & 0,9445 & B2 & 0,004392 & 0,9445 \\
\hline B4 & 0,009227 & 0,8274 & B4 & 0,007146 & 0,8157 \\
\hline B5 & 0,001361 & 0,6005 & B5 & 0,001361 & 0,6005 \\
\hline B6 & 0,04435 & 0,7756 & B6 & 0,00608 & 0,6002 \\
\hline B8 & 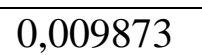 & 0,8917 & B8 & \begin{tabular}{|l|}
0,05232 \\
\end{tabular} & 0,7854 \\
\hline B10 & 0,03609 & 0,9782 & B10 & 0,03609 & 0,9782 \\
\hline B12 & 0,00109 & 0,3783 & B11 & 0,002567 & 0,841 \\
\hline B13 & \begin{tabular}{|l|}
0,002614 \\
\end{tabular} & 0,6864 & B13 & \begin{tabular}{|l|}
0,00252 \\
\end{tabular} & 0,7744 \\
\hline B14 & 0,0495 & 0,9738 & B14 & 0,09995 & 0,9657 \\
\hline B23 & $5,35 \mathrm{E}+28$ & 0,9908 & B19 & \begin{tabular}{|l|}
0,004166 \\
\end{tabular} & 0,9045 \\
\hline B24 & \begin{tabular}{|l|}
0,005458 \\
\end{tabular} & 0,6734 & B23 & $1,29 \mathrm{E}+22$ & 0,9909 \\
\hline
\end{tabular}




\begin{tabular}{|l|l|l|l|l|l|}
\hline B25 & 0,08045 & 0,9771 & B24 & 0,0162 & 0,9189 \\
\hline B26 & 0,03099 & 0,9948 & B25 & 0,1696 & 0,9203 \\
\hline B27 & 0,04549 & 0,948 & B26 & 0,03099 & 0,9948 \\
\hline B28 & 0,006086 & 0,9246 & B27 & 0,02008 & 0,9861 \\
\hline B29 & 0,008796 & 0,879 & B28 & 0,0248 & 0,8824 \\
\hline B31 & 0,4271 & 0,9476 & B29 & 0,01005 & 0,8992 \\
\hline B33 & 0,004588 & 0,9233 & B31 & 0,29 & 0,9892 \\
\hline B34 & 0,03755 & 0,9238 & B33 & 0,000685 & 0,9737 \\
\hline B35 & 0,001072 & 0,1896 & B34 & 0,03755 & 0,9238 \\
\hline B36 & 0,00386 & 0,9546 & B35 & 0,001072 & 0,1896 \\
\hline B38 & 0,002107 & 0,9736 & B36 & 0,00386 & 0,9546 \\
\hline & & & B38 & 0,009599 & 0,9056 \\
\hline & & & B41 & 0,04975 & 0,9766 \\
\hline
\end{tabular}

\begin{tabular}{|c|c|c|c|c|c|}
\hline HIPÉRB. & & & HIPÉRB. & & \\
\hline Quest. B & & & Quest. B & & \\
\hline & \multicolumn{2}{|c|}{ Sit3 } & & \multicolumn{2}{|c|}{ Sit4 } \\
\hline Participante & $\mathbf{k}$ & $\mathbf{R 2}$ & Participante & $\mathbf{k}$ & $\mathbf{R 2}$ \\
\hline B1 & 0,7582 & 0,9775 & B1 & 0,7582 & 0,9775 \\
\hline $\mathrm{B} 2$ & 0,004392 & 0,9445 & $\mathrm{~B} 2$ & 0,003261 & 0,9547 \\
\hline B4 & 0,01684 & 0,8767 & B4 & 0,02363 & 0,836 \\
\hline B5 & 0,001361 & 0,6005 & B5 & 0,00253 & 0,9086 \\
\hline B6 & 0,004332 & 0,7217 & B6 & 0,007417 & 0,7924 \\
\hline $\bar{B} 8$ & 0,0235 & 0,7027 & B8 & 0,1695 & 0,9091 \\
\hline B10 & 0,03548 & 0,9732 & B10 & 0,0505 & 0,958 \\
\hline B12 & 0,003041 & 0,8366 & B11 & 1,854 & 0,5872 \\
\hline B13 & 0,001818 & 0,9636 & B12 & 0,004159 & 0,8055 \\
\hline B14 & 0,1639 & 0,9703 & B13 & 0,000832 & 0,5778 \\
\hline B15 & 0,003552 & 0,4415 & B14 & $2,28 \mathrm{E}+12$ & 0,9912 \\
\hline $\mathrm{B} 23$ & $6,54 \mathrm{E}+22$ & 0,9957 & B15 & 0,003552 & 0,4415 \\
\hline $\mathrm{B} 24$ & 0,02553 & 0,8266 & B19 & 0,006626 & 0,7343 \\
\hline $\mathrm{B} 25$ & 0,1696 & 0,9203 & B23 & $1,60 \mathrm{E}+34$ & 0,9957 \\
\hline B26 & 0,08205 & 0,9759 & B24 & 0,01432 & 0,8423 \\
\hline $\mathrm{B} 27$ & 0,2318 & 0,9424 & B25 & 0,1696 & 0,9203 \\
\hline B28 & 0,01161 & 0,9551 & B26 & 0,08266 & 0,9755 \\
\hline B29 & 0,01622 & 0,9805 & B27 & 0,1665 & 0,9105 \\
\hline B31 & 1,081 & 0,9761 & B28 & 0,5573 & 0,7888 \\
\hline B33 & 0,0329 & 0,8082 & B29 & 0,01364 & 0,9324 \\
\hline B34 & 0,1784 & 0,9892 & B31 & 0,1434 & 0,9416 \\
\hline B35 & 0,00087 & 0,3208 & B33 & 0,001926 & 0,8924 \\
\hline B36 & 0,00386 & 0,9546 & B34 & 0,2323 & 0,9891 \\
\hline B38 & 0,002107 & 0,9736 & B35 & 0,00087 & 0,3208 \\
\hline
\end{tabular}




\begin{tabular}{|l|l|l|l|l|l|}
\hline B40 & 0,004246 & 0,8147 & B36 & 0,00386 & 0,9546 \\
\hline B47 & 0,00253 & 0,9086 & B38 & 0,01161 & 0,7352 \\
\hline & & & B40 & 0,004166 & 0,9045 \\
\hline & & & B41 & 0,08748 & 0,9712 \\
\hline & & & B47 & 0,00479 & 0,9289 \\
\hline
\end{tabular}

\begin{tabular}{|c|c|c|c|c|c|}
\hline EXPON. & & & EXPON. & & \\
\hline Quest. B & & & Quest. B & & \\
\hline & \multicolumn{2}{|c|}{ Sit1 } & & \multicolumn{2}{|c|}{ Sit2 } \\
\hline Participante & $\mathbf{k}$ & $\mathbf{R 2}$ & Participante & $\mathbf{k}$ & $\mathbf{R 2}$ \\
\hline B1 & 0,02341 & 0,9844 & B1 & 0,04193 & 0,9914 \\
\hline B2 & 0,00194 & 0,9795 & B2 & 0,00194 & 0,9795 \\
\hline B4 & 0,03345 & 0,9353 & B4 & 0,02726 & 0,8951 \\
\hline B5 & 0,02349 & 0,8414 & B5 & 0,02349 & 0,8414 \\
\hline B6 & 0,4338 & 0,9192 & B6 & 0,5174 & 0,8724 \\
\hline B8 & 0,01988 & 0,914 & B8 & 0,4149 & 0,9204 \\
\hline B10 & 0,03285 & 0,9826 & B10 & 0,03285 & 0,9826 \\
\hline B12 & 0,08766 & 0,9694 & B11 & $1,82 \mathrm{E}-05$ & 0,8564 \\
\hline B13 & 0,003747 & 0,6836 & B13 & 0,02979 & 0,982 \\
\hline B14 & 0,03867 & 0,9844 & B14 & 0,06245 & 0,9833 \\
\hline B23 & 0,6561 & 0,9989 & B19 & 0,01196 & 0,9355 \\
\hline B24 & 0,04876 & 0,9808 & B23 & 0,6566 & 0,9989 \\
\hline $\mathrm{B} 25$ & 0,05078 & 0,9881 & B24 & 0,0298 & 0,9884 \\
\hline B26 & 0,02031 & 0,9922 & B25 & 0,2568 & 0,921 \\
\hline B27 & 0,03204 & 0,9409 & B26 & 0,02031 & 0,9922 \\
\hline B28 & 0,003795 & 0,9599 & B27 & 0,01861 & 0,9802 \\
\hline B29 & 0,003537 & 0,9634 & B28 & 0,03924 & 0,9625 \\
\hline B31 & 0,3341 & 0,9519 & B29 & 0,01535 & 0,9163 \\
\hline B33 & 0,01743 & 0,9591 & B31 & 0,2028 & 0,977 \\
\hline B34 & 0,02492 & 0,9269 & B33 & 0,003865 & 0,992 \\
\hline B35 & 2,626 & 0,3752 & B34 & 0,02492 & 0,9269 \\
\hline B36 & 0,002912 & 0,9707 & B35 & 2,626 & 0,3752 \\
\hline \multirow[t]{3}{*}{ B38 } & 0,004999 & 0,9768 & B36 & 0,002912 & 0,9707 \\
\hline & & & B38 & 0,02452 & 0,9908 \\
\hline & & & B41 & 0,03925 & 0,9922 \\
\hline
\end{tabular}

\begin{tabular}{|l|l|l|l|l|l|}
\hline EXPON. & & & EXPON. & & \\
\hline Quest. B & \multicolumn{2}{|c|}{ Sit3 } & & Quest. B & \multicolumn{2}{c|}{ Sit4 } \\
\hline & \multicolumn{2}{|c|}{} & Participante & k & R2 \\
\hline Participante & k & R2 & B1 & 0,2933 & 0,9593 \\
\hline B1 & 0,2933 & 0,9593 & B & 0,001103 & 0,9852 \\
\hline B2 & 0,00194 & 0,9795 & B2 & & \\
\hline
\end{tabular}




\begin{tabular}{|l|l|l|l|l|l|}
\hline B4 & 0,02564 & 0,9149 & B4 & 0,302 & 0,8857 \\
\hline B5 & 0,02349 & 0,8414 & B5 & 0,009979 & 0,9439 \\
\hline B6 & 0,03818 & 0,9222 & B6 & 0,02994 & 0,882 \\
\hline B8 & 0,4399 & 0,9113 & B8 & 0,3375 & 0,9161 \\
\hline B10 & 0,03424 & 0,9856 & B10 & 0,04795 & 0,9813 \\
\hline B12 & 0,01995 & 0,9731 & B11 & 1,018 & 0,9933 \\
\hline B13 & $1,24 \mathrm{E}-06$ & 0,9915 & B12 & 0,02877 & 0,9903 \\
\hline B14 & 0,08819 & 0,9491 & B13 & 0,02349 & 0,8414 \\
\hline B15 & 0,08766 & 0,9694 & B14 & 0,6867 & 0,9918 \\
\hline B23 & 0,6197 & 0,9964 & B15 & 0,08766 & 0,9694 \\
\hline B24 & 0,03378 & 0,8685 & B19 & 0,03987 & 0,9909 \\
\hline B25 & 0,2568 & 0,921 & B23 & 0,6207 & 0,9965 \\
\hline B26 & 0,04119 & 0,9935 & B24 & 0,03485 & 0,9182 \\
\hline B27 & 0,2454 & 0,9401 & B25 & 0,2568 & 0,921 \\
\hline B28 & 0,0212 & 0,9823 & B26 & 0,04052 & 0,994 \\
\hline B29 & 0,01571 & 0,9776 & B27 & 0,2626 & 0,9283 \\
\hline B31 & 0,411 & 0,9828 & B28 & 0,5631 & 0,9554 \\
\hline B33 & 0,06259 & 0,9293 & B29 & 0,01196 & 0,9355 \\
\hline B34 & 0,07956 & 0,973 & B31 & 0,2013 & 0,9901 \\
\hline B35 & 0,00075 & 0,341 & B33 & 0,01467 & 0,917 \\
\hline B36 & 0,002912 & 0,9707 & B34 & 0,1776 & 0,9671 \\
\hline B38 & 0,004999 & 0,9768 & B35 & 0,00075 & 0,341 \\
\hline B40 & 0,02878 & 0,957 & B36 & 0,002912 & 0,9707 \\
\hline B47 & 0,009979 & 0,9439 & B38 & 0,05117 & 0,9511 \\
\hline & & & B40 & 0,01196 & 0,9355 \\
\hline & & & B41 & 0,05391 & 0,9898 \\
\hline & & & B47 & 0,009411 & 0,9336 \\
\hline
\end{tabular}

\begin{tabular}{|l|l|l|l|l|l|}
\hline Quest. A & & Quest. A & & Quest. A & \\
\hline Sit1 & & Sit2 & & Sit3 & \\
\hline Participante & AUC & Participante & AUC & Participante & AUC \\
\hline A4 & 0,648 & A4 & 0,648 & A4 & 0,3551 \\
\hline A6 & 0,4653 & A5 & 0,873 & A5 & 0,1667 \\
\hline A8 & 0,3367 & A6 & 0,2827 & A6 & 0,2023 \\
\hline A9 & 0,2304 & A8 & 0,3423 & A8 & 0,1978 \\
\hline A13 & 0,8317 & A9 & 0,1561 & A9 & 0,1666 \\
\hline A14 & 0,3605 & A13 & 0,8317 & A13 & 0,8317 \\
\hline A17 & 0,3153 & A14 & 0,2812 & A14 & 0,3375 \\
\hline A21 & 0,2468 & A17 & 0,6278 & A17 & 0,13 \\
\hline A22 & 0,8813 & A21 & 0,2882 & A21 & 0,0533 \\
\hline A27 & 0,8362 & A22 & 0,7528 & A22 & 0,4502 \\
\hline A33 & 0,2841 & A24 & 0,9563 & A24 & 0,8341 \\
\hline
\end{tabular}




\begin{tabular}{|l|l|l|l|l|l|}
\hline A34 & 0,2721 & A27 & 0,7528 & A27 & 0,7605 \\
\hline A38 & 0,364 & A29 & 0,5143 & A29 & 0,6147 \\
\hline A39 & 0,4787 & A33 & 0,3136 & A33 & 0,2065 \\
\hline A42 & 0,6335 & A34 & 0,2721 & A34 & 0,2721 \\
\hline & & A38 & 0,364 & A38 & 0,165 \\
\hline & & A39 & 0,4557 & A39 & 0 \\
\hline & & A41 & 0,5837 & A41 & 0,6391 \\
\hline & & A42 & 0,5716 & A42 & 0,0176 \\
\hline & & A44 & 0,7605 & A44 & 0,6511 \\
\hline & & A45 & 0,3778 & & \\
\hline
\end{tabular}

\begin{tabular}{|l|l|}
\hline Quest. A & \\
\hline Sit4 & \\
\hline Participante & AUC \\
\hline A4 & 0,3551 \\
\hline A5 & 0,1667 \\
\hline A6 & 0,2668 \\
\hline A8 & 0,1983 \\
\hline A9 & 0,2304 \\
\hline A13 & 0,8317 \\
\hline A14 & 0,2326 \\
\hline A17 & 0,3605 \\
\hline A20 & 0,2021 \\
\hline A21 & 0,0533 \\
\hline A22 & 0,6063 \\
\hline A24 & 0,8043 \\
\hline A27 & 0,726 \\
\hline A29 & 0,5143 \\
\hline A30 & 0,723 \\
\hline A33 & 0,3072 \\
\hline A34 & 0,2721 \\
\hline A39 & 0,4158 \\
\hline A42 & 0,5661 \\
\hline A43 & 0,0128 \\
\hline A44 & 0,3564 \\
\hline & \\
\hline & \\
\hline
\end{tabular}

\begin{tabular}{|l|l|l|l|l|l|}
\hline Quest. B & & Quest. B & & Quest. B & \\
\hline SIt1 & & Sit2 & & Sit3 & \\
\hline Participante & AUC & Participante & AUC & Participante & AUC \\
\hline B1 & 0,2933 & B1 & 0,2311 & B1 & 0,0251 \\
\hline B2 & 0,5855 & B2 & 0,5855 & B2 & 0,5855 \\
\hline B4 & 0,4035 & B4 & 0,4037 & B4 & 0,2479 \\
\hline
\end{tabular}




\begin{tabular}{|l|l|l|l|l|l|}
\hline B5 & 0,6897 & B5 & 0,6897 & B5 & 0,6897 \\
\hline B6 & 0,2229 & B6 & 0,3729 & B6 & 0,3067 \\
\hline B8 & 0,3631 & B8 & 0,2198 & B8 & 0,1942 \\
\hline B10 & 0,255 & B10 & 0,255 & B10 & 0,1317 \\
\hline B12 & 0,6743 & B11 & 0,6023 & B12 & 0,3868 \\
\hline B13 & 0,5073 & B13 & 0,6021 & B13 & 0,507 \\
\hline B14 & 0,2094 & B14 & 0,1335 & B14 & 0,0355 \\
\hline B23 & 0,008 & B19 & 0,548 & B15 & 0,5125 \\
\hline B24 & 0,4933 & B23 & 0,0084 & B23 & 0,0079 \\
\hline B25 & 0,1448 & B24 & 0,1333 & B24 & 0,25 \\
\hline B26 & 0,2001 & B25 & 0,2001 & B25 & 0,1333 \\
\hline B27 & 0,1873 & B26 & 0,2813 & B26 & 0,0857 \\
\hline B28 & 0,498 & B27 & 0,2792 & B27 & 0,1108 \\
\hline B29 & 0,3905 & B28 & 0,398 & B28 & 0,3677 \\
\hline B31 & 0,0712 & B29 & 0,0566 & B29 & 0,3153 \\
\hline B33 & 0,5186 & B31 & 0,998 & B31 & 0,0304 \\
\hline B34 & 0,1218 & B33 & 0,8546 & B33 & 0,3084 \\
\hline B35 & 0,4276 & B34 & 0,1218 & B34 & 0,07 \\
\hline B36 & 0,6063 & B35 & 0,4276 & B35 & 0,8079 \\
\hline B38 & 0,6813 & B36 & 0,6063 & B36 & 0,6063 \\
\hline & & B38 & 0,3874 & B38 & 0,6813 \\
\hline & & B41 & 0,2063 & B40 & 0,5327 \\
\hline & & & & B47 & 0,4245 \\
\hline
\end{tabular}

\begin{tabular}{|l|l|}
\hline Quest. B & \\
\hline Sit4 & \\
\hline Participante & AUC \\
\hline B1 & 0,0251 \\
\hline B2 & 0,4342 \\
\hline B4 & 0,2334 \\
\hline B5 & 0,4245 \\
\hline B6 & 0,3294 \\
\hline B8 & 0,0587 \\
\hline B10 & 0,1219 \\
\hline B11 & 0,2418 \\
\hline B12 & 0,3524 \\
\hline B13 & 0,5112 \\
\hline B14 & 0,0345 \\
\hline B15 & 0,5125 \\
\hline B19 & 0,4747 \\
\hline B23 & 0,0091 \\
\hline B24 & 0,3232 \\
\hline
\end{tabular}




\begin{tabular}{|l|l|}
\hline B25 & 0,1333 \\
\hline B26 & 0,0786 \\
\hline B27 & 0,1458 \\
\hline B28 & 0,1477 \\
\hline B29 & 0,323 \\
\hline B31 & 0,1851 \\
\hline B33 & 0,6613 \\
\hline B34 & 0,065 \\
\hline B35 & 0,8079 \\
\hline B36 & 0,6063 \\
\hline B38 & 0,3532 \\
\hline B40 & 0,548 \\
\hline B41 & 0,1361 \\
\hline B47 & 0,5313 \\
\hline
\end{tabular}


Apêndice 7

Dados individuais do Estudo 2 - questionários B1 e B2

\begin{tabular}{|c|c|c|c|c|c|}
\hline HIPÉRB. & & & HIPÉRB. & & \\
\hline Sit1 & & & Sit2 & & \\
\hline Participante & $\mathbf{k}$ & $\mathbf{R 2}$ & Participante & $\mathbf{k}$ & $\mathbf{R 2}$ \\
\hline$A 3 \exp 2$ & 0,004051 & 0,7463 & A1exp2 & 0,002309 & 0,989 \\
\hline $\mathrm{A} 4 \exp 2$ & 0,03447 & 0,9958 & A2exp2 & 0,002104 & 0,9738 \\
\hline A6exp2 & 0,01138 & 0,9163 & $\mathrm{~A} 3 \exp 2$ & 0,009941 & 0,8138 \\
\hline A9exp2 & 0,001389 & 0,9034 & $\mathrm{~A} 4 \exp 2$ & 0,3714 & 0,9917 \\
\hline A10exp2 & 0,006011 & 0,9414 & A6exp2 & 0,003077 & 0,8937 \\
\hline A11exp2 & 0,001585 & 0,6021 & A9exp2 & 0,0000247 & 0,8492 \\
\hline A13exp2 & 0,01457 & 0,9339 & A10exp2 & 0,004918 & 0,9426 \\
\hline A14exp2 & 0,0009817 & 0,1665 & A11exp2 & 0,002294 & 0,976 \\
\hline A15exp2 & 0,00194 & 0,8377 & A12exp2 & 0,001124 & 0,9925 \\
\hline A18exp2 & 0,003613 & 0,5759 & A15exp2 & 0,0005586 & 0,9618 \\
\hline A20exp2 & 0,001578 & 0,9145 & A17exp2 & 0,000215 & 0,99 \\
\hline A22exp2 & 0,008632 & 0,771 & A19exp2 & 0,0008712 & 0,9101 \\
\hline A23exp2 & 0,002104 & 0,9738 & A20exp2 & 0,004166 & 0,9045 \\
\hline A24exp2 & $5,677 \mathrm{E}-05$ & 0,002998 & A22exp2 & 0,00264 & 0,6857 \\
\hline A25exp2 & 0,0274 & 0,9097 & A23exp2 & 0,0004303 & 0,9884 \\
\hline A28exp2 & 0,004936 & 0,992 & A24exp2 & 0,000215 & 0,99 \\
\hline A30exp2 & 0,0189 & 0,9806 & A25exp2 & 2,039 & 0,7854 \\
\hline A31exp2 & 0,0008654 & 0,728 & A28exp2 & 0,004727 & 0,9841 \\
\hline A33exp2 & 0,006253 & 0,959 & A29exp2 & 0,002163 & 0,9677 \\
\hline A34exp2 & 0,02239 & 0,9935 & A30exp2 & 0,009923 & 0,7713 \\
\hline A $35 \exp 2$ & 0,008312 & 0,9852 & A31exp2 & 0,002163 & 0,9677 \\
\hline B $1 \exp 2$ & 0,00479 & 0,9289 & A33exp2 & 0,07695 & 0,9389 \\
\hline B2exp2 & 0,114 & 0,9653 & A35exp2 & 0,006571 & 0,9512 \\
\hline B4exp2 & 0,002163 & 0,9677 & B1exp2 & 0,001056 & 0,9762 \\
\hline B7exp2 & 0,001729 & 0,9323 & B2exp2 & 20,73 & 0,9873 \\
\hline B12exp2 & 0,002108 & 0,9938 & B4exp2 & 0,002163 & 0,9677 \\
\hline B13exp2 & 0,00648 & 0,9565 & B5exp2 & 0,004392 & 0,9445 \\
\hline B14exp2 & 0,0009394 & 0,9573 & B7exp2 & 0,0004151 & 0,9659 \\
\hline B15exp2 & 0,004719 & 0,9333 & B9exp2 & 0,000109 & 0,5367 \\
\hline B16exp2 & 0,001753 & 0,9582 & B12exp2 & 0,002105 & 0,9942 \\
\hline B17exp2 & 0,01548 & 0,9877 & B13exp2 & 0,00111 & 0,9801 \\
\hline B18exp2 & 0,01691 & 0,9512 & B14exp2 & 0,0003009 & 0,9699 \\
\hline B20exp2 & 0,004698 & 0,965 & B15exp2 & 0,001007 & 0,9793 \\
\hline B21exp2 & 0,0009139 & 0,8347 & B16exp2 & $2,102 \mathrm{E}-05$ & 0,8408 \\
\hline B22exp2 & 0,02755 & 0,8828 & B17exp2 & 0,001856 & 0,964 \\
\hline B24exp2 & 0,05101 & 0,7414 & B18exp2 & 0,002041 & 0,9969 \\
\hline B26exp2 & 0,04465 & 0,9895 & B19exp2 & 0,01381 & 0,999 \\
\hline
\end{tabular}




\begin{tabular}{|l|l|l|l|l|l|}
\hline B30exp2 & 0,01055 & 0,8384 & B20exp2 & 0,0004188 & 0,9999 \\
\hline B31exp2 & 0,007473 & 0,9844 & B21exp2 & 0,0004188 & 0,9999 \\
\hline & & & B22exp2 & 0,03116 & 0,8955 \\
\hline & & & B26exp2 & 0,00132 & 0,8978 \\
\hline & & & B27exp2 & 0,0001992 & 0,8352 \\
\hline & & & B30exp2 & 0,0003895 & 0,9325 \\
\hline & & & B31exp2 & 0,001007 & 0,9793 \\
\hline
\end{tabular}

\begin{tabular}{|c|c|c|c|c|c|}
\hline HIPÉRB. & & & HIPÉRB. & & \\
\hline Sit3 & & & Sit4 & & \\
\hline Participante & $\mathbf{k}$ & $\mathbf{R 2}$ & Participante & $\mathbf{k}$ & $\mathbf{R 2}$ \\
\hline A2exp2 & 0,01055 & 0,8384 & A1exp2 & 0,002309 & 0,989 \\
\hline A3exp2 & 0,004649 & 0,735 & A2exp2 & 0,001386 & 0,8303 \\
\hline $\mathrm{A} 4 \exp 2$ & 0,3188 & 0,9893 & $\mathrm{~A} 3 \exp 2$ & 0,003683 & 0,4582 \\
\hline A6exp2 & 0,00507 & 0,8781 & A6exp2 & 0,00281 & 0,8766 \\
\hline A9exp2 & 0,001389 & 0,9034 & A9exp2 & 0,002119 & 0,9906 \\
\hline A10exp2 & 0,004979 & 0,9219 & A10exp2 & 0,002787 & 0,8231 \\
\hline A11exp2 & 0,004271 & 0,9216 & A11exp2 & 0,00132 & 0,8978 \\
\hline A12exp2 & 0,00109 & 0,3783 & A12exp2 & 0,0006572 & 0,9666 \\
\hline A15exp2 & 0,002327 & 0,8644 & A14exp2 & 2,071 & 0,5122 \\
\hline A17exp2 & 0,002104 & 0,9738 & A15exp2 & 0,0009664 & 0,9707 \\
\hline A20exp2 & 0,001721 & 0,9734 & A17exp2 & 0,000215 & 0,99 \\
\hline A22exp2 & 0,003147 & 0,7105 & A19exp2 & 0,0008712 & 0,9101 \\
\hline A23exp2 & 0,001389 & 0,9034 & A20exp2 & 0,002239 & 0,7986 \\
\hline A25exp2 & 0,02776 & 0,6306 & A22exp2 & 0,00264 & 0,6857 \\
\hline A28exp2 & 0,004936 & 0,992 & A23exp2 & 0,0004303 & 0,9884 \\
\hline A29exp2 & 0,001389 & 0,9034 & A24exp2 & 0,000215 & 0,99 \\
\hline A $30 \exp 2$ & 0,01137 & 0,9945 & A25exp2 & 0,03462 & 0,7436 \\
\hline A31exp2 & 0,0008654 & 0,728 & A28exp2 & 0,004936 & 0,992 \\
\hline A33exp2 & 0,009808 & 0,8874 & A29exp2 & 0,002163 & 0,9677 \\
\hline A34exp2 & 0,02239 & 0,9935 & A30exp2 & 0,001839 & 0,9624 \\
\hline A $35 \exp 2$ & 0,008312 & 0,9852 & A31exp2 & 0,002104 & 0,9738 \\
\hline B1exp2 & 0,00479 & 0,9289 & A33exp2 & 0,0552 & 0,9202 \\
\hline B2exp2 & 0,01383 & 0,9326 & A35exp2 & 0,006571 & 0,9512 \\
\hline B3exp2 & 0,001361 & 0,6005 & B1exp2 & 0,001056 & 0,9762 \\
\hline B4exp2 & 0,004236 & 0,9871 & B2exp2 & 0,0996 & 0,9644 \\
\hline B7exp2 & 0,001721 & 0,9734 & B3exp2 & 0,002132 & 0,6266 \\
\hline B9exp2 & 0,002239 & 0,7986 & B4exp2 & 0,002104 & 0,9738 \\
\hline B10exp2 & 0,02381 & 0,9937 & B5exp2 & 0,004392 & 0,9445 \\
\hline B12exp2 & 0,002108 & 0,9938 & B $7 \exp 2$ & 0,0008082 & 0,9621 \\
\hline B13exp2 & 0,00648 & 0,9565 & B9exp2 & 0,0001251 & 0,8557 \\
\hline B14exp2 & 0,001007 & 0,9793 & B10exp2 & 0,02381 & 0,9937 \\
\hline
\end{tabular}




\begin{tabular}{|l|l|l|l|l|l|}
\hline B15exp2 & 0,004719 & 0,9333 & B12exp2 & 0,002105 & 0,9942 \\
\hline B16exp2 & 0,001649 & 0,7442 & B13exp2 & 0,00111 & 0,9801 \\
\hline B17exp2 & 0,0142 & 0,871 & B14exp2 & 0,000215 & 0,99 \\
\hline B18exp2 & 0,01619 & 0,9528 & B15exp2 & 0,001007 & 0,9793 \\
\hline B19exp2 & 0,004606 & 0,8703 & B16exp2 & $3,644 \mathrm{E}-05$ & 0,7922 \\
\hline B20exp2 & 0,005573 & 0,9726 & B17exp2 & 0,000473 & 0,6469 \\
\hline B21exp2 & 0,001743 & 0,9806 & B18exp2 & 0,002046 & 0,9985 \\
\hline B22exp2 & 0,007307 & 0,8683 & B19exp2 & 0,01381 & 0,999 \\
\hline B23exp2 & 0,002104 & 0,9738 & B20exp2 & 0,0004188 & 0,9999 \\
\hline B24exp2 & 0,009433 & 0,8949 & B21exp2 & 0,0004188 & 0,9999 \\
\hline B26exp2 & 0,01269 & 0,8682 & B22exp2 & 0,004837 & 0,9446 \\
\hline B27exp2 & 0,01564 & 0,9831 & B23exp2 & 0,001007 & 0,9793 \\
\hline B29exp2 & 0,003147 & 0,7105 & B26exp2 & 0,004184 & 0,9221 \\
\hline B30exp2 & 0,004201 & 0,9134 & B27exp2 & 0,002106 & 0,9998 \\
\hline B31exp2 & 0,01497 & 0,9492 & B29exp2 & 0,0001042 & 0,5344 \\
\hline B32exp2 & 0,002104 & 0,9738 & B30exp2 & 0,0003033 & 0,8769 \\
\hline & & & B31exp2 & 0,0008712 & 0,9101 \\
\hline
\end{tabular}

\begin{tabular}{|c|c|c|c|c|c|}
\hline HIPÉRB. & & & HIPÉRB. & & \\
\hline Sit5 & & & Sit6 & & \\
\hline Participante & $\mathbf{k}$ & $\mathbf{R 2}$ & Participante & $\mathbf{k}$ & $\mathbf{R 2}$ \\
\hline A1exp2 & 0,007049 & 0,9298 & A1exp2 & 0,0002603 & 0,976 \\
\hline A2exp2 & 0,004842 & 0,9324 & A2exp2 & 0,003866 & 0,8992 \\
\hline $\mathrm{A} 3 \exp 2$ & 37,44 & 0,9533 & $\mathrm{~A} 3 \exp 2$ & 0,007399 & 0,5623 \\
\hline $\mathrm{A} 4 \exp 2$ & 0,04465 & 0,995 & A4exp2 & 0,1608 & 0,9474 \\
\hline A6exp2 & 0,07025 & 0,9115 & A6exp2 & 0,05618 & 0,9837 \\
\hline A9exp2 & 0,001145 & 0,8334 & A9exp2 & 0,000257 & 0,9175 \\
\hline A10exp2 & 0,003683 & 0,953 & A10exp2 & 0,0001248 & 0,9908 \\
\hline A11exp2 & 0,01054 & 0,9633 & A11exp2 & 0,001911 & 0,7914 \\
\hline A12exp2 & 0,0001344 & 0,7756 & A13exp2 & 0,001876 & 0,8589 \\
\hline A13exp2 & 0,00165 & 0,9653 & A17exp2 & 0,0001056 & 0,9215 \\
\hline A17exp2 & 0,0001106 & 0,9651 & A20exp2 & 0,00118 & 0,9045 \\
\hline A18exp2 & 0,002252 & 0,5759 & A22exp2 & 0,001481 & 0,6249 \\
\hline A20exp2 & 0,002395 & 0,7442 & A23exp2 & 0,001194 & 0,8197 \\
\hline A22exp2 & 0,00123 & 0,1513 & A24exp2 & $3,959 \mathrm{E}-05$ & 0,9659 \\
\hline A23exp2 & 0,002753 & 0,5695 & A25exp2 & 3,516 & 0,7854 \\
\hline A24exp2 & 9,044E-07 & 0,9913 & A28exp2 & 0,0004424 & 0,992 \\
\hline A25exp2 & 0,01993 & 0,5741 & A29exp2 & 0,0001979 & 0,07758 \\
\hline A28exp2 & 0,0004424 & 0,992 & A30exp2 & 0,00234 & 0,948 \\
\hline A29exp2 & 0,0004361 & 0,07939 & A31exp2 & 0,0005026 & 0,8671 \\
\hline A30exp2 & 0,07138 & 0,9976 & A33exp2 & 0,4216 & 0,9262 \\
\hline A31exp2 & 0,0005042 & 0,8921 & A35exp2 & 0,001569 & 0,9512 \\
\hline
\end{tabular}




\begin{tabular}{|l|l|l|l|l|l|}
\hline A33exp2 & 0,4216 & 0,9262 & B1exp2 & 0,03779 & 0,9368 \\
\hline A34exp2 & 0,002376 & 0,9935 & B2exp2 & 0,2182 & 0,9263 \\
\hline A35exp2 & 0,001147 & 0,9852 & B3exp2 & 0,0002541 & 0,8632 \\
\hline B1exp2 & 0,03779 & 0,9368 & B4exp2 & 0,001879 & 0,7915 \\
\hline B2exp2 & 1,253 & 0,8898 & B5exp2 & 0,0004933 & 0,7927 \\
\hline B4exp2 & 0,01529 & 0,9627 & B7exp2 & 0,0008574 & 0,9129 \\
\hline B7exp2 & 0,003527 & 0,6839 & B9exp2 & 0,0007906 & 0,8244 \\
\hline B9exp2 & 0,001361 & 0,6005 & B12exp2 & 0,002105 & 0,9942 \\
\hline B12exp2 & 0,002108 & 0,9938 & B13exp2 & 0,001028 & 0,9899 \\
\hline B13exp2 & 0,01611 & 0,9967 & B14exp2 & 0,0003009 & 0,9699 \\
\hline B14exp2 & 0,0009394 & 0,9573 & B15exp2 & 0,001007 & 0,9793 \\
\hline B15exp2 & 0,004719 & 0,9333 & B16exp2 & 0,00002 & 0,8476 \\
\hline B16exp2 & 0,0008735 & 0,854 & B17exp2 & 0,005461 & 0,6781 \\
\hline B17exp2 & 0,8813 & 0,8791 & B18exp2 & 0,008353 & 0,9687 \\
\hline B18exp2 & 0,224 & 0,9987 & B21exp2 & 0,0003974 & 0,9734 \\
\hline B19exp2 & 0,01832 & 0,963 & B24exp2 & 0,009785 & 0,862 \\
\hline B21exp2 & 0,002107 & 0,9736 & B26exp2 & 0,01889 & 0,803 \\
\hline B22exp2 & 2,438 & 0,9205 & B30exp2 & 0,001856 & 0,9077 \\
\hline B24exp2 & 0,02593 & 0,8321 & B31exp2 & 0,002135 & 0,9934 \\
\hline B26exp2 & 0,04863 & 0,9697 & & & \\
\hline B30exp2 & 0,02172 & 0,9959 & & & \\
\hline B31exp2 & 0,007868 & 0,9607 & & & \\
\hline B32exp2 & 0,002104 & 0,9738 & & & \\
\hline B33exp2 & 0,003295 & 0,8334 & & & \\
\hline
\end{tabular}

\begin{tabular}{|c|c|c|c|c|c|}
\hline HIPÉRB. & & & HIPÉRB. & & \\
\hline Sit7 & & & Sit8 & & \\
\hline Participante & $\mathbf{k}$ & $\mathbf{R 2}$ & Participante & $\mathbf{k}$ & $\mathbf{R 2}$ \\
\hline A1exp2 & 0,005427 & 0,817 & A1exp2 & 0,002174 & 0,9808 \\
\hline A2exp2 & 0,1051 & 0,9575 & A2exp2 & 0,03375 & 0,8663 \\
\hline $\mathrm{A} 3 \exp 2$ & 0,007108 & 0,7944 & $\mathrm{~A} 3 \exp 2$ & 0,001253 & 0,6043 \\
\hline $\mathrm{A} 4 \exp 2$ & 0,1902 & 0,9769 & $\mathrm{~A} 4 \exp 2$ & 0,06782 & 0,7947 \\
\hline A6exp2 & 0,05272 & 0,9857 & $\mathrm{~A} 5 \exp 2$ & 0,0008693 & 0,3269 \\
\hline A9exp2 & 0,01457 & 0,9339 & A6exp2 & 0,01704 & 0,985 \\
\hline A10exp2 & 0,01389 & 0,953 & A9exp2 & 0,003966 & 0,5695 \\
\hline A11exp2 & 0,06053 & 0,9743 & A10exp2 & 0,00187 & 0,9908 \\
\hline A13exp2 & 0,007328 & 0,9147 & A11exp2 & 0,00192 & 0,9617 \\
\hline A15exp2 & 0,003247 & 0,8599 & A12exp2 & 0,0003979 & 0,7044 \\
\hline A17exp2 & 0,002104 & 0,9738 & A13exp2 & 0,002163 & 0,9677 \\
\hline A18exp2 & 0,003613 & 0,5759 & A15exp2 & 0,002085 & 0,9796 \\
\hline A20exp2 & 0,002284 & 0,5725 & A17exp2 & 0,0004303 & 0,9884 \\
\hline A22exp2 & 0,002155 & 0,3244 & A19exp2 & $-0,000387$ & 0,8154 \\
\hline
\end{tabular}




\begin{tabular}{|c|c|c|c|c|c|}
\hline A23exp2 & 0,01943 & 0,7203 & A20exp2 & 0,003253 & 0,5872 \\
\hline A24exp2 & 0,0004287 & 0,9929 & A22exp2 & 0,002745 & 0,6249 \\
\hline $\mathrm{A} 25 \exp 2$ & 2,039 & 0,7854 & A23exp2 & 0,002199 & 0,7802 \\
\hline A28exp2 & 0,004936 & 0,992 & A24exp2 & 0,0004617 & 0,9387 \\
\hline A30exp2 & 0,3519 & 0,9406 & A25exp2 & 2,039 & 0,7854 \\
\hline A31exp2 & 0,00219 & 0,9174 & A28exp2 & 0,004936 & 0,992 \\
\hline A33exp2 & 0,5327 & 0,8839 & A30exp2 & 0,002008 & 0,9817 \\
\hline A34exp2 & 0,02239 & 0,9935 & A31exp2 & 0,00208 & 0,8921 \\
\hline A35exp2 & 0,008312 & 0,9852 & A33exp2 & 0,6564 & 0,9262 \\
\hline B1exp2 & 0,03779 & 0,9368 & A35exp2 & 0,006571 & 0,9512 \\
\hline B2exp2 & 0,05273 & 0,9289 & B1exp2 & 1,073 & 0,9368 \\
\hline B3exp2 & 0,02313 & 0,9155 & B2exp2 & 1,238 & 0,9476 \\
\hline B4exp2 & 0,008768 & 0,8678 & B3exp2 & 0,9774 & 0,8385 \\
\hline B5exp2 & 0,03391 & 0,8256 & B4exp2 & 0,931 & 0,847 \\
\hline B7exp2 & 0,003721 & 0,5187 & B5exp2 & 0,935 & 0,8349 \\
\hline B9exp2 & 0,003689 & 0,6641 & B7exp2 & 0,9744 & 0,8834 \\
\hline B12exp2 & 0,002108 & 0,9938 & B9exp2 & 0,9575 & 0,6005 \\
\hline B13exp2 & 0,009952 & 0,9771 & B12exp2 & 1,015 & 0,9942 \\
\hline B14exp2 & 0,0009394 & 0,9573 & B13exp2 & 0,9966 & 0,9903 \\
\hline B15exp2 & 0,004719 & 0,9333 & B14exp2 & 1,006 & 0,9699 \\
\hline B16exp2 & 0,0007142 & 0,7843 & B15exp2 & 1,015 & 0,9793 \\
\hline B17exp2 & 0,1603 & 0,9756 & B16exp2 & 0,9989 & 0,7769 \\
\hline B18exp2 & 0,2238 & 0,9986 & B17exp2 & 0,8423 & 0,7893 \\
\hline B19exp2 & 0,02585 & 0,9694 & B18exp2 & 0,9941 & 0,988 \\
\hline B21exp2 & 0,002107 & 0,9736 & B19exp2 & 0,987 & 0,9831 \\
\hline B22exp2 & 2,344 & 0,8827 & B21exp2 & 0,9964 & 0,9815 \\
\hline B23exp2 & 0,0008323 & 0,5778 & B22exp2 & 0,698 & 0,5296 \\
\hline B24exp2 & 0,02917 & 0,9657 & B23exp2 & 0,6422 & 0,5778 \\
\hline B26exp2 & 0,02267 & 0,9937 & B26exp2 & 0,9214 & 0,7105 \\
\hline B27exp2 & 0,06903 & 0,9584 & B27exp2 & 0,9753 & 0,9862 \\
\hline B28exp2 & 0,003552 & 0,4415 & B28exp2 & 0,9669 & 0,6641 \\
\hline B29exp2 & 0,001765 & 0,6184 & B29exp2 & 0,8246 & 0,9167 \\
\hline B30exp2 & 0,04139 & 0,9775 & B30exp2 & 0,9682 & 0,9048 \\
\hline B31exp2 & 0,02336 & 0,9378 & B31exp2 & 0,9976 & 0,9659 \\
\hline B32exp2 & 0,002239 & 0,7986 & B33exp2 & 1,719 & 0,6252 \\
\hline B33exp2 & 0,005031 & 0,451 & & & \\
\hline
\end{tabular}

\begin{tabular}{|l|l|l|l|l|l|}
\hline EXPON. & \multicolumn{2}{|l|}{} & EXPON. & & \\
\hline Sit5 & \multicolumn{3}{|l|}{} & Sit6 & \multicolumn{2}{|l|}{} \\
\hline Participante & k & R2 & Participante & k & R2 \\
\hline A1exp2 & 0,01767 & 0,9205 & A1exp2 & 0,006795 & 0,9905 \\
\hline A2exp2 & 0,01196 & 0,9355 & A2exp2 & 0,01535 & 0,9163 \\
\hline
\end{tabular}




\begin{tabular}{|c|c|c|c|c|c|}
\hline $\mathrm{A} 3 \exp 2$ & 0,7397 & 0,9858 & $\mathrm{~A} 3 \exp 2$ & 0,471 & 0,9 \\
\hline $\mathrm{A} 4 \exp 2$ & 0,1589 & 0,986 & $\mathrm{~A} 4 \exp 2$ & 0,3114 & 0,9375 \\
\hline A6exp2 & 0,3189 & 0,9223 & A6exp2 & 0,2007 & 0,9496 \\
\hline A9exp2 & 0,01492 & 0,9275 & A9exp2 & 0,006316 & 0,9623 \\
\hline A10exp2 & 0,02143 & 0,9618 & A10exp2 & 0,003132 & 0,9899 \\
\hline A11exp2 & 0,0387 & 0,9817 & A11exp2 & 0,03268 & 0,97 \\
\hline A12exp2 & 0,00528 & 0,9332 & A13exp2 & 0,02519 & 0,9398 \\
\hline A13exp2 & 0,01207 & 0,9815 & A17exp2 & 0,00606 & 0,9595 \\
\hline A17exp2 & 0,0007393 & 0,9665 & A20exp2 & 0,01196 & 0,9355 \\
\hline A18exp2 & 0,05055 & 0,9872 & A22exp2 & 0,04826 & 0,9645 \\
\hline A20exp2 & 0,0387 & 0,9817 & A23exp2 & 0,02413 & 0,9255 \\
\hline A22exp2 & 1,118 & 0,9987 & A24exp2 & 0,001615 & 0,9677 \\
\hline A23exp2 & 0,4259 & 0,8617 & $\mathrm{~A} 25 \exp 2$ & 0,8457 & 0,9755 \\
\hline A24exp2 & 1,44E-06 & 0,9914 & A28exp2 & 0,003443 & 0,997 \\
\hline $\mathrm{A} 25 \exp 2$ & 0,5272 & 0,9602 & A29exp2 & 0,19 & 0,2104 \\
\hline A28exp2 & 0,003443 & 0,997 & A30exp2 & 0,01808 & 0,9663 \\
\hline A29exp2 & 0,1523 & 0,2609 & A31exp2 & 0,01934 & 0,8907 \\
\hline A30exp2 & 0,2588 & 0,9941 & A33exp2 & 0,4329 & 0,9854 \\
\hline A31exp2 & 0,01745 & 0,9376 & A35exp2 & 0,007289 & 0,9339 \\
\hline A $33 \exp 2$ & 0,4329 & 0,9854 & B1exp2 & 0,0438 & 0,9916 \\
\hline A34exp2 & 0,02165 & 0,9951 & B2exp2 & 0,3198 & 0,9086 \\
\hline A 35exp2 & 0,01116 & 0,9764 & B3exp2 & 0,00528 & 0,9332 \\
\hline B1exp2 & 0,0438 & 0,9916 & $\mathrm{~B} 4 \exp 2$ & 0,02584 & 0,9136 \\
\hline B2exp2 & 0,4958 & 0,8652 & B5exp2 & 0,01206 & 0,9513 \\
\hline B4exp2 & 0,01854 & 0,9773 & B7exp2 & $6,99 \mathrm{E}-07$ & 0,9513 \\
\hline B7exp2 & 0,04343 & 0,9642 & B9exp2 & $7,46 \mathrm{E}-07$ & 0,8722 \\
\hline B9exp2 & 0,02349 & 0,8414 & B12exp2 & 0,002455 & 0,9961 \\
\hline B12exp2 & 0,002443 & 0,9957 & B13exp2 & 0,003515 & 0,9975 \\
\hline B13exp2 & 0,0161 & 0,9949 & B14exp2 & $2,20 \mathrm{E}-07$ & 0,9794 \\
\hline B14exp2 & 2,33E-07 & 0,9843 & B15exp2 & 1,24E-06 & 0,9915 \\
\hline B15exp2 & 0,001423 & 0,9832 & B16exp2 & 0,01235 & 0,976 \\
\hline B16exp2 & 0,01501 & 0,8948 & B17exp2 & 0,05011 & 0,939 \\
\hline B17exp2 & 0,5044 & 0,8806 & B18exp2 & 0,006097 & 0,9891 \\
\hline B18exp2 & 0,1175 & 0,9931 & B21exp2 & 0,001478 & 0,9746 \\
\hline B19exp2 & 0,02166 & 0,971 & B24exp2 & 0,1795 & 0,9476 \\
\hline B21exp2 & 0,004999 & 0,9768 & B26exp2 & 0,3498 & 0,9721 \\
\hline B22exp2 & 0,6449 & 0,9413 & B30exp2 & 0,4467 & 0,9056 \\
\hline B24exp2 & 0,02212 & 0,8554 & B31exp2 & 0,33 & 0,9938 \\
\hline B26exp2 & 0,04064 & 0,9889 & & & \\
\hline B30exp2 & 0,01998 & 0,9924 & & & \\
\hline B31exp2 & 0,009331 & 0,9656 & & & \\
\hline B32exp2 & 0,00194 & 0,9795 & & & \\
\hline B33exp2 & 0,01492 & 0,9275 & & & \\
\hline
\end{tabular}




\begin{tabular}{|c|c|c|c|c|c|}
\hline EXPON. & & & EXPON. & & \\
\hline Sit7 & & & Sit8 & & \\
\hline Participante & $\mathbf{k}$ & $\mathbf{R 2}$ & Participante & $\mathbf{k}$ & $\mathbf{R 2}$ \\
\hline A1exp2 & 0,02582 & 0,8809 & A1exp2 & 0,00581 & 0,9909 \\
\hline A2exp2 & 0,0693 & 0,9747 & A2exp2 & 0,05206 & 0,9862 \\
\hline A3exp2 & 0,03417 & 0,9157 & A3exp2 & 0,02933 & 0,9235 \\
\hline $\mathrm{A} 4 \exp 2$ & 0,2199 & 0,946 & $\mathrm{~A} 4 \exp 2$ & 0,2429 & 0,9847 \\
\hline A6exp2 & 0,0313 & 0,982 & A5exp2 & 0,2113 & 0,9798 \\
\hline A9exp2 & 0,0121 & 0,9432 & A6exp2 & 0,01493 & 0,976 \\
\hline A10exp2 & 0,02143 & 0,9618 & A9exp2 & 0,4259 & 0,8617 \\
\hline A11exp2 & 0,03906 & 0,9904 & A10exp2 & 0,003132 & 0,9899 \\
\hline A13exp2 & 0,01968 & 0,9351 & A11exp2 & 0,002731 & 0,9589 \\
\hline A15exp2 & 0,02132 & 0,916 & A12exp2 & 0,02307 & 0,9711 \\
\hline A17exp2 & 0,00194 & 0,9795 & A13exp2 & 0,004176 & 0,9686 \\
\hline A18exp2 & 0,05055 & 0,9872 & A $15 \exp 2$ & 0,004204 & 0,9805 \\
\hline A20exp2 & 0,338 & 0,9247 & A17exp2 & 0,0003776 & 0,9891 \\
\hline A22exp2 & 0,2961 & 0,9572 & A19exp2 & 0,00528 & 0,9332 \\
\hline A23exp2 & 0,04761 & 0,8672 & A20exp2 & 0,3083 & 0,8754 \\
\hline A24exp2 & 0,0004779 & 0,9933 & A22exp2 & 0,04826 & 0,9645 \\
\hline A25exp2 & 0,8457 & 0,9755 & A23exp2 & 0,02249 & 0,9141 \\
\hline A28exp2 & 0,003443 & 0,997 & A24exp2 & 0,005464 & 0,9854 \\
\hline A $30 \exp 2$ & 0,2855 & 0,9028 & A25exp2 & 0,8457 & 0,9755 \\
\hline A31exp2 & 0,006347 & 0,9253 & A28exp2 & 0,003443 & 0,997 \\
\hline A33exp2 & 0,4567 & 0,9664 & A30exp2 & 0,004173 & 0,9825 \\
\hline A34exp2 & 0,02165 & 0,9951 & A31exp2 & 0,01745 & 0,9376 \\
\hline A35exp2 & 0,01116 & 0,9764 & A33exp2 & 0,4329 & 0,9854 \\
\hline B1exp2 & 0,0438 & 0,9916 & A35exp2 & 0,007289 & 0,9339 \\
\hline B2exp2 & 0,02558 & 0,9271 & B1exp2 & 0,0438 & 0,9916 \\
\hline B3exp2 & 0,03588 & 0,9888 & B2exp2 & 0,489 & 0,9328 \\
\hline B4exp2 & 0,02088 & 0,9454 & B3exp2 & 0,02413 & 0,9753 \\
\hline B5exp2 & 0,04204 & 0,8896 & B4exp2 & 0,0209 & 0,8713 \\
\hline B7exp2 & 0,2819 & 0,9286 & B5exp2 & 0,009406 & 0,9693 \\
\hline B9exp2 & 0,02349 & 0,8414 & B7exp2 & 0,01164 & 0,9894 \\
\hline B12exp2 & 0,002443 & 0,9957 & B9exp2 & 0,02349 & 0,8414 \\
\hline B13exp2 & 0,01622 & 0,9917 & B12exp2 & 0,002455 & 0,9961 \\
\hline B14exp2 & $2,33 \mathrm{E}-07$ & 0,9843 & B13exp2 & $1,245 \mathrm{E}-06$ & 0,9794 \\
\hline B15exp2 & 0,001423 & 0,9832 & B14exp2 & $2,20 \mathrm{E}-07$ & 0,9794 \\
\hline B16exp2 & 0,02085 & 0,9241 & B15exp2 & $1,24 \mathrm{E}-06$ & 0,9915 \\
\hline B17exp2 & 0,06438 & 0,9481 & B16exp2 & 0,01726 & 0,8414 \\
\hline B18exp2 & 0,1248 & 0,9902 & B17exp2 & 0,03077 & 0,9665 \\
\hline B19exp2 & 0,02708 & 0,9788 & B18exp2 & 0,008939 & 0,9982 \\
\hline
\end{tabular}




\begin{tabular}{|l|l|l|l|l|l|}
\hline B21exp2 & 0,004999 & 0,9768 & B19exp2 & 0,007063 & 0,9996 \\
\hline B22exp2 & 0,7231 & 0,9624 & B21exp2 & 0,003176 & 0,9935 \\
\hline B23exp2 & 0,02349 & 0,8414 & B22exp2 & 0,6059 & 0,94 \\
\hline B24exp2 & 0,0292 & 0,9893 & B23exp2 & 0,02349 & 0,8414 \\
\hline B26exp2 & 0,01859 & 0,9856 & B26exp2 & 0,03601 & 0,9695 \\
\hline B27exp2 & 0,03399 & 0,9534 & B27exp2 & $3,72 \mathrm{E}-06$ & 0,9878 \\
\hline B28exp2 & 0,08766 & 0,9694 & B28exp2 & 0,02349 & 0,8414 \\
\hline B29exp2 & 0,04115 & 0,9935 & B29exp2 & 0,007276 & 0,9543 \\
\hline B30exp2 & 0,0365 & 0,9886 & B30exp2 & 0,007171 & 0,9465 \\
\hline B31exp2 & 0,02856 & 0,9626 & B31exp2 & 0,001615 & 0,9677 \\
\hline B32exp2 & 0,01687 & 0,8548 & B33exp2 & 0,6432 & 0,9979 \\
\hline B33exp2 & 0,7054 & 0,9394 & & & \\
\hline
\end{tabular}

\begin{tabular}{|l|l|l|l|l|l|}
\hline Sit1 & & Sit2 & & Sit3 & \\
\hline Participante & AUC & Participante & AUC & Participante & AUC \\
\hline A3exp2 & 0,4851 & A1exp2 & 0,6838 & A2exp2 & 0,4335 \\
\hline A4exp2 & 0,191 & A2exp2 & 0,723 & A3exp2 & 0,4217 \\
\hline A6exp2 & 0,3422 & A3exp2 & 0,4295 & A4exp2 & 0,0549 \\
\hline A9exp2 & 0,7647 & A4exp2 & 0,0325 & A6exp2 & 0,4573 \\
\hline A10exp2 & 0,4999 & A6exp2 & 0,5788 & A9exp2 & 0,7647 \\
\hline A11exp2 & 0,637 & A9exp2 & 0,9911 & A10exp2 & 0,5207 \\
\hline A13exp2 & 0,3005 & A10exp2 & 0,5237 & A11exp2 & 0,5487 \\
\hline A14exp2 & 1,0023 & A11exp2 & 0,6626 & A12exp2 & 0,6743 \\
\hline A15exp2 & 0,649 & A12exp2 & 0,7997 & A15exp2 & 0,6137 \\
\hline A18exp2 & 0,5202 & A15exp2 & 0,8876 & A17exp2 & 0,723 \\
\hline A20exp2 & 0,7775 & A17exp2 & 0,9538 & A20exp2 & 0,7246 \\
\hline A22exp2 & 0,4502 & A19exp2 & 0,8738 & A22exp2 & 0,5577 \\
\hline A23exp2 & 0,723 & A20exp2 & 0,548 & A23exp2 & 0,7647 \\
\hline A24exp2 & 0,776 & A22exp2 & 0,5538 & A25exp2 & 0,326 \\
\hline A25exp2 & 0,24 & A23exp2 & 0,9154 & A28exp2 & 0,5438 \\
\hline A28exp2 & 0,5438 & A24exp2 & 0,9538 & A29exp2 & 0,7647 \\
\hline A30exp2 & 0,2899 & A25exp2 & 0,1774 & A30exp2 & 0,3645 \\
\hline A31exp2 & 0,7945 & A28exp2 & 0,5572 & A31exp2 & 0,7945 \\
\hline A33exp2 & 0,4773 & A29exp2 & 0,6855 & A33exp2 & 0,411 \\
\hline A34exp2 & 0,2861 & A30exp2 & 0,3685 & A34exp2 & 0,2861 \\
\hline A35exp2 & 0,4438 & A31exp2 & 0,6855 & A35exp2 & 0,4438 \\
\hline B1exp2 & 0,5313 & A33exp2 & 0,199 & B1exp2 & 0,5313 \\
\hline B2exp2 & 0,066 & A35exp2 & 0,4888 & B2exp2 & 0,2743 \\
\hline B4exp2 & 0,6855 & B1exp2 & 0,8042 & B3exp2 & 0,6897 \\
\hline B7exp2 & 0,7076 & B2exp2 & 0,0469 & B4exp2 & 0,5688 \\
\hline B12exp2 & 0,7114 & B4exp2 & 0,6855 & B7exp2 & 0,7246 \\
\hline B13exp2 & 0,4903 & B5exp2 & 0,5855 & B9exp2 & 0,648 \\
\hline
\end{tabular}




\begin{tabular}{|l|l|l|l|l|l|}
\hline B14exp2 & 0,856 & B7exp2 & 0,9047 & B10exp2 & 0,2749 \\
\hline B15exp2 & 0,573 & B9exp2 & 0,954 & B12exp2 & 0,7114 \\
\hline B16exp2 & 0,6941 & B12exp2 & 0,7112 & B13exp2 & 0,4903 \\
\hline B17exp2 & 0,2866 & B13exp2 & 0,7895 & B14exp2 & 0,8397 \\
\hline B18exp2 & 0,2762 & B14exp2 & 0,944 & B15exp2 & 0,573 \\
\hline B20exp2 & 0,5344 & B15exp2 & 0,8397 & B16exp2 & 0,6423 \\
\hline B21exp2 & 0,798 & B16exp2 & 0,9908 & B17exp2 & 0,354 \\
\hline B22exp2 & 0,3362 & B17exp2 & 0,6773 & B18exp2 & 0,2718 \\
\hline B24exp2 & 0,2791 & B18exp2 & 0,7034 & B19exp2 & 0,5855 \\
\hline B26exp2 & 0,195 & B19exp2 & 0,3326 & B20exp2 & 0,5135 \\
\hline B30exp2 & 0,4335 & B20exp2 & 0,9106 & B21exp2 & 0,7112 \\
\hline B31exp2 & 0,4578 & B21exp2 & 0,9106 & B22exp2 & 0,4374 \\
\hline & & B22exp2 & 0,2761 & B23exp2 & 0,723 \\
\hline & & B26exp2 & 0,74 & B24exp2 & 0,4155 \\
\hline & & B27exp2 & 0,9431 & B26exp2 & 0,4202 \\
\hline & & B30exp2 & 0,9025 & B27exp2 & 0,3227 \\
\hline & & B31exp2 & 0,8397 & B29exp2 & 0,5577 \\
\hline & & & & B30exp2 & 0,5403 \\
\hline & & & & B31exp2 & 0,3681 \\
\hline & & & B32exp2 & 0,723 \\
\hline
\end{tabular}

\begin{tabular}{|l|l|l|l|l|l|}
\hline Sit4 & & Sit5 & & Sit6 & \\
\hline Participante & AUC & Participante & AUC & Participante & AUC \\
\hline A1exp2 & 0,6838 & A1exp2 & 0,2569 & A1exp2 & 0,6626 \\
\hline A2exp2 & 0,8214 & A2exp2 & 0,0646 & A2exp2 & 0,398 \\
\hline A3exp2 & 0,5081 & A3exp2 & 0,0923 & A3exp2 & 0,3465 \\
\hline A6exp2 & 0,5875 & A4exp2 & 0,0308 & A4exp2 & 0,0458 \\
\hline A9exp2 & 0,7123 & A6exp2 & 0,0926 & A6exp2 & 0,0373 \\
\hline A10exp2 & 0,5903 & A9exp2 & 0,573 & A9exp2 & 0,754 \\
\hline A11exp2 & 0,74 & A10exp2 & 0,2535 & A10exp2 & 0,68 \\
\hline A12exp2 & 0,8524 & A11exp2 & 0,2625 & A11exp2 & 0,5233 \\
\hline A14exp2 & 1,0148 & A12exp2 & 0,8987 & A13exp2 & 0,516 \\
\hline A15exp2 & 0,8181 & A13exp2 & 0,2935 & A17exp2 & 0,8449 \\
\hline A17exp2 & 0,9538 & A17exp2 & 0,8192 & A20exp2 & 0,548 \\
\hline A19exp2 & 0,8738 & A18exp2 & 0,5202 & A22exp2 & 0,5362 \\
\hline A20exp2 & 0,648 & A20exp2 & 0,5077 & A23exp2 & 0,5286 \\
\hline A22exp2 & 0,5538 & A22exp2 & 0,5 & A24exp2 & 0,9047 \\
\hline A23exp2 & 0,9154 & A23exp2 & 0,4172 & A25exp2 & 0,1774 \\
\hline A24exp2 & 0,9538 & A24exp2 & $9,93 E-04$ & A28exp2 & 0,5438 \\
\hline A25exp2 & 0,276 & A25exp2 & 0,299 & A29exp2 & 0,9669 \\
\hline A28exp2 & 0,5438 & A28exp2 & 0,5438 & A30exp2 & 0,3643 \\
\hline A29exp2 & 0,6855 & A29exp2 & 0,8702 & A31exp2 & 0,6848 \\
\hline
\end{tabular}




\begin{tabular}{|c|c|c|c|c|c|}
\hline A30exp2 & 0,697 & A30exp2 & 0,0102 & A33exp2 & 0,135 \\
\hline A31exp2 & 0,723 & A31exp2 & 0,6634 & $\mathrm{~A} 35 \exp 2$ & 0,4888 \\
\hline A33exp2 & 0,2321 & A33exp2 & 0,135 & B1exp2 & 0,2875 \\
\hline A35exp2 & 0,4888 & A34exp2 & 0,2861 & B2exp2 & 0,0452 \\
\hline B1exp2 & 0,8042 & A $35 \exp 2$ & 0,4438 & B3exp2 & 0,9344 \\
\hline B2exp2 & 0,1377 & B1exp2 & 0,2875 & B4exp2 & 0,6382 \\
\hline B3exp2 & 0,6171 & B2exp2 & 0,0179 & B5exp2 & 0,8609 \\
\hline B4exp2 & 0,723 & B4exp2 & 0,3058 & B7exp2 & 0,8669 \\
\hline B5exp2 & 0,5855 & B7exp2 & 0,5125 & B9exp2 & 0,8825 \\
\hline B7exp2 & 0,8289 & B9exp2 & 0,6897 & B12exp2 & 0,7112 \\
\hline B9exp2 & 0,9647 & B12exp2 & 0,7114 & B13exp2 & 0,7876 \\
\hline B10exp2 & 0,2749 & B13exp2 & 0,2872 & B14exp2 & 0,944 \\
\hline B12exp2 & 0,7112 & B14exp2 & 0,856 & B15exp2 & 0,8397 \\
\hline B13exp2 & 0,7895 & B15exp2 & 0,573 & B16exp2 & 0,9907 \\
\hline B14exp2 & 0,9538 & B16exp2 & 0,7651 & B17exp2 & 0,2986 \\
\hline B15exp2 & 0,8397 & B17exp2 & 0,0514 & B18exp2 & 0,4082 \\
\hline B16exp2 & 0,9844 & B18exp2 & 0,0592 & B21exp2 & 0,9036 \\
\hline B17exp2 & 0,7734 & B19exp2 & 0,2576 & B24exp2 & 0,3472 \\
\hline B18exp2 & 0,6997 & B21exp2 & 0,6813 & B26exp2 & 0,3958 \\
\hline B19exp2 & 0,3326 & B22exp2 & 0,0437 & B30exp2 & 0,6872 \\
\hline B20exp2 & 0,9106 & B24exp2 & 0,1998 & B31exp2 & 0,7025 \\
\hline B21exp2 & 0,9106 & B26exp2 & 0,2213 & & \\
\hline B22exp2 & 0,5232 & B30exp2 & 0,2852 & & \\
\hline B23exp2 & 0,8397 & B31exp2 & 0,4355 & & \\
\hline B26exp2 & 0,5438 & B32exp2 & 0,723 & & \\
\hline B27exp2 & 0,7004 & B33exp2 & 0,573 & & \\
\hline B29exp2 & 0,9535 & & & & \\
\hline B30exp2 & 0,9116 & & & & \\
\hline B31exp2 & 0,8738 & & & & \\
\hline
\end{tabular}

\begin{tabular}{|l|l|l|l|}
\hline Sit7 & & Sit8 & \\
\hline Participante & AUC & Participante & AUC \\
\hline A1exp2 & 0,4555 & A1exp2 & 0,6614 \\
\hline A2exp2 & 0,1387 & A2exp2 & 0,3375 \\
\hline A3exp2 & 0,2798 & A3exp2 & 0,6807 \\
\hline A4exp2 & 0,0513 & A4exp2 & 0,138 \\
\hline A6exp2 & 0,0943 & A5exp2 & 0,6705 \\
\hline A9exp2 & 0,3005 & A6exp2 & 0,2982 \\
\hline A10exp2 & 0,2535 & A9exp2 & 0,4172 \\
\hline A11exp2 & 0,1492 & A10exp2 & 0,68 \\
\hline A13exp2 & 0,3943 & A11exp2 & 0,7031 \\
\hline A15exp2 & 0,4925 & A12exp2 & 0,7888 \\
\hline
\end{tabular}




\begin{tabular}{|l|l|l|l|}
\hline A17exp2 & 0,723 & A13exp2 & 0,6855 \\
\hline A18exp2 & 0,5202 & A15exp2 & 0,6828 \\
\hline A20exp2 & 0,5123 & A17exp2 & 0,9154 \\
\hline A22exp2 & 0,5048 & A19exp2 & 0,9483 \\
\hline A23exp2 & 0,3074 & A20exp2 & 0,4981 \\
\hline A24exp2 & $9,14 \mathrm{E}-04$ & A22exp2 & 0,5362 \\
\hline A25exp2 & 0,1774 & A23exp2 & 0,6012 \\
\hline A28exp2 & 0,5438 & A24exp2 & 0,8869 \\
\hline A30exp2 & 0,02 & A25exp2 & 0,1774 \\
\hline A31exp2 & 0,6711 & A28exp2 & 0,5438 \\
\hline A33exp2 & 0,1442 & A30exp2 & 0,6806 \\
\hline A34exp2 & 0,2861 & A31exp2 & 0,6634 \\
\hline A35exp2 & 0,4438 & A33exp2 & 0,135 \\
\hline B1exp2 & 0,2875 & A35exp2 & 0,4888 \\
\hline B2exp2 & 0,067 & B1exp2 & 0,2875 \\
\hline B3exp2 & 0,3459 & B2exp2 & 0,032 \\
\hline B4exp2 & 0,4073 & B3exp2 & 0,4638 \\
\hline B5exp2 & 0,2376 & B4exp2 & 0,6142 \\
\hline B7exp2 & 0,4717 & B5exp2 & 0,8556 \\
\hline B9exp2 & 0,5355 & B7exp2 & 0,8499 \\
\hline B12exp2 & 0,7114 & B9exp2 & 0,6897 \\
\hline B13exp2 & 0,3442 & B12exp2 & 0,7112 \\
\hline B14exp2 & 0,856 & B13exp2 & 0,8278 \\
\hline B15exp2 & 0,573 & B14exp2 & 0,944 \\
\hline B16exp2 & 0,777 & B15exp2 & 0,8397 \\
\hline B17exp2 & 0,0661 & B16exp2 & 0,9922 \\
\hline B18exp2 & 0,0521 & B17exp2 & 0,5109 \\
\hline B19exp2 & 0,2616 & B18exp2 & 0,3347 \\
\hline B21exp2 & 0,6813 & B19exp2 & 0,3507 \\
\hline B22exp2 & 0,0673 & B21exp2 & 0,8781 \\
\hline B23exp2 & 0,5112 & B22exp2 & 0,337 \\
\hline B24exp2 & 0,2643 & B23exp2 & 0,5112 \\
\hline B26exp2 & 0,1351 & B26exp2 & 0,5577 \\
\hline B27exp2 & 0,0552 & B27exp2 & 0,9022 \\
\hline B28exp2 & 0,5125 & B28exp2 & 0,5355 \\
\hline B29exp2 & 0,2105 & B29exp2 & 0,6417 \\
\hline B30exp2 & 0,24 & B30exp2 & 0,8407 \\
\hline B32exp2 & $0,6486 \operatorname{exp2~}$ & 0,9047 \\
\hline B32 2 & 0,2534 \\
\hline
\end{tabular}




\section{Apêndice 8}

Figuras com médias - Estudo 1.

Sit1 - Questionário A

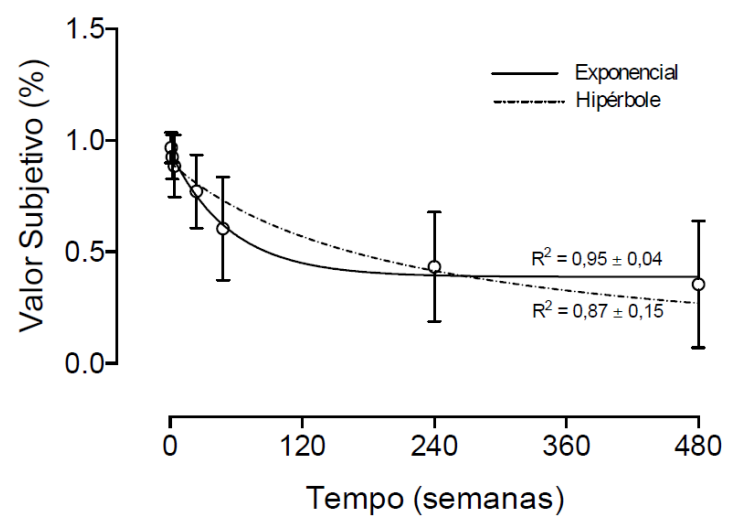

Sit3 - Questionário A

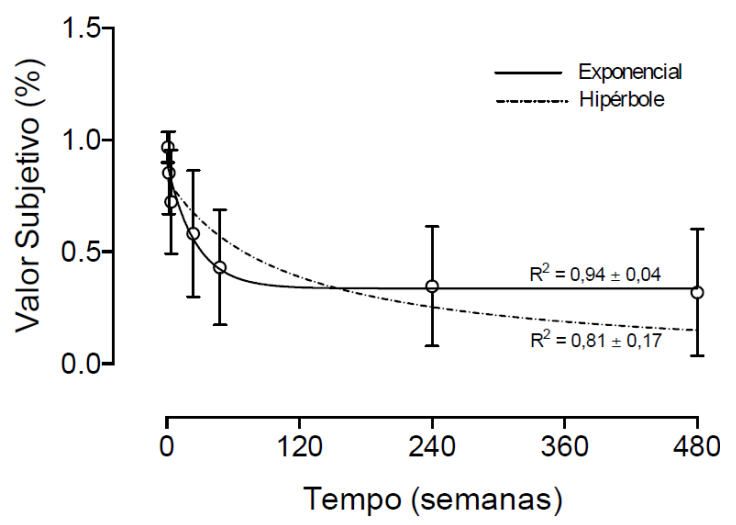

Sit2 - Questionário A

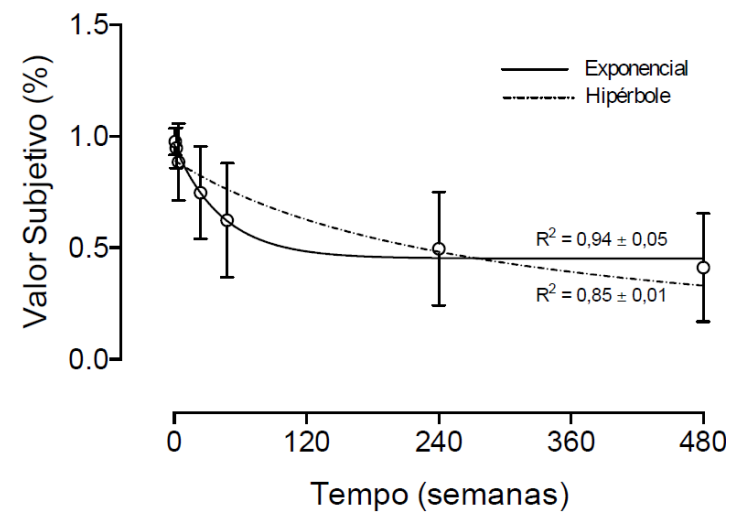

Sit4 - Questionário A

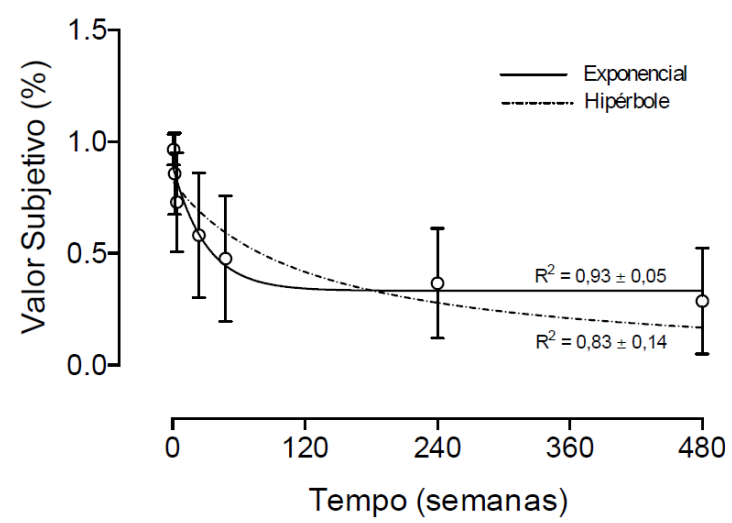

Figura extra 1. Valor subjetivo médio da consequência (\%) em função dos atrasos (semanas) e curvas de ajuste - hipérbole e exponencial - com os respectivos valores médios de $\mathrm{R}^{2}$, para cada uma das situações do Questionário A. 
Sit1 - Questionário B

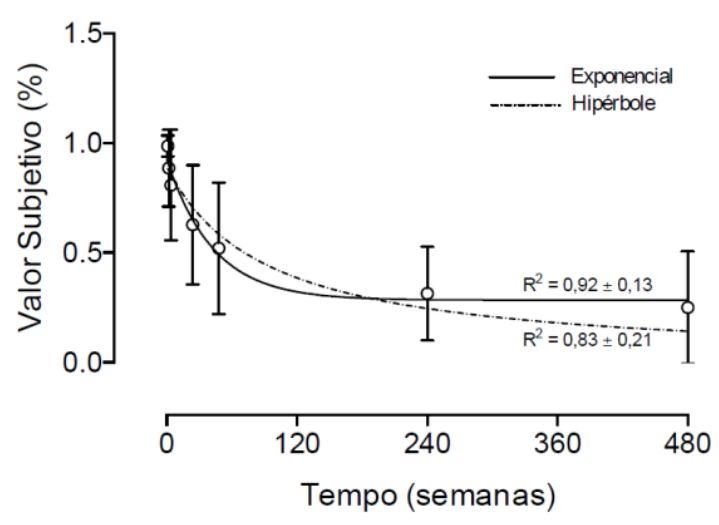

Sit3 - Questionário B

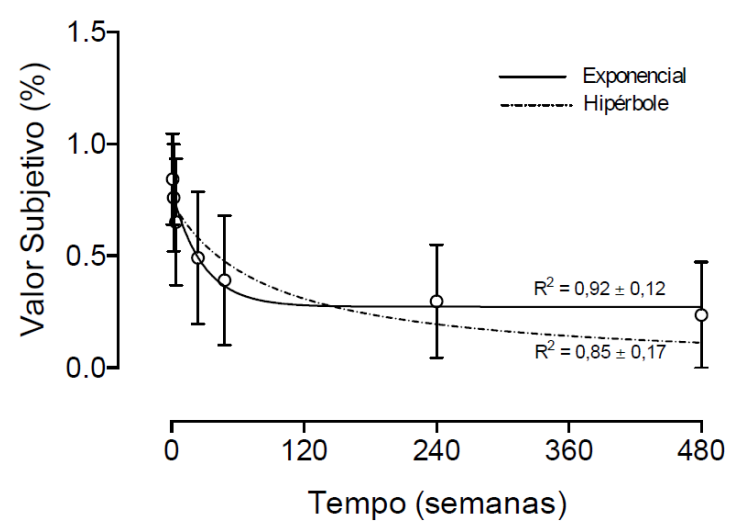

Sit2 - Questionário B

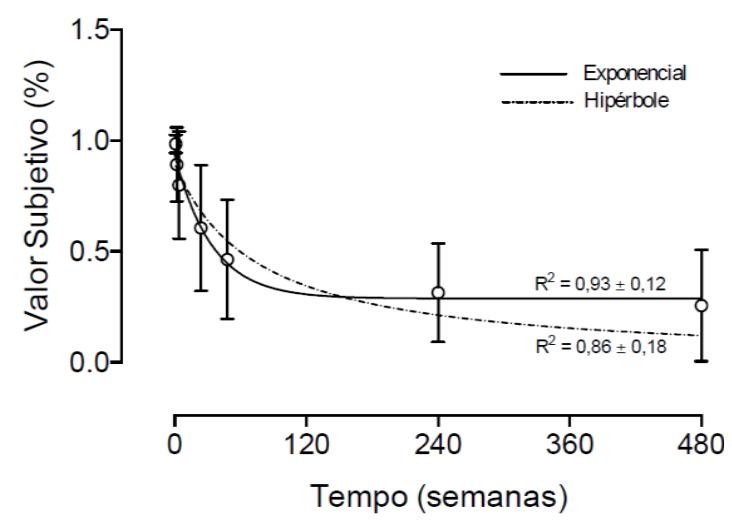

Sit4 - Questionário B

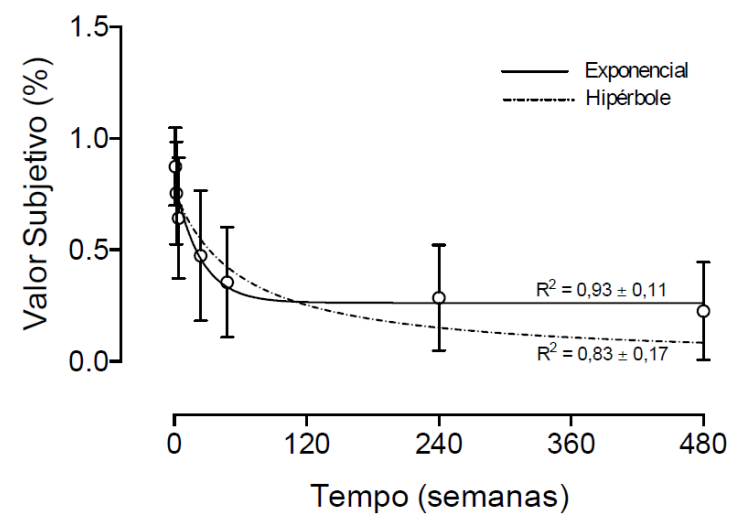

Figura extra 2. Valor subjetivo médio da consequência (\%) em função dos atrasos (semanas) e curvas de ajuste - hipérbole e exponencial - com os respectivos valores médios de $\mathrm{R}^{2}$, para cada uma das situações do Questionário B. 
Figuras com médias - Estudo 2.

Sit1

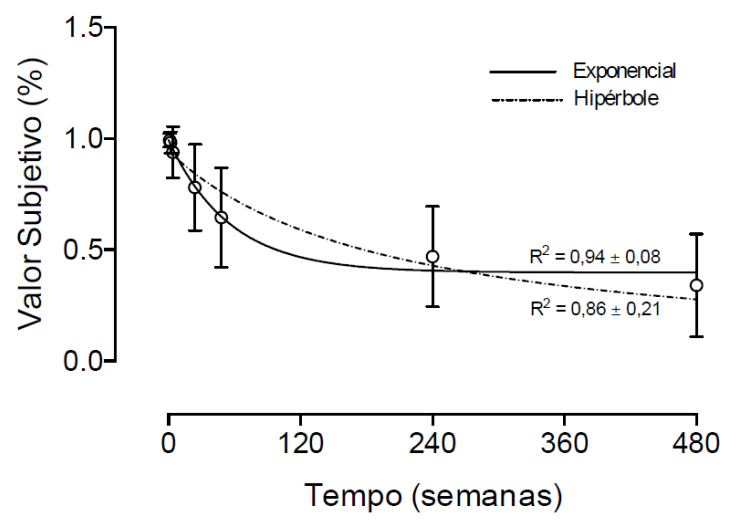

Sit 3

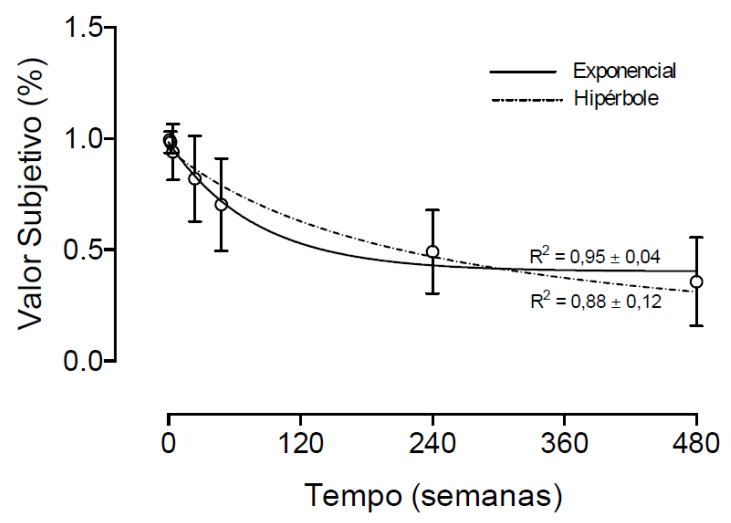

Sit5

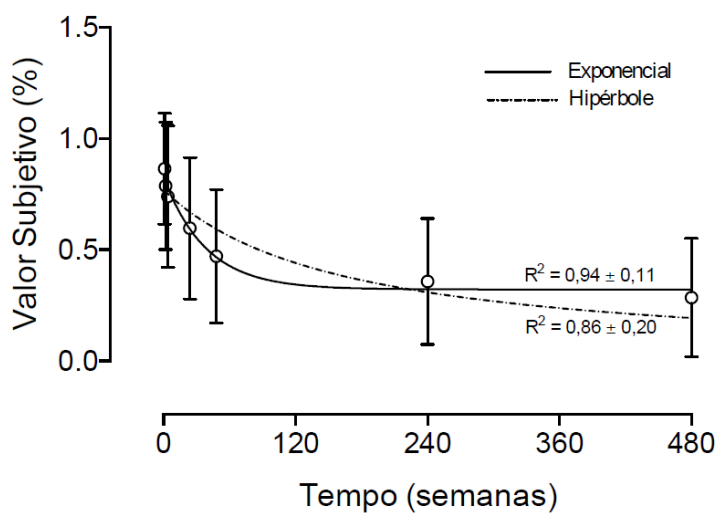

Sit2

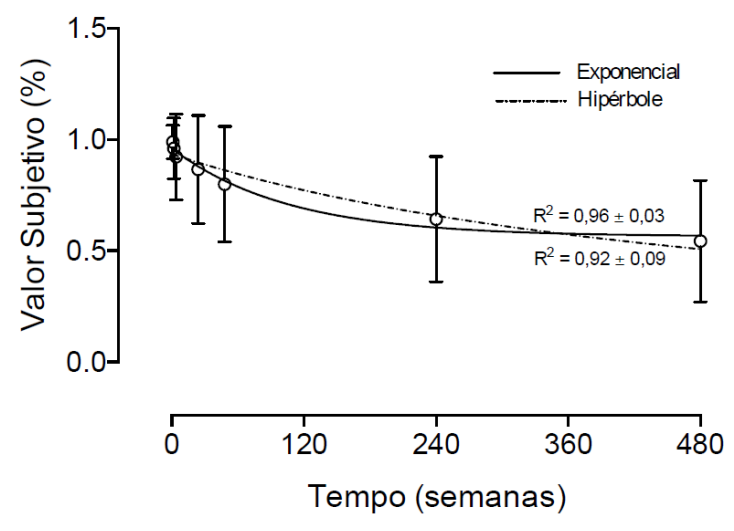

Sit4

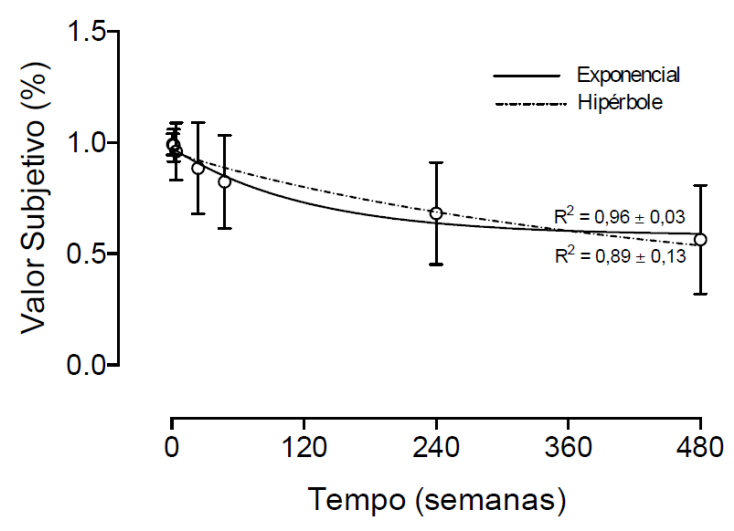

Sit6

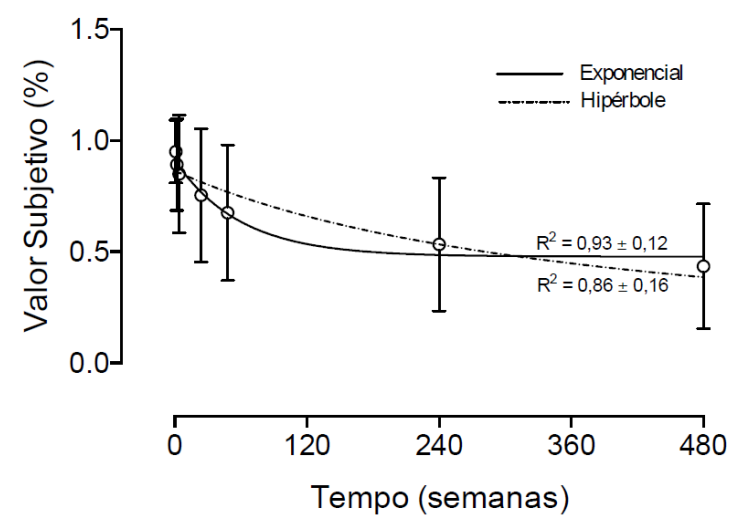


Sit7

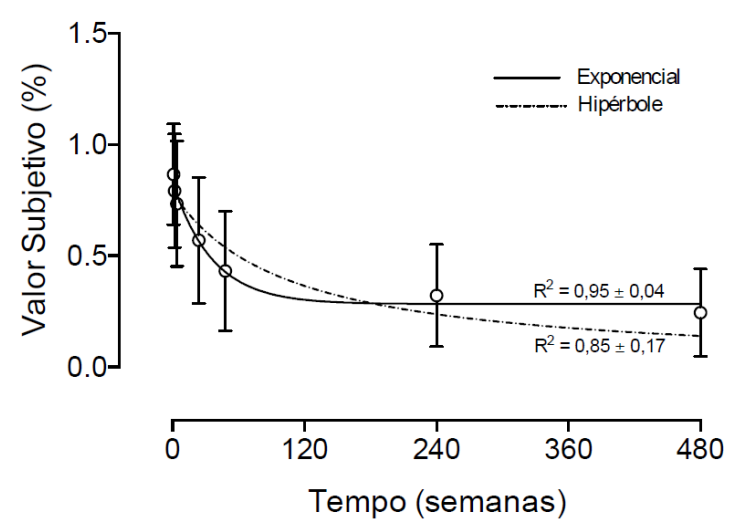

Sit8

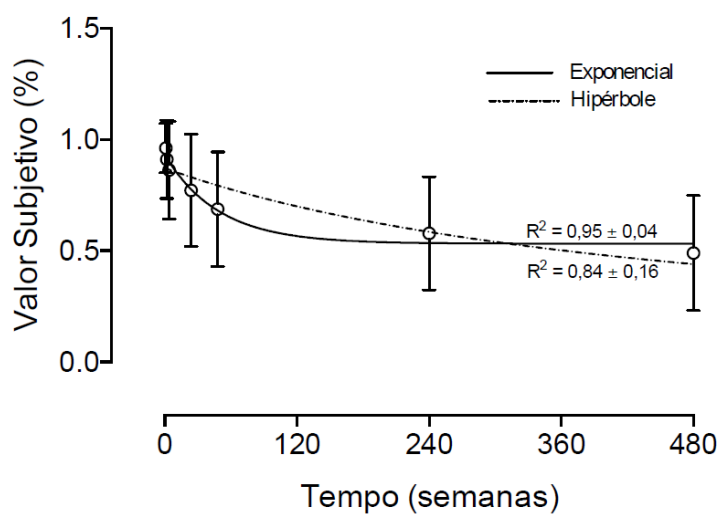

Figura extra 3. Curvas hiperbólica e exponencial, obtidas através dos valores médios de $k$ em função dos atrasos. Os valores médios de $\mathrm{R}^{2}$, bem como seu desvio padrão, estão apresentados em suas respectivas curvas. 